\title{
Recoding of viral mRNAs by -1 programmed ribosome frameshifting
}

\author{
Dissertation \\ for the award of the degree \\ "Doctor rerum naturalium" (Dr.rer.nat.) \\ of the Georg-August-Universität Göttingen \\ within the doctoral program IMPRS Molecular Biology \\ of the Georg-August University School of Science (GAUSS) \\ submitted by \\ Natalia Korniy \\ from L'viv, Ukraine
}

Göttingen, 2019 


\section{Thesis Committee:}

Prof. Dr. Marina V. Rodnina

Department of Physical Biochemistry

Max Planck Institute for Biophysical Chemistry, Göttingen, Germany

Prof. Dr. Holger Stark

Department of Structural Dynamics

Max Planck Institute for Biophysical Chemistry, Göttingen, Germany

Prof. Dr. Stefan Pöhlmann

Infection Biology Unit

German Primate Center, Göttingen, Germany

\section{Members of the Examination Board:}

Reviewer: Prof. Dr. Marina V. Rodnina

Department of Physical Biochemistry

Max Planck Institute for Biophysical Chemistry, Göttingen, Germany



Department of Structural Dynamics

Max Planck Institute for Biophysical Chemistry, Göttingen, Germany

Further members of the Examination Board:

Prof. Dr. Peter Rehling

Department of Cellular Biochemistry

University Medical Center Göttingen, Germany

Prof. Dr. Henning Urlaub

Research Group of Bioanalytical Mass Spectrometry

Max Planck Institute for Biophysical Chemistry, Göttingen, Germany

Prof. Dr. Wolfgang Wintermeyer

Research Group of Ribosome Dynamics

Max Planck Institute for Biophysical Chemistry, Göttingen, Germany

Date of oral examination: $17^{\text {th }}$ of May 2019 


\section{Related publications}

1. Korniy, N., Samatova, E., Anokhina, M.M., Peske, F., \& Rodnina, M.V. (2019). Mechanisms and biomedical implications of -1 programmed ribosome frameshifting on viral and bacterial mRNAs (review article, accepted to FEBS Lett).

2. Korniy, N., Goyal, A., Hoffmann, M., Samatova, E., Peske, F., Pöhlmann, S., \& Rodnina, M.V. (2019). Modulation of HIV-1 Gag/Gag-Pol frameshifting by tRNA abundance. NAR. pii: gkz202. doi: 10.1093/nar/gkz202.

3. Bock, L., Caliskan, N., Korniy, N., Peske, F., Rodnina, M.V. \& Grubmüller, H. (2019). Thermodynamic control of -1 programmed ribosomal frameshifting (submitted to Nat Commun).

4. Caliskan, N., Wohlgemuth, I., Korniy, N., Pearson, M., Peske, F., Rodnina, M.V. (2017). Conditional switch between frameshifting regimes upon translation of dnaX mRNA. Mol Cell. 66(4), 558-567.e4. doi: 10.1016/j.molcel.2017.04.023. 


\section{Affidavit}

I hereby declare that the presented dissertation entitled "Recoding of viral mRNAs by -1 programmed ribosome frameshifting" has been written independently and with no other sources and aids than quoted.

Göttingen, March 19 $9^{\text {th }}, 2019$

Natalia Korniy 


\section{Table of contents}

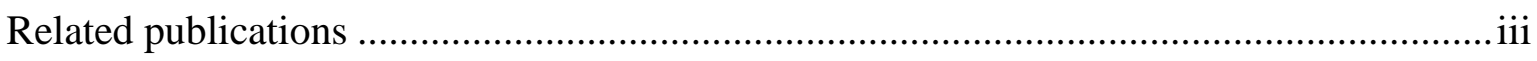

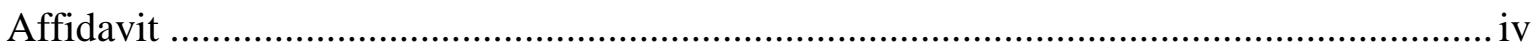



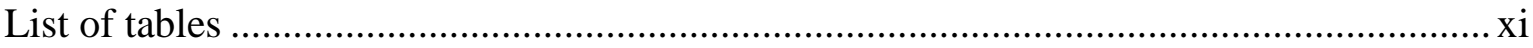

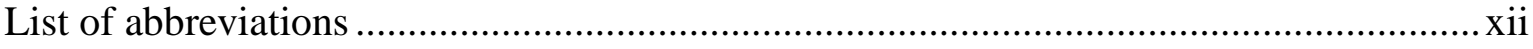

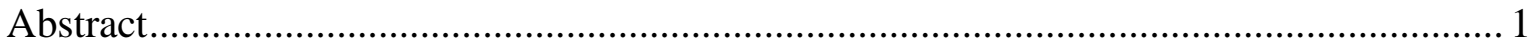



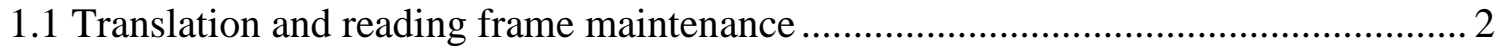



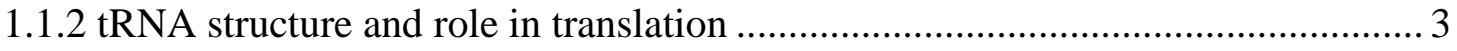

1.1.3 Stages of translation and reading frame maintenance ….................................... 5

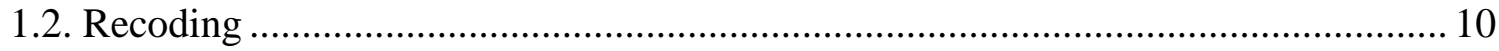

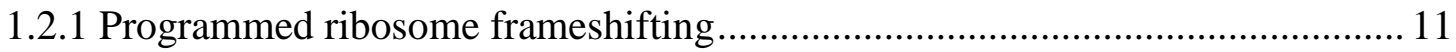

1.2.1.1 +1 Programmed ribosome frameshifting ................................................ 11

1.2.1.2 -1 Programmed ribosome frameshifting ............................................... 12



1.2.1.4 Role of cis-acting enhancer sequences in +1 and -1 PRF .......................... 17

1.3. -1 Programmed ribosome frameshifting in human immunodeficiency virus .......... 19

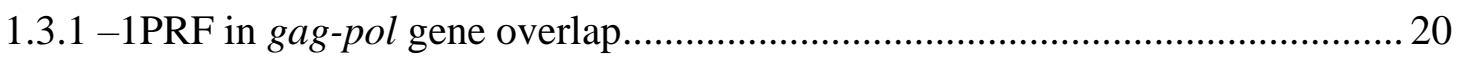

1.3.1.1 Structure of the gag-pol frameshifting site............................................. 21

1.3.1.2 Different models of -1PRF on gag-pol overlap ...................................... 22

1.3.2 Second putative frameshifting site within gag-pol overlap ............................. 24

1.3.3 Anti-HIV therapeutics targeting frameshifting .............................................. 25

1.4. -1 Programmed ribosome frameshifting in alphaviruses ....................................... 26



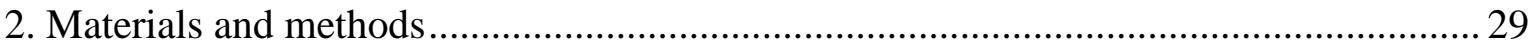

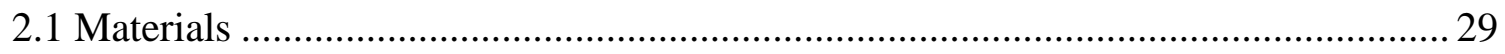

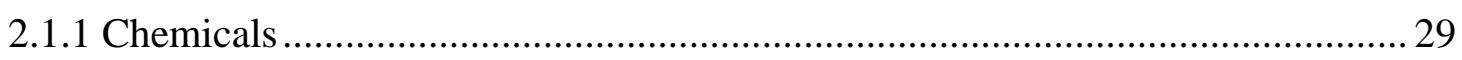

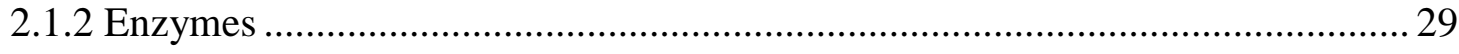




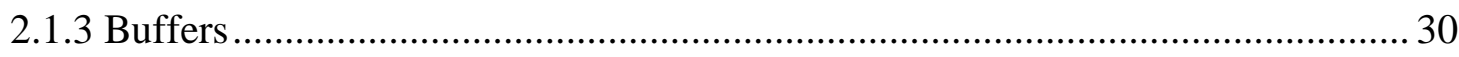

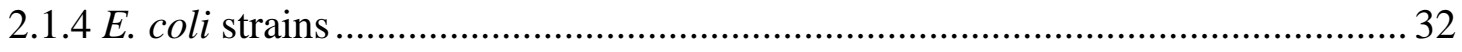

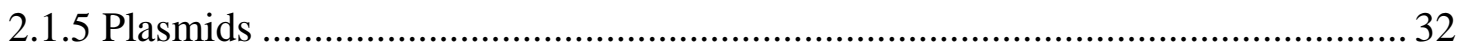

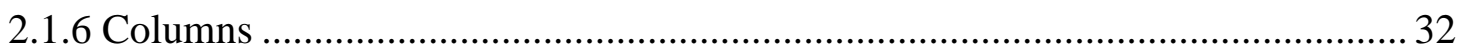

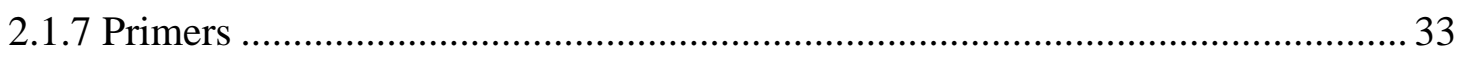



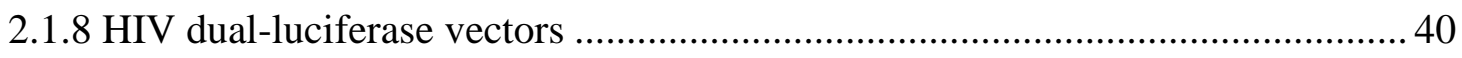



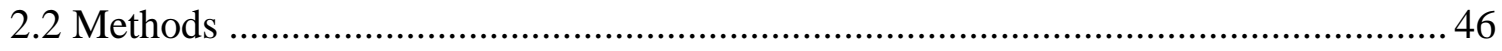

2.2.1 Vector construction by polymerase chain reaction ......................................... 46

2.2.1.1 Preparation of dual-luciferase vectors ...................................................... 47

2.2.2 Transformation and purification of plasmid DNA …...................................... 47



2.2.3.1 Design of HIV-1 mRNAs for bacterial and mammalian systems ................ 49

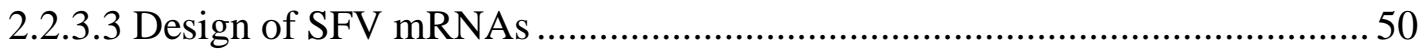





2.2.4.1 Aminoacylation and purification of individual tRNAs from $E$. coli ............50

2.2.4.2 Purification of total tRNA from HeLa cell extracts ..................................52

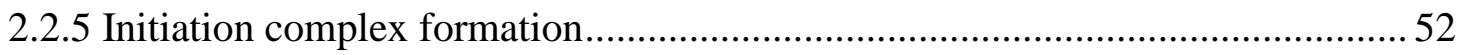

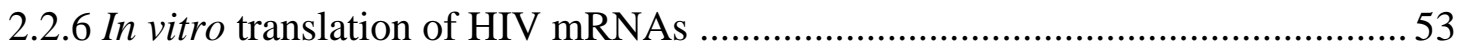

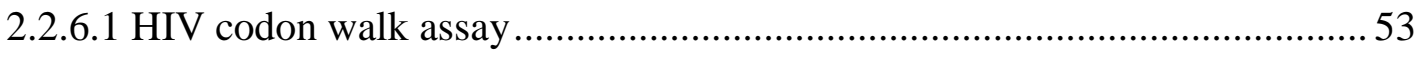

2.2.6.2 End-point translation assay of -2 / +1 HIV mRNA …................................. 54

2.2.6.3 Arg-tRNA ${ }^{\mathrm{Arg}}$ incorporation assay on HIV control mRNAs ........................ 54

2.2.6.4 End-point translation of HIV mRNAs with enhancer variants.................... 55

2.2.6.5 Analysis of TC formation by electrophoretic mobility shift assay...............55

2.2.6.6 Translation of long HIV and $\gamma \mathrm{B}$-crystallin mRNAs using human tRNAs and



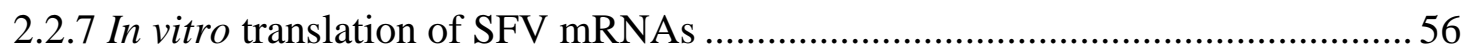

2.2.7.1 End-point translation assay of short SFV mRNAs ................................... 56

2.2.8 Chemical probing of SFV mRNA secondary structure ...................................57

2.2.9 End-point translation of dnaX mRNA variants............................................... 58 
2.2.10 Translation in in vitro reconstituted mammalian system 60

2.2.10.1 80S Initiation complex formation

2.2.10.2 Ternary complex formation and translation

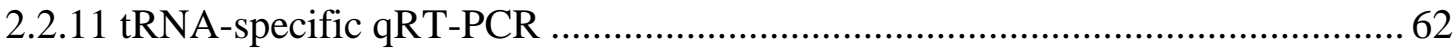

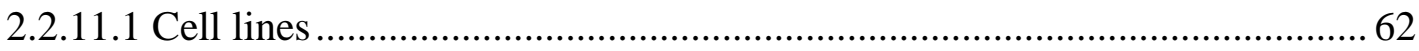

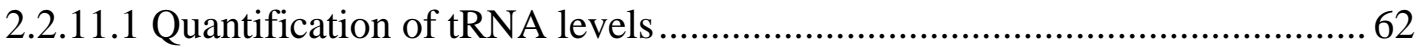

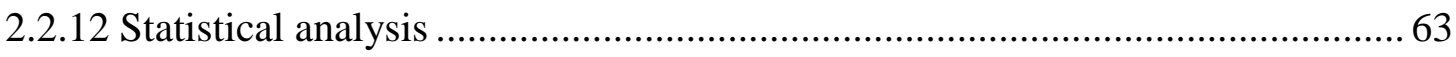

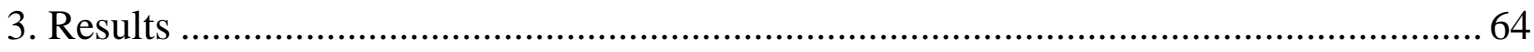

3.1 -1PRF mechanism and its modulation at the gag-pol slippery site of HIV-1 ...........64

3.1.1 In vitro reconstituted E. coli translation and peptide analysis system ................ 64

3.1.2 Two regimes for-1PRF on the gag-pol slippery site ….................................. 67

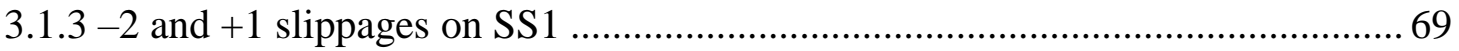

3.1.4 Kinetics of FFR and FLR -1 frameshifting pathway ….................................... 71

3.1.5 -1PRF in HIV-1 studied with native human aa-tRNA ….................................. 74



3.1.7 Frameshifting efficiency in HIV-1 measured with human 80S ribosomes ..........83

3.2 Investigation of the role of the mRNA secondary structure and a potential enhancer

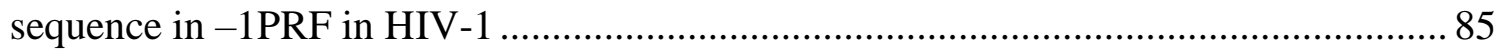

3.2.1 Studying potential enhancer sequence in the gag-pol gene of HIV-1 using the

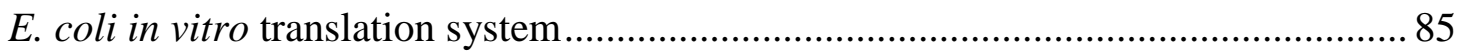

3.3 Characterization of frameshifting motif and frameshifting efficiency in 6K mRNA of

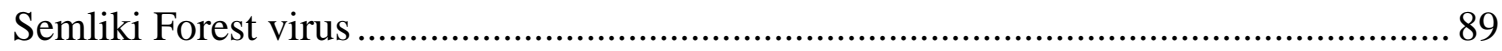

3.3.1 Determination of mRNA secondary structure in SFV .................................... 89

3.3.2 Characterization of -1 frameshifting on SFV frameshifting motif .................... 92

3.3.3 -1PRF in SFV measured with total human tRNA ............................................ 95

3.4 Thermodynamic control of -1 programmed ribosomal frameshifting in dnaX......... 98

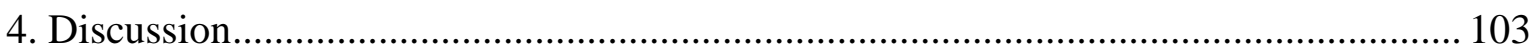



4.1.1 Routes to frameshifting on gag-pol HIV-1 mRNA......................................... 103

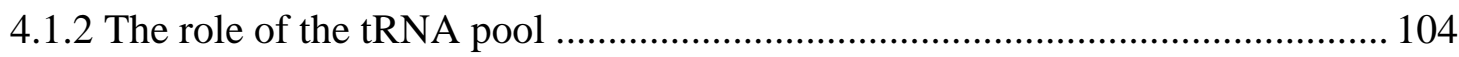

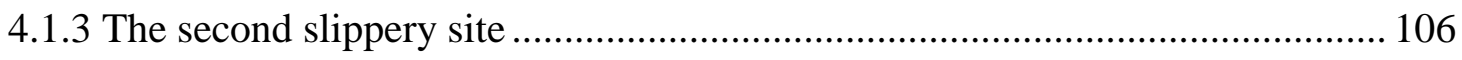

4.1.4 The contribution of an mRNA enhancer sequence ....................................... 106 
4.3 Conclusions.

5. References .

Acknowledgements 132 


\section{List of figures}

Figure 1. Architecture of bacterial and eukaryotic ribosomes and their common structural core.

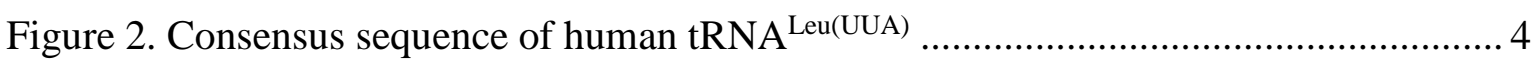

Figure 3. Comparison between translation cycles in bacteria and eukaryotes ..................... 6

Figure 4. Programmed recoding events: read-through, bypassing and -1 frameshifting .... 11

Figure 5. Kinetic model of translocation-dependent -1PRF on 1a/1b mRNA of IBV ....... 15

Figure 6. Structure of the frameshifting motif of the dnaX mRNA .................................. 16

Figure 7. Comparison between translocation-dependent and "hungry" pathways of -1PRF

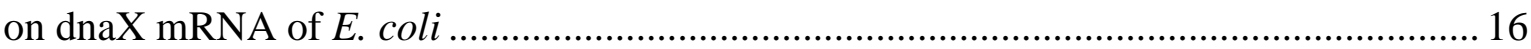

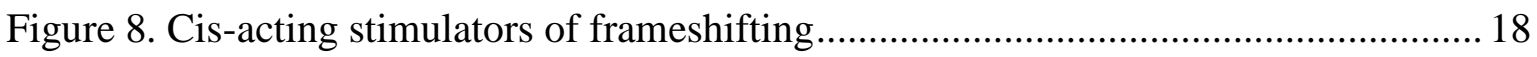

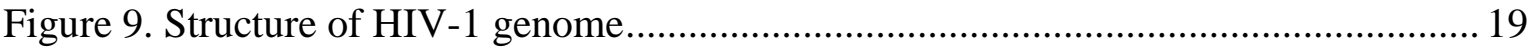

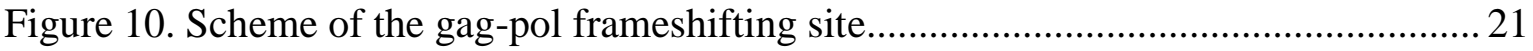

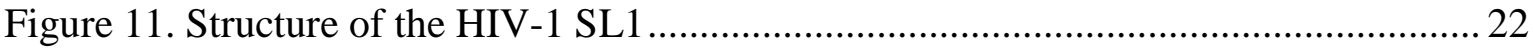

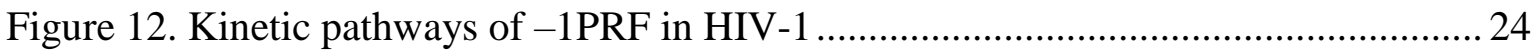



Figure 14. Optimization of an in vitro translation and peptide analysis system to study

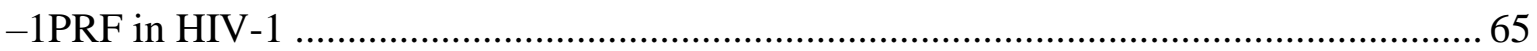

Figure 15. Characterization of frameshifting regimes on the gag-pol SS1 .......................6 68

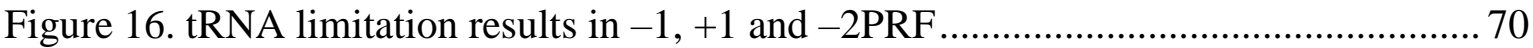

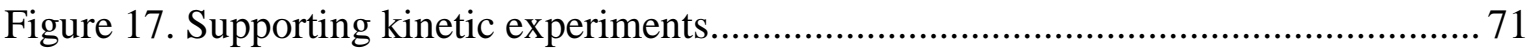

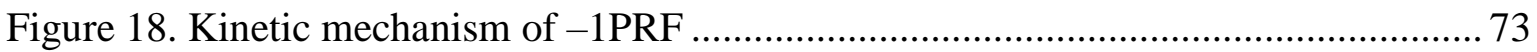

Figure 19. Relative abundance of tRNA isoacceptors in different cell types..................... 75

Figure 20. Characterization of the heterologous in vitro translation system....................... 76

Figure 21. Translation and frameshifting with native human aa-tRNAs .......................... 78

Figure 22. Characterization of translation intermediates on HIV long wt mRNA.............. 79

Figure 23. Frameshifting efficiency and its modulation on SS1 of gag-pol overlap measured in $E$. coli heterologous translation system with native human tRNA................................ 81

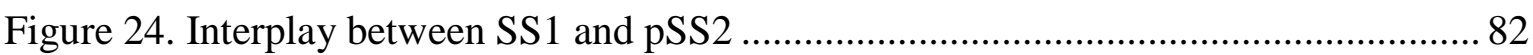

Figure 25. Translation of the eukaryotic gag-pol wt mRNA using a fully reconstituted homologous mammalian in vitro translation system.

Figure 26. Effect of variations in the potential enhancer sequence following the SS1 in the gag-pol frameshifting site of HIV-1 
Figure 27. Determination of the mRNA secondary structure in SFV 6K frameshifting site

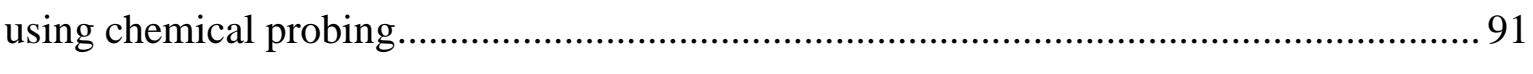
Figure 28. Characterisation of the FFS and FLS -1 frameshifting regimes with the SFV

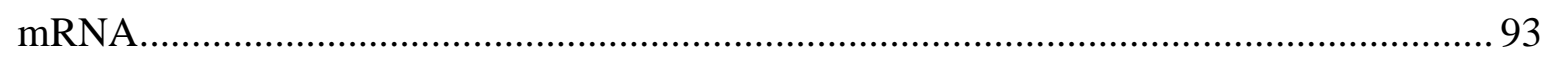

Figure 29. -1PRF in SFV determined with human total tRNA ...................................... 96

Figure 30. Variations of the E. coli dnaX SS and measured -1PRF efficiencies............... 99 Figure 31. Comparison of frameshifting sites derived from different HIV-1 subtypes of

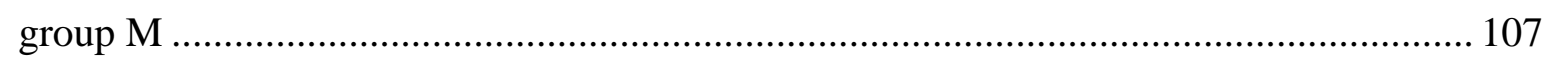

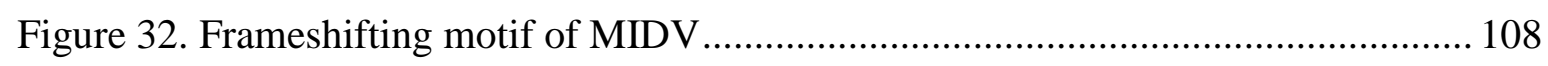




\section{List of tables}

Table 1. Examples of -1PRF in three domains of life..................................................... 13

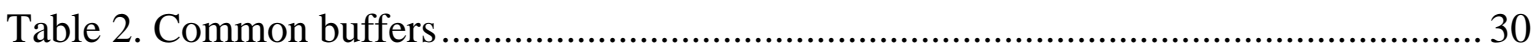

Table 3. Primers for HIV constructs for bacterial translation system …............................ 33

Table 4. Primers for HIV constructs for mammalian translation system ............................ 35

Table 5. Primers for HIV in vivo studies in human cell culture .......................................... 35

Table 6. Primers for SFV constructs for bacterial translation system ............................... 37

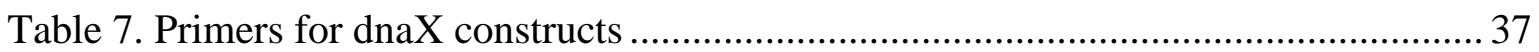

Table 8. HIV dual-luciferase vectors for in vivo studies in human cell culture .................. 40

Table 9. Sequences of HIV mRNAs used in bacterial translation system .......................... 41

Table 10. Long HIV mRNAs with SS1 and pSS2 variants ............................................. 42

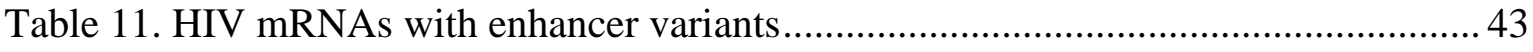

Table 12. Sequences of HIV mRNAs used in mammalian translation system .................... 44

Table 13. Sequences of SFV mRNAs used in bacterial translation system ........................ 44

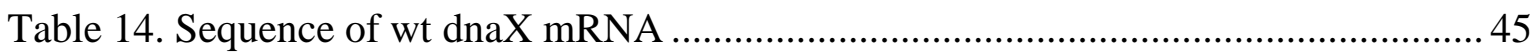

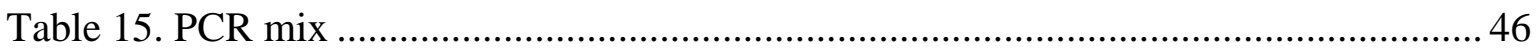

Table 16. Two-step PCR program conditions ................................................................. 46

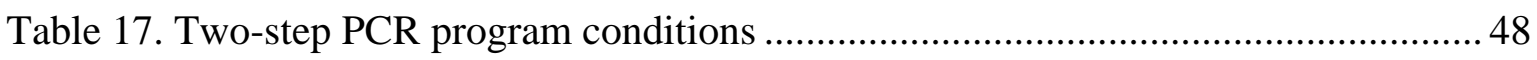

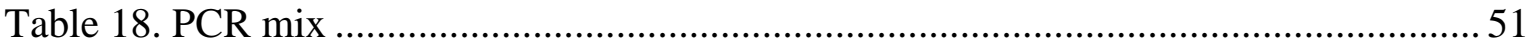

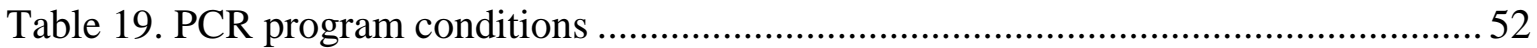

Table 20. Composition of separating, spacer and stacking gels .....................................56

Table 21. Scheme of chemical probing with DMS, KE and CMCT .................................57



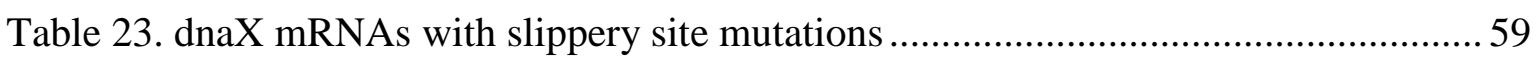



Table 25. Rate constants of translation and frameshifting ............................................. 74

Table 26. Correspondence between stalling sites and low-abundant codons..................... 80

Table 27. -1PRF efficiencies for the indicated dnaX slippery sequence variants ............... 99 


\section{List of abbreviations}

aa

aa-tRNA

Amp

bp

$\mathrm{ACN}$

AMP

ATP

dNTP

ddNTP

DTT

EDTA

EF

FPLC

GMP

GTP

HFBA

HIV-1

IC

Kan

LB

LSU

MIDV

mRNA

nt

ORF

PEP

PK

RP-HPLC

PRF

rRNA

$\mathrm{S}$

$\mathrm{SD}$

SFV amino acid

aminoacyl-tRNA

ampicillin

base pair

acetonitrile

adenosine monophosphate

adenosine triphospate

deoxynucleoside triphosphate

dideoxynucleoside triphosphate

dithiothreitol

ethylenediaminetetraacetic acid

elongation factor

fast protein liquid chromatography

guanosine monophosphate

guanosine triphosphate

heptafluorobutyric acid

human immunodeficiency virus type 1

initiation complex

kanamycin

lysogeny broth

large ribosome subunit

Middleburg virus

messenger RNA

nucleotide

open reading frame

phosphoenolpyruvate

protein kinase

reverse-phase high-performance liquid chromatography

programmed ribosome frameshifting

ribosomal RNA

Svedberg unit, a sedimentation rate $\left(10^{-13} \mathrm{~s}\right)$

Shine-Dalgarno sequence

Semliki Forest virus 
SL

SS

SSU

TC

TF

TFA

tRNA

UTR stem-loop

slippery site

small ribosome subunit

ternary complex

TransFrame protein

trifluoracetic acid

transfer RNA

untranslated region in mRNA 


\begin{abstract}
-1 programmed ribosome frameshifting $(-1 \mathrm{PRF})$ is commonly used in many viruses and cellular genes. The current study focuses on the -1PRF in two human viruses, human immunodeficiency virus type 1 (HIV-1) and Semliki Forest virus (SFV), which share the same slippery site (SS) sequence, but have different mRNA secondary structures. -1PRF on the gag-pol mRNA of HIV-1 results in the production of structural proteins of the capsid (Gag, 0-frame) and viral enzymes (Gag-Pol, -1-frame), and its dysregulation is detrimental for the structural integrity of the virion and its infectivity. In SFV -1PRF is responsible for the synthesis of the structural proteins $6 \mathrm{~K}$ and TransFrame (TF), which contribute to the virus pathogenicity. Here we show that $-1 \mathrm{PRF}$ in both viruses operates via two conserved kinetic pathways: tRNA dual-slippage during translocation under saturated translation conditions and single P-site tRNA slippage when the A site is vacant due to the limited supply of tRNAs. $-1 P R F$ is modulated by the abundance of Leu-tRNA ${ }^{\text {Leu }}$ that reads the rare UUA codon at the mRNA SS. In HIV-1 the Gag to Gag-Pol ratio is maintained by switching between two frameshifting mechanisms depending on the tRNA ${ }^{\text {Leu(UUA) }}$ availability. LeutRNA $^{\text {Leu(UUA) }}$ is rare in human cell lines derived from $\mathrm{CD}^{+}{ }^{+}$-lymphocytes - a natural target of HIV-1 infection. -1PRF in HIV-1 is additionally stimulated by a downstream enhancer sequence located within the first $12 \mathrm{nt}$ after the SS. Finally, a second potential SS downstream of the first one is normally inefficient but can also support -1-frameshifting when altered by a compensatory resistance mutation in response to current anti-HIV drug therapy. With regard to SFV, we determined that its frameshifting site contains an extended stem-loop (SL) following the SS, which could act as a modulator of frameshifting under the limited supply of Leu-tRNA ${ }^{\text {Leu(UUA) }}$. The previously predicted enhancer sequence does not seem to play a role in $-1 \mathrm{PRF}$ in SFV. Described different frameshifting regimes and stimulators allow the viruses to maintain a constant -1PRF efficiency regardless of environmental or therapeutical influence to ensure high viral load and successful virus propagation.
\end{abstract}




\section{Introduction}

\subsection{Translation and reading frame maintenance}

\subsubsection{Ribosome structure and function}

Translation is the fundamental process by which the nucleotide (nt) sequence of a messenger RNA (mRNA) is converted into the amino acid (aa) sequence of a protein. The key molecular player of translation is a ribosome - a large ribonucleoprotein complex that consists of two unequal subunits with distinct functions. The RNA core of the ribosome is built of ribosomal RNA (rRNA) and proteins conserved throughout all kingdoms of life, whereas on the periphery both RNA and protein amounts and composition vary significantly (Fig. 1) (Melnikov et al., 2012). Prokaryotic ribosomes are designated as 70S where S stands for Svedberg unit, which defines the rate of ribosome sedimentation during ultracentrifugation. 70S ribosomes consist of a small (SSU) or 30S subunit and a large (LSU) or 50S subunit. In turn, the SSU contains the $16 \mathrm{~S}$ rRNA and 21 proteins while the LSU has both the $5 \mathrm{~S}$ and the $23 \mathrm{~S}$ rRNAs along with 31 proteins. Eukaryotic ribosomes are denoted 80S; they are larger due to increased rRNA and protein content at the periphery of the ribosome (Fig. 1). 80S ribosomes are built of a $40 \mathrm{~S}$ and a $60 \mathrm{~S}$ subunits in analogy with prokaryotic ribosomes. The $40 \mathrm{~S}$ subunit contains the $18 \mathrm{~S}$ rRNA and 33 proteins, and the $60 \mathrm{~S}$ subunit is composed of three rRNAs, the $5 \mathrm{~S}$, the $28 \mathrm{~S}$ and the $5.8 \mathrm{~S}$ rRNA, and 46 proteins. In addition to cytoplasmic ribosomes, eukaryotes also contain organellar ribosomes, namely in mitochondria and chloroplasts. In humans, such mitoribosomes consist of two subunits named 28S and 39S together forming a 55S particle (Bieri et al., 2018).
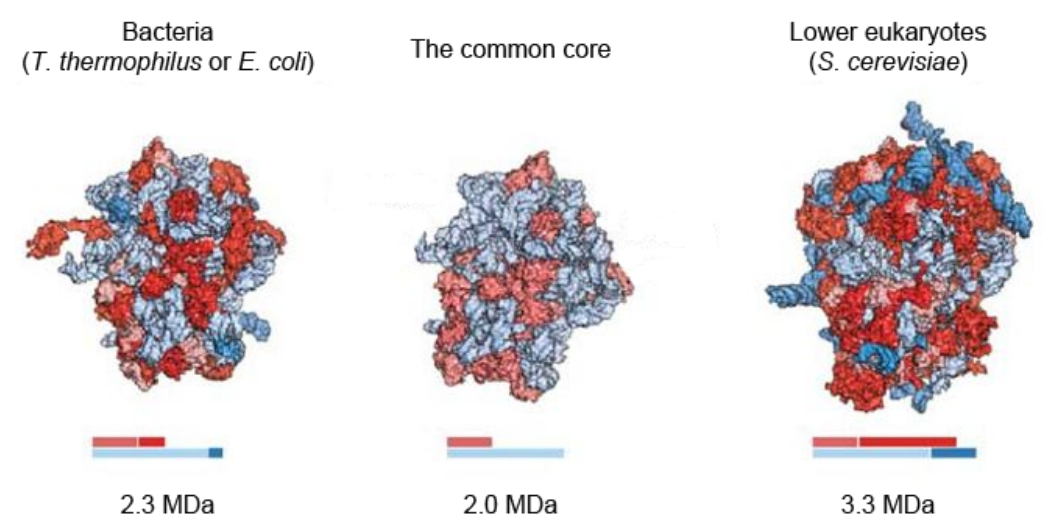

Figure 1. Architecture of bacterial and eukaryotic ribosomes and their common structural core. Numbers below the structures refer to the size of ribosomes in megadaltons (MDa). Conserved rRNA and protein moieties are depicted in light blue and light red, respectively, while rRNA and proteins 
specific to each domain of life are in blue and red, respectively. The figure is adapted from (Melnikov et al., 2012).

\subsection{2 tRNA structure and role in translation}

Apart from ribosomes, translation requires the presence of mRNAs, multiple accessory proteins (translation factors) and transfer RNAs (tRNAs). tRNAs are short (76-90 nt) noncoding RNA molecules which deliver aa to the ribosome. tRNAs decode the nt sequence of the mRNA by pairing between the mRNA codon and the anticodon of tRNA. Codon usage bias defines frequencies of occurrence of synonymous codons in the genome. Synonymous codons are triplets of nt that encode the same aa. tRNAs "reading" synonymous codons but containing different anticodons are called isoacceptors. For instance, the human tRNA ${ }^{\text {Leu }}$ family comprises five isoacceptors reading six Leu codons (Breitschopf et al., 1995; Geslain and Pan, 2010). If the anticodon identity is the same, but the tRNA sequences outside the anticodon are different, the tRNAs are designated as isodecoders (Geslain and Pan, 2010; Goodenbour and Pan, 2006). For example, the human tRNA ${ }^{\mathrm{Ala}(\mathrm{GCU})}$ isoacceptor has fifteen isodecoders. Individual isoacceptors and isodecoders show different expression levels and may have regulatory functions unrelated to protein synthesis (Geslain and Pan, 2010).

The translation-adaptation hypothesis suggests that codon usage correlates with tRNA isoacceptor levels in the cell to provide optimal translation rates (Bulmer, 1987; Dong et al., 1996). Indeed, in bacteria and lower eukaryotes, the abundance of tRNAs is directly proportional to the codon usage bias. In humans however, tRNA isoacceptors show tissuespecific differences in their expression levels (Dittmar et al., 2006; Mahlab et al., 2012). That is why the correlation between the tRNA frequency and the preferred codons is significant only in the subset of highly expressed genes within specific tissues.

Mature tRNAs adopt a distinctive cloverleaf-like structure, which consists of the following elements: acceptor stem, D (dihydrouridine) loop, anticodon loop, variable loop

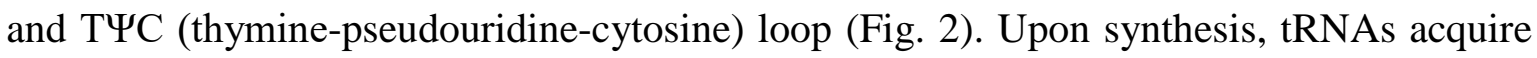
extensive post-transcriptional modifications which define unique properties of each tRNA (Bjork, 1995; Pan, 2018). On average, nuclear-encoded tRNAs bear more modifications (13 per molecule) than mitochondrial tRNAs (3 per molecule) (Pan, 2018). Nuclear-encoded eukaryotic tRNAs are also more heavily modified than their prokaryotic homologues (Machnicka et al., 2014). One of the most heavily modified tRNAs is tRNA ${ }^{\text {Tyr }}$ from human placenta which contains 17 modifications (van Tol et al., 1987). The most common modifications are found at positions 34 (a wobble position of the anticodon) and conserved 
purine 37 (3' of the anticodon) (Fig. 2) (Lorenz et al., 2017). The functions of modifications are to increase the ability of a tRNA to decode multiple synonymous codons, to stabilize codon-anticodon interactions and to prevent frameshift mutations thus to ensure proper codon reading and high fidelity of translation (Lorenz et al., 2017; Novoa et al., 2012; Pan, 2018; Urbonavicius et al., 2001). Wrong tRNA modification patterns are linked to multiple diseases including type II diabetes, mitochondrial and neurological disorders (Bednarova et al., 2017; Bohnsack and Sloan, 2018; Torres et al., 2014).

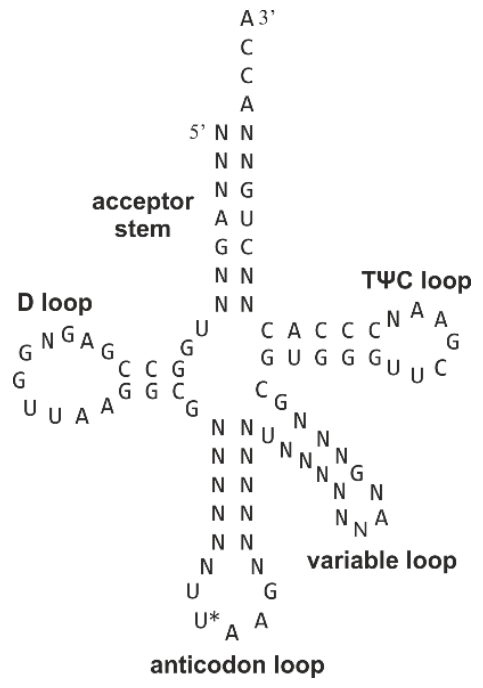

Figure 2. Consensus sequence of human $\operatorname{RNA}^{\mathrm{Leu(UUA})}$ (UUA is a codon read by this Leu isoacceptor). The structure was derived by comparing all five human tRNA ${ }^{\text {Leu }}$ isoacceptors. $\mathrm{N}$ represents any nt $\mathrm{A}, \mathrm{U}, \mathrm{G}$ or $\mathrm{C}$ capable of base pairing with a given nt on the opposite side. $\mathrm{U}^{*}$ indicates a posttranscriptional modification in the position 34 of the anticodon.

A special class of enzymes called aminoacyl-tRNA (aa-tRNA) synthetases is responsible for addition of an aa to a tRNA in the process of aminoacylation. Aa-tRNA synthetases first activate the aa in an ATP-dependent manner forming aa-AMP, and then facilitate the transfer of the aa to either the 2'- or the 3'-OH of the last tRNA nt at the 3 '-end. To select a correct tRNA for aminoacylation, synthetases recognize specific identity elements within the tRNA structure (Soll, 1990). Wrong aa are either discriminated against by the active center of the aa-tRNA synthetase before aminoacylation can occur or after the transfer to a tRNA, by hydrolysing the incorrectly charged aa-tRNA in the editing centre of the enzyme. The selection mechanisms together contribute to the high fidelity of aminoacylation, which normally ensures that the error frequency of aminoacylation is about $10^{-6}$ (Fersht, 1977; Soll, 1990). 


\subsubsection{Stages of translation and reading frame maintenance}

The sequence of an mRNA that is translated into the sequence of a polypeptide and is enclosed by a start and a stop codons is called an open reading frame (ORF). Given the triplet nature of the genetic code, each mRNA has three potential ORFs, and it is a task of the ribosome to select the correct beginning of an ORF, and to maintain the frame until the protein is fully synthesized (Dinman, 2012).

The start of the frame is established at the beginning of translation during the stage called initiation (Rodnina, 2018). Initiation mechanisms are quite different between prokaryotes and eukaryotes, however, both use the same start codon AUG encoding methionine (Met) (Fig. 3). In bacteria, many mRNAs contain a Shine-Dalgarno (SD) sequence 8-10 nt upstream of the initiation codon, which makes specific contacts to the anti-SD sequence in $16 \mathrm{~S}$ rRNA in SSU, resulting in the correct positioning of the ribosome on the start codon and thereby promoting initiation (Milon and Rodnina, 2012; Rodnina, 2018; Steitz and Jakes, 1975). During initiation in bacteria, an mRNA and an initiator tRNA, fMet-tRNA ${ }^{\mathrm{fMet}}$, are recruited to the SSU with the help of initiation factors IF3, IF2-GTP, and IF1 (which bind to the SSU in this order) thus forming the $30 \mathrm{~S}$ initiation complex (IC) (Milon and Rodnina, 2012). Upon 50S subunit joining and hydrolysis of IF2-bound GTP, initiation factors dissociate, and the mature 70S IC is formed which is now ready for translation (Milon and Rodnina, 2012). Translation initiation in bacteria entails multiple quality control checkpoints, which ensure selection of abundant mRNAs with weak folds, selection of correct start codons and monitoring of SD-aSD and AUG-fMet-tRNA ${ }^{\text {fMet }}$ interactions (Rodnina, 2016, 2018). Prokaryotes also have mRNAs without SD (non-SD-led mRNAs) and even without 5' UTR (leaderless mRNAs), which initiate via different mechanisms (Milon and Rodnina, 2012). Initiation of non-SD-mRNAs remains poorly understood, but they are known to contain an AUG start codon residing in the single-stranded region of the mRNA, supposedly to facilitate its recognition by the ribosome. Leaderless mRNAs contain an AUG close to its 5' end and could bind directly to the pre-assembled 70S ribosome. 


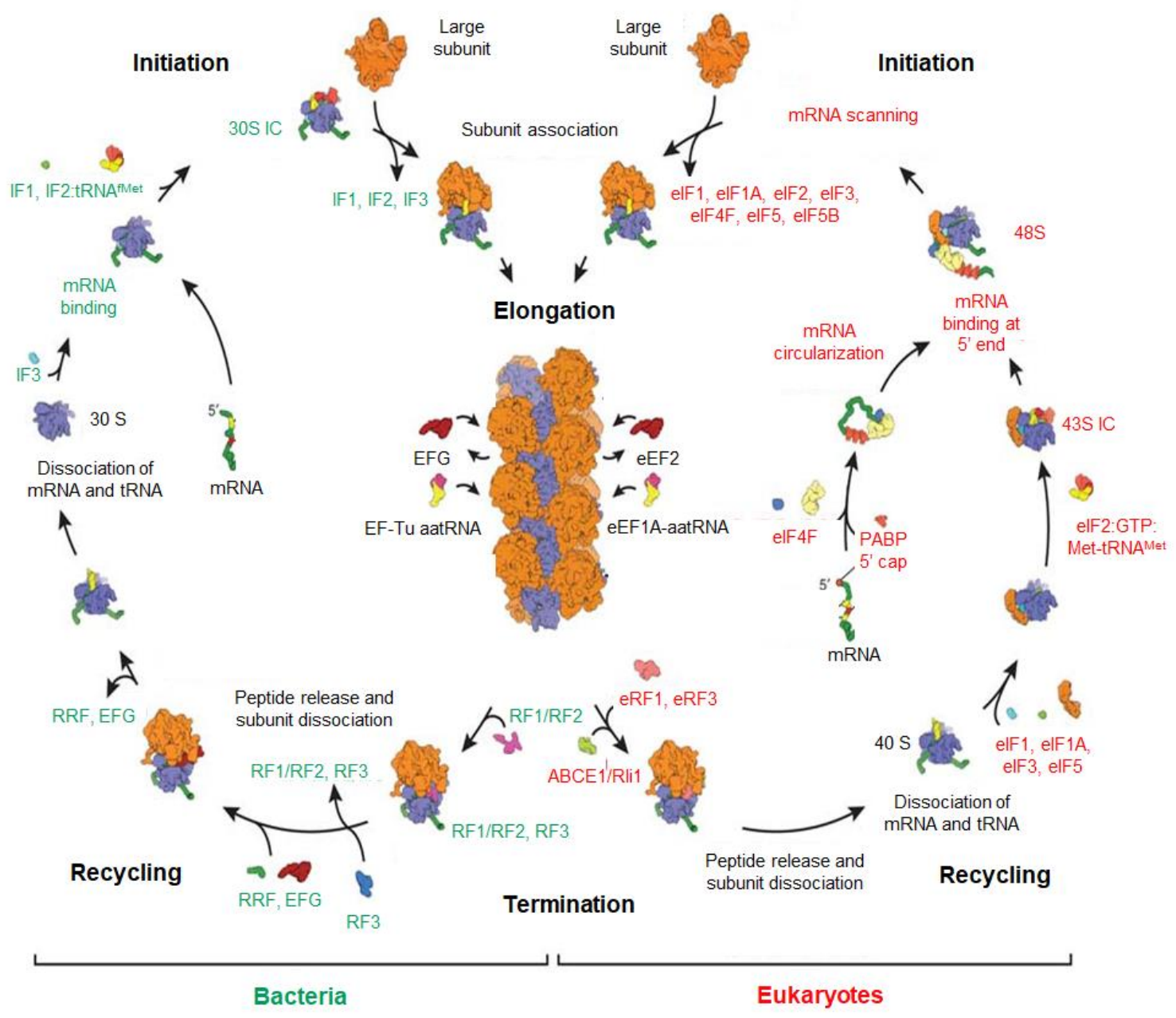

Figure 3. Comparison between translation cycles in bacteria (green) and eukaryotes (red). Key processes and molecular players are indicated. Major similarities and differences are discussed in details in the text. The figure was adapted from (Melnikov et al., 2012).

Initiation in eukaryotes is more complex and proceeds via multiple stages (Fig. 3). First, eukaryotic initiation factor 2 (eIF2) binds to initiator tRNA Met-tRNA ${ }_{i}{ }^{\text {Met }}$ thereby promoting the formation of a ternary complex (TC) eIF2-GTP-Met-tRNA ${ }_{i}{ }^{M e t}$. Next, TC together with eIF1, eIF1A, eIF3 and eIF5 assemble on the 40S SSU forming a so-called 43S pre-initiation complex (PIC). Eukaryotic mRNAs contain a 5' cap composed of a 7-methyl guanosine and a 3' poly-A tail made of several consecutive adenosine residues. The 43S PIC binds to the cap-proximal region of the mRNA with the help of eIF3, the poly(A)-binding protein (PABP), eIFs 4B, 4H (in mammals), and 4F complex. The eIF4F complex consists of eIF4E (cap-binding protein), eIF4G (large scaffolding protein) and eIF4A (DEAD box RNA helicase) proteins. Notably, PABP binds to the 3' poly-A tail and circularizes the mRNA, which leads to mRNA stabilization, and thus bolsters initiation (Munroe and Jacobson, 1990). Then, 43S PIC scans the 5' UTR of the mRNA in 5' to 3' direction until it encounters an initiator codon AUG (Jackson et al., 2010). To facilitate the selection of a correct AUG 
during scanning, the start codon is embedded in a consensus Kozak sequence, 5'-GCCGCC(A/G)CCAUGG-3' (Kozak, 1987). Upon start codon recognition the 48S IC is formed, which changes the conformation of the scanning complex into "closed" and causes displacement of eIF1, which, in turn, allows eIF5-mediated hydrolysis of eIF2-bound GTP and subsequent $\mathrm{P}_{\mathrm{i}}$ release (Maag et al., 2005; Passmore et al., 2007). Next, the 60S LSU joins the 48S IC leading to the dissociation of eIF2-GDP along with other factors (eIF1, eIF3, eIF4B, eIF4F and eIF5) mediated by eIF5B. Eventually, GTP bound to eIF5B is hydrolyzed leading to displacement of eIF5B and eIF1A, and thereby making 80S ribosomes ready for elongation (Jackson et al., 2010). Some eukaryotic mRNAs lack a cap structure and utilize a so-called internal ribosome entry site (IRES) to initiate (Jang et al., 1990; Shatsky et al., 2018). This cap-independent initiation does not require the process of mRNA scanning and the ribosome is positioned directly on the start codon AUG (Shatsky et al., 2018).

Once the ribosome has established the ORF during initiation, it must maintain the frame throughout the next step of translation called elongation. Elongation is similar in prokaryotes and eukaryotes and entails three main steps: decoding, peptide bond formation and translocation (Rodnina, 2018) (Fig. 3). The decoding center is located in the SSU of the ribosome. During decoding, the sequence of codons in the mRNA is translated into the respective aa in the growing peptide chain. The ribosome has three centers for interactions with tRNAs: the A or aminoacyl site where newly selected cognate aa-tRNA is accommodated, the $\mathrm{P}$ or peptidyl site where a tRNA bearing a growing peptide chain is positioned, and the E or exit site where deacylated tRNA is transferred to before its dissociation from the ribosome. A codon positioned in the A site is recognized by aa-tRNAs bearing appropriate aa. In prokaryotes, aa-tRNAs are delivered to the ribosome in the TC with elongation factor EF-Tu-GTP (Rodnina, 2018; Rodnina et al., 1995). During decoding, the ribosome has to select an aa-tRNA that is cognate to the codon presented in the A site and reject all other aa-tRNA that do not match the codon. The fidelity of aa-tRNA selection is on average high with most errors occurring at the rate of $10^{-7}-10^{-5}$ (Garofalo et al., 2019). The selection of the cognate aa-tRNA is achieved in several steps. Upon initial selection prior to GTP hydrolysis, binding of correct aa-tRNA to the ribosome is stabilized due to codon-anticodon recognition and the closure of the ribosome elements at the decoding site on the cognate codon-anticodon complex (Fischer et al., 2016; Loveland et al., 2017; Rodnina et al., 2017). If the incoming tRNA is correct, EF-Tu-bound GTP is hydrolyzed followed by EF-Tu-GDP rearrangements and $\mathrm{P}_{\mathrm{i}}$ release, leading to the accommodation of 
the aa-tRNA in the A site (Rodnina, 2012). After GTP hydrolysis by EF-Tu, the correct aa-tRNA moves to the A site on the LSU where it donates its aa to the growing nascent peptide chain, whereas incorrect tRNAs are rejected at a stage called proofreading (Rodnina, 2018; Rodnina and Wintermeyer, 2001a, b). EF-Tu-GDP dissociates from the ribosome and is recycled by its nucleotide-exchange factor EF-Ts, which substitutes GDP with GTP thus allowing EF-Tu to enter a new cycle of decoding (Rodnina, 2018; Rodnina et al., 2000; Rodnina and Wintermeyer, 1995). In eukaryotes, decoding proceeds via the same steps involving EF-Tu and EF-Ts analogues called eEF1A and eEF1B, respectively (Dever and Green, 2012; Rodnina and Wintermeyer, 2009).

Next, in the peptidyl transferase center of the LSU, a peptidyl-tRNA in the P site and a newly accommodated aa-tRNA in the A site react to form a peptide bond. The mechanism of peptide bond formation entails the nucleophilic attack of the amino group of the aa-tRNA on the carbonyl carbon of the ester bond in peptidyl-tRNA (Rodnina et al., 2006). The peptidyl transferase center is composed solely of RNA making the ribosome the largest known RNA catalyst (Rodnina, 2018; Rodnina et al., 2006). As compared to the reaction between model substrates in solution, the ribosome increases the rate of peptide bond formation by about $10^{7}$-fold. This enhancement is achieved by ordering water molecules, correct positioning of rRNA and tRNA, and electrostatic shielding.

In the rare cases when an erroneous aa was incorporated into the nascent peptide despite all the discrimination mechanisms, the ribosome is capable of retrospective editing (Zaher and Green, 2009). The ribosome monitors the quality of codon-intercodon interactions in the $\mathrm{P}$ site, and if the mismatch was identified, the fidelity of tRNA selection in the A site is significantly decreased. The drop in fidelity leads to accumulation of more mismatches, eventually leading to premature termination and degradation of the wrong peptide (Zaher and Green, 2009).

The last step of elongation, translocation, is driven by a ribosome-activated GTPase EF-G (in prokaryotes) or eEF2 (in eukaryotes) at the expense of GTP hydrolysis (Rodnina and Wintermeyer, 2009). In the pre-translocation ribosome, immediately after peptide bond formation, the peptidyl-tRNA in the A site and the deacylated tRNA in the P site adopt classical states meaning that their anticodons and 3 ' ends are positioned in $\mathrm{A}(\mathrm{A} / \mathrm{A})$ and $\mathrm{P}$ $(\mathrm{P} / \mathrm{P})$ site, respectively. In the absence of EF-G, this complex is dynamic, and tRNAs can fluctuate between classical and hybrid states (Moazed and Noller, 1987). In the hybrid states the 3' acceptor stems of the tRNAs in the A and P site can spontaneously move to the P 
$(\mathrm{A} / \mathrm{P})$ and the $\mathrm{E}$ site $(\mathrm{P} / \mathrm{E})$, respectively. EF-G can bind to the ribosome irrespective of the tRNA state, but it stabilizes the hybrid state (Holtkamp et al., 2014b; Sharma et al., 2016). EF-G binding and subsequent GTP hydrolysis promote a conformational change in the 30S subunit and drive the ribosome into a so-called unlocked state. Unlocking of the decoding center relaxes codon-anticodon interactions and allows the tRNAs along with the mRNA to move through the ribosome (Rodnina et al., 1997; Savelsbergh et al., 2003). Translocation involves large-scale conformational changes such as the rotation of the SSU head and the SSU body relative to the LSU. (Belardinelli et al., 2016). Upon translocation, the peptidyltRNA moves into the classical P/P state while the E-site tRNA and EF-G dissociate from the ribosome; the A site is now vacant and is waiting for the next round of aa-tRNA binding.

The elongation cycle continues until the ribosome encounters a stop codon, which is recognized by release factors (RFs) (Fig. 3). In bacteria, RF1 and RF2 act on UAA/UAG and UAA/UGA stop codons, respectively (Scolnick et al., 1968). Upon stop-codon recognition, RF1 and RF2 facilitate the hydrolysis of an ester bond of the peptidyl-tRNA, this takes place in the peptidyl transferase center of the LSU. Interestingly, the mechanism of peptide bond hydrolysis is different from that of peptide bond formation (Kuhlenkoetter et al., 2011). Finally, a GTPase, RF3, displaces RF1/RF2 from the ribosome at the cost of GTP hydrolysis (Adio et al., 2018; Peske et al., 2014). In eukaryotes, eRF1 recognizes all three stop codons. eRF1 and a GTPase, eRF3, form a complex which is responsible for peptide-bond hydrolysis (Hellen, 2018). Notably, in eukaryotes eRF3-bound GTP is hydrolyzed before the peptide is released (Dever and Green, 2012; Jackson et al., 2012).

After termination, the ribosome enters the last step of translation - recycling (Fig. 3). The aim of recycling is to release the mRNA and the deacylated tRNA, and to split the ribosomal subunits to allow their re-use in a new translation cycle. In bacteria, recycling is mediated by EF-G, ribosome-recycling factor (RRF) and IF3; the latter prevents re-association of the subunits (Peske et al., 2005; Rodnina, 2018). In eukaryotes, recycling is coupled to termination. NTPase ABCE1/Rli1 binds to eRF1 on the post-termination complex, which triggers ATP hydrolysis and subsequent splitting of $80 \mathrm{~S}$ into $60 \mathrm{~S}$ and $40 \mathrm{~S}$ with still bound mRNA and deacylated tRNA. 40S recycling could be achieved by redundant pathways involving initiation factors (eIF1, eIF1A, eIF3 and eIF3j), ligatin and to a lesser extent ligatin homologs MCT-1 (multiple copies in T-cell lymphoma-1) and DENR (densityregulated protein) (Hellen, 2018). 


\subsection{Recoding}

Despite multiple quality control checkpoints and editing mechanisms, the error rate of translation remains at about $10^{-7}-10-^{5}$ with error hotspots of up to $10^{-3}$ (Garofalo et al., 2019). The most severe translation error is a failure to maintain the reading frame because it leads to the production of wrong peptides, which could be toxic and thereby detrimental for the cell viability (Drummond and Wilke, 2009; Kurland, 1979). The error frequency of spontaneous frameshifting is about $10^{-9}-10^{-5}$ (Hardin et al., 2007). However, in some cases the sequence of the synthesized protein differs from that encoded by the 0-frame ORF, which indicates that the mRNA is recoded compared to its initial coding sequence (Fig. 4). Recoding is a change of standard decoding rules after the ribosome encountered specific stimulatory signals embedded in the mRNA sequence or structure (Atkins and Gesteland, 2010; Atkins et al., 2016; Gesteland et al., 1992). The main functions of recoding are to enlarge the genome-coding capacity and genome plasticity, and to regulate gene expression. Recoding events encompass stop-codon read-through, bypassing and PRF (Fig. 4) (Gesteland and Atkins, 1996). Normally, stop codon recognition by the ribosome leads to termination of protein synthesis, however, in a specific mRNA context the meaning of stop codons can be redefined leading to a so-called stop-codon read-through (Baranov et al., 2002; Engelberg-Kulka and Schoulaker-Schwarz, 1988). Read-through is especially prevalent in Drosophila melanogaster, but is also found in several mammalian genes (Loughran et al., 2014). Read-through serves two main functions: to translate a C-terminal peptide downstream of the stop codon or to incorporate non-universal aa selenocysteine and pyrrolysine, which are not decoded by the standard genetic code (Baranov et al., 2002; Loughran et al., 2014). Bypassing (or hopping) is very well studied on the gene $60 \mathrm{mRNA}$ of bacteriophage T4 (Chen et al., 2015; Groisman and Engelberg-Kulka, 1995; Maldonado and Herr, 1998; Samatova et al., 2014). Here the ribosome translates the first 46 codons of the mRNA until it encounters the glycine codon GGA followed by a stop codon UAG. The GGA codon is referred to as a "take-off" codon. Peptidyl-tRNA ${ }^{\text {Gly }}$ disengages from pairing with the GGA codon and is instead retained within the ribosome as it slides over a 50-nt non-coding gap sequence. Upon traversing the gap, $\mathrm{tRNA}^{\mathrm{Gly}}$ re-pairs with the mRNA at another GGA triplet called a "landing site", and normal decoding is resumed (Agirrezabala et al., 2017; Samatova et al., 2014). 


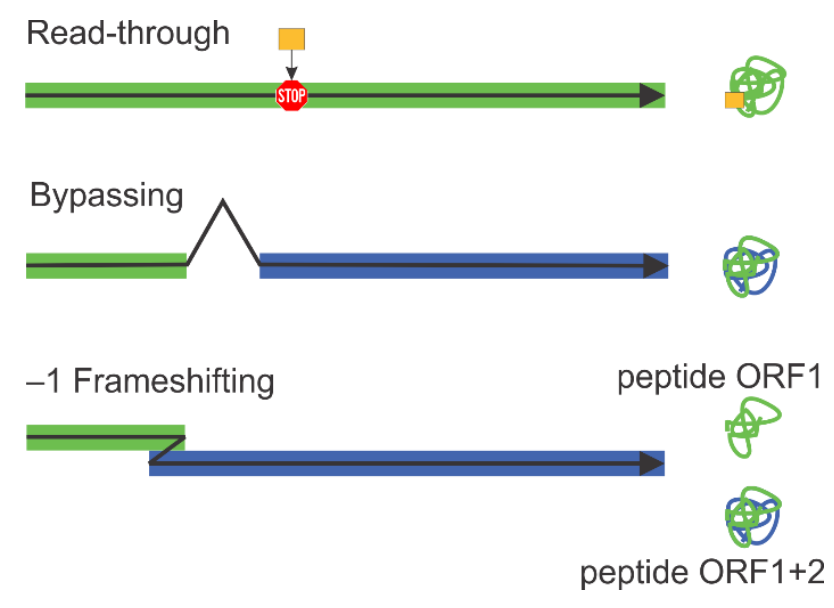

Figure 4. Programmed recoding events: read-through, bypassing and -1 frameshifting. Green and blue colors depict two different ORFs. Black arrows indicate the movement of the ribosomes during recoding. Peptides produced upon normal translation or recoding are drawn on the right. In readthrough, the yellow rectangle represents a non-universal aa incorporated at the stop codon (STOP). Figure from (Caliskan et al., 2015).

\subsubsection{Programmed ribosome frameshifting}

PRF allows to produce multiple proteins from the same mRNA by shifting the reading frame in the forward (+PRF) or backward (-PRF) direction (Fig. 4). The slippage is typically by one nt, although two-, four-, five- and six-nt shifts were reported (Fang et al., 2012; Jacks et al., 1988a; Jacks et al., 1988b; Jagger et al., 2012; Weiss et al., 1987; Wickner, 1989; Xu et al., 2004). PRF is a ubiquitous phenomenon occurring in species from the simplest viruses to higher mammals. The main functions of PRF are to increase the genome-coding capacity, to regulate the stoichiometric ratio between proteins, to regulate gene expression by influencing mRNA stability and to contribute to infectivity of pathogenic organisms (Atkins and Gesteland, 2010; Atkins et al., 2016; Farabaugh, 1996, 1997).

\subsubsection{1 +1 Programmed ribosome frameshifting}

+1PRF occurs in viruses, bacteria, yeast and mammalian cells (Farabaugh, 1996). The most well-studied example of $+1 \mathrm{PRF}$ is found in the bacterial prfB gene encoding RF2 (Craigen and Caskey, 1986). The mechanism of this frameshifting is a single slippage of the P-site tRNA caused by the translational pause due to persistently vacant A site (Farabaugh, 1996). Here the A site contains an UGA stop codon, which is recognized by RF2. When the level of RF2 in the cell drops, the recognition of the UGA codon is very slow, resulting in spontaneous +1PRF; on the contrary, if RF2 is abundant, then fast recognition results in termination at the UGA codon. This process represents an autoregulatory loop to control the 
cellular level of RF2 (Craigen and Caskey, 1986; Curran and Yarus, 1988; Donly et al., 1990). Other examples of +1 slippages include gag3 and pol3 genes of the yeast retrotransposon Ty3, yeast gene est 3 and the gene of mammalian ornithine decarboxylase antizyme (Belcourt and Farabaugh, 1990; Farabaugh et al., 1993; Matsufuji et al., 1995; Taliaferro and Farabaugh, 2007).

\subsubsection{2 -1 Programmed ribosome frameshifting}

$-1 \mathrm{PRF}$ is found in all kingdoms of life including higher eukaryotes but it is especially prevalent in viruses and mobile genetic elements (Belcourt and Farabaugh, 1990; Clare et al., 1988; Dinman, 2006; Plant, 2012 ). The efficiency of -1PRF can vary in a wide range between $0.5 \%$ and $80 \%$ depending on the organism (Brierley, 1995; Brierley and Dos Ramos, 2006; Caliskan et al., 2015; Fayet and Prère, 2010; Parkin et al., 1992; Reil et al., 1993; Tsuchihashi and Kornberg, 1990; Wilson et al., 1988). Typically, -1PRF is governed by two cis-acting elements - the SS and a downstream mRNA secondary structure (Caliskan et al., 2015; Farabaugh, 1996, 2000; Qiao et al., 2017). The SS is a repetitive heptanucleotide sequence of a type $\mathrm{X}_{1} \mathrm{XXY}_{4} \mathrm{YYZ}_{7}$, which allows the two tRNAs that read the 0-frame codons XXY and YYZ to re-pair to their cognate XXX and YYY codons after the slippage into the -1-frame (Blinkowa and Walker, 1990). The mRNA secondary structure - a SL or a pseudoknot - acts as a roadblock to hinder translocation and thereby promote frameshifting (Atkinson et al., 1997; Caliskan et al., 2014; Kim et al., 2014). The spacer between the two elements is crucial for the correct positioning of the ribosome, and in most cases is constrained to between 5 and 9 nt (Atkinson et al., 1997; Brierley, 1995; Lin et al., 2012). In addition, SD-like sequences in bacteria (Larsen et al., 1994), trans-acting proteins in viruses (Kobayashi et al., 2010; Li et al., 2014; Napthine et al., 2017; Wang et al., 2019), G-quadruplexes (Endoh and Sugimoto, 2013; Yu et al., 2014) and miRNAs in mammalian cells (Belew et al., 2014) can modulate the-1PRF efficiency. Examples of -1PRF events in different organisms and their functions are summarized in Table 1. 
Table 1. Examples of -1PRF in three domains of life

\begin{tabular}{|l|l|l|}
\hline Eukaryotes & Bacteria & Archaea \\
\hline $\begin{array}{l}\text { HeT-A, Drosophila sp. } \\
\text { retrotransposon for telomere } \\
\text { formation (Danilevskaya et } \\
\text { al., 1994) }\end{array}$ & $\begin{array}{l}\text { dnaX mRNA, } \text {-subunit of } \\
\text { DNA Pol III holoenzyme } \\
\text { (Tsuchihashi and Kornberg, } \\
\text { 1990) }\end{array}$ & $\begin{array}{l}\text { fucA1 mRNA, } \alpha \text {-L-fucosidase } \\
\text { of thermoacidophile } \\
\text { Sulfolobus solfataricus } \\
\text { (Cobucci-Ponzano et al., } \\
\text { 2006; Cobucci-Ponzano et al., } \\
\text { 2012) }\end{array}$ \\
\hline $\begin{array}{l}\text { Edr1 (human PEG10) mRNA, } \\
\text { mammalian embryonal } \\
\text { carcinoma differentiation } \\
\text { regulated gene (Cardno et al., } \\
\text { 2015; Clark et al., 2007; } \\
\text { Manktelow et al., 2005) }\end{array}$ & $\begin{array}{l}\text { cdd mRNA, cytidine } \\
\text { deaminase of Bacillus subtilis } \\
\text { (Mejlhede et al., 1999) }\end{array}$ & \\
\hline $\begin{array}{l}\text { Ma3 mRNA, human } \\
\text { paraneoplastic antigen (Wills } \\
\text { et al., 2006) }\end{array}$ & $\begin{array}{l}\text { IS1, transposition activity of } \\
\text { the E. coli insertion element } \\
\text { (LCR5 mRNA, co-receptor for }\end{array}$ & \\
$\begin{array}{l}\text { HIV-1 entry (Belew et al., } \\
\text { 2014) }\end{array}$ & & \\
\hline
\end{tabular}

$-1 \mathrm{PRF}$ is often used by bacteriophages (Mu phage, Enterobacteria phage P2) and viruses infecting fungi and unicellular protozoans (Giardia lamblia virus, Saccharomyces cerevisiae (S. cerevisiae) virus L-A); plants (Pea enation mosaic virus-1, Barley yellow dwarf virus (BYDV)); birds (Turkey astrovirus 1, Avian infectious bronchitis virus (IBV)) and mammals including humans (Human astrovirus 1, Porcine reproductive and respiratory syndrome virus, Human coronavirus 229E, Human SARS coronavirus, Mouse mammary tumor virus (MMTV), HIV-1, SFV, Middleburg virus (MIDV)) (Brierley, 1995; Plant, 2012). In most viruses the function of frameshifting is to produce viral replicases; in retroviruses (e.g., HIV-1) PRF also produces a viral integrase and a protease (Jacks et al., 1988b). However, frameshifting could also serve many non-canonical functions. In phage $\mathrm{Mu}-2 \mathrm{PRF}$ is responsible for structural proteins needed for its tail assembly (Xu et al., 2004). -1-frame NS1 protein of flaviviruses plays a role in viral neuroinvasiveness by regulating innate immune response (Melian et al., 2010). In alphaviruses (e.g., SFV) frameshifting on $6 \mathrm{~K}$ mRNA results in the synthesis of the structural proteins $\mathrm{TF}$ and $6 \mathrm{~K}$ needed for virion assembly and involved in infectivity (Firth et al., 2008; Snyder et al., 2013).

\subsubsection{Mechanism of -1PRF}

Two main mechanisms of -1PRF were elucidated up-to-date. The first mechanism was revealed by rapid kinetic methods using the 1a/1b model mRNA of IBV (Fig. 5) (Caliskan et al., 2014; Caliskan et al., 2015). The IBV frameshifting motif consists of a SS U $\mathrm{UUA}_{4}$ $\mathrm{AAG}_{7}$ encoding leucine (UUA) and lysine (AAG), and a pseudoknot positioned $6 \mathrm{nt}$ 
downstream. Here-1PRF occurs during the late stage of translocation when the confirmation of the ribosome resembles a chimeric hybrid state with $\mathrm{tRNA}^{\mathrm{Leu}}$ in the pe/E and tRNA ${ }^{\mathrm{Lys}}$ in the ap/P states (Belardinelli et al., 2016; Caliskan et al., 2014) (Fig. 5). Lower-case letters are used to indicate that the tRNA is bound in a chimeric state within SSU or LSU, whereas upper-case letters refer to canonical A, P or E sites on either subunit. For instance, pe/E state means that the anticodon loop of the tRNA is bound between the P site of the SSU head and the E site of the SSU body, whereas the tRNA acceptor stem makes contacts to the classical E site of the LSU (Belardinelli et al., 2016). The downstream pseudoknot structure impedes the closing movement of the 30S SSU head, which, in turn, hinders the release of a deacylated tRNA from the E site (Caliskan et al., 2014; Chen et al., 2013; Chen et al., 2014; Kim et al., 2014). The presence of a strong secondary structure element leads to translational pausing during which EF-G may take multiple attempts to complete translocation while the ribosome tries to resolve the secondary structure to continue canonical decoding in 0 -frame (Chen et al., 2014; Namy et al., 2006; Yan et al., 2015). Numerous EF-G attempts together with the SSU head rotation seem to destabilize the codon-anticodon interactions on the SS and thereby promote the simultaneous leftward slippage of tRNA ${ }^{\text {Leu }}$ and tRNA ${ }^{\text {Lys }}$. Notably, $-1 \mathrm{PRF}$ appears favorable for translation because the ribosomes which shifted the frame complete translocation and release EF-G three times faster as compared to those remaining in 0-frame (Fig. 5) (Caliskan et al., 2014). Hence, -1PRF could be considered as a rescue mechanism to resolve a persistent translational block caused by a secondary structure, and resume translation at its normal rate. Translocation-dependent -1PRF seems to be responsible for most cases of dual backward slippages described in the literature including bacterial dnaX (Fig. 6 \& 7, upper panel) (Caliskan et al., 2017; Chen et al., 2014; Kim et al., 2014; Yan et al., 2015). 


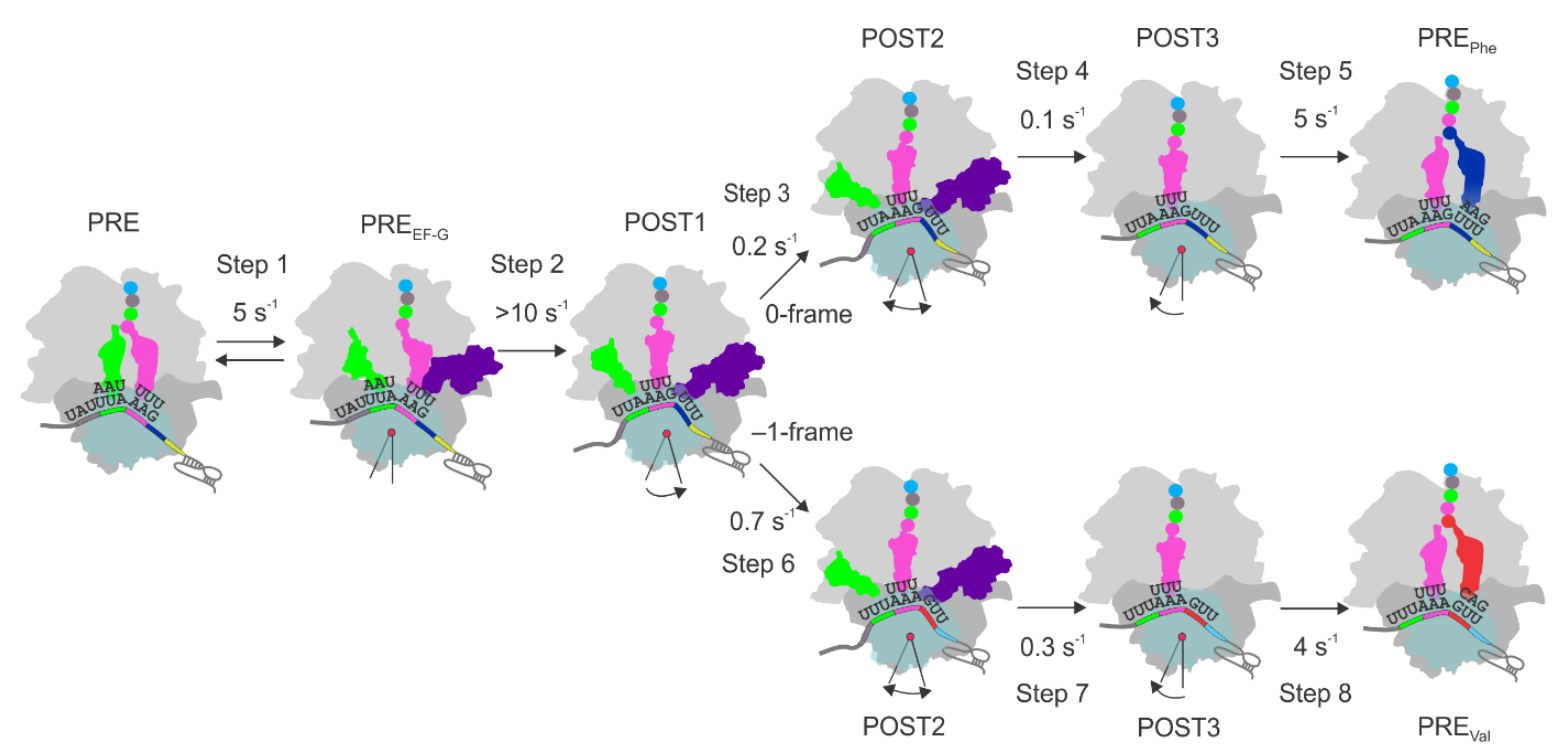

Figure 5. Kinetic model of translocation-dependent -1 PRF on $1 \mathrm{a} / 1 \mathrm{~b}$ mRNA of IBV. PRE (pretranslocation) and POST (post-translocation) refer to different conformational states of the ribosome prior to and after tRNA translocation, respectively. SS-bound tRNAs Leu-tRNA ${ }^{\text {Leu }}$ and Lys-tRNA ${ }^{\text {Lys }}$ are depicted in light green and magenta, respectively. tRNAs reading the codon after the SS in 0 -frame (Phe-tRNA ${ }^{\mathrm{Phe}}$ ) and -1-frame (Val-tRNA ${ }^{\mathrm{Val}}$ ) are in blue and red, respectively; EF-G is in purple. Colored circles attached to a peptidyl-tRNA represent a growing peptide. Rates of different steps are given. Commitment to the -1 -frame takes place during step 6 . The figure is from (Caliskan et al., 2014).

Translation of the dnaX mRNA produces the full-length $\tau$ protein and the shorter $\gamma$ protein as a result of frameshifting. Both products are essential for the loading of the sliding clamp onto the DNA strand and formation of DNA polymerase III holoenzyme complex in E. coli (Larsen et al., 1994; Tsuchihashi and Brown, 1992; Tsuchihashi and Kornberg, 1990). The frameshifting efficiency measured in bacterial cells is about 70\%-80\% (Caliskan et al., 2017; Tsuchihashi and Brown, 1992). The dnaX mRNA frameshifting site contains an internal SD-like sequence, SS and a downstream SL (Fig. 6). The SD-like sequence is located $11 \mathrm{nt}$ upstream of the SS and might be involved in base pairing with the $3^{\prime}$ end of the 16S rRNA (Larsen et al., 1994). The $\mathrm{SS}$ has the sequence of $\mathrm{A}_{1} \mathrm{AAA}_{4} \mathrm{AAG}_{7}$ coding for two Lys residues (Blinkowa and Walker, 1990). The SS and the SL are separated by a 6-nt spacer, which is responsible for the correct positioning of the ribosome with regard to the secondary structure during frameshifting. Mutations or removal of any frameshifting elements greatly reduce the efficiency of -1 PRF in dnaX (Larsen et al., 1994; Tsuchihashi and Brown, 1992). 


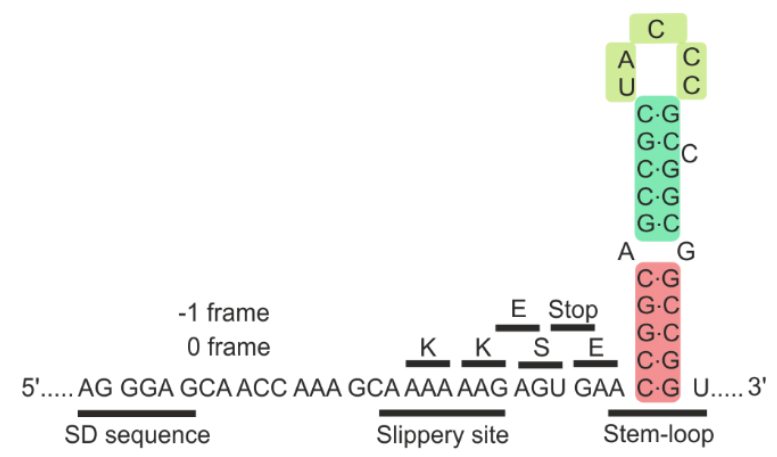

Figure 6. Structure of the frameshifting motif of the dnaX mRNA. The main elements of the dnaX frameshifting sequence are underlined. The loop is shown in light green, stem 1 - in orange, stem 2 - in green. The 0- (non-frameshifting) and the -1-frame (frameshifting) peptides are given. Figure is from (Caliskan et al., 2015).

Notably, $-1 \mathrm{PRF}$ in dnaX can proceed via two alternative mechanisms, of which one is activated by aa-tRNA limitation (Fig. 7, lower panel) (Caliskan et al., 2017). Here the A site remains vacant due to the absence of the cognate aa-tRNA causing a pause in translation which eventually stimulates a single slippage of the P-site tRNA (Fig. 7, lower panel). Once the ribosome encounters a codon which could be decoded by available aa-tRNAs, normal translation is resumed (Caliskan et al., 2017). This frameshifting route could take place at any codon, and it is independent of the downstream mRNA secondary structure. In addition, as compared to translocation-dependent -1PRF, this so-called "hungry" frameshifting is very slow (Caliskan et al., 2017). This mechanism can also explain the appearance of peptides from multiple alternative frames (e.g., $-2,+2$ or -4 ) and accumulation of incomplete peptides during in vitro translation of dnaX (Fig. 7, lower panel) (Yan et al., 2015).

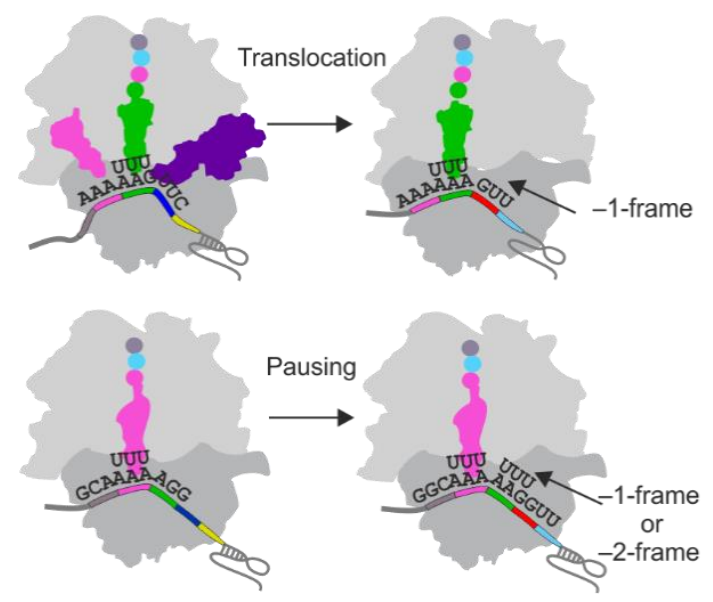

Figure 7. Comparison between translocation-dependent (upper panel) and "hungry" (lower panel) pathways of -1PRF on dnaX mRNA of $E$. coli. SS tRNAs are in magenta and green, EF-G is in 
purple. The two mechanisms are discussed in details in the text. The figure is from (Caliskan et al., 2017).

\subsubsection{Role of cis-acting enhancer sequences in +1 and $-1 P R F$}

Frameshifting can be stimulated by cis-acting elements following the SS, known as enhancers, which usually do not fold into stable mRNA secondary structures but are thought to make interactions with the ribosome based on sequence specificity. Enhancers are known to stimulate $+1 \mathrm{PRF}$ in the gag3-pol3 gene overlap of yeast retrotransposon Ty3 and yeast gene est3, and could be responsible for -1PRF stimulation in SFV and BYDV (Fig. 8). +1PRF in Ty3 and EST3 mRNAs occurs by a mechanism which does not require conventional tRNA slippage but relies on particular peptidyl-tRNAs (Farabaugh et al., 1993; Vimaladithan and Farabaugh, 1994). For instance, in Ty3 frameshifting takes place on a $\mathrm{GCG}_{3} \mathrm{AGU}_{6} \mathrm{U}_{7} \mathrm{SS}$ and depends on the presence of peptidyl-tRNA ${ }^{\mathrm{Ala}}$ reading GCG codon, and translational pausing caused by slow decoding of a low-abundance AGU codon (Fig. 8A). The frameshifting product is generated without a P-site tRNA slippage by out-offrame binding of a tRNA ${ }^{\mathrm{Val}}$ to the GUU codon while the A site is vacant (Vimaladithan and Farabaugh, 1994). In Ty3 the SS is followed by a downstream 14-nt sequence, often called a Ty3 context or stimulator, which increases the frameshifting efficiency by almost 8 -fold (Guarraia et al., 2007). The est3 gene contains a 27-nt enhancer after the SS providing a similar level of frameshifting stimulation (Fig. 8B) (Taliaferro and Farabaugh, 2007). The EST3 stimulator is more complex and consists of three individual domains each responsible for an about 2-fold increase in +1PRF. Ty3 and EST3 enhancers do not share primary sequence similarity; however, mutations of nt in positions 8 and 9 following the SS have detrimental effects on frameshifting efficiencies (Guarraia et al., 2007). The exact mechanism of their action remains unknown, but these stimulators seem to interact with rRNA or other parts of the ribosome, thereby promoting frameshifting. A potential enhancer was identified to mediate -1PRF in 6K mRNA of an alphavirus SFV. Similarly to Ty3 and EST3, in SFV the SS is followed by a 18-nt sequence, in which mutations or deletions significantly decrease the efficiency of -1PRF (Fig. 8C) (Chung et al., 2010). Notably, the potential enhancer sequence might reside within a SL structure predicted by bioinformatics analysis (Chung et al., 2010).

Plant virus BYDV uses upstream and downstream enhancers to promote $-1 P R F$ in its RNA polymerase gene (Fig. 8D) (Barry and Miller, 2002). BYDV contains a classical frameshifting motif made of a slippery heptamer $\mathrm{G}_{1} \mathrm{GGU}_{4} \mathrm{UUU}_{7}$ followed by a bulged SL. 
The upstream enhancer forms two SLs, deletions in which decrease the frameshifting efficiency by about $50 \%$. Their probable functions are to slow down the ribosome already before the SS to enhance frameshifting or to act as an "insulator" to prevent misfolding of the downstream stimulators. The downstream stimulator is located 3 kilobases away from the SS, and its deletion abolishes -1PRF. This long-distance frameshifting element is predicted to fold into a SL structure, which could base pair with the bulge of the SL following the SS thereby stimulating -1PRF (Fig. 8D). Frameshifting stimulation by a long-distant base pairing is conserved among different BYDV isolates and is also predicted for a BYDVlike virus, Soybean dwarf virus (Barry and Miller, 2002).

A

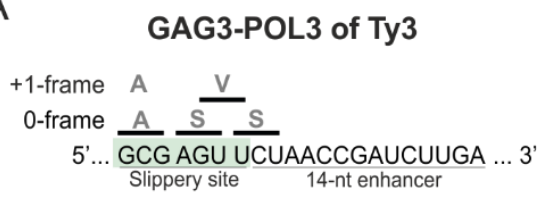

C

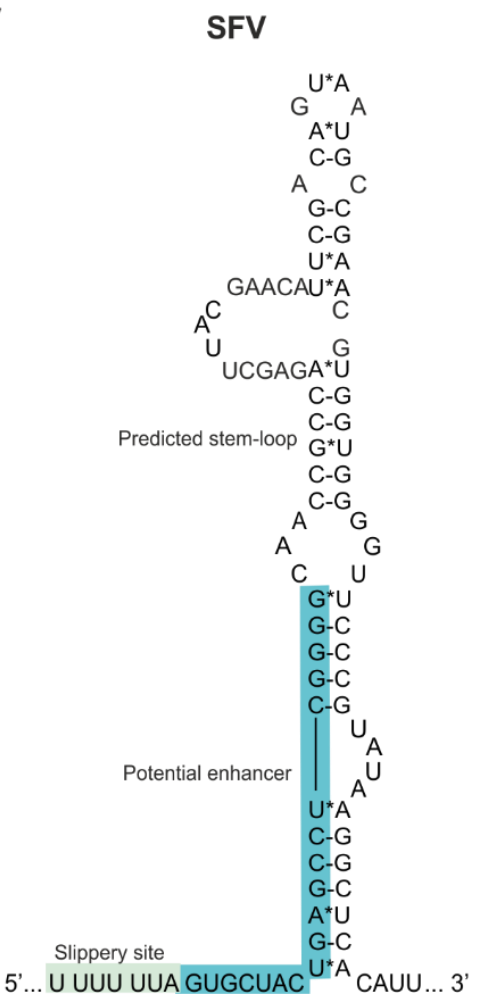

B

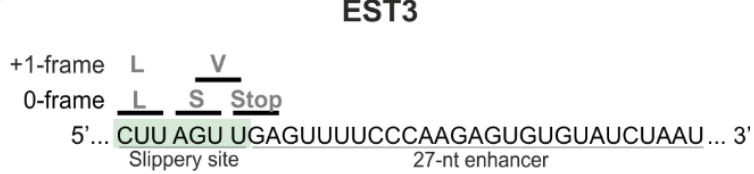

D

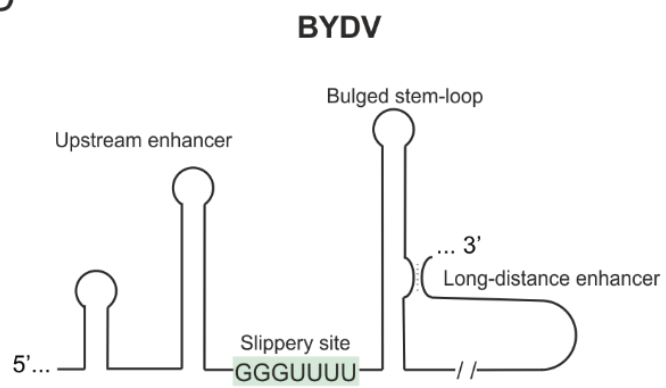

Figure 8. Cis-acting stimulators of +1 frameshifting in GAG3-POL3 mRNA of S. cerevisiae retrotransposon Ty3 (A), S. cerevisiae mRNA EST3 (B), and -1 frameshifting in Semliki Forest virus (SFV) 6K mRNA (C) and Barley yellow dwarf virus (BYDV) (D). SS are highlighted light green, potential enhancer in SFV is in blue. Products of 0- and +1-frames are indicated in (A) and (B). 


\section{3. -1 Programmed ribosome frameshifting in human immunodeficiency virus}

HIV is the causative agent of the acquired immunodeficiency syndrome (AIDS). In 2017, about 40 million people worldwide were infected with HIV, and about 1 million died from AIDS or AIDS-related illnesses. HIV belongs to the genus Lentivirus within the family Retroviridae. Based on the origin, genetic characteristics and differences in viral antigens, HIV is classified into HIV-1 and HIV-2, with HIV-1 being more common. HIV-1 is further subdivided into $\mathrm{O}, \mathrm{P}, \mathrm{N}$ and $\mathrm{M}$ groups, with the $\mathrm{M}$ group being predominant. Viruses within M group are divided into subtypes, and subtype B is the most widespread among HIVinfected individuals. Non-human primates are infected by another retrovirus similar to HIV called simian immunodeficiency virus (SIV).

The HIV virion contains the HIV genome and is built of an outer layer called envelope with spikes of glycoproteins (gp) and an inner core called capsid. The HIV genome is built of two identical single-stranded RNA molecules and contains 9 genes whose protein products are responsible for viral particle formation and replication (gag, pol, env, tat, rev) and for infectivity (nef, vif, vpr, vpu) (Turner and Summers, 1999) (Fig. 9). HIV genes can be subdivided into early genes (tat, rev and nef) which are expressed upon viral entry into the host cell and late genes (gag, pol, env, vif, vpu and vpr) transcribed before virion formation and virus release from the cell (Cullen, 1991). Notably, the codon usage of HIV early-expressed genes corresponds to that of highly expressed host genes, but the codon bias of the late genes is remarkably different posing the question about the mechanism of their efficient translation (van Weringh et al., 2011).

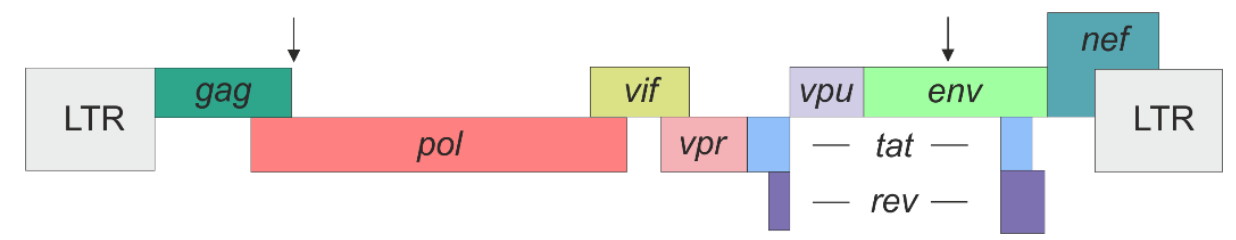

Figure 9. Structure of HIV-1 genome. LTR stands for long non-translated repeats. Arrows indicate genes in which -1PRF takes place.

HIV infects a variety of immune cells including $\mathrm{CD} 4^{+} \mathrm{T}-$-lymphocytes, macrophages and microglial cells. To enter the host cell, HIV envelope protein gp120 attaches to the cell surface receptor $\mathrm{CD}^{+}$and its signaling co-receptor CCR5 or CXCR4. Receptor recognition triggers virus-host membrane-fusion, upon which the viral capsid is released into the cytoplasm. Here the viral enzyme reverse transcriptase (RT) converts the HIV RNA into DNA, which is then transported into the nucleus of the infected cell. Inside the nucleus, 
another viral enzyme called integrase inserts the HIV DNA into the cellular genome. After integration, HIV uses the cellular machinery for its DNA replication, transcription and protein synthesis. Newly produced proteins along with genomic RNA assemble on the cell surface to form new HIV virions, which are then ready to bud off from the host cell. Viral progeny is non-infectious at first, but upon budding an HIV protease processes viral proteins, which leads to mature particles that can now infect another host cell (Maartens et al., 2014).

Frameshifting in HIV-1 takes place at two positions of the genome: in the env gene and in the gag-pol gene overlap (Fig. 9) (Jacks et al., 1988b; Olubajo and Taylor, 2005). The env gene encodes structural proteins, which together with the outer lipid membrane constitute a viral envelope. $-1 \mathrm{PRF}$ in the env gene leads to the production of a truncated glutathione peroxidase homologue with both antioxidant and antiapoptotic activities. The frameshifting motif of $e n v$ consists of a SS $\mathrm{A}_{1} \mathrm{AAA}_{4} \mathrm{AGA}_{7}$ followed by a pseudoknot. The AGA arginine codon is "hungry" because it is read by a rare tRNA ${ }^{\mathrm{Arg}}$ isoacceptor. In infected cells arginine deficiency in the culture media greatly increases the frameshifting efficiency leading to accumulation of the glutathione peroxidase, which apparently evolved to protect HIV against oxidative stress in the host cell (Olubajo and Taylor, 2005).

\subsection{1 -1PRF in gag-pol gene overlap}

Two HIV-1 genes, gag and pol, encoding structural proteins and enzymes, respectively, overlap by 205 nt. pol does not have its own initiation codon and is positioned out-of-frame with regard to gag (Fig. 9) (Ratner et al., 1985; Sanchez-Pescador et al., 1985; Wain-Hobson et al., 1985). The SS is found at the end of the gag gene, and-1PRF over the slippery sequence leads to the production of a Gag-Pol fusion polyprotein, which is then processed into mature enzymes: RT with intrinsic RNAse $\mathrm{H}$ activity, protease and integrase (Jacks et al., 1988b). The ratio between the Gag and Gag-Pol polyproteins is crucial for virus viability. Changes in the ratio are detrimental for replication, particle formation and infectivity of HIV (Biswas et al., 2004; Karacostas et al., 1993; Park and Morrow, 1991; Shehu-Xhilaga et al., 2001). The efficiency of gag-pol-1PRF in human cells is about $2 \%$ to $11 \%$, as measured with reporter constructs containing either the frameshifting motif or a complete gap-pol overlap sequence using a dual-luciferase assay (Cassan et al., 1994; Grentzmann et al., 1998a; Mathew et al., 2015; Plant and Dinman, 2006). The frameshifting efficiencies measured in human cells were recapitulated in different heterologous systems in vivo or in vitro with the help of mammalian, yeast or E. coli translation extracts, suggesting that $-1 \mathrm{PRF}$ in HIV employs mechanisms evolutionary conserved through all the kingdoms of 
life (Bidou et al., 1997; Brunelle et al., 1999; Dulude et al., 2002; Horsfield et al., 1995; Jacks et al., 1988b; Parkin et al., 1992; Plant and Dinman, 2006; Reil et al., 1993; Weiss et al., 1989; Wilson et al., 1988; Yelverton et al., 1994).

\subsubsection{Structure of the gag-pol frameshifting site}

The gag-pol SS1 has the sequence of $\mathrm{U}_{1} \mathrm{UUU}_{4} \mathrm{UUA}_{7}$ encoding Phe and Leu in 0-frame (Fig. 10) (Jacks et al., 1988b). Mutations of any $U$ to any other nt are detrimental for the frameshifting efficiency (Doyon et al., 1998; Girnary et al., 2007; Jacks et al., 1988b; Weiss et al., 1989; Wilson et al., 1988). In the majority of the HIV strains, the SS1 is followed by a SL element (Fig. 10), except for the O-group viruses where a pseudoknot is found in the same position (Baril et al., 2003b; Dulude et al., 2002; Jacks et al., 1988b). Notably, the SL1 structures of SIV and HIV-2 have an identical geometry and differ only by single nucleotide polymorphism while HIV-1 contains a completely different SL1 (Marcheschi et al., 2007).

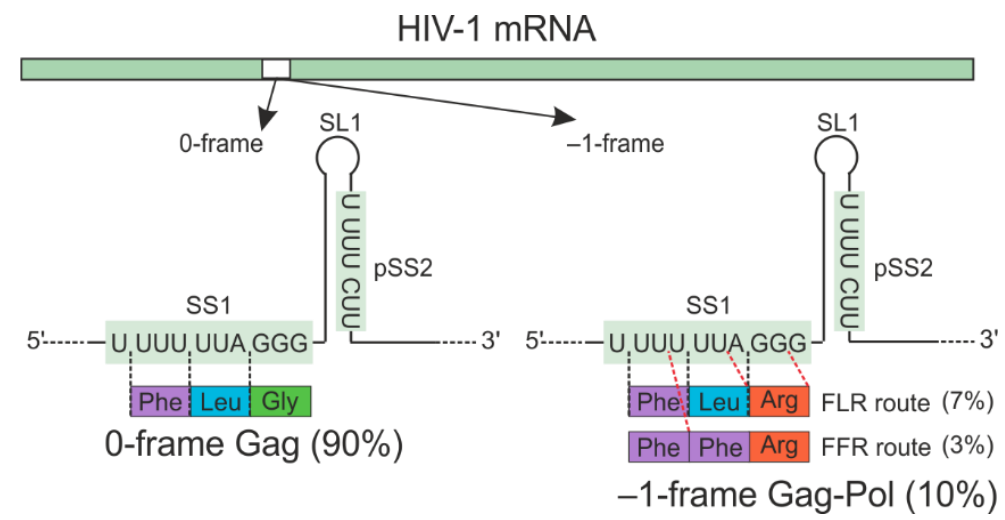

Figure 10. Scheme of the gag-pol frameshifting site. The first slippery site (SS1) and the putative second slippery site (pSS2) are highlighted in green; the stimulatory mRNA structure element downstream of the SS1 is indicated as a stem-loop 1 (SL1). Aa incorporated into 0-frame and -1 -frame peptides as well as the potential-1PRF routes and in vivo efficiencies are shown below the frameshifting sites.

The SL1 of HIV-1 contains an upper and a lower stems separated by a 3-nt purine bulge GGA, which introduces a $60^{\circ}$ angle between the stems (Fig. 11) (Dulude et al., 2002; Gaudin et al., 2005; Kang, 1998; Low et al., 2014; Staple and Butcher, 2003, 2005). The upper stem is highly thermostable $\left(\mathrm{T}_{\mathrm{m}}>90^{\circ} \mathrm{C}\right)$; it is made of 11 Watson-Crick base pairs capped with an ACAA tetraloop (Fig. 11). On the contrary, the lower stem, built of 8 weak base pairs, is unstable $\left(\mathrm{T}_{\mathrm{m}}=47^{\circ} \mathrm{C}\right)$. During translation, the ribosome must unwind the lower stem before it reaches the slippery sequence, but then is presumably stalled by a highly stable upper stem (Mazauric et al., 2009; Staple and Butcher, 2003, 2005). All HIV subtypes of group M 
contain SL1 with a similar geometry despite multiple sequence variations (Baril et al., 2003a; Telenti et al., 2002). Sequence variability is reflected in different overall thermodynamic stabilities of the structures; however, the frameshifting efficiency remains unchanged between the subtypes (Baril et al., 2003a; Chang et al., 1999). This notion suggests that not the global but the local thermodynamic stability of the SL1 element influences the frameshifting efficiency in HIV (Garcia-Miranda et al., 2016; Mouzakis et al., 2013). Multiple publications reported a modulatory effect of the SL1 on -1PRF (Bidou et al., 1997; Cassan et al., 1994; Garcia-Miranda et al., 2016; Kollmus et al., 1994; Parkin et al., 1992). Other reports argue that the mRNA stimulatory element in HIV-1 is not a simple SL but a complex intramolecular triplex RNA structure, which could fold into different pseudoknot types (Dinman et al., 2002). Moreover, numerous papers suggest that the SS1 alone could stimulate a significant level of -1PRF while the SL1 is dispensable for frameshifting in HIV-1 (Brunelle et al., 1999; Honda et al., 1995; Reil et al., 1993; Wilson et al., 1988). Hence, the identity and the contribution of the mRNA secondary structure to - 1PRF in HIV are still to be elucidated.



Figure 11. Structure of the HIV-1 SL1. The SS1 is highlighted in light green; SL1 elements: tetraloop is in grey, upper stem is in blue, bulge is in magenta, lower stem is in yellow.

\subsubsection{Different models of -1PRF on gag-pol overlap}

$-1 \mathrm{PRF}$ on the gag-pol SS1 gives rise to two frameshifting products, one which contains the 0 -frame peptide Phe-Leu followed by the -1-frame aa sequence and another with a Phe incorporated instead of Leu, i.e., Phe-Phe followed by the -1-frame sequence. The ratio of the two -1PRF products is about $70 \%$ to $30 \%$ (Fig. 10) (Cardno et al., 2015; Jacks et al., 1988b; Liao et al., 2011; Yelverton et al., 1994). The mechanism of frameshifting on the gag-pol mRNA is unclear and multiple models were developed to explain it. To account for 
the two frameshifting products, Liao and co-workers proposed three potential kinetic pathways (Fig. 12) (Liao et al., 2011). In Pathway I, -1PRF occurs during translocation when the ribosome moves from its position on the AAU and UUU codons in the $\mathrm{P}$ and A sites to the UUU and UUA codons of the SS1, respectively. After the slippage, Phe incorporates in -1-frame; the alternative-1PRF product containing the Phe-Leu peptide cannot form. In the alternative pathway III, -1PRF may result from incomplete translocation over the two SS1 codons, which will result in the Phe-Leu but not the Phe-Phe frameshifting peptide. As mentioned before, the mechanism that entails simultaneous slippage of two tRNAs during translocation represents the major frameshifting pathway in IBV $1 a / 1 b$ and $d n a X$ genes as well as in other studied systems (Caliskan et al., 2014; Caliskan et al., 2017; Chen et al., 2013; Chen et al., 2014; Horsfield et al., 1995; Kim et al., 2014; Leger et al., 2007; Mathew et al., 2015; Mazauric et al., 2009; Yan et al., 2015). In contrast to pathways I and III, which lead to frameshifting during tRNA translocation, -1PRF may also occur during accommodation of Leu-tRNA $^{\text {Leu }}$ into the A site (pathway II) (Liao et al., 2011), thereby producing the Phe-Leu-1-frame product, in agreement with previous suggestions (Brunelle et al., 1999; Jacks et al., 1988a; Jacks et al., 1988b). The Phe-Phe frameshifting product can form either through pathway I (Liao et al., 2011); or, alternatively, it could be formed by yet another pathway through a slippage of a single P-site peptidyl-tRNA ${ }^{\text {Phe }}$ in the presence of the vacant A site (Fig. 12) (Brunelle et al., 1999; Cardno et al., 2015; Horsfield et al., 1995; Yelverton et al., 1994). The latter frameshifting mechanism can operate when the A-site aa-tRNA is in short supply, as described for frameshifting on dnaX mRNA (Atkinson et al., 1997; Brunelle et al., 1999; Caliskan et al., 2017; Cardno et al., 2015; Farabaugh, 1996; Horsfield et al., 1995; Yelverton et al., 1994). Moreover, the HIV SS1 was reported to support-2PRF (Lin et al., 2012); as in those experiments the frameshifting sequence was placed into an unnatural context followed by an antisense oligonucleotide-binding site, the extent of alternative slippages on the HIV heptamer is still to be determined. 


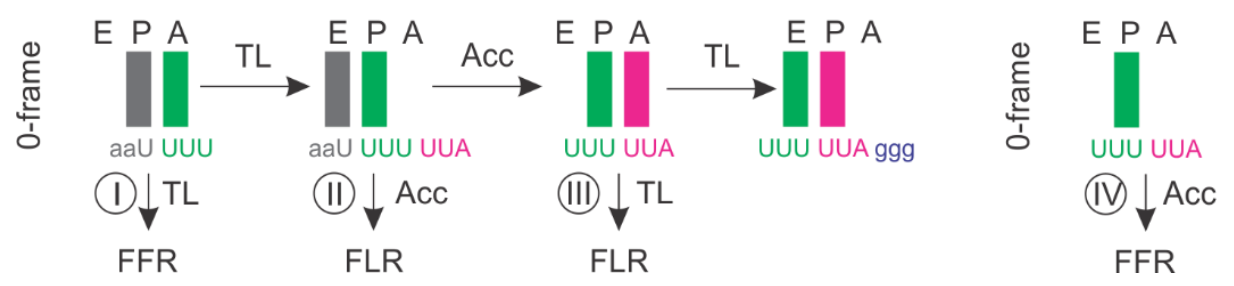

Figure 12. Kinetic pathways of $-1 P R F$ in HIV-1. Pathways I, II, III and IV describe alternative routes by which FFR and FLR frameshifting products could be formed. I, II and III correspond to pathways proposed by (Liao et al., 2011); IV refers to a single P-site tRNA slippage. The codon preceding the SS1 is in grey, SS1 codons are in green and magenta, the codon following the SS1 is in purple. Colored rectangles represent tRNAs. TL stands for translocation, Acc - for accommodation. E, P, A are ribosomal sites for interactions with tRNAs. Figure is modified from (Caliskan et al., 2014).

\subsubsection{Second putative frameshifting site within gag-pol overlap}

In addition to the classical frameshifting motif, the gap-pol gene was predicted to have a pSS2 $38 \mathrm{nt}$ downstream of the canonical SS1 positioned within the SL1 (Fig. 10) (Brierley and Dos Ramos, 2006; Doyon et al., 1998; Garcia-Miranda et al., 2016; Girnary et al., 2007; Knops et al., 2012). The second site has a sequence $\mathrm{U}_{1} \mathrm{UUU}_{4} \mathrm{CUU}_{7}$ coding for Phe and Leu in 0-frame; the existence of the downstream mRNA secondary structure element was not investigated (Fig. 10). Normally, the sequence is not slippery, but a mutation $\mathrm{C}_{5}$ to $\mathrm{U}\left(\mathrm{C}_{5} \mathrm{U}\right)$, which appears as compensatory resistance mechanism upon anti-HIV therapy, may facilitate additional frameshifting at this normally silent site (Doyon et al., 1998; Garcia-Miranda et al., 2016; Girnary et al., 2007; Knops et al., 2012). The mechanism, which favors the $\mathrm{C}_{5} \mathrm{U}$ mutation, is well understood. Anti-HIV therapy with protease inhibitors leads to accumulation of mutations in the HIV protease that impair the recognition of its specific cleavage sites. To allow polyprotein maturation by the mutated protease, secondary mutations arise at the pSS2, which harbors the p1/p6 cleavage site of the Gag polyprotein (Bally et al., 2000; Banke et al., 2009; de Oliveira et al., 2003; Larrouy et al., 2011; Pettit et al., 2002). The $\mathrm{C}_{5} \mathrm{U}$ mutation changes Leu for Phe, which enhances van der Waals interactions between the substrate and the mutant protease, thereby increasing the protease activity by about 10 -fold (Ozen et al., 2014). 


\subsubsection{Anti-HIV therapeutics targeting frameshifting}

Recent advances in the development of anti-retroviral therapeutics significantly decreased the mortality rate of HIV-infected patients and made an important impact on their quality of life. The most common therapy to control AIDS progression and severity is a so-called highly active antiretroviral therapy (HAART), which is a combination of drugs targeting viral proteins at different stages of the viral life cycle. However, due to the high mutation rate of HIV-1, virus isolates emerge that are resistant to one or multiple components of the HAART (Saini et al., 2012). That is why the quest for better targets and efficient therapeutics against HIV continues. The HIV frameshifting motif is an attractive target for antiviral drug design because its slippery heptamer SS1 is an invariant sequence conserved among HIV-1 isolates, and even between HIV-1, HIV-2 and SIV viruses (Baril et al., 2003a), and the frameshifting efficiency is linked to viral replication and particle formation (Biswas et al., 2004). Multiple attempts were made to design synthetic molecules against the frameshifting site of HIV-1. The first synthetic compound was 1,4-bis[N-(3-N,Ndimethylpropyl)amidino]-benzene tetrahydrochloride known as RG501 targeting the major groove of the upper stem in SL1 (Hung et al., 1998). RG501 stimulated -1PRF, altered the Gag/Gag-Pol ratio and inhibited viral replication and particle formation. However, this compound displayed non-specific binding to other RNA molecules and the ribosome along with high cytotoxicity. Other examples of compounds targeting HIV-1 frameshifting site include guanidinoneomycin, idarubicin, doxorubicin, hydrazide derivatives and Arg-rich peptides; however, their off-target effects and cytotoxicity limit their use as therapeutics (Brakier-Gingras et al., 2012; Ofori et al., 2014). Miller et al. developed disulfide-containing peptides that bind specifically to the HIV SL1 and are not cytotoxic, however, their effects on the HIV life cycle were not assessed yet (Ofori et al., 2014). Modified oligonucleotides can also be used to target frameshifting signals. By now, no specific oligonucleotides were designed against HIV-1, however, an antisense-peptide oligonucleotide was used successfully to modulate-1PRF in SARS virus-infected cells (Ahn et al., 2011). 


\section{4. -1 Programmed ribosome frameshifting in alphaviruses}

The genus Alphavirus belongs to the family of Togaviridae and includes multiple species pathogenic to humans and livestock causing infectious arthritis, fewer, rushes and potentially fatal encephalitis. Alphavirus genome is a single-stranded $(+)$ RNA, which contains two ORFs encoding 9 proteins. The 5' proximal ORF codes for enzymes (NSP1NSP4) while the 3' proximal ORF encodes a structural polyprotein (C-E3-E2-6K-E1), which is further processed by proteases to yield mature proteins (Fig. 13). A frameshifting motif is located within the $6 \mathrm{~K}$ gene coding sequence, and -1PRF results in the production of another structural protein TF. $6 \mathrm{~K}$ and TF are membrane proteins enriched in cysteine residues and acylated (Fig. 13). They have identical hydrophobic N-termini, but different C-termini: the $6 \mathrm{~K} \mathrm{C}$-terminus is a membrane segment while the $\mathrm{C}$-terminus of $\mathrm{TF}$ is a hydrophilic cytoplasmic extension (Chung et al., 2010; Firth et al., 2008). 6K and TF seem important for envelope protein processing, membrane permeabilization, virion assembly and virus budding. Deletion of both proteins is not lethal for the virus, but it decreases viral load in the cell by 10-100-fold, and produced virions lack structural integrity and are less infectious as compared to wild-type (wt) (Ramsey and Mukhopadhyay, 2017). Recent data in Venezuelan equine encephalitis virus also suggests that TF can pass through the blood-brain barrier and is responsible for the neuroinvasiveness of the virus (Kendra et al., 2017).

\begin{tabular}{|c|c|c|c|c|c|}
\hline NSP1 & NSP2 & NSP3 & NSP4 & C E3 E2 6 & KK E1 \\
\hline
\end{tabular}

Figure 13. Genome structure of alphaviruses. Arrow indicates the gene in which -1 PRF takes place.

As described before, one prominent example of alphaviruses is SFV, which is pathogenic to humans but is also used as a tool in gene therapy, vaccination and cancer research (Firth et al., 2008). The efficiency of -1PRF in SFV measured with dual-luciferase reporters in human cells was reported to be about $15 \%$. Its SS is identical to that of HIV-1 and has a sequence of $\mathrm{U}_{1} \mathrm{UUU}_{4} \mathrm{UUA}_{7}$ encoding Phe and Leu in 0 -frame. On the other hand, the presence of the mRNA secondary structure in the frameshifting motif of SFV remains elusive. As shown in Fig. 8C, bioinformatics analysis predicted the existence of an extended SL 6 nt downstream of the SS. However, mutations disturbing the SL do not seem to have a significant effect on the frameshifting efficiency. On the other hand, as mentioned before, the first 18-20 nt after the SS were shown critical to maintain the frameshifting efficiency and could represent a cis-acting enhancer (Chung et al., 2010). 


\subsection{Scope of the thesis}

The aim of the thesis was to study the mechanisms of PRF in viruses pathogenic to humans and domestic animals, such as HIV-1 and SFV, and to investigate the mechanism of tRNA slippage by a mutational study in the bacterial dnaX mRNA. The variety of proposed pathways explaining -1PRF on gag-pol mRNA of HIV-1, the lack of information about alternative slippage events and an unclear contribution of the pSS2 prompted us to dissect this frameshifting event in real time using a fully reconstituted E. coli in vitro translation system. The specific objectives of the study were:

1. To unravel the kinetic mechanism governing -1PRF in HIV-1;

2. To compare the mechanism of $-1 P R F$ in HIV-1 with that of IBV and dnaX;

3. To identify key factors defining the ratio between the two-1PRF products containing the FFR and FLR motifs;

4. To investigate alternative slippage events (e.g., $-2 \mathrm{PRF}$ or $+1 \mathrm{PRF}$ );

5. To unravel the significance of the pSS2 and study the interplay between SS1 and pSS2 using native total human tRNA.

Upon discovering that Leu-tRNA ${ }^{\mathrm{Leu}(\mathrm{UUA})}$ plays a role as a major modulator of -1PRF in HIV-1, we set out to quantify its abundance in human cell lines of different origin including $\mathrm{CD}^{+}$T-lymphocytes, which are natural reservoirs of HIV-1 infection. The analysis was done by tRNA-specific qRT-PCR in collaboration with Dr. Markus Hoffmann and Prof. Dr. Stefan Pöhlmann (Infection Biology Unit, German Primate Center, Göttingen). Furthermore, to bridge the gap between frameshifting data obtained in vivo in human cells and in vitro with bacterial components and to exclude potential artefacts arising from using E. coli ribosomes, we aimed to establish an in vitro reconstituted translation system with mammalian components and validate our key findings concerning the mechanism of frameshifting in HIV and its modulation by the tRNA ${ }^{\text {Leu(UUA) }}$ abundance (in collaboration with Dr. Akanksha Goyal, Department of Physical Biochemistry, Max Planck Institute for Biophysical Chemistry, Göttingen).

The classical gag-pol frameshifting motif consists of the SS1 followed by the SL1. Both elements were studied in detail, however, their exact contribution to frameshifting in HIV-1 remained elusive. In particular, the significance of the SL1 as a stimulator of frameshifting remained unclear, which prompted us to study the function of sequences downstream of the SS1 using sequential mutational analysis. We aimed to distinguish between the effects of 
SL1 and potential enhancer sequence on frameshifting in HIV-1 and to discover how two frameshifting routes, FFR and FLR, are modulated by cis-acting elements following the SS1.

$-1 \mathrm{PRF}$ in SFV was studied in vivo in human cells while the mechanistic understanding of this process was lacking. SFV contains the same SS as HIV-1 but the stimulatory element of SFV remained unknown, which prompted us to examine its structure by chemical probing and then study its role in -1PRF. Our other goal was to understand the mechanism and modulation of -1PRF in SFV and to compare it to the one of HIV-1. Furthermore, we aimed at deciphering the significance of the potential enhancer following the SS. Chemical probing was carried out in collaboration with Dr. Maria M. Anokhina (Department of Cellular Biochemistry, Max Planck Institute for Biophysical Chemistry, Göttingen; currently Institute of Pathology, University Hospital of Cologne).

$-1 P R F$ in dnaX is governed by three frameshifting elements: the SD-like sequence, the SS and the downstream SL. Although the contribution of each element to frameshifting was studied in detail, some results obtained with SS mutants are difficult to interpret, because there is no unifying hypothesis concerning the thermodynamic mechanism of frameshifting. The goal of this study was to create a library of dnaX SS mutants and correlate the frameshifting efficiencies with the thermodynamics of codon-anticodon interactions in different frames. This work was carried out in collaboration with Dr. Lars Bock and Prof. Dr. Helmut Grübmüller (Department of Theoretical and Computational Biophysics, Max Planck Institute for Biophysical Chemistry, Göttingen). 


\section{Materials and methods}

\subsection{Materials}

\subsubsection{Chemicals}

Chemicals were purchased from Sigma-Aldrich (Steinheim, Germany), Roche Diagnostics (Mannheim, Germany), Merck (Darmstadt, Germany), Carl Roth (Karlsruhe, Germany) and Serva (Heidelberg, Germany), unless stated otherwise. GTP was from Jena Bioscience (Jena, Germany), DNA SmartLadder was from Eurogentec (Seraing, Belgium), GelRed was from Biotium (Fremont, USA). Kits for plasmid DNA purification, NucleoSpin ${ }^{\circledR}$ Gel and PCR Clean-up kits were from Macherey-Nagel (Düren, Germany), kits for mRNA purification (RNeasy kits) were from Qiagen (Hilden, Germany). Nitrocellulose and cellulose acetate filters and syringe filters were from Sartorious Biolab (Göttingen, Germany). DNA oligonucleotides were from Eurofins Genomics (Ebersberg, Germany) and from IBA (Göttingen, Germany). Synthetic mRNAs were from IBA. Radioactive aa were from Hartmann Analytic (Braunschweig, Germany) and PerkinElmar (Massachusetts, USA). Scintillation cocktails Ultima Gold ${ }^{\mathrm{TM}}$ XR and Quickzint 361 were purchased from PerkinElmar (Massachusetts, USA) and Zinsser analytic (Frankfurt, Germany), respectively. Chemical probing reagents dimethyl sulfate (DMS) and 1-cyclohexyl-3-(2-morpholinoethyl) carbodiimide metho-p-toluenesulfonate (CMCT) were purchased from Sigma-Aldrich, $\beta$-ethoxy- $\alpha$-ketobutyraldehyde (kethoxal, KE) was provided by the Department of Cellular Biochemistry, Max Planck Institute for Biophysical Chemistry, Göttingen.

\subsubsection{Enzymes}

\section{Cloning enzymes}

Q5 High-Fidelity DNA Polymerase

Phusion® High-Fidelity DNA Polymerase

Pfu DNA Polymerase

DpnI

T4 Polynucleotide Kinase
NEB (Frankfurt, Germany)

Thermo Fisher Scientific (Finnzymes)

Promega (Mannheim, Germany)

NEB

NEB 
T4 DNA Ligase

NEB

\section{Transcription enzymes}

Pyrophosphatase

Sigma-Aldrich

T7 RNA Polymerase

made in-house

Translation enzymes

Pyruvate Kinase

Sigma-Aldrich

\section{Chemical probing and RT enzymes}

Proteinase K

NEB

Sequenase Version 2.0 DNA Polymerase

Thermo Fisher Scientific

\subsubsection{Buffers}

Table 2. Common buffers

\begin{tabular}{|c|c|}
\hline Buffer name & Content \\
\hline \multicolumn{2}{|c|}{ General buffers and solutions } \\
\hline LB medium & $\begin{array}{l}10 \mathrm{~g} / 1 \mathrm{NaCl} \\
10 \mathrm{~g} / 1 \text { tryptone } \\
5 \mathrm{~g} / 1 \text { yeast extract }\end{array}$ \\
\hline LB agar & $\begin{array}{l}10 \mathrm{~g} / \mathrm{l} \mathrm{NaCl} \\
10 \mathrm{~g} / \mathrm{l} \text { tryptone } \\
5 \mathrm{~g} / \mathrm{l} \text { yeast extract } \\
15 \mathrm{~g} / \mathrm{l} \text { agar }\end{array}$ \\
\hline 10X TBE & $\begin{array}{l}0.89 \mathrm{M} \text { Tris- } \mathrm{HCl}, \mathrm{pH} 8.3 \\
0.89 \mathrm{M} \text { boric acid } \\
25 \mathrm{mM} \text { EDTA }\end{array}$ \\
\hline 10X TAE & $\begin{array}{l}0.4 \mathrm{M} \text { Tris- } \mathrm{HCl}, \mathrm{pH} 8.4 \\
0.2 \mathrm{M} \text { acetic acid } \\
10 \mathrm{mM} \text { EDTA }\end{array}$ \\
\hline 2X RNA loading dye & $\begin{array}{l}2 \mathrm{mM} \text { Tris-HCl, pH } 7.5 \\
20 \mathrm{mM} \text { EDTA } \\
8 \mathrm{M} \text { urea } \\
20 \% \text { glycerol } \\
0.05 \%(\mathrm{w} / \mathrm{v}) \text { bromophenol blue } \\
0.05 \%(\mathrm{w} / \mathrm{v}) \text { xylene cyanol }\end{array}$ \\
\hline 5X DNA loading dye & $\begin{array}{l}5 \mathrm{mM} \text { EDTA, } \mathrm{pH} 8.0 \\
30 \% \text { glycerol } \\
0.25 \%(\mathrm{w} / \mathrm{v}) \text { bromophenol blue } \\
0.25 \%(\mathrm{w} / \mathrm{v}) \text { xylene cyanol }\end{array}$ \\
\hline Transcription buffer & $\begin{array}{l}50 \mathrm{mM} \text { Tris-HCl, pH } 7.5 \\
15 \mathrm{mM} \mathrm{MgCl}_{2}\end{array}$ \\
\hline
\end{tabular}




\begin{tabular}{|c|c|}
\hline & $\begin{array}{l}5 \mathrm{mM} \text { DTT } \\
2 \mathrm{mM} \text { spermidine } \\
\end{array}$ \\
\hline Aminoacylation buffer & $\begin{array}{l}50 \mathrm{mM} \mathrm{HEPES} \mathrm{pH} 7.5 \\
70 \mathrm{mM} \mathrm{NH}_{4} \mathrm{Cl} \\
30 \mathrm{mM} \mathrm{KCl} \\
20 \mathrm{mM} \mathrm{MgCl}_{2}\end{array}$ \\
\hline \multicolumn{2}{|c|}{ Translation buffers } \\
\hline $\mathrm{TAKM}_{7}$ buffer & $\begin{array}{l}50 \mathrm{mM} \text { Tris-HCl, } \mathrm{pH} 7.5 \\
70 \mathrm{mM} \mathrm{NH}_{4} \mathrm{Cl} \\
30 \mathrm{mM} \mathrm{KCl} \\
7 \mathrm{mM} \mathrm{MgCl}_{2}\end{array}$ \\
\hline HiFi buffer & $\begin{array}{l}50 \mathrm{mM}^{\mathrm{m}} \text { ris- } \mathrm{HCl}, \mathrm{pH} 7.5 \\
70 \mathrm{mM} \mathrm{NH}_{4} \mathrm{Cl} \\
30 \mathrm{mM} \mathrm{KCl} \\
3.5 \mathrm{mM} \mathrm{MgCl}_{2} \\
8 \mathrm{mM} \text { putrescine } \\
0.5 \mathrm{mM} \text { spermidine }\end{array}$ \\
\hline Eukaryotic translation buffer & $\begin{array}{l}20 \mathrm{mM} \text { HEPES, pH } 7.5 \\
100 \mathrm{mM} \mathrm{KCl} \\
2.5 \mathrm{mM} \mathrm{MgCl}_{2} \\
0.25 \mathrm{mM} \text { spermidine } \\
1 \mathrm{mM} \text { ATP } \\
0.5 \mathrm{mM} \mathrm{GTP}\end{array}$ \\
\hline \multicolumn{2}{|c|}{ Buffers for peptide separation } \\
\hline HPLC buffer A & $0.1 \%$ TFA \\
\hline HPLC buffer B & $\begin{array}{l}0.1 \% \text { TFA } \\
65 \% \text { ACN } \\
\end{array}$ \\
\hline HPLC buffer C & $0.1 \%$ HFBA \\
\hline HPLC buffer D & $\begin{array}{l}0.1 \% \text { HFBA } \\
65 \% \mathrm{ACN} \\
\end{array}$ \\
\hline \multicolumn{2}{|c|}{ Buffers for aa-tRNA purification } \\
\hline HPLC buffer E & $\begin{array}{l}20 \mathrm{mM} \text { ammonium acetate, } \mathrm{pH} 5.0 \\
10 \mathrm{mM} \text { magnesium acetate } \\
400 \mathrm{mM} \mathrm{NaCl}\end{array}$ \\
\hline HPLC buffer F & $\begin{array}{l}20 \mathrm{mM} \text { ammonium acetate, } \mathrm{pH} 5.0 \\
10 \mathrm{mM} \text { magnesium acetate } \\
400 \mathrm{mM} \mathrm{NaCl} \\
15 \% \text { ethanol }\end{array}$ \\
\hline \multicolumn{2}{|c|}{ Buffers for mRNA purification } \\
\hline FPLC buffer A & $\begin{array}{l}30 \mathrm{mM} \text { Bis-Tris, pH } 6.0 \\
1 \mathrm{mM} \text { EDTA } \\
300 \mathrm{mM} \mathrm{NaCl}\end{array}$ \\
\hline FPLC buffer B & $\begin{array}{l}30 \mathrm{mM} \text { Bis-Tris, } \mathrm{pH} 6.0 \\
1 \mathrm{mM} \text { EDTA } \\
1.5 \mathrm{M} \mathrm{NaCl}\end{array}$ \\
\hline \multicolumn{2}{|c|}{ Buffers for tRNA transcript purification } \\
\hline FPLC buffer $\mathrm{C}$ & $\begin{array}{l}30 \mathrm{mM} \text { Bis-Tris, pH } 6.0 \\
5 \mathrm{mM} \mathrm{MgCl}_{2} \\
300 \mathrm{mM} \mathrm{NaCl}\end{array}$ \\
\hline FPLC buffer D & $\begin{array}{l}30 \mathrm{mM} \text { Bis-Tris, } \mathrm{pH} 6.0 \\
5 \mathrm{mM} \mathrm{MgCl}_{2} \\
1.5 \mathrm{M} \mathrm{NaCl} \\
\end{array}$ \\
\hline \multicolumn{2}{|c|}{ Buffers for total tRNA purification } \\
\hline FPLC buffer E & $\begin{array}{l}50 \mathrm{mM} \text { sodium acetate, } \mathrm{pH} 4.5 \\
10 \mathrm{mM} \mathrm{MgCl}_{2}\end{array}$ \\
\hline FPLC buffer $F$ & $\begin{array}{l}50 \mathrm{mM} \text { sodium acetate, } \mathrm{pH} 4.5 \\
10 \mathrm{mM} \mathrm{MgCl}_{2}\end{array}$ \\
\hline
\end{tabular}




\begin{tabular}{|c|c|}
\hline & $1.1 \mathrm{M} \mathrm{KCl}$ \\
\hline \multicolumn{2}{|c|}{ Buffers for von Jagow Tris-Tricine SDS PAGE } \\
\hline $10 \mathrm{X}$ cathode buffer & $\begin{array}{l}1 \mathrm{M} \text { Tris } \\
1 \mathrm{M} \text { Tricine } \\
1 \%(\mathrm{w} / \mathrm{w}) \text { SDS } \\
\mathrm{pH} \text { is } 8.25 \text { without adjusting }\end{array}$ \\
\hline 10X anode buffer & 2 M Tris- $\mathrm{HCl}, \mathrm{pH} 8.9$ \\
\hline $3 X$ gel buffer & $\begin{array}{l}3 \mathrm{M} \text { Tris-HCl, pH } 8.45 \\
0.3 \% \text { (w/w) SDS }\end{array}$ \\
\hline 2X sample buffer & $\begin{array}{l}0.1 \mathrm{M} \text { Tris-HCl, } \mathrm{pH} 6.8 \\
24 \%(\mathrm{w} / \mathrm{v}) \text { glycerol } \\
2 \%(\mathrm{v} / \mathrm{v}) \beta \text {-mercaptoethanol } \\
10 \% \text { SDS }\end{array}$ \\
\hline $\begin{array}{l}49.5 \% \mathrm{~T}, 3 \% \mathrm{C} \text { mixture of } \\
\text { acrylamide/bis }\end{array}$ & $\begin{array}{l}48 \mathrm{~g} \text { acrylamide } \\
1.5 \mathrm{~g} \text { bis-acrylamide } \\
\text { Up to } 100 \mathrm{~mL} \text { Milli-Q } \mathrm{H}_{2} \mathrm{O}\end{array}$ \\
\hline $\begin{array}{l}49.5 \% \mathrm{~T}, 6 \% \mathrm{C} \text { mixture of } \\
\text { acrylamide/bis }\end{array}$ & $\begin{array}{l}46.5 \mathrm{~g} \text { acrylamide } \\
3 \mathrm{~g} \text { bis-acrylamide } \\
\mathrm{Up} \text { to } 100 \mathrm{~mL} \text { Milli-Q } \mathrm{H}_{2} \mathrm{O}\end{array}$ \\
\hline
\end{tabular}

\subsubsection{E. coli strains}

MRE 600 (1/2 log) (UAB Fermentation Facility)

NovaBlue (Merck (origin), prepared in house)

\subsubsection{Plasmids}

pEX-A2 (Eurofins Genomics): $2450 \mathrm{bp}$, carrying the gene for Amp resistance

pUC18 with E. coli Trp gene (Dr. Michael Thommen): 2680 bp (without insert), carrying the gene for Amp resistance

pET24a with dnaX wt insert (Dr. Neva Caliskan): 5310 bp, carrying the gene for Kan resistance

pSGDLuc (Prof. John Atkins, Addgene plasmid \# 87323): 5853 bp, carrying the gene for Amp resistance

\subsubsection{Columns}

LiChrospher 100 RP-8 (5 mm) LiChroCART 250-4 (Merck)

LiChrospher WP 300 (5 mm) RP-18 (Merck)

Sepharose 4B gel filtration base matrix (GE Healthcare (Chicago, USA)) 
Phenyl Sepharose High Performance (GE Healthcare)

DEAE Toyopearl 650M (Tosoh Bioscience (Tokyo, Japan))

Protino Ni-IDA 2000 Packed Columns (Macherey-Nagel)

HiTrap Q HP column 5 ml (GE Healthcare)

Mono Q 5/50 GL 550 mm (GE Healthcare)

\subsubsection{Primers}

Table 3. Primers for HIV constructs for bacterial translation system

\begin{tabular}{|c|c|c|}
\hline $\begin{array}{l}\text { Primer } \\
\text { name }\end{array}$ & Sequence (5', to 3') & Function \\
\hline $\begin{array}{l}\mathrm{HIV} \\
156 \mathrm{~F} / \mathrm{R}\end{array}$ & $\begin{array}{l}\text { AATGCAGGCTAATTTCTTAGGGAAGATCTG } \\
\text { TCCCTAAGAAATTAGCCTGCATTATACACCT }\end{array}$ & $\mathrm{U}_{4} \mathrm{C}$ HPLC \\
\hline $\begin{array}{l}\text { HIV } \\
106 \mathrm{~F} / \mathrm{R}\end{array}$ & $\begin{array}{l}\text { GCTAATTTTTTATGGAAGATCTGGCC } \\
\text { CTTCCATAAAAAATTAGCCTGCATTATAC }\end{array}$ & $-2 /+1$ HPLC \\
\hline $\begin{array}{l}\text { HIV } \\
133 \mathrm{~F} / \mathrm{R}\end{array}$ & $\begin{array}{l}\text { GGGAAGATCTGGCCTTCCTACAAG } \\
\text { TACGAAGTTAGCCTGTCTCTCAGTACAAT }\end{array}$ & 0 -frame control gel \\
\hline $\begin{array}{l}\text { HIV } \\
157 \mathrm{~F} / \mathrm{R}\end{array}$ & $\begin{array}{l}\text { TACAAGGGAAGGCCAGGGAATTTCCTTTCAGAGCAGAC } \\
\text { GGAAGGCCAGATCTTCCCTTACGAAGTTAGCCTGTCT }\end{array}$ & -2 -frame control gel \\
\hline $\begin{array}{l}\mathrm{HIV} \\
142 \mathrm{~F} / \mathrm{R}\end{array}$ & $\begin{array}{l}\text { GGCTAATTTTTTCGGGAAGATCTGG } \\
\text { TCCCGAAAAAATTAGCCTGTCTCTC }\end{array}$ & SS1: T TTT TTc \\
\hline $\begin{array}{l}\text { HIV } \\
136 \mathrm{~F} / \mathrm{R}\end{array}$ & $\begin{array}{l}\text { CAGGCTAATTTTCTGGGGAAGATCTGG } \\
\text { TCCCCAGAAAATTAGCCTGTCTCTCAG }\end{array}$ & SS1: T TTT cTg \\
\hline $\begin{array}{l}\text { HIV } \\
137 \mathrm{~F} / \mathrm{R}\end{array}$ & $\begin{array}{l}\text { GACAGGCTAACTTCGTAGGGAAGATC } \\
\text { CTACGAAGTTAGCCTGTCTCTCAGTAC }\end{array}$ & SS1: c TTc gTa \\
\hline $\begin{array}{l}\text { HIV } \\
153 \mathrm{~F} / \mathrm{R}\end{array}$ & $\begin{array}{l}\text { CCAGGGAATTTTCTTCAGAGCAGAC } \\
\text { CTGAAGAAAATTCCCTGGCCTTCC }\end{array}$ & $\begin{array}{l}\text { Wt long gel, no SC in } \\
\text {-2-frame }\end{array}$ \\
\hline $\begin{array}{l}\mathrm{HIV} \\
140 \mathrm{~F} / \mathrm{R}\end{array}$ & $\begin{array}{l}\text { CAGGGAATTTTTTTCAGAGCAGACC } \\
\text { TGAAAAAAATTCCCTGGCCTTCCC }\end{array}$ & SS2: T TTT tTT \\
\hline $\begin{array}{l}\mathrm{HIV} \\
139 \mathrm{~F} / \mathrm{R}\end{array}$ & $\begin{array}{l}\text { GGCCAGGGAATTTCCTGCAGAGCAGACC } \\
\text { CTGCAGGAAATTCCCTGGCCTTCССТTG }\end{array}$ & SS2: T TTc CTg \\
\hline $\begin{array}{l}\text { HIV } \\
138 \mathrm{~F} / \mathrm{R}\end{array}$ & $\begin{array}{l}\text { GGGAATTTTCTGCAGAGCAGACC } \\
\text { TCTGCAGAAAATTCCCTGGCCTTC }\end{array}$ & SS2: T TTT CTg \\
\hline $\begin{array}{l}\text { HIV } \\
154 \mathrm{~F} / \mathrm{R}\end{array}$ & $\begin{array}{l}\text { GGCCAGGGAACTTTTTTCAGAG } \\
\text { AAAAGTTCCCTGGCCTTCCCTT }\end{array}$ & SS2: c TTT uTT \\
\hline $\begin{array}{l}\mathrm{HIV} \\
155 \mathrm{~F} / \mathrm{R}\end{array}$ & $\begin{array}{l}\text { CAGGGAATTTCTTTCAGAGCAGA } \\
\text { TGAAAGAAATTCCCTGGCCTTC }\end{array}$ & SS2: T TTc tTT \\
\hline $\begin{array}{l}\text { HIV } \\
144 \mathrm{~F} / \mathrm{R}\end{array}$ & $\begin{array}{l}\text { AGCTTCAGATCAGGAGTAGAGACAACAACTCCCCCTC } \\
\text { CTCCTCTGGTGGTGCTGTTGGCTCTGGTCT }\end{array}$ & Mutated pSL2 \\
\hline $\begin{array}{l}\text { HIV } 86 \\
\text { seq }\end{array}$ & GTGTCGGGGCTGGCTTAACTATGC & $\begin{array}{l}\text { Fwd primer for } \\
\text { transcription templates } \\
\text { and sequencing }\end{array}$ \\
\hline $\begin{array}{l}\text { HIV } \\
131 \mathrm{R}\end{array}$ & TGATAAAACCTCCAATTCCССCTATCATTTTTGG & $\begin{array}{l}\text { Rev primer for long gel } \\
\text { mRNAs }\end{array}$ \\
\hline HIV 97R & GGTCTGCTCTGAAGAAAATTCCCTGGC & $\begin{array}{l}\text { Rev primer for short } \\
\text { HPLC mRNAs with full } \\
\text { SL }\end{array}$ \\
\hline $\begin{array}{l}\text { HIV } 94 \\
+/-\end{array}$ & TTGTAGGAAGGCCAGATCTTCCC & Rev primer, half SL \\
\hline $\begin{array}{l}\mathrm{HIV} \\
158 \mathrm{R}\end{array}$ & СТАСТTСССТАAАAАATTAGCСТGCATTATACACC & $\begin{array}{l}\text { Rev primer, } 6 \text { nt after } \\
\text { SS1 and TAG }\end{array}$ \\
\hline
\end{tabular}




\begin{tabular}{|c|c|c|}
\hline $\begin{array}{l}\text { HIV } \\
161 \mathrm{R}\end{array}$ & TTGTAGGAACCGGTCATCTTCCCTAAAAAATTAG & $\begin{array}{l}\text { Rev primer, half SL, } \\
\text { gaccgg mutations }\end{array}$ \\
\hline $\begin{array}{l}\mathrm{HIV} \\
163 \mathrm{R}\end{array}$ & TTGATCCTTGGCCAGATCTTCCCTAAAAAATTAG & $\begin{array}{l}\text { Rev primer, half SL, } \\
\text { aaggat mutations }\end{array}$ \\
\hline $\begin{array}{l}\mathrm{HIV} \\
143 \mathrm{~F} / \mathrm{R}\end{array}$ & $\begin{array}{l}\text { GAAGACCGGGGAATTTTCTTCAGAGCAGACCA } \\
\text { CCTTGTACGATGGCCATATCTTCCCTAAAAAATTAGCCT }\end{array}$ & Mutated SL1 \\
\hline $\begin{array}{l}\mathrm{HIV} \\
170 \mathrm{R}\end{array}$ & TAGGAAGGCCAGATCTTCCCTAAAAAATTAGCC & $\begin{array}{l}\text { Rev primer, } 20 \mathrm{nt} \text { after } \\
\text { SS1 }\end{array}$ \\
\hline $\begin{array}{l}\mathrm{HIV} \\
171 \mathrm{R}\end{array}$ & GAAGGCCAGATCTTCCCTAAAAAATTAGCCTG & $\begin{array}{l}\text { Rev primer, } 17 \mathrm{nt} \text { after } \\
\text { SS1 }\end{array}$ \\
\hline $\begin{array}{l}\mathrm{HIV} \\
172 \mathrm{R}\end{array}$ & GGCCAGATCTTCCCTAAAAAATTAGCCTGCATTA & $\begin{array}{l}\text { Rev primer, } 14 \text { nt after } \\
\text { SS1 }\end{array}$ \\
\hline $\begin{array}{l}\mathrm{HIV} \\
173 \mathrm{R}\end{array}$ & CAGATCTTCCCTAAAAAATTAGCCTGCATTATACACCT & $\begin{array}{l}\text { Rev primer, } 11 \mathrm{nt} \text { after } \\
\text { SS1 }\end{array}$ \\
\hline $\begin{array}{l}\mathrm{HIV} \\
174 \mathrm{R}\end{array}$ & ATCTTCCCTAAAAAATTAGCCTGCATTATACACCTCAT & $\begin{array}{l}\text { Rev primer, } 8 \mathrm{nt} \text { after } \\
\text { SS1 }\end{array}$ \\
\hline $\begin{array}{l}\mathrm{HIV} \\
175 \mathrm{R}\end{array}$ & TTCCCTAAAAAATTAGCCTGCATTATACACCTCATAG & $\begin{array}{l}\text { Rev primer, } 5 \mathrm{nt} \text { after } \\
\text { SS1 }\end{array}$ \\
\hline $\begin{array}{l}\mathrm{HIV} \\
178 \mathrm{~F} / \mathrm{R}\end{array}$ & $\begin{array}{l}\text { GGCTAATTTTTTAGGGCTCTACTGGCCTTCCTAC } \\
\text { GCCAGTAGAGCCCTAAAAAATTAGCCTGCATTATAC }\end{array}$ & GGGctctaCTGG \\
\hline $\begin{array}{l}\mathrm{HIV} \\
179 \mathrm{~F} / \mathrm{R}\end{array}$ & $\begin{array}{l}\text { TAATTTTTTAGGGCTCTAGTAACCTTCCTACAAGGGA } \\
\text { GAAGGTTACTAGAGCCCTAAAAAATTAGCCTGCATT }\end{array}$ & GGGctctagTaa \\
\hline $\begin{array}{l}\mathrm{HIV} \\
181 \mathrm{~F} / \mathrm{R}\end{array}$ & $\begin{array}{l}\text { ATTTTTTAGGGCAGATCTGGCCTTCCTA } \\
\text { GCCAGATCTGCCCTAAAAAATTAGCCTG }\end{array}$ & GGGcAGATCTGG \\
\hline $\begin{array}{l}\mathrm{HIV} \\
182 \mathrm{~F} / \mathrm{R}\end{array}$ & $\begin{array}{l}\text { TTTTTAGGGATGATCTGGCCTTCCT } \\
\text { CCAGATCATCCCTAAAAAATTAGCCTG }\end{array}$ & GGGAtGATCTGG \\
\hline $\begin{array}{l}\mathrm{HIV} \\
183 \mathrm{~F} / \mathrm{R}\end{array}$ & $\begin{array}{l}\text { TTTTTAGGGAACATCTGGCCTTCCTAC } \\
\text { GCCAGATGTTCCCTAAAAAATTAGCCTG }\end{array}$ & GGGAAcATCTGG \\
\hline $\begin{array}{l}\mathrm{HIV} \\
184 \mathrm{~F} / \mathrm{R}\end{array}$ & $\begin{array}{l}\text { TTTTAGGGAAGTTCTGGCCTTCCTA } \\
\text { CCAGAACTTCCCTAAAAAATTAGCCTG }\end{array}$ & GGGAAGtTCTGG \\
\hline $\begin{array}{l}\mathrm{HIV} \\
185 \mathrm{~F} / \mathrm{R}\end{array}$ & $\begin{array}{l}\text { TTTAGGGAAGAACTGGCCTTCCTAC } \\
\text { GCCAGTTCTTCCCTAAAAAATTAGCC }\end{array}$ & GGGAAGAaCTGG \\
\hline $\begin{array}{l}\mathrm{HIV} \\
186 \mathrm{~F} / \mathrm{R}\end{array}$ & $\begin{array}{l}\text { TTAGGGAAGATGTGGCCTTCCTACAA } \\
\text { AGGCCACATCTTCCCTAAAAAATTAGC }\end{array}$ & GGGAAGATgTGG \\
\hline $\begin{array}{l}\mathrm{HIV} \\
187 \mathrm{~F} / \mathrm{R}\end{array}$ & $\begin{array}{l}\text { TTTAGGGAAGATCAGGCCTTCCTACAAG } \\
\text { AAGGCCTGATCTTCCCTAAAAAATTAGCC }\end{array}$ & GGGAAGATCaGG \\
\hline $\begin{array}{l}\mathrm{HIV} \\
188 \mathrm{~F} / \mathrm{R}\end{array}$ & $\begin{array}{l}\text { AGGGAAGATCTAGCCTTCCTACAAG } \\
\text { AAGGCTAGATCTTCCCTAAAAAATTA }\end{array}$ & GGGAAGATCTaG \\
\hline $\begin{array}{l}\mathrm{HIV} \\
189 \mathrm{~F} / \mathrm{R}\end{array}$ & $\begin{array}{l}\text { AGGGAAGATCTCGCCTTCCTACAAG } \\
\text { AAGGCGAGATCTTCCCTAAAAAATTAGC }\end{array}$ & GGGAAGATCTcG \\
\hline $\begin{array}{l}\mathrm{HIV} \\
190 \mathrm{~F} / \mathrm{R}\end{array}$ & $\begin{array}{l}\text { AGGGAAGATCTGACCTTCCTACAAGG } \\
\text { GAAGGTCAGATCTTCCCTAAAAAATTAGC }\end{array}$ & GGGAAGATCTGa \\
\hline $\begin{array}{l}\text { HIV } \\
191 \mathrm{~F} / \mathrm{R}\end{array}$ & $\begin{array}{l}\text { AGGGAAGATCTGCCCTTCCTACAAGG } \\
\text { GAAGGGCAGATCTTCCCTAAAAAATTAGC }\end{array}$ & GGGAAGATCTGc \\
\hline $\begin{array}{l}\mathrm{HIV} \\
199 \mathrm{~F} / \mathrm{R}\end{array}$ & $\begin{array}{l}\text { ATTTTTTAGGGGAGATCTGGCCTTCCTA } \\
\text { GCCAGATCTCCCCTAAAAAATTAGCCTG }\end{array}$ & GGGgAGATCTGG \\
\hline $\begin{array}{l}\mathrm{HIV} \\
200 \mathrm{~F} / \mathrm{R}\end{array}$ & $\begin{array}{l}\text { ATTTTTTAGGGTAGATCTGGCCTTCCTA } \\
\text { GCCAGATCTACCCTAAAAAATTAGCCTG }\end{array}$ & GGGtAGATCTGG \\
\hline $\begin{array}{l}\mathrm{HIV} \\
201 \mathrm{~F} / \mathrm{R}\end{array}$ & $\begin{array}{l}\text { TTTTTAGGGAGGATCTGGCCTTCCT } \\
\text { CCAGATCCTCCCTAAAAAATTAGCCTG }\end{array}$ & GGGAgGATCTGG \\
\hline $\begin{array}{l}\text { HIV } \\
202 \mathrm{~F} / \mathrm{R}\end{array}$ & $\begin{array}{l}\text { TTTTTAGGGACGATCTGGCCTTCCT } \\
\text { CCAGATCGTCCCTAAAAAATTAGCCTG }\end{array}$ & GGGAcGATCTGG \\
\hline $\begin{array}{l}\mathrm{HIV} \\
203 \mathrm{~F} / \mathrm{R}\end{array}$ & $\begin{array}{l}\text { TTTTTAGGGAAAATCTGGCCTTCCTAC } \\
\text { GCCAGATTTTCCCTAAAAAATTAGCCTG }\end{array}$ & GGGAAaATCTGG \\
\hline $\begin{array}{l}\text { HIV } \\
\text { 204F/R }\end{array}$ & $\begin{array}{l}\text { TTTTTAGGGAATATCTGGCCTTCCTAC } \\
\text { GCCAGATATTCCCTAAAAAATTAGCCTG }\end{array}$ & GGGAAtATCTGG \\
\hline $\begin{array}{l}\text { HIV } \\
205 \mathrm{~F} / \mathrm{R}\end{array}$ & $\begin{array}{l}\text { TTTTAGGGAAGGTCTGGCCTTCCTA } \\
\text { CCAGACCTTCCCTAAAAAATTAGCCTG }\end{array}$ & GGGAAGgTCTGG \\
\hline $\begin{array}{l}\mathrm{HIV} \\
206 \mathrm{~F} / \mathrm{R}\end{array}$ & $\begin{array}{l}\text { TTTTAGGGAAGCTCTGGCCTTCCTA } \\
\text { CCAGAGCTTCCCTAAAAAATTAGCCTG }\end{array}$ & GGGAAGcTCTGG \\
\hline
\end{tabular}




\begin{tabular}{|l|l|l|}
\hline $\begin{array}{l}\text { HIV } \\
207 F / R\end{array}$ & TAATTTTTTAGGGCCTCAATAACCTTCCTACAAGG & GGGcctcaaTaa \\
\hline $\begin{array}{l}\text { HIV } \\
210 \mathrm{R}\end{array}$ & TTCCCTGGCCTTCCCTTGTAGGAAG & $\begin{array}{l}\text { Rev primer, 38 nt after } \\
\text { SS1 }\end{array}$ \\
\hline $\begin{array}{l}\text { HIV } \\
211 \mathrm{~F} / \mathrm{R}\end{array}$ & AAGGGAAGGCCAGGGAAAGAAGTTCAGAG & $\begin{array}{l}\text { GAAGA to ctttt } \\
\text { (nt 88-93) } \\
\text { TTTTC to agaag } \\
\text { (nt 124-129) }\end{array}$ \\
\hline $\begin{array}{l}\text { HIV } \\
212 \mathrm{R}\end{array}$ & GGTCTGCTCTGAACTTCTTTCCCTGG & $\begin{array}{l}\text { Rev primer for above } \\
\text { construct, full SL }\end{array}$ \\
\hline
\end{tabular}

Mutated nt are in small letters in bold.

Table 4. Primers for HIV constructs for mammalian translation system

\begin{tabular}{|l|l|l|}
\hline $\begin{array}{l}\text { Primer } \\
\text { name }\end{array}$ & Sequence (5' to 3') & Function \\
\hline $\begin{array}{l}\text { Aki HIV } \\
\text { 1F/R }\end{array}$ & $\begin{array}{l}\text { CAGACCACCATGGTAGCTAATTTTTTAGG } \\
\text { TAGCTACCATGGTGGTCTGTTTTGGAT }\end{array}$ & GTA Val codon in SS1 \\
\hline $\begin{array}{l}\text { Aki HIV } \\
\text { 2F/R }\end{array}$ & $\begin{array}{l}\text { CACCATGGTAGCTAACTTCCTCGGGAAGATCTGG } \\
\text { TCCCGAGGAAGTTAGCTACCATGGTGGTCTGTTTT }\end{array}$ & 0-frame control \\
\hline $\begin{array}{l}\text { Aki HIV } \\
\text { 3F/R }\end{array}$ & $\begin{array}{l}\text { CACCATGGTAGCTAACTTCCTCCGGGAAGATCTGG } \\
\text { TCCCGGAGGAAGTTAGCTACCATGGTGGTCTGTTTT }\end{array}$ & -1-frame control \\
\hline $\begin{array}{l}\text { Aki HIV } \\
\text { 10F/R }\end{array}$ & AATTTTTTAGGGCCTCAATAACCTTCCTACAAG & GGGcctcaaTaa \\
\hline $\begin{array}{l}\text { Aki HIV } \\
\text { 11R }\end{array}$ & TTGTAGTATTGAGGCCCTAAAAAATTAGCTACCATG & $\begin{array}{l}\text { Rev primer, } \\
\text { GGGcctcaaTaa, half SL }\end{array}$ \\
\hline $\begin{array}{l}\text { FS } \\
\text { mRNA } \\
\text { Fwd }\end{array}$ & GAATTCTAATACGACTCACTATAGGG & Fwd primer for mRNAs \\
\hline $\begin{array}{l}\text { Aki HIV } \\
\text { 12R }\end{array}$ & TTCCCTAAAAAATTAGCTACCATGGTG & $\begin{array}{l}\text { Rev primer, } 5 \text { nt after the } \\
\text { SS1 }\end{array}$ \\
\hline $\begin{array}{l}\text { Aki HIV } \\
\text { 13R }\end{array}$ & TTCCCGAGGAAGTTAGCTACCATGG & $\begin{array}{l}\text { Rev primer, } 5 \text { nt after the } \\
\text { SS1, SS1 like in 0-frame } \\
\text { control }\end{array}$ \\
\hline $\begin{array}{l}\text { FS } \\
\text { mRNA } \\
\text { Rev }\end{array}$ & AAGCTTGACCTTCCCTCACAC & $\begin{array}{l}\text { Rev primer for long } \\
\text { mRNAs }\end{array}$ \\
\hline
\end{tabular}

Mutated nt are in small letters in bold.

Table 5. Primers for HIV in vivo studies in human cell culture

\begin{tabular}{|c|c|c|}
\hline $\begin{array}{l}\text { Primer } \\
\text { name }\end{array}$ & Sequence (5' to 3') & Function \\
\hline $\begin{array}{l}\text { HIV } \\
\text { insert } \\
\text { Fwd/Rev }\end{array}$ & $\begin{array}{l}\text { ACAAGGGAAGGCCAGGGAATTTTCTTCAGAGCAGACCAG } \\
\text { ATCTGAGGCACGGCATAAGCAAAAGATCGTA } \\
\text { AGGAAGGCCAGATCTTCCCTAAAAAATTAGCCTGCATTAA } \\
\text { GCTTCTGCTCGAGTAGGGCCCGGGGT }\end{array}$ & $\begin{array}{l}\text { HIV wt sequence } \\
\text { insertion into pSGDLuc }\end{array}$ \\
\hline $\begin{array}{l}\text { HIV } \\
\text { insert } \\
\text { control } \\
\text { Rev }\end{array}$ & $\begin{array}{l}\text { AGGAAGGCCAGATCTTCCCGGAGGAAGTTAGCCTGCATTA } \\
\text { AGCTTCTGCTCGAGTAGGGCCCGGGGT }\end{array}$ & $\begin{array}{l}\text { HIV -1-frame control } \\
\text { sequence insertion into } \\
\text { pSGDLuc }\end{array}$ \\
\hline $\begin{array}{l}\text { Luc } \\
\text { vector } \\
\text { sequencin } \\
\text { g }\end{array}$ & GTGAAACAGACTTTGAATTTTGA & pSGDLuc sequencing \\
\hline $\begin{array}{l}\text { HIV half } \\
\text { SL } \\
\text { Fwd/Rev }\end{array}$ & $\begin{array}{l}\text { GATCTGAGGCACGGCATAAGCAAAAG } \\
\text { CTTGTAGGAAGGCCAGATCTTCCCTAA }\end{array}$ & $\begin{array}{l}\text { pSGDLuc HIV wt } \\
\text { sequence with half SL }\end{array}$ \\
\hline
\end{tabular}




\begin{tabular}{|c|c|c|}
\hline $\begin{array}{l}\text { HIV no } \\
\text { SL Rev }\end{array}$ & CCCTAAAAAATTAGCCTGCATTAAGCTTCT & $\begin{array}{l}\text { pSGDLuc HIV wt } \\
\text { sequence, } 3 \text { nt after SS1 }\end{array}$ \\
\hline $\begin{array}{l}\text { pLuc } \\
\text { halfSL } \\
\text { Rev } \\
\text { control }\end{array}$ & CTTGTAGGAAGGCCAGATCTTCCCG & $\begin{array}{l}\text { pSGDLuc HIV -1-frame } \\
\text { control sequence with } \\
\text { half SL }\end{array}$ \\
\hline $\begin{array}{l}\text { pLuc } \\
\text { noSL Rev } \\
\text { control }\end{array}$ & CCCGGAGGAAGTTAGCCTGCATTA & $\begin{array}{l}\text { pSGDLuc HIV -1-frame } \\
\text { control sequence, } 3 \mathrm{nt} \\
\text { after SS1 }\end{array}$ \\
\hline $\begin{array}{l}\text { pLuc } 149 \\
\text { control } \\
\text { Fwd/Rev }\end{array}$ & $\begin{array}{l}\text { ATGCAGGCTAACTTCCTCCGGGCTCTAG } \\
\text { GGAGGAAGTTAGCCTGCATTAAGCTTCTGC }\end{array}$ & $\begin{array}{l}\text { pSGDLuc HIV }-1 \text {-frame } \\
\text { control sequence, } 149 \\
\text { construct }\end{array}$ \\
\hline $\begin{array}{l}\text { pLuc } 177 \\
\text { control } \\
\text { Fwd/Rev }\end{array}$ & $\begin{array}{l}\text { CAGGCTAACTTCCTCCGGGCCTCAA } \\
\text { GGAGGAAGTTAGCCTGCATTAAGCTTCT }\end{array}$ & $\begin{array}{l}\text { pSGDLuc HIV }-1 \text {-frame } \\
\text { control sequence, } 177 \\
\text { construct }\end{array}$ \\
\hline $\begin{array}{l}\text { pLuc } 179 \\
\text { control lig } \\
\text { Fwd/Rev }\end{array}$ & $\begin{array}{l}\text { CTCCGGCTTTTTCTGGCCTTCCT } \\
\text { GAAGTTAGCCTGCATTAAGCTTCTGC }\end{array}$ & $\begin{array}{l}\text { pSGDLuc HIV }-1 \text {-frame } \\
\text { control sequence, } 179 \\
\text { construct }\end{array}$ \\
\hline $\begin{array}{l}\text { pLuc } 180 \\
\text { Rev }\end{array}$ & ССCTGGCCTTCCCTTGTAGGAAG & $\begin{array}{l}\text { pSGDLuc HIV, } 36 \mathrm{nt} \\
\text { after SS1 }\end{array}$ \\
\hline $\begin{array}{l}\text { tRNA } \\
\text { V_CAC } \\
\text { RT }\end{array}$ & $\begin{array}{l}\text { GTCGTATCCAGAATTTGTTGCAACGAACAGGTCTGGATAC } \\
\text { GACTTTCYGCCCG }\end{array}$ & $\mathrm{RT}, \mathrm{tRNA}^{\mathrm{Val}(\mathrm{GUG})}$ \\
\hline $\begin{array}{l}\text { tRNA } \\
\text { V_TAC } \\
\text { RT }\end{array}$ & $\begin{array}{l}\text { GTCGTATCCAGAATTTGTTGCAACGAACAGGTCTGGATAC } \\
\text { GACTTTCCACTGG }\end{array}$ & $\mathrm{RT}, \mathrm{tRNA} \mathrm{Val}(\mathrm{GUA})^{\mathrm{N}}$ \\
\hline $\begin{array}{l}\text { tRNA } \\
\text { L_both } \\
\text { RT }\end{array}$ & $\begin{array}{l}\text { GTCGTATCCAGAATTTGTTGCAACGAACAGGTCTGGATAC } \\
\text { GACTAACCCACGC }\end{array}$ & $\begin{array}{l}\text { RT, tRNA }{ }^{\text {Leu(UUA) }} \text { and } \\
\text { tRNA }^{\text {Leu(CUG) }}\end{array}$ \\
\hline $\begin{array}{l}\text { 18S } \\
\text { rRNA RT }\end{array}$ & $\begin{array}{l}\text { GTCGTATCCAGAATTTGTTGCAACGAACAGGTCTGGATAC } \\
\text { GACTAATGATC }\end{array}$ & RT, 18S rRNA \\
\hline $\begin{array}{l}\text { tRNA } \\
\text { V_CAC } \\
\text { PCR }\end{array}$ & TAGTGGTTATCACGTTCGCCTCAC & qRT-PCR, tRNA $\mathrm{Val(GUG)}$ \\
\hline $\begin{array}{l}\text { tRNA } \\
\text { V_TAC } \\
\text { PCR }\end{array}$ & TAGTGGTTATCACGTCTGCTTTAC & qRT-PCR, tRNA ${ }^{\mathrm{Val}(\mathrm{GUA})}$ \\
\hline $\begin{array}{l}\text { tRNA } \\
\text { L_TAA } \\
\text { PCR }\end{array}$ & GAGTGGATAAGGCGTTGGACTTAA & qRT-PCR, tRNA ${ }^{\mathrm{Leu}(\mathrm{UUA})}$ \\
\hline $\begin{array}{l}\text { tRNA } \\
\text { L_CAG } \\
\text { PCR }\end{array}$ & GGTCTAAGGCGCTGCGTTCAG & qRT-PCR, tRNA ${ }^{\mathrm{Leu}(\mathrm{CUG})}$ \\
\hline $\begin{array}{l}18 \mathrm{~S} \\
\text { rRNA } \\
\text { PCR }\end{array}$ & GTAACAAGGTTTCCGTAGGTGA & qRT-PCR, 18S rRNA \\
\hline $\begin{array}{l}\text { Rev } \\
\text { primer } \\
\text { PCR }\end{array}$ & GTTGCAACGAACAGGTCTGGATACG & $\begin{array}{l}\text { qRT-PCR, common for } \\
\text { all }\end{array}$ \\
\hline $\begin{array}{l}\text { tRNA } \\
\text { L_TAA_ } \\
\text { NK PCR }\end{array}$ & GAGTGGTTAAGGCGTTGGACTTAA & qRT-PCR, tRNA ${ }^{\mathrm{Leu}(\mathrm{UUA})}$ \\
\hline
\end{tabular}

Sequences highlighted in green are complementary to respective sequences in tRNAs.

Anticodons are highlighted in blue. 
Table 6. Primers for SFV constructs for bacterial translation system

\begin{tabular}{|c|c|c|}
\hline $\begin{array}{l}\text { Primer } \\
\text { name }\end{array}$ & Sequence (5' to 3') & Function \\
\hline oliSFV 10 & TTATACGGGAACCCCACCACG & $\begin{array}{l}\text { RT for chemical probing, } \\
\text { labelled with Atto647N } \\
\text { at 5' end }\end{array}$ \\
\hline $\begin{array}{l}\text { oliSFV } \\
002 F / R\end{array}$ & $\begin{array}{l}\text { GGGCGCACGCAGCTAGTGTGGC } \\
\text { CTTATACGGGAACCCCACCACGTTC }\end{array}$ & $\begin{array}{l}\text { amplification of SFV } \\
\text { gene fragment }\end{array}$ \\
\hline $\begin{array}{l}\text { oliSFV } \\
\text { 003F/R }\end{array}$ & $\begin{array}{l}\text { TAATACGACTCACTATAGGGGCGCACGCAGCTAGTG } \\
\text { CCGCTGAGCAATAACTAGCTTATACGGGAACCCCAC }\end{array}$ & $\begin{array}{l}\text { Gibson assembly, } \\
\text { introduction of linkers } \\
\text { into SFV fragment }\end{array}$ \\
\hline $\begin{array}{l}\text { oliSFV } \\
006 \mathrm{~F} / \mathrm{R}\end{array}$ & $\begin{array}{l}\text { CACTATAGGGTATTGCCTCAGAAAC } \\
\text { AGTCGTATTACGTGATGATGAGGATG }\end{array}$ & $\begin{array}{l}\text { introduction of } \mathrm{T} 7 \\
\text { promoter }\end{array}$ \\
\hline $\begin{array}{l}\text { oliSFV } \\
15 \mathrm{~F} / \mathrm{R}\end{array}$ & $\begin{array}{l}\text { GGTTGCTGTATGAGCAAGTCTTTTTTAGTGCTACT } \\
\text { AAAAGACTTGCTCATACAGCAACCTCCTTCGT }\end{array}$ & CTT to AAG mutation \\
\hline $\begin{array}{l}\text { oliSFV } \\
\text { 19F/R }\end{array}$ & $\begin{array}{l}\text { CATTCGACAGTAATGCCGAACGTGGT } \\
\text { CGGCATTACTGTCGAATGTTCGTAAGCT }\end{array}$ & ATC to ATG reversion \\
\hline $\begin{array}{l}\text { HIV } 86 \\
\text { seq }\end{array}$ & GTGTCGGGGCTGGCTTAACTATGC & $\begin{array}{l}\text { Forward primer for } \\
\text { transcription templates }\end{array}$ \\
\hline $\begin{array}{l}\text { oliSFV } \\
13 \mathrm{R}\end{array}$ & AATGTGAGCCTTATACGGGAACCCCAC & $\begin{array}{l}\text { Reverse primer, short } \\
\text { HPLC mRNAs, full SL }\end{array}$ \\
\hline $\begin{array}{l}\text { oliSFV } \\
\text { 14R }\end{array}$ & ACCTGCTTTTGCTCGCTTGGATCCG & $\begin{array}{l}\text { Reverse primer, short } \\
\text { HPLC mRNAs, cut SL }\end{array}$ \\
\hline $\begin{array}{l}\text { oliSFV } \\
24 \mathrm{~F} / \mathrm{R}\end{array}$ & $\begin{array}{l}\text { GTTCCCGTATAAGGCTCACATTGAAAGGCCAGGATATAGC } \\
\text { CCCACCACGTTCGGCATTACTGTCGAATGTTCCTAAG }\end{array}$ & Wt long gels \\
\hline $\begin{array}{l}\text { oliSFV } \\
25 \mathrm{~F} / \mathrm{R}\end{array}$ & $\begin{array}{l}\text { CCGCCAGAGCTTAGGAACATTCGACAG } \\
\text { ATGTTCCTAAGCTCTGGCGGTTGCCC }\end{array}$ & $\begin{array}{l}\text { Stop codon TAG in } 0- \\
\text { frame }\end{array}$ \\
\hline $\begin{array}{l}\text { oliSFV } \\
21 F / R\end{array}$ & $\begin{array}{l}\text { AGCCTTTCCTTCGTAGTGCTACTGA } \\
\text { CTACGAAGGAAAGGCTCATTATACACC }\end{array}$ & 0 -frame control gels \\
\hline $\begin{array}{l}\text { oliSFV } \\
\text { 22F/R }\end{array}$ & $\begin{array}{l}\text { CTTTCCTTCGTAAGTGCTACTGAGC } \\
\text { GCACTTACGAAGGAAAGGCTCATTATAC }\end{array}$ & -1 -frame control gels \\
\hline $\begin{array}{l}\text { oliSFV } \\
23 \mathrm{R}\end{array}$ & GCTATATCCTGGCCTTTCAATGTGAGCC & $\begin{array}{l}\text { Reverse primer, long gel } \\
\text { mRNAs }\end{array}$ \\
\hline $\begin{array}{l}\text { oliSFV } \\
27 \mathrm{~F} / \mathrm{R}\end{array}$ & $\begin{array}{l}\text { CCTTTCTTTTTCAGTGCTACTGAG } \\
\text { GCACTGAAAAAGAAAGGCTCATTATAC }\end{array}$ & SS: T TTT TTc \\
\hline $\begin{array}{l}\text { oliSFV } \\
\text { 29F/R }\end{array}$ & $\begin{array}{l}\text { GTAATGCCAAATGTAGTAGGATTTCCATATAAAGCCCATA } \\
\text { TTGAAAGGCCAGGATATAGCCCCCTCACTTTGCAGATGCA } \\
\text { GG } \\
\text { CGTGGAGTGTTCCTATGCTCTTGCTGTTGCGCCTAGACTGA } \\
\text { GTAGCACTAAAAAAGAAAGGCTCATTATACACCTCATAGA } \\
\text { AC }\end{array}$ & Mutated SL \\
\hline $\begin{array}{l}\text { oliSFV } \\
28 \mathrm{R}\end{array}$ & GCTATATCCTGGCCTTTCAATATGGGCT & $\begin{array}{l}\text { Reverse primer for } \\
\text { transcription, mutated SL }\end{array}$ \\
\hline $\begin{array}{l}\text { oliSFV } \\
\text { 30F/R }\end{array}$ & $\begin{array}{l}\text { TTCTTTTTTAGTCGATCTGAGCCTCG } \\
\text { TCAGATCGACTAAAAAAGAAAGGCTCA }\end{array}$ & TTTTTTAGTcgat \\
\hline $\begin{array}{l}\text { oliSFV } \\
31 \mathrm{~F} / \mathrm{R}\end{array}$ & $\begin{array}{l}\text { TTTAGTGCTAGACTGCCTCGGGGCAA } \\
\text { AGGCAGTCTAGCACTAAAAAAGAAAGGCTC }\end{array}$ & TTTTTTAGTGCTAgact \\
\hline $\begin{array}{l}\text { oliSFV } \\
36 \mathrm{~F} / \mathrm{R}\end{array}$ & $\begin{array}{l}\text { GCCTTTCCTTCGTAAGTGCTACTCAGT } \\
\text { GCACTTACGAAGGAAAGGCTCATTATACAC }\end{array}$ & $\begin{array}{l}-1 \text {-frame control of } \\
\text { mutated SL }\end{array}$ \\
\hline
\end{tabular}

Mutated nt are in small letters in bold.

Table 7. Primers for dnaX constructs

\begin{tabular}{|l|l|l|}
\hline $\begin{array}{l}\text { Primer } \\
\text { name }\end{array}$ & Sequence (5' to 3') & Function \\
\hline $\begin{array}{l}\text { olidnaX } \\
\text { 1F/R }\end{array}$ & $\begin{array}{l}\text { AACCAUGGCCAAAAAGTTCTAACCGGC } \\
\text { AACTTTTTGGCCATGGTTGCTCCCTG }\end{array}$ & c AAA AAG \\
\hline
\end{tabular}




\begin{tabular}{|c|c|c|}
\hline $\begin{array}{l}\text { olidnaX } \\
\text { 2F/R }\end{array}$ & $\begin{array}{l}\text { AACCATGGCTAAAAAGTTCTAACCGGC } \\
\text { AACTTTTTAGCCATGGTTGCTCCCTG }\end{array}$ & u AAA AAG \\
\hline $\begin{array}{l}\text { olidnaX } \\
\text { 3F/R }\end{array}$ & $\begin{array}{l}\text { AACCATGGCGAAAAAGTTCTAACCGGC } \\
\text { AACTTTTTCGCCATGGTTGCTCCCTG }\end{array}$ & g AAA AAG \\
\hline $\begin{array}{l}\text { olidnaX } \\
4 \mathrm{~F} / \mathrm{R}\end{array}$ & $\begin{array}{l}\text { AACCATGGCAAAGAAGTTCTAACCGGC } \\
\text { AACTTCTTTGCCATGGTTGCTCCCTG }\end{array}$ & A AAg AAG \\
\hline $\begin{array}{l}\text { olidnaX } \\
5 \mathrm{~F} / \mathrm{R}\end{array}$ & $\begin{array}{l}\text { AACCATGGCCAAGAAGTTCTAACCGGC } \\
\text { AACTTCTTGGCCATGGTTGCTCCCTG }\end{array}$ & c AAg AAG \\
\hline $\begin{array}{l}\text { olidnaX } \\
6 \mathrm{~F} / \mathrm{R}\end{array}$ & $\begin{array}{l}\text { AACCATGGCTAAGAAGTTCTAACCGGC } \\
\text { AACTTCTTAGCCATGGTTGCTCCCTG }\end{array}$ & $\mathbf{u} \mathrm{AAg}$ AAG \\
\hline $\begin{array}{l}\text { olidnaX } \\
7 \mathrm{~F} / \mathrm{R}\end{array}$ & $\begin{array}{l}\text { AACCATGGCGAAGAAGTTCTAACCGGC } \\
\text { AACTTCTTCGCCATGGTTGCTCCCTG }\end{array}$ & g AAg AAG \\
\hline $\begin{array}{l}\text { olidnaX } \\
8 \mathrm{~F} / \mathrm{R}\end{array}$ & $\begin{array}{l}\text { AACCATGGCAAAAAAATTCTAACCGGC } \\
\text { AATTTTTTTGCCATGGTTGCTCCCTG }\end{array}$ & A AAA AAa \\
\hline $\begin{array}{l}\text { olidnaX } \\
\text { 9F/R }\end{array}$ & $\begin{array}{l}\text { AACCATGGCCAAAAAATTCTAACCGGC } \\
\text { AATTTTTTGGCCATGGTTGCTCCCTG }\end{array}$ & c AAA AAa \\
\hline $\begin{array}{l}\text { olidnaX } \\
\text { 10F/R }\end{array}$ & $\begin{array}{l}\text { AACCATGGCTAAAAAATTCTAACCGGC } \\
\text { AATTTTTTAGCCATGGTTGCTCCCTG }\end{array}$ & $\mathbf{u}$ AAA AAa \\
\hline $\begin{array}{l}\text { olidnaX } \\
\text { 11F/R }\end{array}$ & $\begin{array}{l}\text { AACCATGGCGAAAAAATTCTAACCGGC } \\
\text { AATTTTTTCGCCATGGTTGCTCCCTG }\end{array}$ & g AAA AAa \\
\hline $\begin{array}{l}\text { olidnaX } \\
\text { 12F/R }\end{array}$ & $\begin{array}{l}\text { AACCATGGCAAAGAAATTCTAACCGGC } \\
\text { AATTTCTTTGCCATGGTTGCTCCCTG }\end{array}$ & A AAg AAa \\
\hline $\begin{array}{l}\text { olidnaX } \\
\text { 13F/R }\end{array}$ & $\begin{array}{l}\text { AACCATGGCCAAGAAATTCTAACCGGC } \\
\text { AATTTCTTGGCCATGGTTGCTCCCTG }\end{array}$ & c AAg AAa \\
\hline $\begin{array}{l}\text { olidnaX } \\
\text { 14F/R }\end{array}$ & $\begin{array}{l}\text { AACCATGGCTAAGAAATTCTAACCGGC } \\
\text { AATTTCTTAGCCATGGTTGCTCCCTG }\end{array}$ & $\mathbf{u}$ AAg AAa \\
\hline $\begin{array}{l}\text { olidnaX } \\
15 \mathrm{~F} / \mathrm{R}\end{array}$ & $\begin{array}{l}\text { AACCATGGCGAAGAAATTCTAACCGGC } \\
\text { AATTTCTTCGCCATGGTTGCTCCCTG }\end{array}$ & g AAg AAa \\
\hline $\begin{array}{l}\text { olidnaX } \\
\text { 16F/R }\end{array}$ & $\begin{array}{l}\text { AACCATGGCTTTTTTTTTCTAACCGGC } \\
\text { AAAAAAAAAGCCATGGTTGCTCCCTG }\end{array}$ & U UUU UUU \\
\hline $\begin{array}{l}\text { olidnaX } \\
\text { 17F/R }\end{array}$ & $\begin{array}{l}\text { AACCATGGCATTTTTTTTCTAACCGGC } \\
\text { AAAAAAAATGCCATGGTTGCTCCCTG }\end{array}$ & a UUU UUU \\
\hline $\begin{array}{l}\text { olidnaX } \\
18 \mathrm{~F} / \mathrm{R}\end{array}$ & $\begin{array}{l}\text { AACCATGGCCTTTTTTTTCTAACCGGC } \\
\text { AAAAAAAAGGCCATGGTTGCTCCCTG }\end{array}$ & c UUU UUU \\
\hline $\begin{array}{l}\text { olidnaX } \\
\text { 19F/R }\end{array}$ & $\begin{array}{l}\text { AACCATGGCGTTTTTTTTCTAACCGGC } \\
\text { AAAAAAAACGCCATGGTTGCTCCTG }\end{array}$ & g UUU UUU \\
\hline $\begin{array}{l}\text { olidnaX } \\
\text { 20F/R }\end{array}$ & $\begin{array}{l}\text { AACCATGGCTTTCTTTTTCTAACCGGC } \\
\text { AAAAAGAAAGCCATGGTTGCTCCCTG }\end{array}$ & U UUc UUU \\
\hline $\begin{array}{l}\text { olidnaX } \\
\text { 21F/R }\end{array}$ & $\begin{array}{l}\text { AACCATGGCATTCTTTTTCTAACCGGC } \\
\text { AAAAAGAATGCCATGGTTGCTCCCTG }\end{array}$ & a UUc UUU \\
\hline $\begin{array}{l}\text { olidnaX } \\
\text { 22F/R }\end{array}$ & $\begin{array}{l}\text { AACCATGGCCTTCTTTTTCTAACCGGC } \\
\text { AAAAAGAAGGCCATGGTTGCTCCCTG }\end{array}$ & c UUc UUU \\
\hline $\begin{array}{l}\text { olidnaX } \\
23 \mathrm{~F} / \mathrm{R}\end{array}$ & $\begin{array}{l}\text { AACCATGGCGTTCTTTTTCTAACCGGC } \\
\text { AAAAAGAACGCCATGGTTGCTCCCTG }\end{array}$ & g UUc UUU \\
\hline $\begin{array}{l}\text { olidnaX } \\
\text { 24F/R }\end{array}$ & $\begin{array}{l}\text { AACCATGGCTTTTTTCTTCTAACCGGC } \\
\text { AAGAAAAAAGCCATGGTTGCTCCCTG }\end{array}$ & U UUU UUc \\
\hline $\begin{array}{l}\text { olidnaX } \\
\text { 25F/R }\end{array}$ & $\begin{array}{l}\text { AACCATGGCATTTTTCTTCTAACCGGC } \\
\text { AAGAAAAATGCCATGGTTGCTCCCTG }\end{array}$ & a UUU UUc \\
\hline $\begin{array}{l}\text { olidnaX } \\
\text { 26F/R }\end{array}$ & $\begin{array}{l}\text { AACCATGGCCTTTTTCTTCTAACCGGC } \\
\text { AAGAAAAAGGCCATGGTTGCTCCCTG }\end{array}$ & c UUU UUc \\
\hline $\begin{array}{l}\text { olidnaX } \\
\text { 27F/R }\end{array}$ & $\begin{array}{l}\text { AACCATGGCGTTTTTCTTCTAACCGGC } \\
\text { AAGAAAAACGCCATGGTTGCTCCCTG }\end{array}$ & g UUU UUc \\
\hline $\begin{array}{l}\text { olidnaX } \\
28 \mathrm{~F} / \mathrm{R}\end{array}$ & $\begin{array}{l}\text { AACCATGGCTTTCTTCTTCTAACCGGC } \\
\text { AAGAAGAAAGCCATGGTTGCTCCCTG }\end{array}$ & U UUc UUc \\
\hline $\begin{array}{l}\text { olidnaX } \\
\text { 29F/R }\end{array}$ & $\begin{array}{l}\text { AACCATGGCATTCTTCTTCTAACCGGC } \\
\text { AAGAAGAATGCCATGGTTGCTCCCTG }\end{array}$ & a UUc UUc \\
\hline $\begin{array}{l}\text { olidnaX } \\
\text { 30F/R }\end{array}$ & $\begin{array}{l}\text { AACCATGGCCTTCTTCTTCTAACCGGC } \\
\text { AAGAAGAAGGCCATGGTTGCTCCCTG }\end{array}$ & c UUc UUc \\
\hline $\begin{array}{l}\text { olidnaX } \\
31 \mathrm{~F} / \mathrm{R}\end{array}$ & $\begin{array}{l}\text { AACCATGGCGTTCTTCTTCTAACCGGC } \\
\text { AAGAAGAACGCCATGGTTGCTCCCTG }\end{array}$ & g UUc UUc \\
\hline
\end{tabular}




\begin{tabular}{|c|c|c|}
\hline $\begin{array}{l}\text { olidnaX } \\
\text { 32F/R }\end{array}$ & $\begin{array}{l}\text { AACCATGGCAAAATTTTTCTAACCGGC } \\
\text { AAAAATTTTGCCATGGTTGCTCCCTG }\end{array}$ & A AAA UUU \\
\hline $\begin{array}{l}\text { olidnaX } \\
\text { 33F/R }\end{array}$ & $\begin{array}{l}\text { AACCATGGCCAAATTTTTCTAACCGGC } \\
\text { AAAAATTTGGCCATGGTTGCTCCCTG }\end{array}$ & c AAA UUU \\
\hline $\begin{array}{l}\text { olidnaX } \\
\text { 34F/R }\end{array}$ & $\begin{array}{l}\text { AACCATGGCTAAATTTTTCTAACCGGC } \\
\text { AAAAATTTAGCCATGGTTGCTCCCTG }\end{array}$ & u AAA UUU \\
\hline $\begin{array}{l}\text { olidnaX } \\
\text { 35F/R }\end{array}$ & $\begin{array}{l}\text { AACCATGGCGAAATTTTTCTAACCGGC } \\
\text { AAAAATTTCGCCATGGTTGCTCCCTG }\end{array}$ & g AAA UUU \\
\hline $\begin{array}{l}\text { olidnaX } \\
\text { 36F/R }\end{array}$ & $\begin{array}{l}\text { AACCATGGCAAAGTTTTTCTAACCGGC } \\
\text { AAAAACTTTGCCATGGTTGCTCCCTG }\end{array}$ & A AAg UUU \\
\hline $\begin{array}{l}\text { olidnaX } \\
\text { 37F/R }\end{array}$ & $\begin{array}{l}\text { AACCATGGCCAAGTTTTTCTAACCGGC } \\
\text { AAAAACTTGGCCATGGTTGCTCCCTG }\end{array}$ & c AAg UUU \\
\hline $\begin{array}{l}\text { olidnaX } \\
38 \mathrm{~F} / \mathrm{R}\end{array}$ & $\begin{array}{l}\text { AACCATGGCTAAGTTTTTCTAACCGGC } \\
\text { AAAAACTTAGCCATGGTTGCTCCCTG }\end{array}$ & u AAg UUU \\
\hline $\begin{array}{l}\text { olidnaX } \\
\text { 39F/R }\end{array}$ & $\begin{array}{l}\text { AACCATGGCGAAGTTTTTCTAACCGGC } \\
\text { AAAAACTTCGCCATGGTTGCTCCCTG }\end{array}$ & g AAg UUU \\
\hline $\begin{array}{l}\text { olidnaX } \\
40 \mathrm{~F} / \mathrm{R}\end{array}$ & $\begin{array}{l}\text { AACCATGGCAAAATTCTTCTAACCGGC } \\
\text { AAGAATTTTGCCATGGTTGCTCCCTG }\end{array}$ & A AAA UUc \\
\hline $\begin{array}{l}\text { olidnaX } \\
41 \mathrm{~F} / \mathrm{R}\end{array}$ & $\begin{array}{l}\text { AACCATGGCCAAATTCTTCTAACCGGC } \\
\text { AAGAATTTGGCCATGGTTGCTCCCTG }\end{array}$ & c AAA UUc \\
\hline $\begin{array}{l}\text { olidnaX } \\
42 \mathrm{~F} / \mathrm{R}\end{array}$ & $\begin{array}{l}\text { AACCATGGCTAAATTCTTCTAACCGGC } \\
\text { AAGAATTTAGCCATGGTTGCTCCCTG }\end{array}$ & u AAA UUc \\
\hline $\begin{array}{l}\text { olidnaX } \\
\text { 43F/R }\end{array}$ & $\begin{array}{l}\text { AACCATGGCGAAATTCTTCTAACCGGC } \\
\text { AAGAATTTCGCCATGGTTGCTCCCTG }\end{array}$ & g AAA UUc \\
\hline $\begin{array}{l}\text { olidnaX } \\
44 \mathrm{~F} / \mathrm{R}\end{array}$ & $\begin{array}{l}\text { AACCATGGCAAAGTTCTTCTAACCGGC } \\
\text { AAGAACTTTGCCATGGTTGCTCCCTG }\end{array}$ & A AAg UUc \\
\hline $\begin{array}{l}\text { olidnaX } \\
45 \mathrm{~F} / \mathrm{R}\end{array}$ & $\begin{array}{l}\text { AACCATGGCCAAGTTCTTCTAACCGGC } \\
\text { AAGAACTTGGCCATGGTTGCTCCCTG }\end{array}$ & c AAg UUc \\
\hline $\begin{array}{l}\text { olidnaX } \\
46 \mathrm{~F} / \mathrm{R}\end{array}$ & $\begin{array}{l}\text { AACCATGGCTAAGTTCTTCTAACCGGC } \\
\text { AAGAACTTAGCCATGGTTGCTCCCTG }\end{array}$ & u AAg UUc \\
\hline $\begin{array}{l}\text { olidnaX } \\
47 F / R\end{array}$ & $\begin{array}{l}\text { AACCATGGCGAAGTTCTTCTAACCGGC } \\
\text { AAGAACTTCGCCATGGTTGCTCCCTG }\end{array}$ & g AAg UUc \\
\hline $\begin{array}{l}\text { olidnaX } \\
48 \mathrm{~F} / \mathrm{R}\end{array}$ & $\begin{array}{l}\text { AACCATGGCTTTTAAGTTCTAACCGGC } \\
\text { AACTTAAAAGCCATGGTTGCTCCCTG }\end{array}$ & U UUU AAG \\
\hline $\begin{array}{l}\text { olidnaX } \\
\text { 49F/R }\end{array}$ & $\begin{array}{l}\text { AACCATGGCATTTAAGTTCTAACCGGC } \\
\text { AACTTAAATGCCATGGTTGCTCCCTG }\end{array}$ & a UUU AAG \\
\hline $\begin{array}{l}\text { olidnaX } \\
50 \mathrm{~F} / \mathrm{R}\end{array}$ & $\begin{array}{l}\text { AACCATGGCCTTTAAGTTCTAACCGGC } \\
\text { AACTTAAAGGCCATGGTTGCTCCCTG }\end{array}$ & c UUU AAG \\
\hline $\begin{array}{l}\text { olidnaX } \\
51 \mathrm{~F} / \mathrm{R}\end{array}$ & $\begin{array}{l}\text { AACCATGGCGTTTAAGTTCTAACCGGC } \\
\text { AACTTAAACGCCATGGTTGCTCCCTG }\end{array}$ & g UUU AAG \\
\hline $\begin{array}{l}\text { olidnaX } \\
52 \mathrm{~F} / \mathrm{R}\end{array}$ & $\begin{array}{l}\text { AACCATGGCTTTCAAGTTCTAACCGGC } \\
\text { AACTTGAAAGCCATGGTTGCTCCCTG }\end{array}$ & U UUc AAG \\
\hline $\begin{array}{l}\text { olidnaX } \\
53 \mathrm{~F} / \mathrm{R}\end{array}$ & $\begin{array}{l}\text { AACCATGGCATTCAAGTTCTAACCGGC } \\
\text { AACTTGAATGCCATGGTTGCTCCCTG }\end{array}$ & a UUc AAG \\
\hline $\begin{array}{l}\text { olidnaX } \\
54 \mathrm{~F} / \mathrm{R}\end{array}$ & $\begin{array}{l}\text { AACCATGGCCTTCAAGTTCTAACCGGC } \\
\text { AACTTGAAGGCCATGGTTGCTCCCTG }\end{array}$ & c UUc AAG \\
\hline $\begin{array}{l}\text { olidnaX } \\
55 \mathrm{~F} / \mathrm{R}\end{array}$ & $\begin{array}{l}\text { AACCATGGCGTTCAAGTTCTAACCGGC } \\
\text { AACTTGAACGCCATGGTTGCTCCCTG }\end{array}$ & g UUc AAG \\
\hline $\begin{array}{l}\text { olidnaX } \\
56 \mathrm{~F} / \mathrm{R}\end{array}$ & $\begin{array}{l}\text { AACCATGGCTTTTAAATTCTAACCGGC } \\
\text { AATTTAAAAGCCATGGTTGCTCCCTG }\end{array}$ & U UUU AAa \\
\hline $\begin{array}{l}\text { olidnaX } \\
57 \mathrm{~F} / \mathrm{R}\end{array}$ & $\begin{array}{l}\text { AACCATGGCATTTAAATTCTAACCGGC } \\
\text { AATTTAAATGCCATGGTTGCTCCCTG }\end{array}$ & a UUU AAa \\
\hline $\begin{array}{l}\text { olidnaX } \\
58 \mathrm{~F} / \mathrm{R}\end{array}$ & $\begin{array}{l}\text { AACCATGGCCTTTAAATTCTAACCGGC } \\
\text { AATTTAAAGGCCATGGTTGCTCCCTG }\end{array}$ & $\mathbf{c}$ UUU AAa \\
\hline $\begin{array}{l}\text { olidnaX } \\
59 \mathrm{~F} / \mathrm{R}\end{array}$ & $\begin{array}{l}\text { AACCATGGCGTTTAAATTCTAACCGGC } \\
\text { AATTTAAACGCCATGGTTGCTCCCTG }\end{array}$ & g UUU AAa \\
\hline $\begin{array}{l}\text { olidnaX } \\
\text { 60F/R }\end{array}$ & $\begin{array}{l}\text { AACCATGGCTTTCAAATTCTAACCGGC } \\
\text { AATTTGAAAGCCATGGTTGCTCCCTG }\end{array}$ & U UUc AAa \\
\hline $\begin{array}{l}\text { olidnaX } \\
61 \mathrm{~F} / \mathrm{R}\end{array}$ & $\begin{array}{l}\text { AACCATGGCATTCAAATTCTAACCGGC } \\
\text { AATTTGAATGCCATGGTTGCTCCCTG }\end{array}$ & a UUc AAa \\
\hline
\end{tabular}




\begin{tabular}{|l|l|l|}
\hline $\begin{array}{l}\text { olidnaX } \\
\text { 62F/R }\end{array}$ & $\begin{array}{l}\text { AACCATGGCCTTCAAATTCTAACCGGC } \\
\text { AATTTGAAGGCCATGGTTGCTCCCTG }\end{array}$ & c UUc AAa \\
\hline $\begin{array}{l}\text { olidnaX } \\
\text { 63F/R }\end{array}$ & $\begin{array}{l}\text { AACCATGGCGTTCAAATTCTAACCGGC } \\
\text { AATTTGAACGCCATGGTTGCTCCCTG }\end{array}$ & g UUc AAa \\
\hline oliNC87F & GATGTCGGCGATATAGGCGCCAG & $\begin{array}{l}\text { Forward primer for } \\
\text { transcription }\end{array}$ \\
\hline oliNC90 & TTCACCGGCCGCGCGC & $\begin{array}{l}\text { Reverse primer for } \\
\text { transcription }\end{array}$ \\
\hline oliNC002 & GCATTAGGAAGCAGCCCAGTAGT & Sequencing primer \\
\hline
\end{tabular}

Mutated nt are in small letters in bold.

\subsubsection{HIV dual-luciferase vectors}

Table 8. HIV dual-luciferase vectors for in vivo studies in human cell culture

\begin{tabular}{|c|c|c|}
\hline Vector & Insert sequence & Primers used \\
\hline pLuc wt & $\begin{array}{l}\text { ATGCAGGCTAATTTTTTAGGGAAGATCTGGCCTTCCTACA } \\
\text { AGGGAAGGCCAGGGAATTTTCTTCAGAGCAGACCA }\end{array}$ & HIV insert Fwd/Rev \\
\hline $\begin{array}{l}\text { pLuc -1- } \\
\text { frame } \\
\text { control }\end{array}$ & $\begin{array}{l}\text { ATGCAGGCTAAcTTccTccGGGAAGATCTGGCCTTCCTACAA } \\
\text { GGGAAGGCCAGGGAATTTTCTTCAGAGCAGACCA }\end{array}$ & $\begin{array}{l}\text { HIV insert Fwd / HIV } \\
\text { insert control Rev }\end{array}$ \\
\hline pLuc 149 & $\begin{array}{l}\text { ATGCAGGCTAATTTTTTAGGGctctagTaaCCTTCCTACAAGG } \\
\text { GAAGGCCAGGGAATTTTCTTCAGAGCAGACCA }\end{array}$ & HIV $179 \mathrm{~F} / \mathrm{R}$ \\
\hline pLuc 170 & $\begin{array}{l}\text { ATGCAGGCTAATTTTTTAGGGtAGATCTGGCCTTCCTACAA } \\
\text { GGGAAGGCCAGGGAATTTTCTTCAGAGCAGACCA }\end{array}$ & HIV 200F/R \\
\hline pLuc 172 & $\begin{array}{l}\text { ATGCAGGCTAATTTTTTAGGGAcGATCTGGCCTTCCTACAA } \\
\text { GGGAAGGCCAGGGAATTTTCTTCAGAGCAGACCA }\end{array}$ & HIV 202F/R \\
\hline pLuc 174 & $\begin{array}{l}\text { ATGCAGGCTAATTTTTTAGGGAAtATCTGGCCTTCCTACAA } \\
\text { GGGAAGGCCAGGGAATTTTCTTCAGAGCAGACCA }\end{array}$ & HIV 204F/R \\
\hline pLuc 176 & $\begin{array}{l}\text { ATGCAGGCTAATTTTTTAGGGAAGcTCTGGCCTTCCTACAA } \\
\text { GGGAAGGCCAGGGAATTTTCTTCAGAGCAGACCA }\end{array}$ & HIV 206F/R \\
\hline pLuc 177 & $\begin{array}{l}\text { ATGCAGGCTAATTTTTTAGGGcetcaaTaaCCTTCCTACAAGG } \\
\text { GAAGGCCAGGGAATTTTCTTCAGAGCAGACCA }\end{array}$ & HIV 207F/R \\
\hline $\begin{array}{l}\text { pLuc half } \\
\text { SL }\end{array}$ & ATGCAGGCTAATTTTTTAGGGAAGATCTGGCCTTCCT & HIV half SL Fwd/Rev \\
\hline $\begin{array}{l}\text { pLuc no } \\
\text { SL }\end{array}$ & ATGCAGGCTAATTTTTTAGGG & $\begin{array}{l}\text { HIV half SL Fwd / HIV } \\
\text { no SL Rev }\end{array}$ \\
\hline $\begin{array}{l}\text { pLuc -1- } \\
\text { frame } \\
\text { control } \\
\text { half SL }\end{array}$ & ATGCAGGCTAAcTTccTccGGGAAGATCTGGCCTTCCT & $\begin{array}{l}\text { HIV half SL Fwd / pLuc } \\
\text { halfSL Rev control }\end{array}$ \\
\hline $\begin{array}{l}\text { pLuc }-1- \\
\text { frame } \\
\text { control no } \\
\text { SL }\end{array}$ & ATGCAGGCTAAcTTccTccGGG & $\begin{array}{l}\text { HIV half SL Fwd / pLuc } \\
\text { noSL Rev control }\end{array}$ \\
\hline $\begin{array}{l}\text { pLuc }-1- \\
\text { frame } \\
\text { control } \\
149\end{array}$ & $\begin{array}{l}\text { ATGCAGGCTAAcTTccTccGGGctctagTaaCCTTCCTACAAGGG } \\
\text { AAGGCCAGGGAATTTTCTTCAGAGCAGACCA }\end{array}$ & $\begin{array}{l}\text { pLuc } 149 \text { control } \\
\text { Fwd/Rev }\end{array}$ \\
\hline $\begin{array}{l}\text { pLuc }-1- \\
\text { frame } \\
\text { control } \\
177\end{array}$ & $\begin{array}{l}\text { ATGCAGGCTAAcTTccTccGGGcctcaaTaaCCTTCCTACAAGG } \\
\text { GAAGGCCAGGGAATTTTCTTCAGAGCAGACCA }\end{array}$ & $\begin{array}{l}\text { pLuc } 177 \text { control } \\
\text { Fwd/Rev }\end{array}$ \\
\hline pLuc 179 & $\begin{array}{l}\text { ATGCAGGCTAATTTTTTAGGettttTCTGGCCTTCCTACAAGG } \\
\text { GAAGGCCAGGGAAagaagTTCAGAGCAGACCA }\end{array}$ & HIV 208F/R \\
\hline $\begin{array}{l}\text { pLuc }-1- \\
\text { frame }\end{array}$ & $\begin{array}{l}\text { ATGCAGGCTAAcTTccTccGGcttttTCTGGCCTTCCTACAAGG } \\
\text { GAAGGCCAGGGAAagaagTTCAGAGCAGACCA }\end{array}$ & $\begin{array}{l}\text { pLuc } 179 \text { control lig } \\
\text { Fwd/Rev }\end{array}$ \\
\hline
\end{tabular}




\begin{tabular}{|l|l|l|}
\hline $\begin{array}{l}\text { control } \\
179\end{array}$ & & \\
\hline pLuc 180 & $\begin{array}{l}\text { ATGCAGGCTAATTTTTTAGGGAAGATCTGGCCTTCCTACA } \\
\text { AGGGAAGGCCAGGG }\end{array}$ & $\begin{array}{l}\text { HIV half SL Fwd / pLuc } \\
180 \text { Rev }\end{array}$ \\
\hline $\begin{array}{l}\text { pLuc }-1- \\
\text { frame } \\
\text { control } \\
180\end{array}$ & $\begin{array}{l}\text { ATGCAGGCTAAcTTccTccGGGAAGATCTGGCCTTCCTACAA } \\
\text { GGGAAGGCCAGGG }\end{array}$ & $\begin{array}{l}\text { HIV half SL Fwd / pLuc } \\
180 \text { Rev }\end{array}$ \\
\hline
\end{tabular}

Start codon ATG is in bold, SS is underlined, mutated nt are in small letters in bold.

\subsection{9 mRNA sequences}

Table 9. Sequences of HIV mRNAs used in bacterial translation system

\begin{tabular}{|c|c|}
\hline mRNA & Sequence \\
\hline wt short HPLC & $\begin{array}{l}\text { GGGAGACCGGAAUUCGAGCUCGCCCAAACGCGGUUGGAUUCCUGAUGAAAA } \\
\text { GUUCUAUGAGGUGUAUAAUGCAGGCUAAUUUUUUAGGGAAGAUCUGGCCUU } \\
\text { CCUACAAGGGAAGGCCAGGGAAUUUUCUUCAGAGCAGACC }\end{array}$ \\
\hline $\mathrm{U}_{4} \mathrm{C}$ HPLC & $\begin{array}{l}\text { GGGAGACCGGAAUUCGAGCUCGCCCAAACGCGGUUGGAUUCCUGAUGAAAA } \\
\text { GUUCUAUGAGGUGUAUAAUGCAGGCUAAUUUcUUAGGGAAGAUCUGGCCUU } \\
\text { CCUACAAGGGAAGGCCAGGGAAUUUUCUUCAGAGCAGACC }\end{array}$ \\
\hline$-2 /+1$ HPLC & $\begin{array}{l}\text { GGGAGACCGGAAUUCGAGCUCGCCCAAACGCGGUUGGAUUCCUGAUGAAAA } \\
\text { GUUCUAUGAGGUGUAUAAUGCAGGCUAAUUUUUUAuGGAAGAUCUGGCCUU } \\
\text { CCUACAAGGGAAGGCCAGGGAAUUUUCUUCAGAGCAGACC }\end{array}$ \\
\hline wt long gel & $\begin{array}{l}\text { GGGAGACCGGAAUUCGAGCUCGCCCAAACGCGGUUGGAUUCCUGAUGAAAA } \\
\text { GUUCUAUGAGGUGUAUAAUGAAAGAUUGUACUGAGAGACAGGCUAAUUUU } \\
\text { UUAGGGAAGAUCUGGCCUUCCUACAAGGGAAGGCCAGGGAAUUUUCUUCAG } \\
\text { AGCAGACCAGAGCCAACAGCCCACCAGAAGAGAGCUUCAGGUCUGGGGUA } \\
\text { GAGACAACAACUCCCCUCAGUAGCAGGAGCCGAUAGACAAGGAACUGUAU } \\
\text { CCUUUAACUUCCCUCAGGUCACUCUUUGGCAACGACCCCUCGUCACAAUAAA } \\
\text { GAUAGGGGGGCAACUAAAGGAAGCUCUAUUAGAUACAGGAGCAGAUGAUAC } \\
\text { AGUAUUAGAAGAAAUGAGUUUGCCAGGAAGAUGGAAACCAAAAAUGAUAG } \\
\text { GGGGAAUUGGAGGUUUUAUCA }\end{array}$ \\
\hline $\begin{array}{l}\text { 0-frame control } \\
\text { gel }\end{array}$ & $\begin{array}{l}\text { GGGAGACCGGAAUUCGAGCUCGCCCAAACGCGGUUGGAUUCCUGAUGAAAA } \\
\text { GUUCUAUGAGGUGUAUAAUGAAAGAUUGUACUGAGAGACAGGCUAAcUUcg } \\
\text { UAGGGAAGAUCUGGCCUUCCUACAAGGGAAGGCCAGGGAAUUUcCUUCAGA } \\
\text { GCAGACCAGAGCCAACAGCCCCACCAGAAGAGAGCUUCAGGUCUGGGGUAG } \\
\text { AGACAACAACUCCCCUCAGUAGCAGGAGCCGAUAACAAGGACUGUAUCC } \\
\text { UUUAACUUCCCUCAGGUCACUCUUUGGCAACGACCCCUCGUCACAAUAAAG } \\
\text { AUAGGGGGGCAACUAAAGGAAGCUCUAUUAGAUACAGGAGCAGAUGAUACA } \\
\text { GUAUUAGAAGAAAUGAGUUUGCCAGGAAGAUGGAAACCAAAAAUGAUAGG } \\
\text { GGGAAUUGGAGGUUUUAUCA }\end{array}$ \\
\hline $\begin{array}{l}\text {-1-frame } \\
\text { control gel }\end{array}$ & $\begin{array}{l}\text { GGGAGACCGGAAUUCGAGCUCGCCCAAACGCGGUUGGAUUCCUGAUGAAAA } \\
\text { GUUCUAUGAGGUGUAUAAUGAAAGAUUGUACUGAGAGACAGGCUAAcUUcg } \\
\text { UAaGGGAAGAUCUGGCCUUCCUACAAGGGAAGGCCAGGGAAUUUcCUUCAGA } \\
\text { GCAGACCAGAGCCAACAGCCCCACCAGAAGAGAGCUUCAGGUCUGGGGUAG } \\
\text { AGACAACAACUCCCCUCAGUAGCAGGAGCCGAUAGACAAGGAACUGUAUCC } \\
\text { UUUAACUUCCCUCAGGUCACUCUUUGGCAACGACCCCUCGUCACAAUAAAG } \\
\text { AUAGGGGGGCAACUAAAGGAAGCUCUAUUAGAUACAGGAGCAGAUGAUACA } \\
\text { GUAUUAGAAGAAAUGAGUUUGCCAGGAAGAUGGAAACCAAAAAUGAUAGG } \\
\text { GGGAAUUGGAGGUUUUAUCA }\end{array}$ \\
\hline $\begin{array}{l}\text {-2-frame } \\
\text { control gel }\end{array}$ & $\begin{array}{l}\text { GGGAGACCGGAAUUCGAGCUCGCCCAAACGCGGUUGGAUUCCUGAUGAAAA } \\
\text { GUUCUAUGAGGUGUAUAAUGAAAGAUUGUACUGAGAGACAGGCUAAcUUcg } \\
\text { UAaGGGAAGAUCUGGCCUUCCUACAAGGGAAGGCCAGGGAAUUUcCUUuCAG } \\
\text { AGCAGACCAGAGCCAACAGCCCCACCAGAAGAGAGCUUCAGGUCUGGGGUcG } \\
\text { AGACAACAACUCCCCUCAGUAGCAGGAGCCGAUcGACAAGGAACUGUAUCC } \\
\text { UUUcACUUCCCUCAGGUCACUCUUUGGAACGACCCUCGUCACAAUAAAGA } \\
\text { UAGGGGGGCAACUAAAGGAAGCUCUAUUAGAUACAGGAGCAGAUcAUACAG } \\
\text { UAUUAGAAGAAAUGAGUUUGCCAGGAAGAUGGAAACCAAAAAUGAUAGGG } \\
\text { GGAAUUGGAGGUUUUAUCA }\end{array}$ \\
\hline
\end{tabular}




\begin{tabular}{|c|c|}
\hline $\begin{array}{l}\text { fM-F(UUC)-T- } \\
\text { Stop }\end{array}$ & GGCAAGGAGGUAAAUAAUGUUCUAAACGAUU \\
\hline $\begin{array}{l}\text { fM-L(UUA)-V- } \\
\text { Stop }\end{array}$ & GGCAAGGAGGUAAAUAAUGUUAGUUAUU \\
\hline $\begin{array}{l}\text { fM-G(GGG)-F- } \\
\text { Stop }\end{array}$ & GUUAACAGGUAUACAUACUAUGGGGUUCUAA \\
\hline $\begin{array}{l}\text { fM-R(AGG)-V- } \\
\text { Stop }\end{array}$ & GGCAAGGAGGUAAAUAAUGAGGGUUAUU \\
\hline $\begin{array}{l}\text { fM-F-R(AGG)- } \\
\text { Stop }\end{array}$ & GUUAACAGGUAUACAUACUAUGUUCAGGAUUAC \\
\hline $\begin{array}{l}\text { fM-L-R(AGG)- } \\
\text { Stop }\end{array}$ & GUUAACAGGUAUACAUACUAUGUUAAGGAUUAC \\
\hline $23 \mathrm{nt}$ & $\begin{array}{l}\text { GGGAGACCGGAAUUCGAGCUCGCCCAAACGCGGUUGGAUUCCUGAUGAAAA } \\
\text { GUUCUAUGAGGUGUAUAAUGCAGGCTAATTTTTTAGGGAAGATCTGGCCTTC } \\
\text { CTACAA }\end{array}$ \\
\hline $20 \mathrm{nt}$ & $\begin{array}{l}\text { GGGAGACCGGAAUUCGAGCUCGCCCAAACGCGGUUGGAUUCCUGAUGAAAA } \\
\text { GUUCUAUGAGGUGUAUAAUGCAGGCUAAUUUUUUAGGGAAGAUCUGGCCUU } \\
\text { CCUA }\end{array}$ \\
\hline $17 \mathrm{nt}$ & $\begin{array}{l}\text { GGGAGACCGGAAUUCGAGCUCGCCCAAACGCGGUUGGAUUCCUGAUGAAAA } \\
\text { GUUCUAUGAGGUGUAUAAUGCAGGCUAAUUUUUUAGGGAAGAUCUGGCCUU } \\
\text { C }\end{array}$ \\
\hline $14 \mathrm{nt}$ & $\begin{array}{l}\text { GGGAGACCGGAAUUCGAGCUCGCCCAAACGCGGUUGGAUUCCUGAUGAAAA } \\
\text { GUUCUAUGAGGUGUAUAAUGCAGGCUAAUUUUUUAGGGAAGAUCUGGCC }\end{array}$ \\
\hline $11 \mathrm{nt}$ & $\begin{array}{l}\text { GGGAGACCGGAAUUCGAGCUCGCCCAAACGCGGUUGGAUUCCUGAUGAAAA } \\
\text { GUUCUAUGAGGUGUAUAAUGCAGGCUAAUUUUUUAGGGAAGAUCUG }\end{array}$ \\
\hline $8 \mathrm{nt}$ & $\begin{array}{l}\text { GGGAGACCGGAAUUCGAGCUCGCCCAAACGCGGUUGGAUUCCUGAUGAAAA } \\
\text { GUUCUAUGAGGUGUAUAAUGCAGGCUAAUUUUUUAGGGAAGAU }\end{array}$ \\
\hline $5 \mathrm{nt}$ & $\begin{array}{l}\text { GGGAGACCGGAAUUCGAGCUCGCCCAAACGCGGUUGGAUUCCUGAUGAAAA } \\
\text { GUUCUAUGAGGUGUAUAAUGCAGGCUAAUUUUUUAGGGAA }\end{array}$ \\
\hline $\begin{array}{l}\text { Inverted lower } \\
\text { stem }\end{array}$ & $\begin{array}{l}\text { GGGAGACCGGAAUUCGAGCUCGCCCAAACGCGGUUGGAUUCCUGAUGAAAA } \\
\text { GUUCUAUGAGGUGUAUAAUGCAGGCUAAUUUUUUAGGcuuuUCUGGCCUUC } \\
\text { CUACAAGGGAAGGCCAGGGAAagaagUUCAGAGCAGACC }\end{array}$ \\
\hline $38 \mathrm{nt}$ & $\begin{array}{l}\text { GGGAGACCGGAAUUCGAGCUCGCCCAAACGCGGUUGGAUUCCUGAUGAAAA } \\
\text { GUUCUAUGAGGUGUAUAAUGCAGGCUAAUUUUUUAGGGAAGAUCUGGCCUU } \\
\text { CCUACAAGGGAAGGCCAGGGAA }\end{array}$ \\
\hline
\end{tabular}

AUG is in bold, SS are underlined, UAG stop codon in 0-frame is in italic, and mutated nt are in small letters in bold. Same in Tables 10-13.

Table 10. Long HIV mRNAs with SS1 and pSS2 variants

\begin{tabular}{|l|l|l|l|}
\hline SS1 & pSS2 & pSL2 & $\begin{array}{l}\text { No stop codons in } \\
\text {-2-frame }\end{array}$ \\
\hline U UUU UUA & U UUU CUU & + & \\
\hline U UUU UUc & U UUU CUU & + & \\
\hline U UUU cUg & U UUU CUU & + & \\
\hline c UUc gUA & U UUU CUU & + & \\
\hline U UUU UUA & U UUU CUU & + & $*$ \\
\hline U UUU UUA & U UUU uUU & + & \\
\hline U UUU UUA & U UUU uUU & + & $*$ \\
\hline U UUU UUA & U UUc CUg & + & \\
\hline U UUU UUA & U UUU CUg & + & \\
\hline U UUU UUA & U UUU CUg & + & $*$ \\
\hline c UUc gUA & U UUU CUU & + & \\
\hline
\end{tabular}




\begin{tabular}{|l|l|l|l|}
\hline c UUc gUA & U UUU CUU & - & \\
\hline c UUc gUA & U UUU uUU & + & \\
\hline c UUc gUA & U UUU uUU & + & $*$ \\
\hline c UUc gUA & U UUU uUU & - & \\
\hline c UUc gUA & c UUU uUU & + & $*$ \\
\hline c UUc gUA & U UUc uUU & + & $*$ \\
\hline
\end{tabular}

Table 11. HIV mRNAs with enhancer variants

\begin{tabular}{|c|c|c|}
\hline $\begin{array}{l}\text { Intrenal } \\
\text { identifier }\end{array}$ & Sequence after SS1 GGG & SL1 \\
\hline $\mathrm{Wt}$ & AAG AUC UGG & + \\
\hline 151 & cAG AUC UGG & + \\
\hline 169 & gAG AUC UGG & + \\
\hline 170 & uAG AUC UGG & + \\
\hline 152 & AuG AUC UGG & + \\
\hline 171 & AgG AUC UGG & + \\
\hline 172 & AcG AUC UGG & + \\
\hline 153 & AAc AUC UGG & + \\
\hline 173 & AAa AUC UGG & + \\
\hline 174 & AAu AUC UGG & + \\
\hline 154 & AAG uUC UGG & + \\
\hline 175 & AAG gUC UGG & + \\
\hline 176 & AAG cUC UGG & + \\
\hline 155 & AAG AaC UGG & + \\
\hline 156 & AAG AUg UGG & + \\
\hline 157 & AAG AUC aGG & + \\
\hline 158 & AAG AUC UaG & + \\
\hline 159 & AAG AUC UcG & + \\
\hline 160 & AAG AUC UGa & + \\
\hline 161 & AAG AUC UGg & + \\
\hline 148 & cuc uaC UGG & + \\
\hline 149 & cuc uag Uaa & + \\
\hline 177 & ccu caa Uaa & + \\
\hline 178 & ccu caa Uaa & - \\
\hline
\end{tabular}


Table 12. Sequences of HIV mRNAs used in mammalian translation system

\begin{tabular}{|c|c|}
\hline mRNA & Sequence \\
\hline $\begin{array}{l}\text { Eukaryotic HIV } \\
\text { wt }\end{array}$ & $\begin{array}{l}\text { GGCAACAACAACAACAAGGAUCCAAAACAGACCACCAUGguaGCUAAUUUUU } \\
\text { UAGGGAAGAUCUGGCCUUCCUACAAGGGAAGGCCAGGGAAUUUUCUUCAGA } \\
\text { GCAGACCAGAGUAAUAACCAACAGCCCCACCAGAAGAGAGCUUCAGGUCUG } \\
\text { GGGUAGAGACUAAUAACUCCCCCUCAGAAGCAGGAGCCGAUACAGAGUGUG } \\
\text { AGGGAAGGUCAAGCUU }\end{array}$ \\
\hline $\begin{array}{l}\text { Eukaryotic HIV } \\
\text { 0-frame control }\end{array}$ & $\begin{array}{l}\text { GGCAACAACAACAACAAGGAUCCAAAACAGACCACCAUGguaGCUAAcUUccU } \\
\text { cGGGAAGAUCUGGCCUUCCUACAAGGGAAGGCCAGGGAAUUUUCUUCAGAG } \\
\text { CAGACCAGAGUAAUAACCAACAGCCCACCAGAAGAGAGCUUCAGGUCUGG } \\
\text { GGUAGAGACUAAUAACUCCCCUCAGAAGCAGGAGCCGAUACAGAGUGUGA } \\
\text { GGGAAGGUCAAGCUU }\end{array}$ \\
\hline $\begin{array}{l}\text { Eukaryotic HIV } \\
-1 \text {-frame } \\
\text { control }\end{array}$ & $\begin{array}{l}\text { GGCAACAACAACAACAAGGAUCCAAAACAGACCACCAUGguaGCUAAcUUceU } \\
\text { ccGGGAAGAUCUGGCCUUCCUACAAGGGAAGGCCAGGGAAUUUUCUUCAGAG } \\
\text { CAGACCAGAGUAAUAACCAACAGCCCACCAGAAGAGAGCUUCAGGUCUGG } \\
\text { GGUAGAGACUAAUAACUCCCCCUCAGAAGCAGGAGCCGAUACAGAGUGUGA } \\
\text { GGGAAGGUCAAGCUU }\end{array}$ \\
\hline
\end{tabular}

Table 13. Sequences of SFV mRNAs used in bacterial translation system

\begin{tabular}{|c|c|}
\hline mRNA & Sequence \\
\hline $\begin{array}{l}\text { test mRNA for } \\
\text { chemical } \\
\text { probing }\end{array}$ & $\begin{array}{l}\text { GGGUAUUGCCUCAGAAACGAAGGAGGUUGCUGUAUGAGCCUUUCUUUUUUA } \\
\text { GUGCUACUGAGCCUCGGGGCAACCGCCAGAGCUUACGAACAUUCGACAGUA } \\
\text { AUcCCGAACGUGGUGGGGUUCCCGUAUAAGGCUCACAUU }\end{array}$ \\
\hline $\begin{array}{l}\text { wt mRNA for } \\
\text { chemical } \\
\text { probing }\end{array}$ & $\begin{array}{l}\text { GGGGCGCACGCAGCUAGUGUGGCAGAGACUAUGGCCUACUUGUGGGACCAA } \\
\text { AACCAAGCGUUGUUCUGGUUGGAGUUUGCGGCCCCUGUUGCCUGCAUCCUC } \\
\text { AUCAUCACGUAUUGCCUCAGAAACGUGCUGUGUUGCUGUAAGAGCCUUUC } \\
\text { UUUUUAGUGCUACUGAGCCUCGGGGCAACCGCCAGAGCUUACGAACAUUCG } \\
\text { ACAGUAAUGCCGAACGUGGUGGGGUUCCCGUAUAAG }\end{array}$ \\
\hline SS/SL short & $\begin{array}{l}\text { GGGUAUUGCCUCAGAAACGAAGGAGGUUGCUGUAUGAGCaagUCUUUUUUAG } \\
\text { UGCUACUGAGCCUCGGGGCAACCGCCAGAGCUUACGAACAUUCGACAGUAA } \\
\text { UGCCGAACGUGGUGGGGUUCCCGUAUAAGGCUCACAUU }\end{array}$ \\
\hline SS/- short & $\begin{array}{l}\text { GGGUAUUGCCUCAGAAACGAAGGAGGUUGCUGUAUGAGCaagUCUUUUUUAG } \\
\text { UGCUACUGAGCCUCGGG }\end{array}$ \\
\hline SS/SL long & $\begin{array}{l}\text { GGGUAUUGCCUCAGAAACGAAGGAGGUUGCUGUAUGAGCCUUUCUUUUUUA } \\
\text { GUGCUACUGAGCCUCGGGGCAACCGCCAGAGCUUAgGAACAUUCGACAGUAA } \\
\text { UGCCGAACGUGGUGGGGUUCCCGUAUAAGGCUCACAUUGAAAGGCCAGGAU } \\
\text { AUAGC }\end{array}$ \\
\hline $\begin{array}{l}0 \text {-frame control } \\
\text { long }(0)\end{array}$ & $\begin{array}{l}\text { GGGUAUUGCCUCAGAAACGAAGGAGGUUGCUGUAUGAGCCUUUC. UUcgUAG } \\
\text { UGCUACUGAGCCUCGGGGCAACCGCCAGAGCUUAgGAACAUUCGACAGUAAU } \\
\text { GCCGAACGUGGUGGGGUUCCCGUAUAAGGCUCACAUUGAAAGGCCAGGAUA } \\
\text { UAGC }\end{array}$ \\
\hline $\begin{array}{l}-1 \text {-frame } \\
\text { control long } \\
(-1)\end{array}$ & $\begin{array}{l}\text { GGGUAUUGCCUCAGAAACGAAGGAGGUUGCUGUAUGAGCCUUUC. UUcgUAa } \\
\text { GUGCUACUGAGCCUCGGGGCAACCGCCAGAGCUUAgGAACAUUCGACAGUAA } \\
\text { UGCCGAACGUGGUGGGGUUCCCGUAUAAGGCUCACAUUGAAAGGCCAGGAU } \\
\text { AUAGC }\end{array}$ \\
\hline SS/- long & $\begin{array}{l}\text { GGGUAUUGCCUCAGAAACGAAGGAGGUUGCUGUAUGAGCCUUUCUUUUUUA } \\
\text { GUGCUACUcAGuCUaGGcGCAAcaGCaAGAGCaUagGAACAcUCcACgGUAAUGC } \\
\text { CaAAuGUaGUaGGaUUuCCaUAUAAaGCcCAuAUUGAAAGGCCAGGAUAUAGC }\end{array}$ \\
\hline SS/- mut1 long & $\begin{array}{l}\text { GGGUAUUGCCUCAGAAACGAAGGAGGUUGCUGUAUGAGCCUUUCUUUUUUA } \\
\text { GUGCUACUGAGCCUCGGGGCAACCGCCAGAGCUUAgGAACAUUCGACAGUAA } \\
\text { UGCCGAACGUGGUGGGGUUgggcaAUAAccgaCACAUUGAAAGGCCAGGAUAUA } \\
\text { GC }\end{array}$ \\
\hline SS/- mut2 long & $\begin{array}{l}\text { GGGUAUUGCCUCAGAAACGAAGGAGGUUGCUGUAUGAGCCUUUCUUUUUUA } \\
\text { GUGCUACUGAGCCUCGGGGCAACCGggAGAcCUUAgGAACAUUCGACAGUAA } \\
\text { UGCCGAACGUGGUGGGGUUgggcaAUAAccgaCACAUUGAAAGGCCAGGAUAUA } \\
\text { GC }\end{array}$ \\
\hline
\end{tabular}




\begin{tabular}{|l|l|}
\hline $\begin{array}{l}\text { UUA to UUc } \\
\text { long }\end{array}$ & $\begin{array}{l}\text { GGGUAUUGCCUCAGAAACGAAGGAGGUUGCUGUAUGAGCCUUUCUUUUUUc } \\
\text { GUGCUACUGAGCCUCGGGGCAACCGCCAGAGCUUAgGAACAUUCGACAGUAA } \\
\text { UGCCGAACGUGGUGGGGUUCCGUAUAAGGCUCACAUUGAAAGGCCAGGAU } \\
\text { AUAGC }\end{array}$ \\
\hline CGAU & $\begin{array}{l}\text { GGGUAUUGCCUCAGAAACGAAGGAGGUUGCUGUAUGAGCCUUUCUUUUUUA } \\
\text { GUcgauCUGAGCCUCGGGGCAACCGCCAGAGCUUAgGAACAUUCGACAGUAAU } \\
\text { GCCGAACGUGGUGGGGUUCCCGUAUAAGGCUCACAUUGAAAGGCCAGGAUA } \\
\text { UAGC }\end{array}$ \\
\hline GACU & $\begin{array}{l}\text { GGGUAUUGCCUCAGAAACGAAGGAGGUUGCUGUAUGAGCCUUUCUUUUUUA } \\
\text { GUGCUAgacuGCCUCGGGGCAACCGCCAGAGCUUAgGAACAUUCGACAGUAAU } \\
\text { GCCGAACGUGGUGGGGUUCCCGUAUAAGGCUCACAUUGAAAGGCCAGGAUA } \\
\text { UAGC }\end{array}$ \\
\hline-1 SS/- long & $\begin{array}{l}\text { GGGUAUUGCCUCAGAAACGAAGGAGGUUGCUGUAUGAGCCUUUCcUUcgUAa } \\
\text { GUGCUACUcAGuCUaGGcGCAAcaGCaAGAGCaUagGAACAcUCcACgGUAAUGC } \\
\text { CaAAuGUaGUaGGaUUuCCaUAUAAaGCcCAuAUUGAAAGGCCAGGAUAUAGC }\end{array}$ \\
\hline
\end{tabular}

Table 14. Sequence of wt dnaX mRNA

\begin{tabular}{|l|l|}
\hline mRNA & Sequence \\
\hline dnaX wt & $\begin{array}{l}\text { GGGAAUUGUGAGCGGAUAACAAUUCCCCUCUAGAGCAGUUGCAGCGCGUGC } \\
\text { AGGGAGCAACCAUGGCAAAAAAGUUCUAACCGGCAGCCGCUACCCGCGCGC } \\
\text { GGCCGGUGAA }\end{array}$ \\
\hline
\end{tabular}

AUG is in bold, SS is underlined, SL is highlighted in green. 


\subsection{Methods}

\subsubsection{Vector construction by polymerase chain reaction}

Insertions, deletions and nucleotide substitutions were introduced by a two-step polymerase chain reaction (PCR) (Mullis, 1990) in the thermocycler (peqSTAR 96 Universal Gradient, PeqLab), as outlined in Tables 15 and 16. Forward and reverse primers are summarized in Tables 3-8.

Table 15. PCR mix

\begin{tabular}{|c|c|}
\hline Component & Final concentration \\
\hline Template DNA & $50-600 \mathrm{ng}$ \\
\hline dNTPs & $0.2 \mathrm{mM}$ \\
\hline Forward primer & $0.5 \mu \mathrm{M}$ \\
\hline Reverse primer & $0.5 \mu \mathrm{M}$ \\
\hline $\begin{array}{c}\text { Q5 reaction buffer or } \\
\text { Phusion HF buffer }\end{array}$ & $1 \mathrm{X}$ \\
\hline $\begin{array}{c}\text { DMSO } \\
\text { Q5 or Phusion DNA } \\
\text { polymerase }\end{array}$ & $0.02 \mathrm{u} / \mu \mathrm{l}$ \\
\hline
\end{tabular}

* DMSO was added to decrease the melting temperature $\left(\mathrm{T}_{\mathrm{m}}\right)$ of DNA primers.

Table 16. Two-step PCR program conditions

\begin{tabular}{|c|c|c|c|}
\hline Cycle step & Temperature, ${ }^{\circ} \mathrm{C}$ & Time, s & Cycles \\
\hline Initial denaturation & 98 & 60 & 1 \\
\hline Denaturation & 98 & 20 & \multirow{3}{*}{5} \\
\hline Annealing & $*$ & 30 & \\
\hline Extension & 72 & $* * *$ & \\
\hline Denaturation & 98 & 20 & \multirow{3}{*}{25} \\
\hline Annealing & $* *$ & 30 & \\
\hline Extension & 72 & $* * *$ & \\
\hline Final extension & 72 & 300 & 1 \\
\hline
\end{tabular}

* Annealing temperature depends on the $\mathrm{T}_{\mathrm{m}}$ of primers. During the first 5 cycles, the annealing temperature is $10{ }^{\circ} \mathrm{C}$ lower than $\mathrm{T}_{\mathrm{m}}$ to achieve optimal primer binding.

** During the next 25 cycles, the annealing temperature is increased by $5^{\circ} \mathrm{C}$ to assure specific primer binding. *** Extension time depends on the size of the vector: typically, $30 \mathrm{~s}$ per $1 \mathrm{~kb}(1000 \mathrm{bp})$.

PCR products were incubated with $\operatorname{DpnI}(0.02 \mathrm{u} / \mu \mathrm{l})$ for 2 hours at $37^{\circ} \mathrm{C}$. DpnI treatment removes the template DNA because it can cleave only when its recognition site is methylated, which is not the case in the PCR product. Deletion mutagenesis results in linear 
PCR products with blunt ends. To re-circularize the plasmid, the ends of the vector are phosphorylated with the T4 Polynucleotide kinase kit and then ligated with T4 DNA Ligase or the Quick Ligase kit according to the manufacturer's recommendations.

HIV (for both bacterial and mammalian mRNAs) and SFV inserts were cloned into the pEX-A2 vector as described above. HIV inserts were designed based on the HIV-1 reference genome (NCBI Reference Sequence: NC_001802.1) and encompassed nt 1601-1961 in bacterial mRNAs and 1626-1772 in mammalian mRNAs. The SFV insert was derived from the complete SFV genome (NCBI Reference Sequence: NC_003215.1), nt positions 9814-9939. dnaX fragment was cloned into pET24a as described (Caliskan et al., 2017).

\subsubsection{Preparation of dual-luciferase vectors}

Dual-luciferase constructs were prepared by site-directed mutagenesis as described above using the pSGDLuc vector and primers listed in Tables 5 and 8. The HIV fragment (NCBI Reference Sequence: NC_001802.1, 1623-1694 nt) was inserted between Renilla (Rluc) and Firefly (Fluc) luciferase reporters (positions 1592-1666 in pSGDLuc). To allow for translation initiation, an AUG start codon was introduced before the HIV fragment. The insert is embedded in StopGo sequences, which allow to synthesize two proteins from a single ORF, rather than a fusion protein containing both reporters (Loughran et al., 2014). In the dual-luciferase constructs, Rluc is produced constitutively while Fluc is synthesized only upon -1PRF. To check the efficiency of -1 -frame peptide formation, we designed a control vector (pLuc-1-frame control) which encodes the frameshifted sequence in frame and contains a mutated SS to prevent further slippages. To check background or "leaky" expression of Fluc, we utilized an empty pSGDLuc vector without HIV insert. The frameshifting efficiency was calculated according to the formula:

$$
-1 \text { PRF efficiency, } \%=\frac{\text { Fluc test } / \text { Rluc test }}{\text { Fluc control/Rluc control }} * 100 \text {, }
$$

where test is any construct where $-1 \mathrm{PRF}$ takes place, control is the pLuc -1-frame control

\subsubsection{Transformation and purification of plasmid DNA}

PCR or ligation products (10-200 ng) were transformed into NovaBlue E. coli competent cells $(50 \mu 1)$. Competent cells were incubated for $30 \mathrm{~min}$ on ice and subsequently subjected to heat-shock at $42^{\circ} \mathrm{C}$ for $45 \mathrm{~s}$. Following heat-shock, cells were kept on ice for 2 min for recovery and then incubated in LB medium without antibiotic with constant shaking 
(750 rpm) for $30 \mathrm{~min}$ at $37^{\circ} \mathrm{C}$ in a thermomixer. Cells harboring the desired plasmid were transferred to LB agar plates containing Amp $(100 \mu \mathrm{g} / \mathrm{ml})$ or Kan $(30 \mu \mathrm{g} / \mathrm{ml})$ and grown overnight at $37^{\circ} \mathrm{C}$. A single colony was inoculated in $2 \mathrm{ml}$ of LB-medium with an appropriate antibiotic and grown overnight at $37^{\circ} \mathrm{C}$ with constant shaking (180 rpm) (New Brunswick Scientific Innova 4400). The cells were harvested by centrifugation for $10 \mathrm{~min}$ at 4,000 rpm and at $4{ }^{\circ} \mathrm{C}$ (Eppendorf Centrifuge 5810R).

Plasmids were purified using the Macherey-Nagel Plasmid Preparation Kit (Mini, Midi or Maxi scale) according to the manufacturer's protocols. All constructs were verified by sequencing (Seqlab - Sequence Laboratories, Göttingen). The concentration and quality of the DNA preparations were checked by spectroscopic measurements at $260 \mathrm{~nm}$ (NanoDrop 2000c, PeqLab) and agarose gel electrophoresis (AGE). To prepare samples for AGE, DNA (50-200 ng) was mixed with 5X DNA loading dye. Agarose gels (1\%) were pre-stained with Stain G (1:50,000 dilution) and AGE was performed in $1 \mathrm{X}$ TAE running buffer at $100 \mathrm{~V}$ for 60 min. Pictures of the gels were taken using a UV transilluminator (PeqLab).

\subsubsection{Transcription and purification of mRNAs}

mRNAs were produced by in vitro transcription with T7 RNA polymerase (Milligan et al., 1987; Tabor and Richardson, 1985). Short linear DNA transcription templates were prepared by PCR with Q5 DNA polymerase using the program described in Table 17.

Table 17. Two-step PCR program conditions

\begin{tabular}{|c|c|c|c|}
\hline Cycle step & Temperature, ${ }^{\circ} \mathrm{C}$ & Time, s & Cycles \\
\hline Initial denaturation & 98 & 30 & 1 \\
\hline Denaturation & 98 & 10 & \multirow{3}{*}{8} \\
\hline Annealing & $55^{*}$ & 10 & \\
\hline Extension & 72 & 10 & \\
\hline Denaturation & 98 & 10 & \multirow{3}{*}{25} \\
\hline Annealing & $60 *$ & 10 & \\
\hline Extension & 72 & 10 & \\
\hline
\end{tabular}

* Primers to make transcription templates were designed with $\mathrm{T}_{\mathrm{m}} \leq 65^{\circ} \mathrm{C}$.

Transcription mix contained transcription buffer (1X), DTT (10 mM), NTPs (3 mM), GMP $(5 \mathrm{mM})$, DNA transcription template $(0.2 \mu \mathrm{M})$, pyrophosphatase $(0.005 \mathrm{U} / \mu \mathrm{l})$, T7 RNA polymerase $(1.6 \mathrm{U} / \mu \mathrm{l})$ and RNase inhibitor $(0.2 \mathrm{U} / \mu \mathrm{l})$. The efficiency of transcription was checked by the analytical transcription assay. Samples of transcription mix were taken over a time course of $4 \mathrm{~h}$ and the transcription reactions were stopped by adding 
2X RNA loading dye. Samples were further analyzed by $7.5 \mathrm{M}$ urea polyacrylamide gel electrophoresis (urea-PAGE) performed in $1 \mathrm{X}$ TBE buffer at $200 \mathrm{~V}$ for $1 \mathrm{~h}$ at the room temperature. Gels were fixed with acetic acid (10\%) for $10 \mathrm{~min}$ and then stained with methylene blue $(0.04 \%)$ in sodium acetate $(2 \mathrm{M})$ solution, $\mathrm{pH} 5.0$, for $20 \mathrm{~min}$. Gels were destained with water and pictures were taken with a UV transilluminator.

Products of preparative in vitro transcription (1-5 ml) were purified via a Mono Q 5/50 GL anion-exchange column on an ÄKTA system (GE Amersham ÄKTA FPLC UPC-960, P-920, Frac-920) using FPLC buffers A and B. Fractions were analyzed by UV measurements at $260 \mathrm{~nm}$ and peak fractions were pooled and precipitated with $0.3 \mathrm{M}$ potassium acetate and $100 \%$ ethanol at $-20^{\circ} \mathrm{C}$ overnight. The pellets were dissolved in Milli-Q $\mathrm{H}_{2} \mathrm{O}$. Alternatively, mRNA transcripts were purified using the RNeasy kit according to the manufacturer's recommendations. Purified mRNAs were stored at $-80^{\circ} \mathrm{C}$. The quality and purity of produced mRNAs were checked by 7.5 M urea-PAGE as described above. mRNA concentrations were determined from spectroscopic measurements at $260 \mathrm{~nm}$ using a spectrophotometer (Perkin Elmer LAMBDA Bio+ Spectrophotometer, Terra Universal). To estimate the yield, the molecular weight of the mRNAs was calculated by the formula below:

Molecular weight, $g / m o l=\left(A_{n} \times 329.21\right)+\left(U_{n} \times 306.2\right)+\left(C_{n} \times 305.2\right)+\left(G_{n} \times 345.2\right)+159$ where $A_{n}, U_{n}, C_{n}$, and $G_{n}$ are the number of each respective $n t$ within the polynucleotide. Addition of $159.0 \mathrm{~g} / \mathrm{mole}$ to the molecular weight takes into account the 5' triphosphate.

\subsubsection{Design of HIV-1 mRNAs for bacterial and mammalian systems}

Control mRNAs used to establish saturating concentrations of ternary complexes and to determine the rate of Arg-tRNA ${ }^{\text {Arg }}$ incorporation in 0 -frame were made by chemical synthesis and contained an E. coli SD sequence inserted $9 \mathrm{nt}$ upstream of the start codon AUG. In HIV model mRNAs a SD sequence was inserted $6 \mathrm{nt}$ upstream of the start codon AUG. In the short mRNAs used in the codon walk experiments, AUG was introduced $8 \mathrm{nt}$ upstream of the SS1. In the mRNAs used to study +1 and -2 frameshifting, the GGG codon (Gly) following the SS1 was mutated to UGG (Trp) to distinguish between -1-, -2- and +1-frameshifting products (Mathew et al., 2015). The nearest natural AUG in the gag mRNA was used as a start codon in the long mRNAs to study gag-pol translation products by PAGE. The stop codon UAG was introduced in the 0-frame $156 \mathrm{nt}$ downstream of the AUG and $120 \mathrm{nt}$ after the SS1 to allow the separation between the 0 -frame (52 aa) and -1-frame 
(120 aa) products. 0-, -1 - and -2-frame control mRNAs contained respective sequences cloned in-frame with SS1 and pSS2 being mutated to prevent slippages. All mRNA sequences are listed in Tables 9-11.

Mammalian HIV-1 mRNAs were made with the native 5' UTR from rabbit $\beta$-globin mRNA containing a Kozak sequence with an embedded AUGG site to allow efficient initiation (Table 12). Here the AUG was placed 8 nt upstream of the SS1, and the next codon CAG (Gln) was mutated to GUA (Val) to improve initiation and facilitate product separation by high-performance liquid chromatography (HPLC).

\subsubsection{Design of SFV mRNAs}

In short SFV mRNAs for HPLC analysis the SD was introduced $8 \mathrm{nt}$ before the start codon AUG (Table 13). In turn, AUG was placed 8 nt before the SS. The second codon after AUG, CUU (Leu), was mutated to AAG (Lys) to improve translation efficiency with E. coli purified tRNAs. In long SFV mRNAs used for analysis by PAGE the SD was put 6 nt before the AUG, which had the same position with regard to the SS as in short mRNAs (Table 13). Here the CUU codon remained unchanged because translation was carried out with native human total tRNA. The UAG stop codon was introduced into 0 -frame $51 \mathrm{nt}$ downstream of the AUG to distinguish between 0-frame (17 aa) and -1-frame (32 aa) products.

\subsubsection{Design of dnaX mRNAs}

dnaX wt mRNA contained a variant of the original dnaX frameshifting site modified as described previously (Caliskan et al., 2017) (Table 14). All mRNA mutants had the same length as wt and contained the native SL structure, but differed in the SS sequence, as shown in Tables 7, 23 and 27.

\subsection{4 tRNA preparation}

\subsubsection{Aminoacylation and purification of individual tRNAs from E. coli}

Individual tRNAs were prepared from E. coli total tRNA (Roche) and aminoacylated with the respective aa as described below. For preparative aminoacylation, 50-100 $\mu \mathrm{M}$ total tRNA, $1 \%(\mathrm{v} / \mathrm{v})$ aa-tRNA synthetase or $5 \%(\mathrm{v} / \mathrm{v})$ S100 extract (contains a mixture of synthetases), $3 \mathrm{mM}$ ATP, $2 \mathrm{mM}$ DTT, 50-80 $\mu \mathrm{M}$ radioactive-labeled aa or $1 \mathrm{mM}$ cold aa were incubated for $60 \mathrm{~min}$ at $37^{\circ} \mathrm{C}$ in aminoacylation buffer. The aminoacylation efficiency was controlled in an aliquot of the reaction mixture by trichloracetic acid precipitation, 
filtration through a nitrocellulose filter, and scintillation counting with Quickszint 361 cocktail using a Tri-Carb 3110 TR instrument (Perkin Elmer). Potassium acetate (pH 4.5) was added to the samples to a final concentration of $0.3 \mathrm{M}$. The reaction mixture was phenolized to remove proteins. The aa-tRNA was precipitated from the aqueous phase with 2.5 volumes of cold ethanol, and the pellet of aa-tRNA was dissolved in $0.1 \mathrm{M}$ sodium acetate ( $\mathrm{pH} 4.5)$.

fMet-tRNA $^{\text {fMet }}$, BODIPY-Met-tRNA ${ }^{\text {fMet }}$, Phe-tRNA ${ }^{\text {Phe }}$ and Gln-tRNA ${ }^{\text {Gln }}$ were made as described (Holtkamp et al., 2014a; Kothe et al., 2006; Rodnina et al., 1994) and provided by the laboratory facility. Gln-, Ala- and Asn-tRNA mixture, Arg-tRNA ${ }^{\mathrm{Arg}}$, Gly-tRNA ${ }^{\mathrm{Gly}}$, Val-tRNA ${ }^{\mathrm{Val}}$, Ser-tRNA ${ }^{\mathrm{Ser}}$, Thr-tRNA ${ }^{\text {Thr }}$ were prepared from E. coli total tRNA by aminoacylation with the respective aa and subsequent affinity chromatography of the EFTu-GTP-aa-tRNA TCs on a Protino Ni-IDA 2000 Packed Columns in TAKM 7 buffer. Purification was followed by phenolization and ethanol precipitation of the aa-tRNA. tRNA $^{\text {Leu(UUA) }}$, elongator tRNA ${ }^{\text {Met }}$, tRNA ${ }^{\text {Tyr }}$, tRNA ${ }^{\mathrm{Ile}}, \mathrm{tRNA}^{\mathrm{Lys}}, \mathrm{tRNA}^{\mathrm{Ala}}, \mathrm{tRNA}^{\mathrm{Glu}}$ and a mixture of isoacceptors tRNA ${ }^{\mathrm{Leu}(\mathrm{CUN})}$ were prepared by consecutive chromatographies on Sepharose 4B, Phenyl Sepharose and DEAE Toyopearl columns. Upon aminoacylation, these tRNAs were additionally purified by reversed-phase HPLC (RP-HPLC) on a WP-300 RP-18 column using HPLC buffers E and F. tRNA ${ }^{\text {Trp }}$ was prepared by T7 RNA polymerase transcription from pUC18 plasmid carrying the E. coli trp gene using the conditions outlined in Tables 18 and 19. The tRNA transcript was purified by Mono Q 5/50 GL column (see 2.2.3) using FPLC buffers $C$ and D. Upon purification, tRNA ${ }^{\text {Trp }}$ was aminoacylated as described above.

Table 18. PCR mix

\begin{tabular}{|c|c|}
\hline Component & Final concentration \\
\hline Template DNA & $400 \mathrm{ng}$ \\
\hline dNTPs & $0.2 \mathrm{mM}$ \\
\hline Forward primer & $0.5 \mu \mathrm{M}$ \\
\hline Reverse primer & $0.5 \mu \mathrm{M}$ \\
\hline Pfu reaction buffer & $1 \mathrm{X}$ \\
\hline MgSO $_{4}$ & $2 \mathrm{mM}$ \\
\hline Pfu DNA polymerase & $0.03 \mathrm{u} / \mu \mathrm{l}$ \\
\hline
\end{tabular}


Table 19. PCR program conditions

\begin{tabular}{|c|c|c|c|}
\hline Cycle step & Temperature, ${ }^{\circ} \mathbf{C}$ & Time, $\mathbf{s}$ & Cycles \\
\hline Initial denaturation & 95 & 60 & 1 \\
\hline Denaturation & 95 & 30 & \multirow{2}{*}{25} \\
\cline { 1 - 3 } Annealing & 60 & 30 & \\
\hline Extension & 72 & 30 & \multirow{2}{*}{1} \\
\hline Final extension & 72 & 300 & \\
\hline
\end{tabular}

\subsubsection{Purification of total tRNA from HeLa cell extracts}

Total human aa-tRNA was prepared from cell extracts obtained from S10 HeLa cells (Fermentation facility of Max Planck Institute for Biophysical Chemistry, Göttingen). The cytoplasmic fraction of the cell lysate was phenolized and aa-tRNA was purified by anionexchange chromatography on a HiTrap Q HP column using FPLC buffers E and F. Purification was performed at acidic $\mathrm{pH}$ 4.5-5 to avoid deacylation of endogenous aa-tRNA. To prepare tRNA mixes aminoacylated with aa of interest, total tRNA was deacylated by incubation in $0.5 \mathrm{M}$ Tris- $\mathrm{HCl}, \mathrm{pH} 9$ at $37^{\circ} \mathrm{C}$ for 3 hours. Upon tRNA recovery, aminoacylation was carried out as described for E. coli tRNAs but using 5\% (v/v) S30 aminoacylation extract from yeast $S$. cerevisiae (provided by Dr. Namit Ranjan, Department of Physical Biochemistry, Max Planck Institute for Biophysical Chemistry, Göttingen). Concentrations of tRNAs were determined spectrophotometrically at $260 \mathrm{~nm}$ and, where applicable, by radioactivity measurements with Ultima Gold ${ }^{\mathrm{TM}}$ XR scintillation cocktail.

\subsubsection{Initiation complex formation}

$70 \mathrm{~S}$ ribosomes from $E$. coli MRE 600 and initiation factors (IF1, IF2, IF3) were prepared as described (Rodnina and Wintermeyer, 1995) and provided by the laboratory facility. 70S ICs were prepared by incubating $70 \mathrm{~S}(1 \mu \mathrm{M})$ with mRNA $(3-10 \mu \mathrm{M})$, initiation factors IF1, IF2, and IF3 (1.5 $\mu \mathrm{M}$ each), initiator f[ $\left.{ }^{3} \mathrm{H}\right] \mathrm{Met}^{-t R N A}{ }^{\mathrm{fMet}}$ or BODIPY-Met-tRNA ${ }^{\mathrm{fMet}}(2 \mu \mathrm{M})$, DTT $(1 \mathrm{mM})$ and GTP $(1 \mathrm{mM})$ in $\mathrm{TAKM}_{7}$ buffer for $30 \mathrm{~min}$ at $37^{\circ} \mathrm{C}$. To monitor $70 \mathrm{~S} \mathrm{IC}$ formation, samples (10 pmol) were taken over a time course of $45 \mathrm{~min}$ and filtered through a nitrocellulose filter on a vacuum unit. Filters were dissolved in Quickzint 361 scintillation cocktail and radioactivity was counted in the scintillation counter. The efficiency of 70S IC formation was estimated as follows:

$$
\text { Efficiency of 70S IC formation }[\%]=\frac{\text { Radioactivity }\left[{ }^{3} \mathrm{H}\right] \text { measured }(\mathrm{dpm}) \times 100 \%}{\text { Radioactivity }\left[{ }^{3} \mathrm{H}\right] \text { expected }(\mathrm{dpm})}
$$


Radioactivity $\left[{ }^{3} \mathrm{H}\right]$ expected $=70 \mathrm{~S}[\mathrm{pmol}] \times$ specific activity of tRNA ${ }^{\mathrm{fMet}}\left[\frac{\mathrm{dpm}}{\mathrm{pmol}}\right]$

ICs were purified by ultracentrifugation through a $1.1 \mathrm{M}$ sucrose cushion in $\mathrm{TAKM}_{7}$ buffer. Centrifugation was performed in a TLS-55 swing-out rotor in an ultracentrifuge (Beckman Optima XP) at 55,000 rpm at $4^{\circ} \mathrm{C}$ for $2 \mathrm{~h}$. Pellets were dissolved in HiFi buffer. The concentration of the ribosomes was determined from the absorbance measurements at $260 \mathrm{~nm}$ assuming $23 \mathrm{pmol}$ of $70 \mathrm{~S}$ ribosomes per A260 unit. The radioactivity was measured by liquid scintillation counting with Ultima Gold ${ }^{\mathrm{TM}} \mathrm{XR}$ cocktail to calculate the efficiency of 70 S initiation.

\subsubsection{In vitro translation of HIV mRNAs}

\subsubsection{HIV codon walk assay}

Elongation factors EF-Tu and EF-G were prepared as described (Cunha et al., 2013; Doerfel et al., 2013; Savelsbergh et al., 2003). To form EF-Tu-GTP-aa-tRNA TCs, EF-Tu (25-30 $\mu \mathrm{M}$, or 3-fold excess over aa-tRNA) was incubated with GTP (1 $\mathrm{mM})$, phosphoenolpyruvate $(\mathrm{PEP})(3 \mathrm{mM})$, and pyruvate kinase $(\mathrm{PK})(0.1 \mathrm{mg} / \mathrm{ml})$ in $\mathrm{TAKM}_{7}$ buffer with DTT $(1 \mathrm{mM})$ for $15 \mathrm{~min}$ at $37^{\circ} \mathrm{C}$. Then aa-tRNAs were added and incubated for $1 \mathrm{~min}$ at $37^{\circ} \mathrm{C}$. The concentrations of aa-tRNA were optimized to ensure the maximum binding at their respective codon: $1.6 \mu \mathrm{M}$ each for Gln-tRNA ${ }^{\text {Gln }}$, Ala-tRNA ${ }^{\text {Ala }}$, Asn-tRNA ${ }^{\text {Asn }}$, Phe-tRNA ${ }^{\text {Phe }}$, and Arg-tRNA ${ }^{\text {Arg }}, 1.2 \mu \mathrm{M}$ for Gly-tRNA ${ }^{\text {Gly }}$ and different concentrations of Leu-tRNA ${ }^{\mathrm{Leu}(\mathrm{UUA})}$, as indicated. IC $(0.16 \mu \mathrm{M})$ was mixed with TCs (about $20 \mu \mathrm{M}$ final concentration of EF-Tu), EF-G $(1.6 \mu \mathrm{M})$, GTP $(1 \mathrm{mM})$, PEP $(2.4 \mathrm{mM})$ and PK $(0.08 \mathrm{mg} / \mathrm{ml})$ in $\mathrm{HiFi}$ buffer at $37^{\circ} \mathrm{C}$. Incubation times were $0-10 \mathrm{~min}$ for time courses or 2 min for end-point measurements.

The stability of MQANF-tRNA ${ }^{\text {Phe }}$ binding to the ribosome was tested using the nitrocellulose filter binding assay upon translation of HIV wt mRNA. The complexes were prepared by mixing IC with TC(QANF) and incubating for $30 \mathrm{sec}$ to $10 \mathrm{~min}$ at $37^{\circ} \mathrm{C}$, which results in the formation of MQAN, MQANF and -1-frame MQANFFR peptides. Gln-tRNA $^{\text {Gln }}$, Ala-tRNA ${ }^{\text {Ala }}$, Asn-tRNA ${ }^{\text {Asn }}$, Phe-tRNA ${ }^{\text {Phe }}$ and Arg-tRNA ${ }^{\text {Arg }}$ were used at $0.5 \mu \mathrm{M}$ each (10-times over $70 \mathrm{~S})$. The amount of total ribosome-bound peptide was calculated from the $\mathrm{f}\left[{ }^{3} \mathrm{H}\right]$ Met retained on the nitrocellulose membrane upon filtration and scintillation counting in Quickszint 361 cocktail. MQANF and MQANFF peptides were distinguished based on the $\left[{ }^{14} \mathrm{C}\right] \mathrm{Phe} / \mathrm{f}\left[{ }^{3} \mathrm{H}\right]$ Met ratio. 
To prepare samples for the HPLC analysis, the reactions were quenched with $\mathrm{KOH}$ $(0.5 \mathrm{M})$ and hydrolyzed for $30 \mathrm{~min}$ at $37^{\circ} \mathrm{C}$; then the samples were neutralized by the addition of glacial acetic acid. Translation products were separated by RP-HPLC on an RP-8 column using HPLC buffers A and B. Eluted fractions were mixed with Ultima Gold XR scintillation liquid and analyzed by scintillation counting.

The peptide products up to MQAN were not separated from each other, while all other peptides could be identified by either position shift on a chromatogram or by the radioactive label of the respective aa. The amount of each product was determined as a ratio between ${ }^{3} \mathrm{H}$-counts in the respective peak and total ${ }^{3} \mathrm{H}$-counts in the eluate. For samples with $\left[{ }^{3} \mathrm{H}\right] \mathrm{Gly}$ tRNA ${ }^{\text {Gly }},\left[{ }^{14} \mathrm{C}\right]$ Arg-tRNA ${ }^{\operatorname{Arg}}$, or $\left[{ }^{14} \mathrm{C}\right]$ Leu-tRNA ${ }^{\mathrm{Leu}(\mathrm{UUA})}$ the respective peaks were calculated in pmol. Where necessary, the amount of MQANFLR peptide was calculated by subtracting the amount of MQANFLG from that of MQANFL, in pmol. Likewise, the MQANFFR peptide was calculated by subtracting the amount of MQANFLR from the mixed MQANFLR/FFR product, in pmol. Time courses were evaluated by numerical integration using the KinTek Explorer software (Johnson, 2009). The frameshifting efficiency was calculated as a ratio between the -1-frame peptides (MQANFFR and MQANFLR) and the sum of -1- and all 0-frame peptides (MQANF, MQANFL, MQANFLG), multiplied by $100 \%$.

\subsubsection{End-point translation assay of -2 / +1 HIV mRNA}

Translation of $-2 /+1$ mRNA was carried out as described for the codon-walk assay, but with $0.4 \mu \mathrm{M}$ of each Gln-tRNA ${ }^{\text {Gln }}$, Ala-tRNA ${ }^{\text {Ala }}$, Asn-tRNA ${ }^{\text {Asn }}, 0.8 \mu \mathrm{M}$ of Phe-tRNA ${ }^{\text {Phe }}$, $0.08 \mu \mathrm{M}$ of Leu-tRNA ${ }^{\mathrm{Leu}(\mathrm{UUA})}$, and $0.4 \mu \mathrm{M}$ each of Trp-tRNA ${ }^{\text {Trp }}$, Met-tRNA ${ }^{\mathrm{Met}}$, and Tyr-tRNA $^{\text {Tyr }}$. IC $(0.08 \mu \mathrm{M})$ was incubated with TCs (about $10 \mu \mathrm{M}$ final concentration of EF-Tu), EF-G (1.6 $\mu \mathrm{M})$, GTP (1 mM), PEP $(2.4 \mathrm{mM})$ and PK $(0.08 \mathrm{mg} / \mathrm{ml})$ for $2 \mathrm{~min}$ in $\mathrm{HiFi}$ buffer at $37^{\circ} \mathrm{C}$. The efficiency of frameshifting peptide synthesis was calculated by dividing the amount of the respective peptide in pmol by the sum of all peptides in translation excluding MQAN, multiplied by $100 \%$.

\subsubsection{Arg-tRNA ${ }^{A r g}$ incorporation assay on HIV control mRNAs}

To form post-translocation complexes (PTCs), purified ICs $(0.16 \mu \mathrm{M}$ final) were mixed with Phe-tRNA ${ }^{\text {Phe }}(1.6 \mu \mathrm{M})$ or Leu-tRNA ${ }^{\text {Leu(UUA) }}(0.16 \mu \mathrm{M})$ in the presence of EF-G $\left(0.008 \mu \mathrm{M}, 1 / 20\right.$ of the IC concentration) in HiFi buffer and incubated for 1 min at $37^{\circ} \mathrm{C}$. PTCs were then mixed with Arg-tRNA ${ }^{\text {Arg }}(1.6 \mu \mathrm{M})$ and EF-G $(1.6 \mu \mathrm{M})$ and reacted for 
$1-100 \mathrm{~s}$ at $37^{\circ} \mathrm{C}$. Translation products were analyzed by RP-HPLC as described above. The position of MFR and MLR peptides was identified based on $\left[{ }^{14} \mathrm{C}\right] \mathrm{Arg}$ counts and their amounts were calculated in pmol. The rate of Arg incorporation was estimated by singleexponential fitting using the GraphPad Prism software.

\subsubsection{End-point translation of HIV mRNAs with enhancer variants}

Translation of HIV short mRNAs with enhancer variants was done with $0.8 \mu \mathrm{M}$ of each Gln-tRNA $^{\text {Gln }}$, Ala-tRNA ${ }^{\text {Ala }}$, Asn-tRNA ${ }^{\text {Asn }}$, Phe-tRNA $^{\text {Phe }}$ and Arg-tRNA ${ }^{\text {Arg }}, 0.08 \mu \mathrm{M}$ of Leu-tRNA $^{\text {Leu(UUA) }}$ and $0.6 \mu \mathrm{M}$ of Gly-tRNA ${ }^{\text {Gly }}$. IC $(0.08 \mu \mathrm{M})$ was mixed with TCs (about $10 \mu \mathrm{M}$ final concentration of EF-Tu), EF-G $(1.6 \mu \mathrm{M})$, GTP $(1 \mathrm{mM})$, PEP $(2.4 \mathrm{mM})$ and PK $(0.08 \mathrm{mg} / \mathrm{ml})$ and reacted in $\mathrm{HiFi}$ buffer for $2 \mathrm{~min}$ at $37^{\circ} \mathrm{C}$. Produced peptides were separated using RP-HPLC and frameshifting efficiencies were determined as described in 2.2.6.1.

\subsubsection{Analysis of TC formation by electrophoretic mobility shift assay}

Formation of TC between $E$. coli $\mathrm{EF}-\mathrm{Tu}$ and human native aa-tRNA $(1.4 \mu \mathrm{M})$ was monitored at varying concentrations of EF-Tu $(0-300 \mu \mathrm{M})$ using an electrophoretic mobility shift assay. TC formation was analyzed by native gel-electrophoresis using 5\% (w/v) PAGE supplemented with DTT $(125 \mu \mathrm{M})$ and GTP $(10 \mu \mathrm{M})$. The gels were run at $4{ }^{\circ} \mathrm{C}$ at $150 \mathrm{~V}$ (76 mA) for 4-6 h in electrophoresis buffer (50 mM Tris-HCl, pH 7.5, $10 \mathrm{mM}$ magnesium acetate, $75 \mathrm{mM}$ ammonium acetate, $1 \mathrm{mM}$ EDTA, $10 \mu \mathrm{M}$ GTP), stained with Gel Red (Biotium) and scanned using a UV transilluminator (Amersham ${ }^{\mathrm{TM}}$ imager 600). Band intensities were evaluated using the MultiGauge software.

\subsubsection{Translation of long HIV and $\gamma \mathrm{B}$-crystallin mRNAs using human tRNAs and} analysis of translation products

ICs programmed with HIV mRNA constructs prepared with BODIPY-Met-tRNA ${ }^{\text {fMet }}$ $(0.08 \mu \mathrm{M})$ were incubated with EF-Tu $(80 \mu \mathrm{M})$, total aa-tRNA from HeLa cells $(3-10 \mu \mathrm{M})$, EF-G $(1.6 \mu \mathrm{M})$ and RF1 $(0.8 \mu \mathrm{M})$, GTP $(1 \mathrm{mM})$, PEP $(2.4 \mathrm{mM})$ and PK $(0.08 \mathrm{mg} / \mathrm{ml})$ in $\mathrm{HiFi}$ buffer at $37^{\circ} \mathrm{C}$ as indicated or for $30 \mathrm{~min}$ for single-point measurements. RF1 was prepared as described (Florin et al., 2017) and provided by Prajwal Karki (Department of Physical Biochemistry, Max Planck Institute for Biophysical Chemistry, Göttingen). In case of $\gamma \mathrm{B}$-crystallin mRNAs, translation was carried out using IC $(0.02 \mu \mathrm{M})$, EF-Tu $(45 \mu \mathrm{M})$, total aa-tRNA from HeLa $(10 \mu \mathrm{M})$, EF-G $(1 \mu \mathrm{M})$, GTP $(0.8 \mathrm{mM})$, PEP $(1.4 \mathrm{mM})$ and PK $(0.05 \mathrm{mg} / \mathrm{ml})$ for $30 \mathrm{~min}$ in $\mathrm{HiFi}$ buffer at $37^{\circ} \mathrm{C}$. 
To prepare the samples for PAGE, the reactions were stopped with $\mathrm{NaOH}(0.4 \mathrm{M})$ and hydrolyzed as described for the HPLC sample preparation. HEPES (0.2 M, pH 5) was added to neutralize the reactions. Finally, the samples were mixed with equal volumes of 2X sample buffer and separated by Tris-Tricine gel electrophoresis (Schagger and von Jagow, 1987). Tris-Tricine gels were prepared as outlined in Table 20.

Table 20. Composition of separating, spacer and stacking gels*

\begin{tabular}{|l|c|c|c|}
\hline & Stacking gel (1 cm) & Spacer gel (1 cm) & Separating gel \\
\hline & $4 \% \mathrm{~T}, 3 \% \mathrm{C}$ & $10 \% \mathrm{~T}, 3 \% \mathrm{C}$ & $16.5 \% \mathrm{~T}, 6 \% \mathrm{C}$ \\
\hline $\begin{array}{l}49.5 \% \mathrm{~T}, 3 \% \mathrm{C} \text { mixture of } \\
\text { acrylamide/bis** }\end{array}$ & $0.5 \mathrm{ml}$ & $0.6 \mathrm{ml}$ & - \\
\hline $\begin{array}{l}49.5 \% \mathrm{~T}, 6 \% \mathrm{C} \text { mixture of } \\
\text { acrylamide/bis }\end{array}$ & - & - & $2 \mathrm{ml}$ \\
\hline $3 \mathrm{X}$ gel buffer & $2 \mathrm{ml} \mathrm{ml}$ \\
\hline $\begin{array}{l}\text { Milli-Q } \mathrm{H}_{2} \mathrm{O} \text { to a final } \\
\text { volume of }\end{array}$ & $6 \mathrm{ml}(\mathrm{add} 3.5 \mathrm{ml})$ & $3 \mathrm{ml}(\mathrm{add} 1.4 \mathrm{ml})$ & $6 \mathrm{ml}(\mathrm{add} 2 \mathrm{ml})$ \\
\hline TEMED & $20 \mu \mathrm{l}$ & $10 \mu \mathrm{l}$ & $10 \mu \mathrm{l}$ \\
\hline APS $(10 \%)$ & $30 \mu \mathrm{l}$ & $25 \mu \mathrm{l}$ & $25 \mu \mathrm{l}$ \\
\hline
\end{tabular}

* Gel dimensions were $10 \mathrm{~cm}$ x $10 \mathrm{~cm}$ x $0.8 \mathrm{~mm}$

** T stands for the total percentage concentration of both monomers (acrylamide/bis). C refers to the percentage concentration of the crosslinker (bis) relative to the total concentration T (Hjerten, 1962).

The gels were run in PerfectBlue ${ }^{\mathrm{TM}}$ Vertical Double Gel Systems (Peqlab) using $1 \mathrm{X}$ cathode buffer in the inner chamber and $1 \mathrm{X}$ anode buffer in the outer chamber. The electrophoresis was performed at room temperature at $30 \mathrm{~V}(15 \mathrm{~mA})$ until the samples reached the separating gels and then at $150 \mathrm{~V}(76 \mathrm{~mA})$ until the end.

Fluorescent peptides were visualized using a Typhoon ${ }^{\mathrm{TM}}$ FLA-9000 scanner (GE Healthcare Life Sciences) and the band intensities were evaluated using the MultiGauge software. Frameshifting efficiencies were calculated from the band intensities of the -1 -frame product to the sum of -1 - and 0 -frames products as well as of translation intermediates appearing at $20 \mathrm{~s}$ of translation. The correct length of the peptides was confirmed using control 0 -frame, -1 -frame and -2-frame mRNAs.

\subsubsection{In vitro translation of SFV mRNAs}

\subsubsection{End-point translation assay of short SFV mRNAs}

Translation and analysis of short SFV mRNAs was carried out as described for HIV mRNAs (2.2.6.1), but using $0.8 \mu \mathrm{M}$ of each Ser-tRNA ${ }^{\text {Ser }}$ and Phe-tRNA ${ }^{\text {Phe }}$ and $0.25 \mu \mathrm{M}$ of each Lys-tRNA $^{\text {Lys }}$, Val-tRNA ${ }^{\text {Val }}$, Ala-tRNA ${ }^{\text {Ala }}$ and Thr-tRNA ${ }^{\text {Thr }}$. Leu-tRNA ${ }^{\text {Leu(UUA) }}$ was 
used in three different concentrations depending on the experiment: $0 \mu \mathrm{M}, 0.025 \mu \mathrm{M}$ $(0.3 \mathrm{x}$ over $70 \mathrm{~S})$ and $0.08 \mu \mathrm{M}(1 \mathrm{x}$ over $70 \mathrm{~S})$. IC $(0.08 \mu \mathrm{M})$ was mixed with TCs (about $10 \mu \mathrm{M}$ final concentration of EF-Tu), EF-G (1.6 $\mu \mathrm{M})$, GTP $(1 \mathrm{mM})$, PEP $(2.4 \mathrm{mM})$ and PK $(0.08 \mathrm{mg} / \mathrm{ml})$ in $\mathrm{HiFi}$ buffer at $37^{\circ} \mathrm{C}$ and incubated for 2 min unless stated otherwise. Due to limited separation efficiency, 0-frame and -1-frame products were distinguished based on different radioactive labels on terminal aa as follows: $\left[{ }^{14} \mathrm{C}\right]$ Val-tRNA ${ }^{\text {Val }}$ in 0 -frame MSKSFLV and $\left[{ }^{14} \mathrm{C}\right]$ Ala-tRNA ${ }^{\text {Ala }}$ and $\left[{ }^{14} \mathrm{C}\right] \mathrm{Thr}$-tRNA ${ }^{\text {Thr }}$ in -1 -frame peptides MSKSFFAT/MSKSFLAT. To identify -1-frame peptides, two labels were used simultaneously due to their low specific activity. Frameshifting efficiencies were calculated as a ratio between the -1 -frame peptide (MSKSFFAT and MSKSFLAT) and the sum of -1- and all 0-frame peptides (MSKSF, MSKSFL, MSKSFLV), multiplied by $100 \%$. Translation of long SFV mRNAs was carried out as described for $\gamma$ B-crystallin mRNAs (2.2.6.6).

\subsubsection{Chemical probing of SFV mRNA secondary structure}

Chemical probing of SFV mRNA secondary structures was carried out using DMS, KE and CMCT as outlined in Table 21 (Hartmuth et al., 1999).

Table 21. Scheme of chemical probing with DMS, KE and CMCT

\begin{tabular}{|c|c|c|c|}
\hline Modification agent & DMS & KE & CMCT \\
\hline Reaction volume & $100 \mu \mathrm{L}$ & $100 \mu \mathrm{L}$ & $100 \mu \mathrm{L}$ \\
\hline mRNA (1 pmol) & $1 \mu \mathrm{L}(1 \mu \mathrm{M})$ & $1 \mu \mathrm{L}(1 \mu \mathrm{M})$ & $1 \mu \mathrm{L}(1 \mu \mathrm{M})$ \\
\hline $\begin{array}{l}\text { Yeast total tRNA } \\
(10 \mu \mathrm{g} / \mu \mathrm{L})^{*}\end{array}$ & $1 \mu \mathrm{L}$ & $1 \mu \mathrm{L}$ & $1 \mu \mathrm{L}$ \\
\hline IPP buffer** & \multicolumn{3}{|l|}{ Fill up to $100 \mu \mathrm{L}$} \\
\hline Reagent & $0.5 \mu \mathrm{L}$ DMS & $\begin{array}{l}20 \mu \mathrm{L} \text { KE mix }(2 \mu \mathrm{L} \\
\mathrm{KE}+18 \mu \mathrm{L} \text { IPP buffer })\end{array}$ & 0.0075 g CMCT \\
\hline \multicolumn{4}{|c|}{ Incubation } \\
\hline Temperature & $20^{\circ} \mathrm{C}$ & $4^{\circ} \mathrm{C}$ & $20^{\circ} \mathrm{C}$ \\
\hline Time & $8 \mathrm{~min}$ & $90 \mathrm{~min}$ & $20 \mathrm{~min}$ \\
\hline
\end{tabular}

* yeast total tRNA was added to prevent overmodification and facilitate RNA precipitation.

** IPP buffer: 20 mM HEPESs, pH 7.9, $150 \mathrm{mM} \mathrm{NaCl,} 7 \mathrm{mM} \mathrm{MgCl}$.

Reactions with DMS were stopped using 2X DMS-stopper (400 mM Tris acetate, pH 7.5, $400 \mathrm{mM} \beta$-mercaptoethanol, $5 \mathrm{mM}$ EDTA, $600 \mathrm{mM}$ sodium acetate); reaction adducts of $\mathrm{KE}$ treatment were stabilized with $50 \mathrm{mM} \mathrm{K}_{3} \mathrm{BO}_{3}$. Upon chemical probing the modified mRNAs were recovered by precipitation with $3 \mathrm{M}$ sodium acetate $(1 / 10 \mathrm{v} / \mathrm{v})$ and 5 volumes of ice-cold ethanol followed by centrifugation for $30 \mathrm{~min}$ at $13,000 \mathrm{rpm}$ at $4{ }^{\circ} \mathrm{C}$ 
(Eppendorf Centrifuge 5415R). The RNA was re-precipitated three times to remove the remaining modification reagents and to improve the sample purity. After the final centrifugation, pellets were dissolved in Milli-Q $\mathrm{H}_{2} \mathrm{O}$ or $50 \mathrm{mM} \mathrm{K} \mathrm{BO}_{3}$ for KE-treated samples. Modified ICs were processed as described for mRNAs, but in addition the reactions were treated with $3 \%$ proteinase $\mathrm{K}$ and subsequently phenolized to remove proteins. Following mRNA recovery, a RT reaction was conducted as outlined in Table 22.

Table 22. Outline of RT upon chemical probing

\begin{tabular}{|c|c|c|}
\hline Component & Amount & \multirow{4}{*}{$\begin{array}{l}2.5 \mu \mathrm{L} \mathrm{HY} \\
\text { reaction }\end{array}$} \\
\hline Modified mRNA or untreated control mRNA & $100 \mathrm{fmol}$ & \\
\hline 10X HY buffer (0.5 M Tris-HCl, pH 8.4, 0.6 M NaCl, 0.1 M DTT) & $1 \mathrm{X}$ & \\
\hline Reverse primer oliSFV 10 labeled with Atto647N at 5' end & $125 \mathrm{fmol}$ & \\
\hline \multicolumn{3}{|c|}{ Incubated at $96^{\circ} \mathrm{C}$ for $60 \mathrm{sec}$ followed by $5 \mathrm{~min}$ at room temperature } \\
\hline $\begin{array}{l}\text { 10X RT buffer ( } 0.5 \mathrm{M} \text { Tris-HCl, pH 8.4, } 0.08 \mathrm{M} \mathrm{MgCl}_{2}, 0.5 \mathrm{M} \mathrm{NaCl} \text {, } \\
0.1 \mathrm{M} \text { DTT) }\end{array}$ & $1 \mathrm{X}$ & \multirow{3}{*}{$\begin{array}{l}2.5 \mu \mathrm{L} R \mathrm{RT} \\
\text { reaction }\end{array}$} \\
\hline dNTPs & $160 \mu \mathrm{M}$ each & \\
\hline Reverse transcriptase (Sequenase Version 2.0 DNA Polymerase) & $0.5 \mathrm{U} / \mu \mathrm{L}$ & \\
\hline \multicolumn{2}{|l|}{ Incubated at $42^{\circ} \mathrm{C}$ for $45 \mathrm{~min}$} & $5 \mu \mathrm{L}$ total \\
\hline
\end{tabular}

Sequencing lanes were prepared by adding ddNTPs $(100 \mu \mathrm{M}$ each) to the RT reaction. Analysis of the primer extension products was done on $9.6 \%(\mathrm{w} / \mathrm{v})$ polyacrylamide/8.3 M urea sequencing gels with $1 \mathrm{X}$ TBE as running buffer (Hartmuth et al., 1999). Fluorescent products were visualized using a Typhoon ${ }^{\mathrm{TM}} \mathrm{Trio}^{+}$scanner (GE Healthcare Life Sciences) and the band intensities were evaluated using the MultiGauge and Canvas Draw software.

\subsubsection{End-point translation of dnaX mRNA variants}

Translation was carried out as described in 2.2.6 with the following changes. ICs $(0.2 \mu \mathrm{M})$ were reacted with TCs (about 15-20 $\mu \mathrm{M}$ EF-Tu) and EF-G $(2 \mu \mathrm{M})$ in $\mathrm{TAKM}_{7}$ buffer supplemented with $1 \mathrm{mM} \mathrm{GTP}$ at $37^{\circ} \mathrm{C}$ for $1 \mathrm{~min}$. Final concentrations of aa-tRNAs (per codon) were as follows: $0.4 \mu \mathrm{M}$ for Ala-tRNA ${ }^{\text {Ala }}$, Lys-tRNA ${ }^{\text {Lys }}$, Phe-tRNA ${ }^{\text {Phe }}$, Val-tRNA $^{\text {Val }}$ and Ile-tRNA ${ }^{\text {Ile, }} 1 \mu \mathrm{M}$ for Glu-tRNA ${ }^{\text {Glu }}, 1.2 \mu \mathrm{M}_{\text {for Gln-tRNA }}{ }^{\text {Gln }}, 2 \mu \mathrm{M}$ for mixture of isoacceptors Leu-tRNA ${ }^{\text {Leu(CUN)}}$. Formed peptides were separated by RP-HPLC with HPLC buffers A and B or HPLC buffers C and D (for experiments with Lys-Lys containing product). For all experiments, $f\left[{ }^{3} \mathrm{H}\right]$ Met was used to identify the respective peptide peaks; the following radioactive labels were used depending on the mRNA sequence: $\left[{ }^{14} \mathrm{C}\right]$ Val, $\left[{ }^{14} \mathrm{C}\right]$ Ile, $\left[{ }^{14} \mathrm{C}\right]$ Lys, $\left[{ }^{14} \mathrm{C}\right]$ Glu or $\left[{ }^{14} \mathrm{C}\right]$ Leu (Table 23 , mutated nt are in 
small letters in bold, aa sequences of the SS are underlined). The amount of each product was quantified as a ratio between ${ }^{3} \mathrm{H}$-counts in the respective peak and total ${ }^{3} \mathrm{H}$-counts of the sample. Frameshifting efficiencies were calculated as a ratio between the -1 -frame peptide and the sum of -1 - and 0 -frame products multiplied by $100 \%$,

Table 23. dnaX mRNAs with slippery site mutations

\begin{tabular}{|c|c|c|}
\hline Slippery site & 0-frame peptide & Labeled aa in -1-frame peptide \\
\hline A AAA AAG & \multirow{16}{*}{ fMet-Ala-Lys-Lys-Phe } & \multirow{8}{*}[{}^{14}\mathrm{C}]{$\mathrm{Val}$} \\
\hline c AAA AAG & & \\
\hline u AAA AAG & & \\
\hline g AAA AAG & & \\
\hline A AAg AAG & & \\
\hline c AAg AAG & & \\
\hline u AAg AAG & & \\
\hline g AAg AAG & & \\
\hline A AAA AAa & & \multirow{8}{*}[{}^{14}\mathrm{C}]{$\mathrm{Ile}$} \\
\hline c AAA AAa & & \\
\hline u AAA AAa & & \\
\hline g AAA AAa & & \\
\hline A AAg AAa & & \\
\hline c AAg AAa & & \\
\hline u AAg AAa & & \\
\hline g AAg AAa & & \\
\hline U UUU UUU & \multirow{15}{*}{ fMet Ala-Phe-Phe-Phe } & \multirow{15}{*}[{}^{14}\mathrm{C}]{ Leu } \\
\hline a UUU UUU & & \\
\hline c UUU UUU & & \\
\hline g UUU UUU & & \\
\hline U UUc UUU & & \\
\hline a UUc UUU & & \\
\hline c UUc UUU & & \\
\hline g UUc UUU & & \\
\hline U UUU UUc & & \\
\hline a UUU UUc & & \\
\hline c UUU UUc & & \\
\hline g UUU UUc & & \\
\hline U UUc UUc & & \\
\hline a UUc UUc & & \\
\hline c UUc UUc & & \\
\hline
\end{tabular}




\begin{tabular}{|c|c|c|}
\hline g UUc UUc & & \\
\hline A AAA UUU & \multirow{16}{*}{ fMet-Ala-Lys-Phe-Phe } & \multirow{16}{*}[{}^{14}\mathrm{C}]{ Leu } \\
\hline c AAA UUU & & \\
\hline u AAA UUU & & \\
\hline g AAA UUU & & \\
\hline A AAg UUU & & \\
\hline c AAg UUU & & \\
\hline u AAg UUU & & \\
\hline g AAg UUU & & \\
\hline A AAA UUc & & \\
\hline c AAA UUc & & \\
\hline u AAA UUc & & \\
\hline g AAA UUc & & \\
\hline A AAg UUc & & \\
\hline c AAg UUc & & \\
\hline u AAg UUc & & \\
\hline g AAg UUc & & \\
\hline U UUU AAG & \multirow{16}{*}{ fMet Ala-Phe-Lys-Phe } & \multirow{8}{*}[{}^{14}\mathrm{C}]{$\mathrm{Val}$} \\
\hline a UUU AAG & & \\
\hline c UUU AAG & & \\
\hline g UUU AAG & & \\
\hline U UUc AAG & & \\
\hline a UUc AAG & & \\
\hline c UUc AAG & & \\
\hline g UUc AAG & & \\
\hline U UUU AAa & & \multirow{8}{*}[{}^{14}\mathrm{C}]{$\mathrm{Ile}$} \\
\hline a UUU AAa & & \\
\hline c UUU AAa & & \\
\hline g UUU AAa & & \\
\hline U UUc AAa & & \\
\hline a UUc AAa & & \\
\hline c UUc AAa & & \\
\hline g UUc AAa & & \\
\hline
\end{tabular}

\subsubsection{Translation in in vitro reconstituted mammalian system}

40S and 60S ribosomal subunits from HeLa, translation initiation factors eIF1, eIF1A, eIF2, eIF3, eIF4A, eIF4B, eIF5, eIF5B, translation elongation factors eEF1A and eEF2 as well as Met-tRNA ${ }_{i}{ }^{\text {Met }}$ were prepared according to published protocols (Pestova and Hellen, 
2003; Pisarev et al., 2007) and provided by Dr. Akanksha Goyal, Dr. Dmitri Burakovsky and the laboratory facility.

\subsubsection{80S Initiation complex formation}

To form 48S IC, $40 \mathrm{~S}$ subunits $(0.3 \mu \mathrm{M})$ were mixed with initiation factors eIF1 $(0.6 \mu \mathrm{M})$, eIF1A $(0.6 \mu \mathrm{M})$, eIF2 $(0.45 \mu \mathrm{M})$, eIF3 $(0.45 \mu \mathrm{M})$, eIF4A $(0.8 \mu \mathrm{M})$ and eIF4B $(0.5 \mu \mathrm{M})$, Met-tRNA ${ }^{\text {Met }}(0.9 \mu \mathrm{M})$ and mRNA of interest $(0.75 \mu \mathrm{M})$ and incubated in eukaryotic translation buffer supplemented with RNAse inhibitor $(0.5 \mu \mathrm{M})$ for $15 \mathrm{~min}$ at $37^{\circ} \mathrm{C}$. The $\mathrm{KCl}$ concentration in the reaction was adjusted to $90-100 \mathrm{mM}$. Next, initiation factors eIF5A $(0.32 \mu \mathrm{M})$ and eIF5B $(0.35 \mu \mathrm{M})$ were pre-activated in the eukaryotic translation buffer supplemented with RNAse inhibitor $(0.5 \mu \mathrm{M})$ for $5 \mathrm{~min}$ at $37^{\circ} \mathrm{C}$. The incubation was followed by the addition of the $60 \mathrm{~S}$ subunit $(0.45 \mu \mathrm{M})$. To form $80 \mathrm{~S} \mathrm{IC}$ $(0.15 \mu \mathrm{M}), 48 \mathrm{~S}$ IC and $60 \mathrm{~S}$ IC were reacted for $8 \mathrm{~min}$ at $37^{\circ} \mathrm{C}$.

\subsubsection{Ternary complex formation and translation}

PEP $(1 \mathrm{mM})$ and PK $(0.1 \mathrm{mg} / \mathrm{ml})$ were incubated in the eukaryotic translation buffer supplemented with RNAse inhibitor $(0.5 \mu \mathrm{M})$ for $15 \mathrm{~min}$ at $37^{\circ} \mathrm{C}$. Next, elongation factors eEF1A $(10.8 \mu \mathrm{M})$, eEF2 $(5.4 \mu \mathrm{M})$ and yeast Pu3 (10.8 $\mu \mathrm{M}$, eEF1B $\alpha$ analogue $)$ were added to the pump and reacted for another $5 \mathrm{~min}$ at $37^{\circ} \mathrm{C}$. Finally, total human tRNA $(110-150 \mu \mathrm{M})$ aminoacylated with aa of interest was added to the mixture and incubated for 3 min at $37^{\circ} \mathrm{C}$, leading to the formation of the TC.

To allow for translation, 80 S ICs $(0.08 \mu \mathrm{M})$ were reacted with PEP $(0.5 \mathrm{mM})$, PK (0.05 mg/ml), eEF1A $(5.4 \mu \mathrm{M}), \operatorname{eEF} 2(2.7 \mu \mathrm{M})$, Pu3 $(5.4 \mu \mathrm{M})$ and total human tRNA $(55-75 \mu \mathrm{M})$ in the eukaryotic translation buffer for $4-8 \mathrm{~min}$ at $37^{\circ} \mathrm{C}$. Translation products were analyzed on RP-HPLC as described in 2.2.6. -1-frame peptides were identified based on $\left[{ }^{3} \mathrm{H}\right] \mathrm{Arg}$. In the presence of Leu total translation efficiency was quantified using $\left[{ }^{14} \mathrm{C}\right]$ Leu and the frameshifting efficiency was calculated as a ratio between Arg-containing peptides and total translation products multiplied by $100 \%$. In the absence of Leu, total translation efficiency was calculated using -1-frame control, which shows the maximum level of frameshifting peptide produced under the given conditions. Here the frameshifting efficiency was calculated as the ratio between Arg-containing wt peptides and-1-frame control peptides multiplied by $100 \%$. 


\subsubsection{1 tRNA-specific qRT-PCR}

\subsubsection{Cell lines}

Sup-T1 is derived from Non-Hodgkin's T-cell lymphoma isolated from a pleural effusion of an eight-year-old male and subcloned on soft agar; Jurkat is derived from human T-cell lymphoblast; PM1 is a derivative of HUT78, a human cutaneous T-cell lymphoma cell line derived from peripheral blood of a patient with Sezary syndrome; 174xCEM is a fusion product of human B-cell line 721.174 and a human T-cell line CEM; 293T is an epithelial cell line derived from human embryonic kidney cells and expressing a large $\mathrm{T}$ antigen. Information about cell lines is taken from https://aidsreagent.org/ and http://www.lgcstandards-atcc.org/.

The following reagents were obtained through the NIH AIDS Reagent Program, Division of AIDS, NIAID, NIH: 174xCEM cells from Dr. Peter Cresswell, Sup-T1 cells from Dr. Dharam Ablashi, and Jurkat Clone E6-1 cells from Dr. Arthur Weiss. 293T (DSMZ-German Collection of Microorganisms and Cell Cultures, ACC 635) cells were maintained in Dulbecco's modified Eagle medium (DMEM, Pan Biotech) supplemented with $10 \%$ fetal calf serum (Biochrom, FCS) and $1 \%$ of $100 \mathrm{X}$ concentrated penicillin/streptomycin (pen/strep) mix (Pan Biotech). For subculturing, cells were detached by resuspension in phosphate-buffered saline (PBS [293T]) or incubation with trypsin/EDTA solution (Pan Biotech). The human T-cell lines 174xCEM (NIH AIDS Reagent Program, NIH272, (Salter et al., 1985)), PM1 (Lusso et al., 1995), Sup-T1 (NIH AIDS Reagent Program, NIH100, (Ablashi et al., 1995)) and Jurkat (NIH AIDS Reagent Program, NIH177, (Weiss et al., 1984)) were maintained in Roswell Park Memorial Institute 1640 medium (RPMI, Pan Biotech) supplemented with 10\% FCS and 1\% of 100X concentrated pen/strep mix. For subculturing, culture medium containing the suspension cells was centrifuged (600X g, $10 \mathrm{~min}$, room temperature). Then, the supernatant was discarded and pelleted cells were resuspended in $10 \mathrm{ml}$ RPMI medium. Further, $1 \mathrm{ml}$ of this suspension was added to a new culture flask and filled up with $19 \mathrm{ml}$ of RPMI medium.

\subsubsection{Quantification of tRNA levels}

Method description is provided by Dr. Markus Hoffmann. Cellular tRNA levels for tRNA $^{\text {Leu(UUA) }}$, tRNA $^{\mathrm{Leu}(\mathrm{CUG})}, \mathrm{tRNA}^{\mathrm{Val}(\mathrm{GUA})}$ and tRNA ${ }^{\mathrm{Val}(\mathrm{GUG})}$ were quantified using a strategy published by (Wan Makhtar et al., 2017). Total cellular RNA was extracted using the RNeasy Mini Kit according to the manufacturer's protocol. After elution the RNA content 
was determined spectrophotometrically. To eliminate potentially co-isolated DNA from the samples, $0.5 \mu \mathrm{g}$ RNA was incubated with DNase I (NEB) in a final volume of $10 \mu \mathrm{l}$ for 30 $\min$ at $37^{\circ} \mathrm{C}$ and finally heated to $65^{\circ} \mathrm{C}$ for $5 \mathrm{~min}$ to inactivate the enzyme. The primer for the RT entailed a tRNA-specific sequence and a stem-loop sequence (Wan Makhtar et al., 2017). The tRNA-specific primer was the same for tRNA ${ }^{\operatorname{Leu}(U U A)}$ and $\operatorname{tRNA}^{\mathrm{Leu}(\mathrm{CUG})}$ (complementary to positions 47-55) and different for tRNA ${ }^{\mathrm{Val}(\mathrm{GUA})}$ and $\mathrm{tRNA}^{\mathrm{Val}(\mathrm{GUG})}$ (complementary to positions 62-70) (Table 5). cDNA synthesis was performed as described in the manufacturer's instructions (for gene-specific primers) using the SuperScript III FirstStrand Synthesis System (ThermoFisher Scientific) and $5 \mu 1$ of DNase I-digested RNA (0.25 $\mu \mathrm{g})$. Input RNA was removed by incubation with RNaseH. To determine the levels of the tRNAs, $\mathrm{tRNA}^{\mathrm{Leu}(\mathrm{UUA})}, \mathrm{tRNA}^{\mathrm{Leu}(\mathrm{CUG})}, \mathrm{tRNA}^{\mathrm{Val}(\mathrm{GUA})}$ and tRNA ${ }^{\mathrm{Val}(\mathrm{GUG})}$ as well as $18 \mathrm{~S}$ rRNA (housekeeping gene control), quantitative PCR (qPCR) was performed employing the QuantiTect SYBR Green Kit (Qiagen) according to the manufacturer's protocol on a Rotorgene Q device (Qiagen). The primers used for qPCR were taken from (Wan Makhtar et al., 2017); the forward primer for the qPCR is highly specific to each tRNA and the reverse primer is universal (Table 5). For each run, technical triplicates were analyzed for each sample and reactions containing water instead of template cDNA were used as negative control. Cycle conditions were chosen as follows: one cycle at $95^{\circ} \mathrm{C}$ for $15 \mathrm{~min}$, followed by 45 cycles consisting of $15 \mathrm{sec}$ at $94^{\circ} \mathrm{C}, 30 \mathrm{~s}$ at $60^{\circ} \mathrm{C}$ and $30 \mathrm{~s}$ at $72^{\circ} \mathrm{C}$. Finally, a linear temperature increase from 60 to $90^{\circ} \mathrm{C}$ with a ramp of $1^{\circ} \mathrm{C}$ per step and each step lasting $5 \mathrm{~s}$ was performed to obtain a melting curve for each reaction. In order to compare

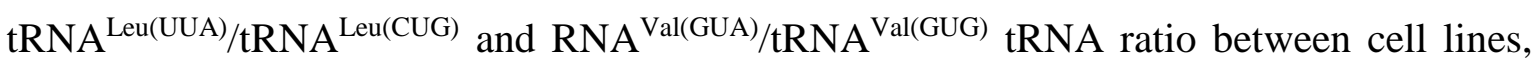
cycle threshold (ct) values for each tRNA were normalized against the respective ct values for 18S rRNA.

\subsubsection{Statistical analysis}

To assure statistical significance of the presented data, all experiments were performed in multiple biological replicates (3-10). qRT-PCR experiments were done in 3 biological replicates with 3 technical repeats each. Error bars represent s.e.m values unless stated otherwise. Where necessary, two-tailed two-sample equal variance t-test was performed. 


\section{Results}

\section{1 -1PRF mechanism and its modulation at the gag-pol slippery site of HIV-1}

\subsubsection{In vitro reconstituted $E$. coli translation and peptide analysis system}

To study -1PRF in HIV-1, we established a fully reconstituted E. coli translation system consisting of purified $70 \mathrm{~S}$ ribosomes, translation factors, aa-tRNAs and HIV-1 gag-pol model mRNAs. The wt HIV mRNA contains a native frameshifting site with the $\mathrm{U}_{1} \mathrm{UUU}_{4}$ $\mathrm{UUA}_{7} \mathrm{SS} 1$ and the downstream SL1; in the $\mathrm{U}_{4} \mathrm{C}$ mRNA the SS1 is mutated to $\mathrm{U}_{1} \mathrm{UUC}_{4}$ UUA7. To allow for efficient translation initiation in bacterial system, we introduced a SD sequence ( $6 \mathrm{nt}$ prior to the start codon AUG) and an initiator codon AUG $8 \mathrm{nt}$ before the SS1. The presence of a SD does not interfere with the frameshifting efficiency due to the large distance to the SS1 (17 nt). Initiation efficiency measured with HIV-1 model mRNAs was $85-100 \%$, which is a prerequisite for efficient translation.

Translation was performed by reacting 70S ICs programmed with gag-pol mRNAs and TCs with desired purified aa-tRNAs in the presence of EF-G-GTP. To achieve maximum translation efficiency at each codon, we determined the optimal concentrations for each aa-tRNA using either wt HIV mRNA or short model mRNAs without frameshifting elements (Fig. 14A-E). The saturating amounts of TCs over 70S were used in all following experiments unless stated otherwise, e. g., 5-10-fold excess of TC(Gln-Ala-Asn), 10-fold excess of TC(Phe), 1-fold excess of TC(Leu-UUA), 5-7-fold excess of TC(Gly) and 10-fold excess of TC(Arg) (Fig. 14A-E). 
A

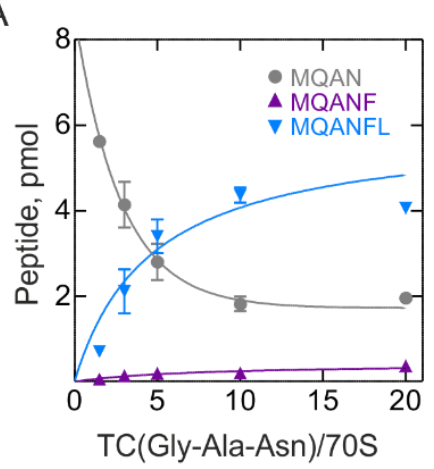

D

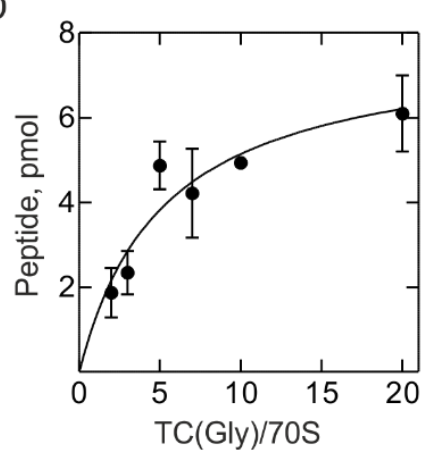

$\mathrm{F}$

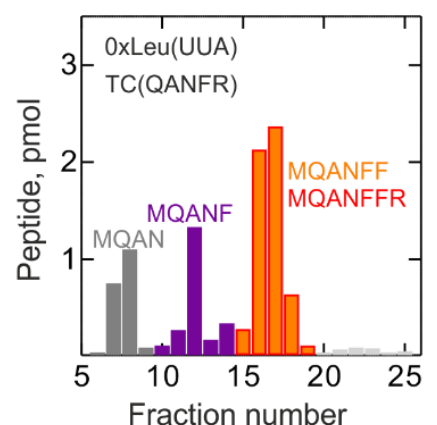

B

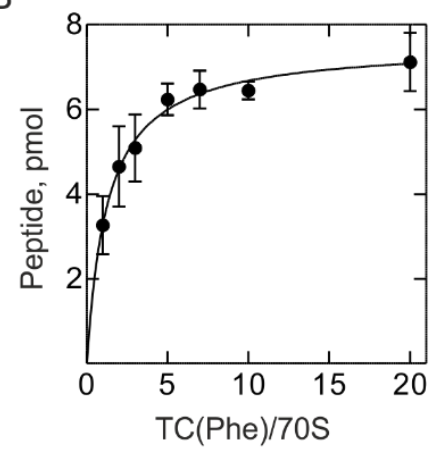

$E$

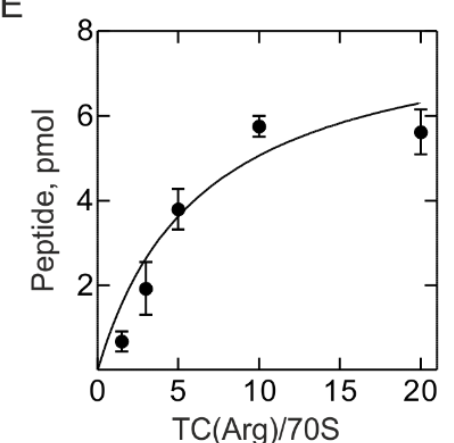

G



C

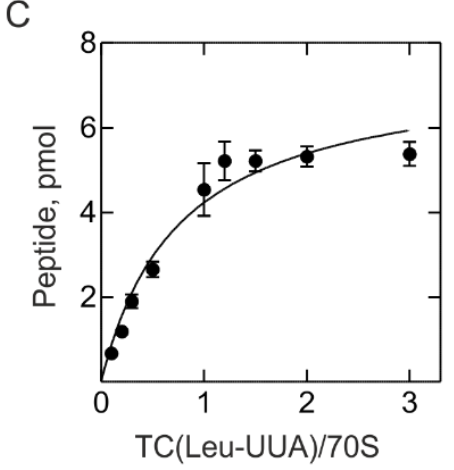

$\mathrm{H}$



।

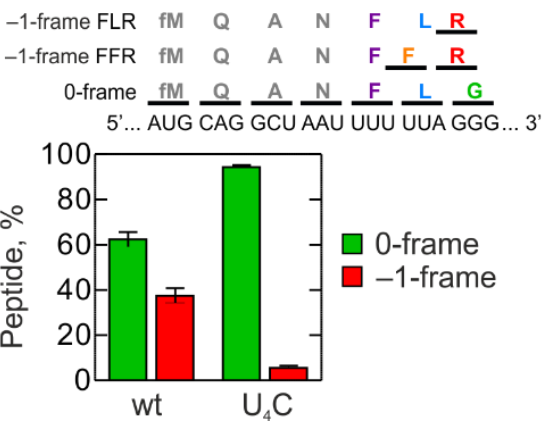

Figure 14. Optimization of an in vitro translation and peptide analysis system to study -1PRF in HIV-1.

(A) Titration of $\mathrm{TC}(\mathrm{Gln}-\mathrm{Ala}-\mathrm{Asn})$ on wt mRNA to determine saturating amounts required for translation. Monitored peptides are MQAN (grey circles), MQANF (purple triangles), and MQANFL (blue downward triangles).

(B) Titration of TC(Phe) on model mRNA encoding fMet-Phe(UUC)-Stop. 
(C) Titration of TC(Leu-UUA) on model mRNA encoding fMet-Leu(UUA)-Val-Stop.

(D) Titration of TC(Gly) on model mRNA encoding fMet-Gly(GGG)-Phe-Stop.

(E) Titration of TC(Arg) on model mRNA encoding fMet-Arg(AGG)-Val-Stop.

(F) Separation of the wt mRNA translation products in the absence of Leu-tRNA ${ }^{\text {Leu(UUA) }}$ (TC(LeuUUA)). tRNAs used for translation are Gln, Ala, Asn, Phe, and Arg (TC(QANFR)). Peptides are indicated: MQAN (grey), MQANF (purple), MQANFF (orange), and MQANFFR (red outline).

(G) Separation of the reaction products in the presence of limiting tRNA ${ }^{\mathrm{Leu}(\mathrm{UUA})}$ (molar ratio 0.3 TC(Leu) per ribosome). tRNAs used for translation were Gln, Ala, Asn, Phe, Leu, Gly and Arg (TC(QANFLGR)). Resulting peptides are MQAN (grey), MQANF (purple), MQANFL (blue outline), MQANFLG (green), and MQANFFR/MQANFLR (red outline).

(H) Same as $(\mathrm{G})$, but with higher excess of tRNA ${ }^{\mathrm{Leu}(\mathrm{UUA})}$ (equimolar to ribosome).

(I) Top panel: Translated sequence of HIV-1 model mRNA. Aa incorporated into 0- and -1-frames are indicated. Bottom panel:-1PRF efficiency with the wt mRNA and $\mathrm{U}_{4} \mathrm{C}$ derivative with disrupted SS1 measured at limiting amounts of Leu-tRNA ${ }^{\text {Leu(UUA) }}$ (molar ratio $0.3 \mathrm{TC}(\mathrm{Leu})$ to $70 \mathrm{~S}$ ribosome).

Translation of HIV-1 mRNAs results in the stepwise incorporation of consecutive aa up to fMet-Gln-Ala-Asn-Phe-Leu-Gly (MQANFLG) upon 0-frame translation and up to fMetGln-Ala-Asn-Phe-Leu-Arg (MQANFLR) or fMet-Gln-Ala-Asn-Phe-Phe-Arg (MQANFFR) in the -1 -frame (Fig. 14F-I). Translation products were analyzed by RP-HPLC and individual peptides were assigned based on different elution positions and confirmed using radioactively labeled aa (Fig. 14F-H; Table 24).

Table 24. Peptide analysis by RP-HPLC

\begin{tabular}{|l|l|l|}
\hline Peptide & $\begin{array}{l}\text { Elution time, } \\
\text { min }\end{array}$ & Radioactive label \\
\hline MQAN & $6-7$ & {$\left[{ }^{14} \mathrm{C}\right] \mathrm{Gln},\left[{ }^{14} \mathrm{C}\right]$ Ala and $\left[{ }^{3} \mathrm{H}\right] \mathrm{Asn}$} \\
\hline MQANF & $11-12$ & {$\left[{ }^{14} \mathrm{C}\right]$ Phe/f $\left[{ }^{3} \mathrm{H}\right]$ Met ratio to distinguish between } \\
peptides
\end{tabular}

Upon establishing optimal translation and peptide analysis conditions, we determined frameshifting efficiency on $\mathrm{HIV}$ wt and $\mathrm{U}_{4} \mathrm{C}$ mRNAs at limiting amounts of Leu-tRNA ${ }^{\text {Leu(UUA) }}$ (molar ratio 0.3 tRNA to 70S) (Fig. 14I). The overall frameshifting efficiency was determined as a ratio of -1-frame Arg incorporation relative to the sum of -1- and 0-frame peptides. Here the 0-frame was defined as the sum of MQANF and MQANFLG peptides while -1-frame corresponded to MQANFFR/FLR peptides. With the 
wt mRNA containing a native slippery sequence, a large fraction of peptides contains Arg, indicating efficient $-1 \mathrm{PRF}$ of about $40 \%$ (Fig. 14I). As expected, the SS1 mutation in $\mathrm{U}_{4} \mathrm{C}$ mRNA prevents efficient slippage and thereby decreases the frameshifting efficiency to less than $10 \%$ (Jacks et al., 1988b).

\subsubsection{Two regimes for-1PRF on the gag-pol slippery site}

Our next goal was to identify the mechanism of -1PRF on SS1. As described above, $-1 \mathrm{PRF}$ can occur at the decoding step of the translation elongation cycle, when only a peptidyl-tRNA is bound in the P site of the ribosome while the A site is vacant (Caliskan et al., 2017; Yelverton et al., 1994); or during translocation, when two tRNAs together with the mRNA move through the ribosome (Caliskan et al., 2014; Chen et al., 2014; Kim et al., 2014; Yan et al., 2015). If slippage occurred during decoding, the -1 frameshifting efficiency must depend on the competition between the 0 -frame and-1-frame aa-tRNAs, Leu-tRNA and Phe-tRNA, for binding at the UUUA sequence in SS1. In fact, increasing the LeutRNA $^{\text {Leu(UUA) }}$ concentration lowers the -1 PRF efficiency dramatically from about $50 \%$ in the absence to about $12 \%$ observed in the presence of saturating amounts of LeutRNA $^{\text {Leu(UUA) }}$ (Fig. 15A). In contrast, titration with a mixture of Leu-tRNA isoacceptors that collectively read the CUN family of Leu codons but not the UUA codon has no effect. The

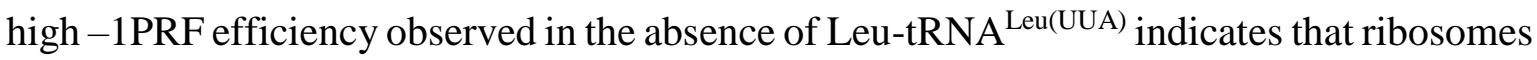
can slip into the -1-frame prior to, and independent of Leu incorporation. In human cells the Leu codon UUA is rare ( $8 \%$ of Leu codons), but it is abundant in the late HIV genes

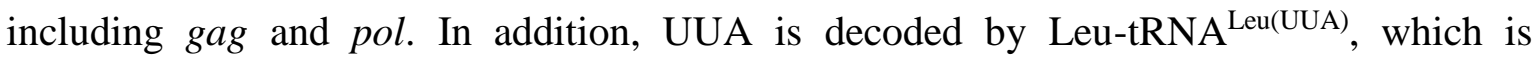
underrepresented in eukaryotic cells as compared to other tRNA ${ }^{\text {Leu }}$ isoacceptors (Chapter 3.1.5 and (Dittmar et al., 2006; Sharp et al., 1988; van Weringh et al., 2011). 
A

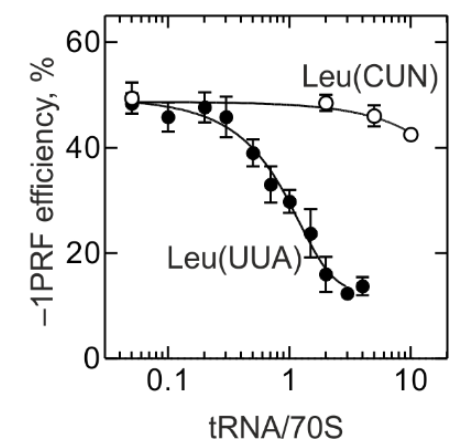

B



C

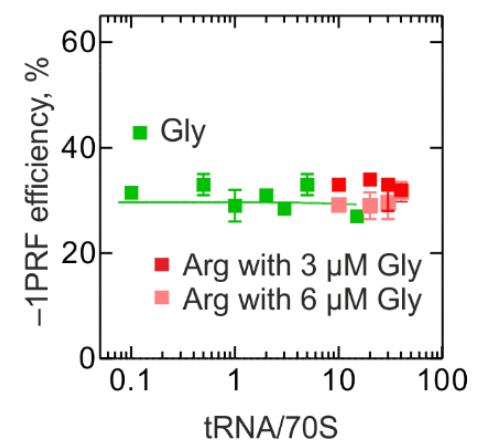

Figure 15. Characterization of frameshifting regimes on the gag-pol SS1.

(A) Concentration dependence of -1PRF efficiency on Leu-tRNA ${ }^{\text {Leu(UUA) }}$ (Leu-UUA, closed circles) or a mixture of tRNA ${ }^{\text {Leu }}$ isoacceptors reading CUN codons (Leu-CUN, open circles) monitored at the end of translation ( $2 \mathrm{~min})$.

(B) Change in the frameshifting regime with the Leu-tRNA ${ }^{\mathrm{Leu}(\mathrm{UUA})}$ concentration. The ratio of FFR route (open circles) vs. FLR (closed circles) route was calculated from peptides with different radioactive labels (described in the text).

(C) -1PRF efficiency in the presence of varying concentrations of Gly-tRNA ${ }^{\text {Gly }}$ in the presence of excess Arg-tRNA ${ }^{\text {Arg }}(2 \mu \mathrm{M})$ (green squares) or with varying concentrations of Arg-tRNA ${ }^{\text {Arg }}$ in the presence of $3 \mu \mathrm{M}$ or $6 \mu \mathrm{M}$ Gly-tRNA ${ }^{\text {Gly }}$ (red and light red squares, respectively).

Next, we thought to determine how the -1PRF pathway changes with the LeutRNA $^{\text {Leu(UUA) }}$ concentration (Fig. 15B). To do so, we estimated the ratio of Leu, Phe and Arg incorporation into the -1 -frame product using different radioactive labels as follows. The sum of FFR and FLR frameshifting products was calculated using $\left[{ }^{14} \mathrm{C}\right] \mathrm{Arg}$. To determine the amount of FLR, the wt mRNA was translated to the 0-frame peptide fMet-Gln-Ala-AsnPhe-Leu-Gly-Lys-Ile (MQANFLGKI). The presence of Ile allows efficient separation between 0-frame MQANFLGKI and -1-frame MQANFLR peptides. The FFR peptide was then determined by subtracting the FLR from the total Arg-containing product. In the absence of Leu-tRNA ${ }^{\text {Leu(UUA) }}$ only the FFR product is formed (Fig. 15B). Upon addition of Leu-tRNA $^{\text {Leu }}$, the amount of the FFR product decreases, whereas the FLR product becomes prevalent. Thus, frameshifting at the gag-pol SS can switch between two regimes and their prevalence depends on the concentration of the critical tRNA. As described, the ratio between the FLR and the FFR route measured in vivo is about $70 \%$ to $30 \%$. Interestingly, in our experiments we observed this ratio at equimolar concentration of Leu-tRNA ${ }^{\text {Leu(UUA) }}$ ( 1 tRNA to 70 S ribosome) suggesting that Leu-tRNA ${ }^{\text {Leu(UUA) }}$ limitation could be of crucial importance for frameshifting in HIV. 
After Leu incorporation, -1 frameshifting could follow different routes: it could take place either during tRNA ${ }^{\text {Leu }}$ translocation or upon decoding of the following Gly codon. Again, if frameshifting took place during decoding, the 0-frame Gly-tRNA ${ }^{\text {Gly }}$ and -1-frame Arg-tRNA ${ }^{\text {Arg }}$ should compete for binding to the ribosome. This is, however, not observed, as the -1PRF efficiency is independent of Gly-tRNA ${ }^{\text {Gly }}$ and Arg-tRNA ${ }^{\mathrm{Arg}}$ concentrations (Fig. 15C). This finding suggests that slippage and commitment to the new reading frame occur after Leu incorporation, but prior to decoding of the next codon by Gly- or Arg-tRNA. This is similar to the well-studied cases of $-1 \mathrm{PRF}$ on IBV $1 \mathrm{a} / 1 \mathrm{~b}$ and dnaX mRNAs, where slippage occurs at a late stage of translocation of the slippery-site tRNAs, and suggests a similar two-tRNA frameshifting mechanism (Caliskan et al., 2014; Caliskan et al., 2017; Chen et al., 2013; Chen et al., 2014; Kim et al., 2014; Yan et al., 2015).

\subsection{3 -2 and +1 slippages on SS1}

Because formation of the-1-frame FFR product depends on the slippage at the "hungry" UUA codon, we further tested whether this also allows -2 and +1 PRF. We note that normally such slippage events would lead to premature termination due to stop codons appearing in the -2 or +1 frames downstream of the frameshifting site and that such peptides are difficult to detect in vivo, but alternative slippage events could change the ratio between the Gag and Gag-Pol polyproteins. To distinguish between the products of the $0-,-1-,-2$ - and +1 -frames, we designed a $-2 /+1$ mRNA, in which the GGG (Gly) codon following the SS1 was changed into a UGG (Trp) codon (Fig. 16). This mutation does not affect the -1PRF efficiency in vivo in human cells (Mathew et al., 2015). In addition to the aa-tRNAs needed for translation of the MQANFL sequence, we added purified Trp-tRNA ${ }^{\operatorname{Trp}}(\mathrm{W})$, elongator Met-tRNA $^{\text {Met }}(\mathrm{M})$ and Tyr-tRNA ${ }^{\text {Tyr }}(\mathrm{Y})$. The expected 0-frame peptide is now MQANFLW and the -1 -frame peptides are MQANFFM and MQANFLM. Shifting into the +1 -frame should yield MQANFY and into the -2-frame MQANFFY and MQANFLY. Translation products were identified based on their elution times on RP-HPLC and differential radioactive labels (Fig. 16B). The presence of a highly hydrophobic Trp residue allowed efficient separation of the 0-frame MQANFLW peptide eluting at $25 \mathrm{~min}$ from -1 - and -2-products eluting at about $18 \mathrm{~min}$. To distinguish co-eluting peaks, radioactive-labeled Phe, Leu, Met and Tyr aa were used. 
A
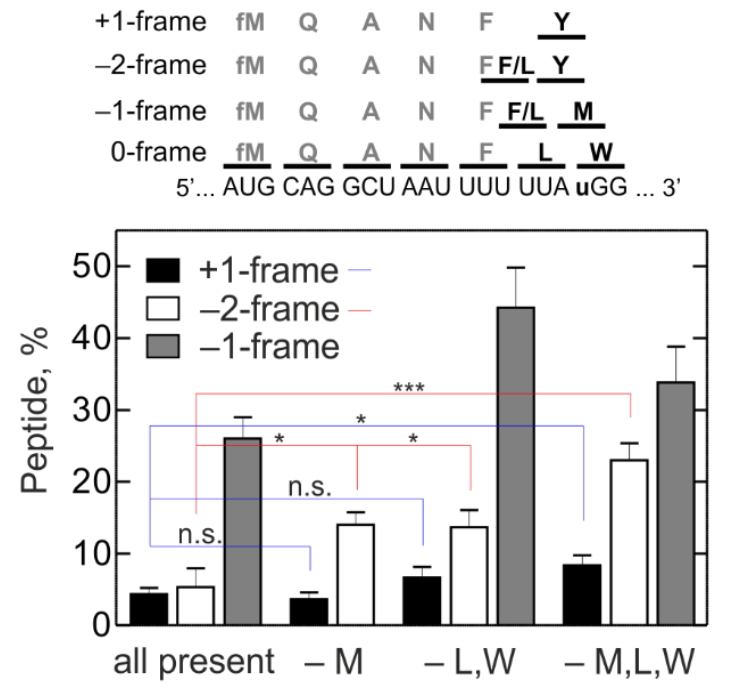

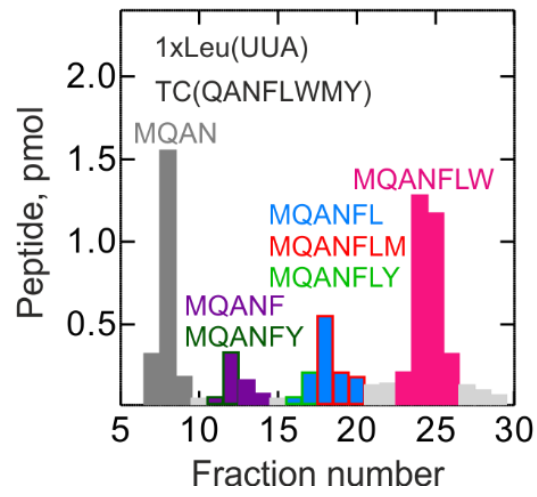

Figure 16. tRNA limitation results in $-1,+1$ and $-2 \mathrm{PRF}$.

(A) Top panel shows the model mRNA and peptides synthesized in all frames. tRNAs for QANF were added to all translation reactions; in addition, Met (M), Leu (L), Trp (W) and Tyr (Y) were added in the "all present" sample; $-\mathrm{M},-\mathrm{L}, \mathrm{W}$ and $-\mathrm{M}, \mathrm{L}, \mathrm{W}$ indicate the aa-tRNAs that were omitted from the respective translation reaction. Positions of peptide peaks in the HPLC analysis were determined using $\left[{ }^{14} \mathrm{C}\right]$-labeled Tyr, Met, Leu or Trp. Two-tailed two-sample equal variance t-test was performed between marked samples; blue lines for +1 peptides and red lines for -2 peptides. n.s., not significant, $*$ indicates $\mathrm{p} \leq 0.05, * * *$ is $\mathrm{p} \leq 0.001$.

(B) HPLC separation of products formed upon translation of $-2 /+1$ mRNA. Translation was performed at 1-fold tRNA ${ }^{\text {Leu(UUA) }}$ over the 70S. Resulting peptides are MQAN (grey), MQANF (purple), MQANFY (dark green outline), MQANFL (blue), MQANFLM (red outline), MQANFLY (light green outline) and MQANFLW (magenta).

When all required aa-tRNAs are present, the -1-frame peptides account for about $25 \%$ of product, consistent with the -1PRF efficiency on the native gag-pol sequence in the presence of equimolar amounts of Leu-tRNA ${ }^{\text {Leu(UUA) }}$ and $70 \mathrm{~S}$ (Fig. $16 \& 15 \mathrm{~A}$ ), whereas the amounts of the +1 and -2 peptides are small. When Met-tRNA ${ }^{\text {Met }}$ is omitted, -2 PRF increases more than two-fold, whereas +1PRF is not changed. $-2 \mathrm{PRF}$ is enhanced because -1 PRF exposes a "hungry" Met codon in the A site, which favors the slippage. In the absence of Leu- and Trp-tRNA, the -1PRF efficiency increases to $45 \%$, as expected; $-2 \mathrm{PRF}$ is unchanged; and again a small amount of the +1 -frame product is formed (Fig. 16). Without addition of Leu-, Trp-, and Met-tRNAs, the products of all three alternative frames are found. These data suggest that -2 and +1 PRF can occur when one or more of the aa-tRNAs are lacking; however, when all aa-tRNAs are available the-1PRF pathway is prevalent. 


\subsubsection{Kinetics of FFR and FLR -1 frameshifting pathway}

To understand the two different -1 frameshifting regimes, we monitored translation and -1PRF efficiency on wt mRNA using the codon-walk approach (Caliskan et al., 2014) in the absence and presence of different amounts of Leu-tRNA ${ }^{\text {Leu(UUA) }}$. The codon-walk method allows us to determine the exact place and timing of frameshifting by comparing rates of incorporation of individual aa into the growing peptide under the assumption that recoding affects the rate of translation. Time courses of aa incorporations are evaluated using numerical integration and the rates are derived according to the developed kinetic models. To verify and substantiate our kinetic analysis provided below, we estimated the rate constants of Arg and Gly incorporation in independent experiments using model mRNAs without or with mutated frameshifting elements (Fig. 17A,B). The rate of Arg incorporation was checked in the context of MFR and MLR peptides to account for both frameshifting regimes. The rate of Gly incorporation was monitored at $\mathrm{U}_{4} \mathrm{C}$ HIV mRNA at 1-fold excess of TC(Leu-UUA) because the translation here mostly results in the 0 -frame peptide MQANFLG.

A

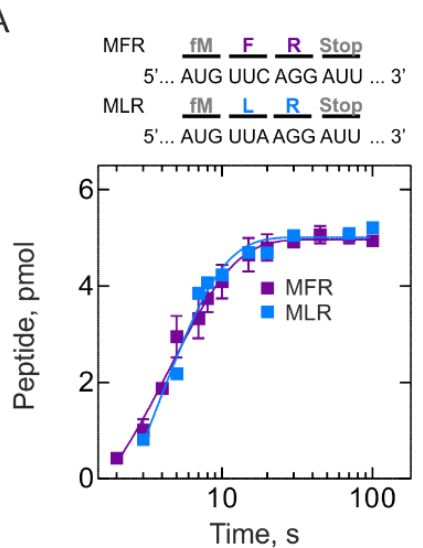

B

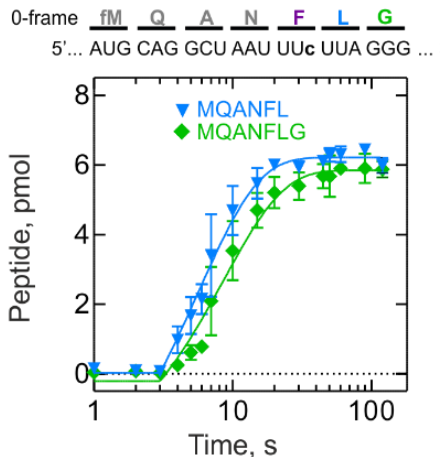

C

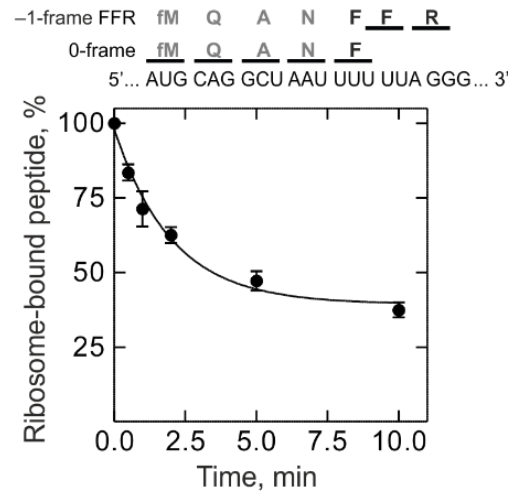

Figure 17. Supporting kinetic experiments.

(A) Time courses of MFR (purple squares) and MLR (blue squares) formation on model fM-FR(AGG)-Stop and fM-L-R(AGG)-Stop mRNAs, respectively. Phe-tRNA ${ }^{\text {Phe }}$, Leu-tRNA ${ }^{\text {Leu(UUA) }}$ and Arg-tRNA ${ }^{\text {Arg }}$ were used at $1.6 \mu \mathrm{M}$ (10-fold over 70S), $0.16 \mu \mathrm{M}$ (1-fold over 70S) and $1.6 \mu \mathrm{M}$ (10-fold over 70S) concentrations, respectively. Single-exponential fits are shown as continues lines. The rates of MFR and MLR formation are $0.22 \pm 0.01 \mathrm{~s}^{-1}$ and $0.27 \pm 0.03 \mathrm{~s}^{-1}$, respectively. The upper panel shows the sequence of the model mRNA and the respective aa.

(B) Time courses of MQANFL (blue downward triangles) and MQANFLG (green diamonds) formation on $\mathrm{U}_{4} \mathrm{C}$ mRNA at 1-fold excess of TC(Leu-UUA). Gly-tRNA ${ }^{\mathrm{Gly}}$ was used at $1.5 \mu \mathrm{M}$ (7.5-fold over 70S). The upper panel shows aa incorporated into 0 -frame peptide. 
(C) Time course of MQANF-tRNA ${ }^{\text {Phe }}$ drop-off from ribosomes upon translation of frameshifting wt mRNA. The upper panel shows the aa incorporated into -1-frame FFR and 0-frame peptide.

For the -1PRF model in the absence of Leu-tRNA ${ }^{\text {Leu(UUA) }}$, we introduced the steps that result in the formation of MQANF and the -1-frame products MQANFF and MQANFFR (Fig. 18A,B). In addition, we introduced two reaction branches that account for the incomplete conversion of the 70S IC into products as follows. Because a fraction of ICs (about 20\%) does not enter translation, we introduced a step that accounts for this unproductive population ( $\mathrm{M} \rightarrow \mathrm{M}_{\mathrm{n}}$, non-reactive). We also noticed that MQANF-tRNA ${ }^{\text {Phe }}$ in the absence of the A-site ligand tends to slowly dissociate from the ribosome over time (Fig. 17C); to account for this loss of peptidyl-tRNA, we introduced the respective drop-off reaction. Global fitting of the time courses using numerical integration yielded a unique solution for all rate constants (Fig. 18B; Table 25). The step leading to the incorporation of the second Phe is slow, $\sim 0.01 \mathrm{~s}^{-1}$, compared to all translation steps, which are at least 10 times faster. MQANFF peptides do not accumulate and are converted to the -1 -frame peptide, MQANFFR. Thus, the incorporation of the second Phe residue is the rate-limiting step of frameshifting, which commits the ribosome to the -1 -frame translation.

In the presence of Leu-tRNA ${ }^{\mathrm{Leu}(\mathrm{UUA})}$, the ribosome synthesizes the 0-frame MQANF peptide and then either continues translation with Leu incorporation in the 0 -frame or shifts into the -1 -frame before Leu-tRNA ${ }^{\text {Leu(UUA) }}$ can bind. If Leu is incorporated, the 0-frame MQANFL product can partition between the 0-frame MQANFLG and the -1 -frame MQANFLR. Global fitting of the time courses gives well-defined rate constants for most of the steps (Fig. 18C-E). The rate-limiting step for the -1 -frame FFR pathway has a rate constant of $\sim 0.03 \mathrm{~s}^{-1}$, similar to that for the isolated FFR pathway. The efficiency of the FFR pathway depends on the ratio of the rates of -1-slippage and Leu-tRNA ${ }^{\text {Leu(UUA) }}$ binding. While the rate of slippage is constant, the rate of Leu-tRNA ${ }^{\text {Leu(UUA) }}$ binding increases with concentration. This explains why the addition of excess Leu-tRNA ${ }^{\text {Leu(UUA) }}$ inhibits the FFR route. At high concentrations of Leu-tRNA ${ }^{\text {Leu(UUA) }}$, the probability to bind Leu-tRNA ${ }^{\text {Leu(UUA) }}$ to the A site is higher than to slip into the -1-frame. At this condition, the FFR pathway is suppressed and only the FLR pathway remains operational. After Leu incorporation, the $-1 P R F$ efficiency of the FLR route is defined at the translocation step, because the partitioning between 0 - and -1-frames takes place before decoding by Gly- and Arg-tRNAs (Fig. 18E). The ratio of the rate constants of Gly and Arg incorporation $\left(0.53 \mathrm{~s}^{-1}\right.$ and $0.04 \mathrm{~s}^{-1}$, respectively; Table 25) gives the $-1 \mathrm{PRF}$ efficiency after Leu incorporation. 
A

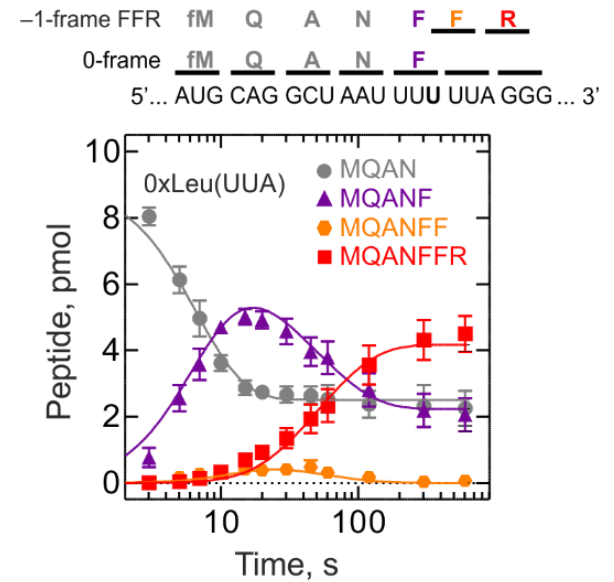

C

-1-frame FLR fM Q A N $\quad \mathrm{F} \quad \mathrm{L} \underline{\mathbf{R}}$

-1-frame FFR fM Q A N F

0-frame $\frac{f M}{\text {. }} \frac{\mathrm{Q}}{\mathrm{AUG}} \frac{\mathrm{A}}{\mathrm{CAG}} \frac{\mathrm{N}}{\mathrm{GCU}} \frac{\mathrm{F}}{\mathrm{AAU}} \frac{\mathrm{L}}{\mathrm{UUU}} \frac{\mathrm{G}}{\mathrm{UUA}}$



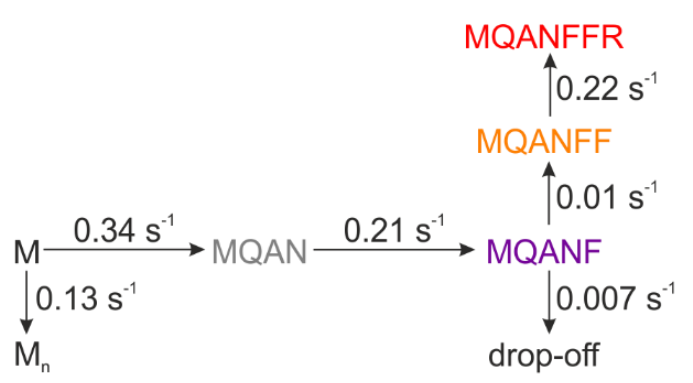

D



E

MQANFFR $\widehat{\uparrow} 0.22 \mathrm{~s}^{-1}$

MQANFF

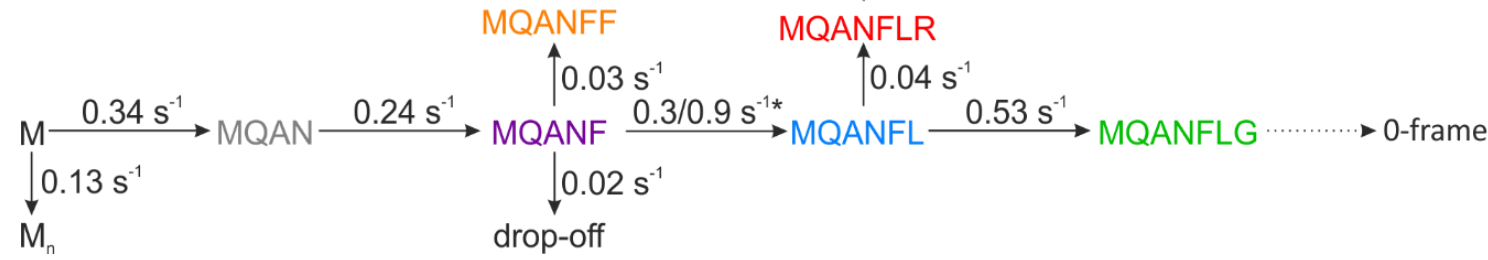

Figure 18. Kinetic mechanism of $-1 \mathrm{PRF}$.

(A) Time courses of translation in the absence of tRNA ${ }^{\mathrm{Leu}(\mathrm{UUA})}$. Peptides are MQAN (grey circles), MQANF (purple tringles), MQANFF (orange hexagons), and MQANFFR (red squares). Global fits are shown as continuous lines. The top panel shows aa in 0 -frame and FFR -1-frame and respective codons on the mRNA.

(B) Kinetic model of the FFR pathway in the absence of tRNA ${ }^{\mathrm{Leu}(\mathrm{UUA})}$. Rates of all steps are calculated by global fitting.

(C \& D) Time courses of translation in the presence of limiting concentrations of tRNA ${ }^{\text {Leu(UUA) }}$ (C, 0.3-fold per ribosome) and near-saturating concentrations of tRNA ${ }^{\mathrm{Leu}(\mathrm{UUA})}$ (D, 1-fold per ribosome). Peptides are MQAN (grey circles), MQANF (purple triangles), MQANFL (blue downward triangles), MQANFLG (green diamonds), and MQANFFR/MQANFLR (red squares). 
Global fits are shown as continuous lines. The top panel shows aa in 0 -frame and -1 -frame and respective codons on the mRNA.

(E) Kinetic model of the FFR/FFL pathways. Rates of all steps are calculated by global fitting. 0 - and -1-frames are indicated by dotted arrows. *Incorporation of Leu-tRNA ${ }^{\text {Leu(UUA) }}$ is a bimolecular reaction and its rate depends on the concentration of tRNA ${ }^{\mathrm{Leu}(\mathrm{UUA})}$. The two rates correspond to 0.3- and 1.0-fold excess of tRNA ${ }^{\text {Leu(UUA) }}$ over ribosomes, respectively.

Table 25. Rate constants of translation and frameshifting

\begin{tabular}{|c|c|c|}
\hline Step & Product & Rate constant, $\mathrm{s}^{-1}$ \\
\hline \multicolumn{3}{|c|}{-Leu-tRNA ${ }^{\text {Leu(UUA) }}$} \\
\hline $\mathrm{k} 1$ & $\mathrm{M} \rightarrow \mathrm{M}_{\mathrm{n}}$ & $0.13 \pm 0.07$ \\
\hline $\mathrm{k} 2$ & MQAN & $0.34 \pm 0.17$ \\
\hline $\mathrm{k} 3$ & MQANF 0-frame & $0.21 \pm 0.06$ \\
\hline $\mathrm{k} 4$ & MQANF drop-off & $0.007 \pm 0.01$ \\
\hline k5 & MQANFF & $0.01 \pm 0.009$ \\
\hline $\mathrm{k} 6^{\mathrm{a}}$ & MQANFFR -1-frame & $0.22 \pm 0.01$ \\
\hline \multicolumn{3}{|c|}{+ +Leu-tRNA ${ }^{\text {Leu(UUA) }}$} \\
\hline $\mathrm{k} 1$ & M drop-off & $0.13 \pm 0.07$ \\
\hline $\mathrm{k} 2$ & MQAN & $0.34 \pm 0.17$ \\
\hline $\mathrm{k} 3$ & MQANF & $0.24 \pm 0.10$ \\
\hline $\mathrm{k} 4$ & MQANF drop-off & $0.02 \pm 0.01$ \\
\hline k5 & MQANFF & $0.03 \pm 0.01$ \\
\hline $\mathbf{k 6 ^ { \mathbf { a } }}$ & MQANFFR -1-frame & $0.22 \pm 0.01$ \\
\hline k7 & MQANFL & $0.33 \pm 0.06 / 0.9 \pm 0.2^{*}$ \\
\hline $\mathbf{k} \mathbf{8}^{\mathbf{b}}$ & MQANFLG 0-frame & $0.53 \pm 0.22$ \\
\hline k9 & MQANFLR -1-frame & $0.04 \pm 0.02$ \\
\hline \multicolumn{3}{|c|}{ Arg-tRNA ${ }^{\text {Arg }}$ incorporation in 0 -frame ${ }^{\mathrm{a}}$} \\
\hline & MFR & $0.22 \pm 0.01 \mathrm{~s}^{-1}$ \\
\hline & MLR & $0.27 \pm 0.03 \mathrm{~s}^{-1}$ \\
\hline
\end{tabular}

* The two rate constants correspond to 0.3 - and 1.0-fold excess of tRNA ${ }^{\mathrm{Leu}(\mathrm{UUA})}$ over ribosomes, respectively.

a The rate constant is from Fig. 17A.

$\mathrm{b}$ The rate constant is from Fig. 17B.

\subsection{5 -1PRF in HIV-1 studied with native human aa-tRNA}

Our finding that Leu-tRNA ${ }^{\text {Leu }}$ isoacceptor reading the UUA codon affects the mechanism and efficiency of -1 PRF prompted us to validate the key results with eukaryotic translation components. First, we analyzed the relative abundance of human LeutRNA $^{\text {Leu(UUA) }}$ in total tRNA from different human cell types using qRT-PCR (Fig. 19). 
HIV-1 mainly infects CD4 ${ }^{+}$T-lymphocytes and macrophages (Freed, 2001). We determined the ratio of Leu- tRNA ${ }^{\mathrm{Leu}(\mathrm{UUA})}$ to Leu-tRNA ${ }^{\mathrm{Leu}(\mathrm{CUG})}$ reading the most abundant Leu codon CUG. Leu-tRNA ${ }^{\text {Leu(UUA) }}$ is 7-17-fold less abundant than Leu-tRNA ${ }^{\text {Leu(CUG) }}$ in cell lines derived from T-lymphocytes, and about 20-fold in HeLa cells, whereas in other types of human cells the ratio is about 1:3 (Fig. 19). As a control, we quantified the relative abundance of Val-tRNA ${ }^{\mathrm{Val}}$ isoacceptors reading a rare GUA codon and an abundant GUG codon, respectively. The tRNA ${ }^{\mathrm{Val}(\mathrm{GUA})}$ isoacceptor reading the rare codon is about 7-8 times less abundant than common tRNA ${ }^{\mathrm{Val}(\mathrm{GUG})}$, except for the $293 \mathrm{~T}$ epithelial cells, where the amount of $\mathrm{tRNA}^{\mathrm{Val}(\mathrm{GUA})}$ is even lower (Fig. 19). Because the relative abundance of tRNA $^{\text {Leu(UUA) }}$ in HeLa cells is similar to that in cells used as a model for the HIV infection, we used total human tRNA purified from HeLa cells for the in vitro translation experiments described below.

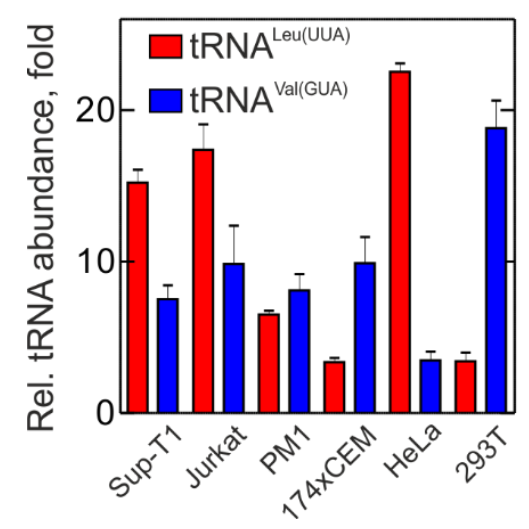

Figure 19. Relative abundance of tRNA isoacceptors in different cell types. Plotted is the ratio of tRNA $^{\mathrm{Leu}(\mathrm{CUG})}$ to $\mathrm{tRNA}^{\mathrm{Leu(UUA)}}$ (red bars) and tRNA ${ }^{\mathrm{Val}(\mathrm{GUG})}$ to tRNA ${ }^{\mathrm{Val}(\mathrm{GUA})}$ (blue bars), that read frequent and rare codons, respectively, in human cell lines. Error bars represent s.e.m of three biological replicates with three technical replicates each. Experimental design of qRT-PCR was according to (Wan Makhtar et al., 2017). Human cell lines are indicated below the graph. Sup-T1, Jurkat and PM1 are derived from human T-lymphocytes; 174xCEM is B-T-lymphocyte fusion; HeLa are derived from cervical epithelial carcinoma; 293T is a kidney epithelial cell line.

To check if HeLa aa-tRNA is active in translation with bacterial translation machinery, we first tested the TC formation between bacterial elongation factor EF-Tu and the tRNA in the presence of GTP. To find the optimal translation conditions, we titrated EF-Tu over the tRNA in a wide range of concentrations (0-300 $\mu \mathrm{M}$ EF-Tu over $1.4 \mu \mathrm{M}$ aa-tRNA). We then employed electrophoretic mobility shift assay using native gel-electrophoresis to distinguish between EF-Tu-bound and free aa-tRNA and to quantify TC formation. About $60 \%$ of human aa-tRNA is found in the TC with EF-Tu at 1:7 molar ratio of the two (Fig. 20A); 
these conditions were used in subsequent experiments. This observation suggests that human aa-tRNA could be efficiently used in the heterologous $E$. coli in vitro translation system.

A

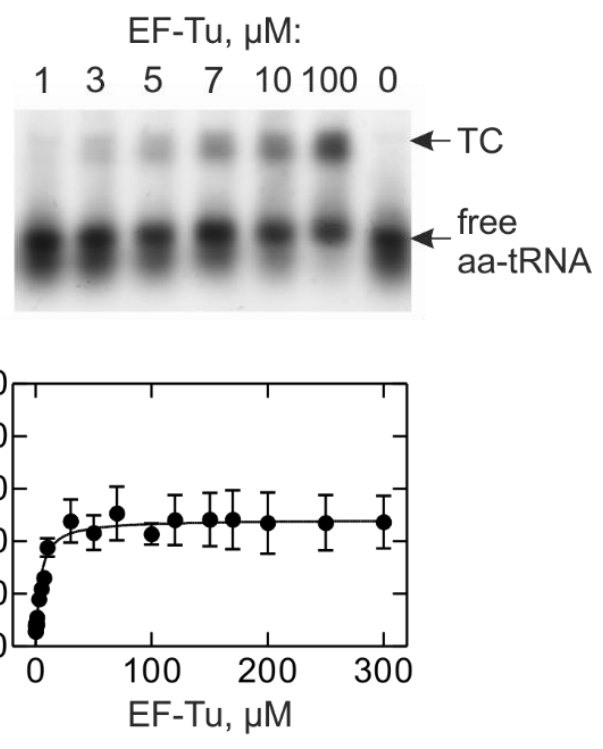

B



Figure 20. Characterization of the heterologous in vitro translation system.

(A) Top panel. Formation of TC between E. coli EF-Tu and human native aa-tRNA $(1.4 \mu \mathrm{M})$ monitored at varying concentrations of EF-Tu by electrophoretic mobility shift assay. The amount of the formed TC was calculated as a ratio between the EF-Tu-bound (TC) and free aa-tRNA multiplied by $100 \%$.

(B) Translation of $\gamma \mathrm{B}$-crystallin $(\gamma \mathrm{BC})$ in a heterologous system with human aa-tRNA using mRNAs with harmonized (E. coli) and native (B. taurus) codon usage. The full-length $\gamma \mathrm{B}$-crystallin is marked with an arrow.

(C) Time courses of synthesis of full-length $\gamma \mathrm{B}$-crystallin on the native mRNA from B. taurus (grey circles) and 0-frame peptide on long wt HIV-1 mRNA (red squares). The fraction of 0-frame was calculated as a ratio between 0 -frame product and all products of translation.

The conformity of the human aa-tRNA to the codon usage of mammalian mRNA was validated by translation of an mRNA coding for bovine Bos taurus (B. taurus) $\gamma \mathrm{B}$-crystallin. The codon usage of $\gamma \mathrm{B}$-crystallin matches the tRNA abundance of its eukaryotic host, but not of E. coli. With native human aa-tRNA, $\gamma \mathrm{B}$-crystallin mRNA is translated efficiently (Fig. 20B). Introducing synonymous mutations in the mRNA to match the codon usage in E. coli, which is different from that in the mammalian host (Buhr et al., 2016), reduces the yield of the full-length product (Fig. 20B). Thus, E. coli heterologous system with human native tRNA is suitable for efficient translation of mammalian mRNAs in vitro. 
Next, we used this system to study-1PRF on long wt HIV mRNA, which was optimized for peptide separation and their visualization with Tris-Tricine PAGE. The long wt mRNA encompasses the region from the nearest native (elongator) AUG codon of the gag mRNA upstream of the SS1, the SS1 with its downstream SL1 and the second putative frameshifting site, pSS2, with a 32-nt downstream sequence, which is predicted to form a SL (pSL2) (Fig. 21A). To distinguish between 0- and-1-frame translation products, we introduced a stop codon UAG in the 0 -frame to obtain a peptide 52 aa in length; -1PRF results in a 120-aa peptide product (Fig. 21B). To identify potential -2-PRF products, we mutated all native stop codons in the -2 -frame downstream of the pSS2 in the original wt mRNA (mRNA denoted as no-stop). Translation of no-stop mRNA leaves the product lengths in the 0 - and -1-frames unchanged, but additionally yields a 120-aa -2-frame product. Despite their identical length, the -1 -frame and -2-frame products have different electrophoretic mobility due to their different aa composition (Fig. 21C). 


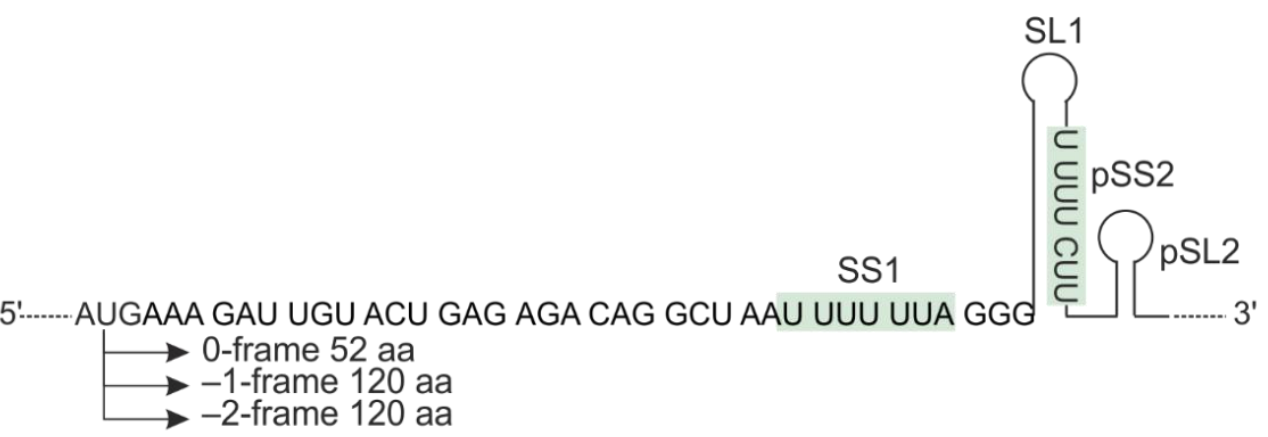

B
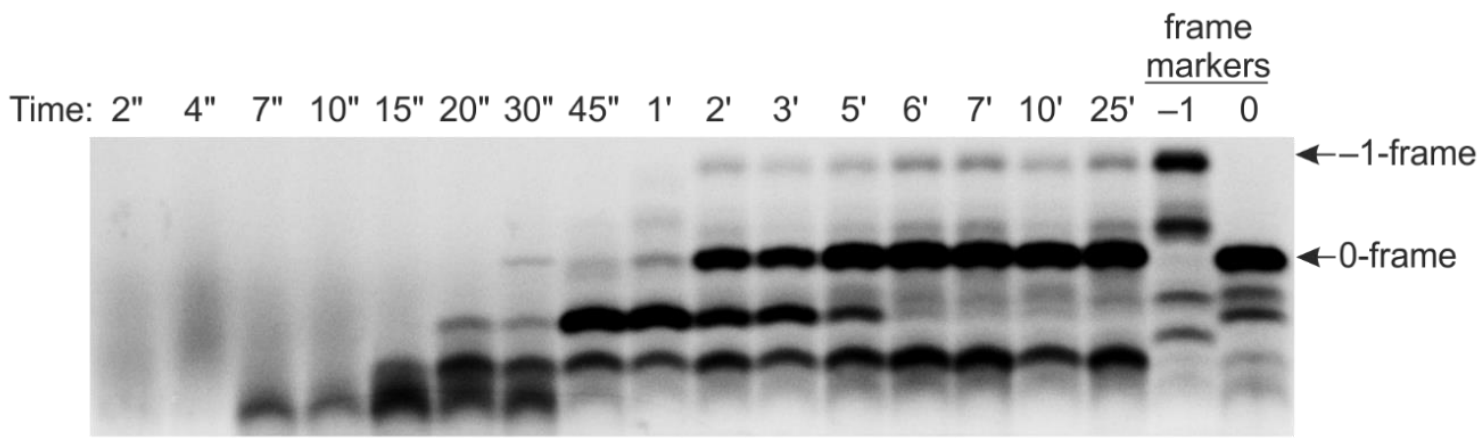

C



Figure 21. Translation and frameshifting with native human aa-tRNAs.

(A) The mRNA used for translation experiments. SS1 and pSS2 are highlighted light green, SL1 and the potential SL element downstream of the pSS2 (pSL2) are shown. Sizes of 0-, -1- and -2-frame peptides formed upon translation of the mRNA are indicated.

(B) Time course of 0 -frame and-1-frame translation on long wt mRNA with native human tRNA. Times of translation and frame markers are shown above the gel. Frames are indicated with arrows. (C) Time courses of $0,-1$, and -2-frame peptides synthesized on no-stop mRNA with native human tRNA.

The rate of translation of long wt HIV mRNA is similar to that of $\gamma \mathrm{B}$-crystallin mRNA and constitutes about $0.5-0.7 \mathrm{aa} / \mathrm{s}$ (Fig. 20C), however, translation of HIV mRNA proceeds via multiple intermediates (Fig. 21B,C). Their identity was identified by comparing marker peptides of defined length with the peptides formed during translation (Fig. 22A,B). Interestingly, many peptide products corresponding to stalling sites could be most likely attributed to the rare codons in the Gag-Pol sequence (Table 26). We note that the codon usage of HIV late-expressing genes including gag and pol is grossly different from that of its human host, which could explain observed translation pauses (Berkhout et al., 2002; Li 
et al., 2012; van Weringh et al., 2011). In addition, codons identified at stalling positions are A- and U-ending, which are overrepresented in the HIV genome, but underrepresented in highly expressed human genes.

A

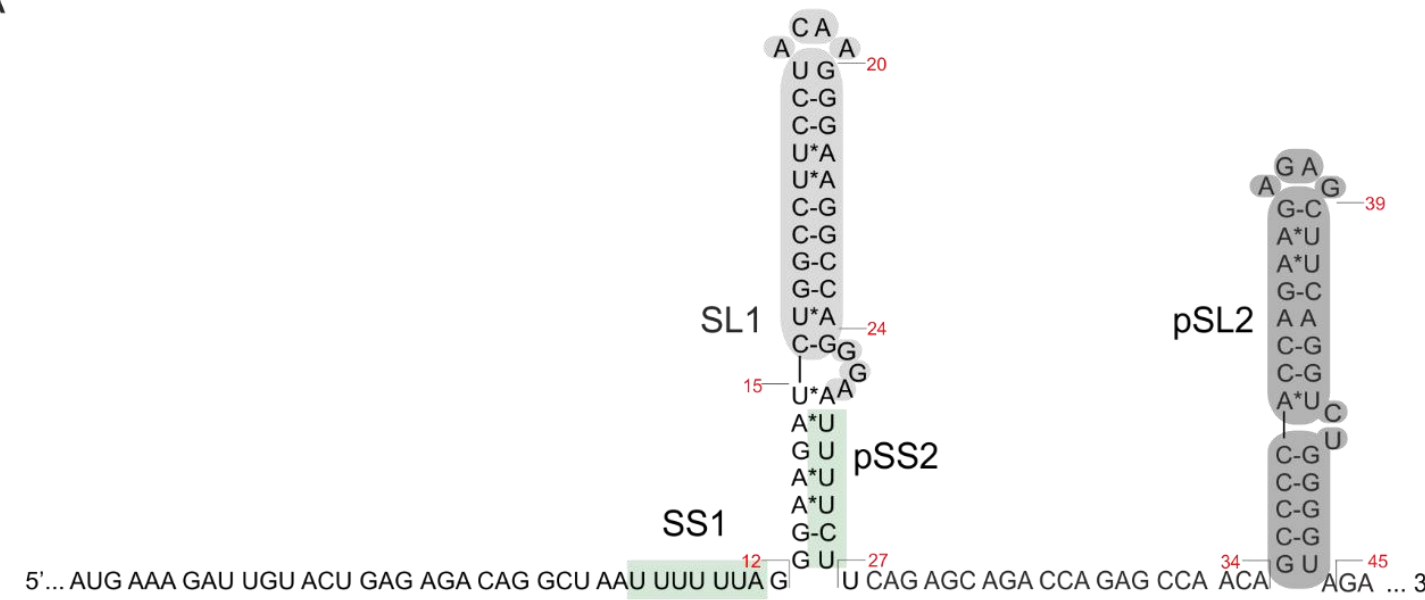

B

Time, sec/min:

Marker peptide, aa: $12 \quad 15 \quad 20 \quad 24 \quad 27 \quad 34 \quad 39 \quad 45$

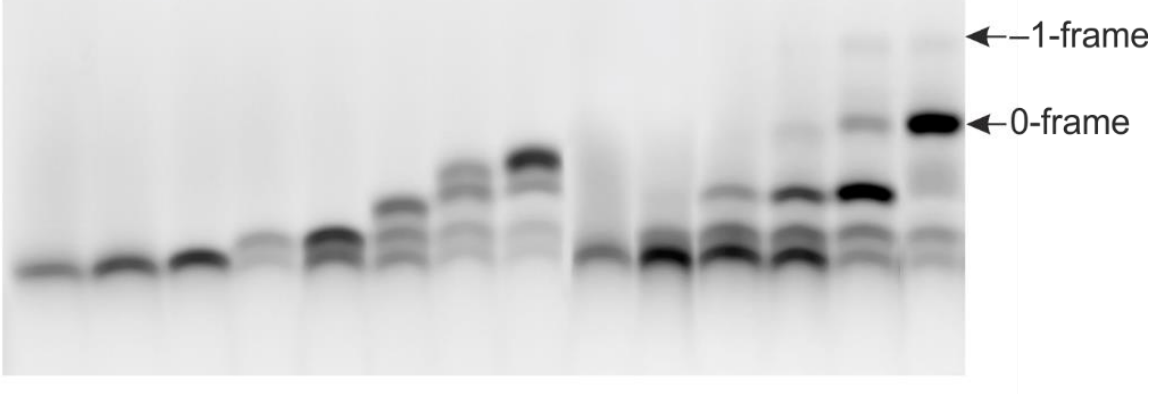

Figure 22. Characterization of translation intermediates on HIV long wt mRNA.

(A) The mRNA constructs used to synthesize the marker peptides shown on the HIV wt mRNA. SL1 and pSL2 are highlighted in light and dark grey, respectively. End positions of shortened mRNAs used to generate marker peptides are marked with lines. Numbers in red indicate the length of peptides (in aa) starting from the start codon AUG.

(B) Translation intermediates formed during translation of long wt mRNA translation with native human tRNA. Marker peptide lengths (in aa) and translation times (15 s-30 min) of the wt mRNA are indicated above the gel. Positions of 0 -frame and -1 -frame peptides are marked with arrows. 
Table 26. Correspondence between stalling sites and low-abundant codons

\begin{tabular}{|l|l|l|l|l|}
\hline $\begin{array}{l}\text { Amino acid position } \\
\text { (from AUG) }\end{array}$ & Frame & Codon & Amino acid & $\begin{array}{l}\text { Fraction per codon per } \\
\text { amino acid }\end{array}$ \\
\hline 12 & 0 and -1 & UUA & Leu & 0.08 \\
\hline 19 & -1 & CUA & Leu & 0.07 \\
\hline 27 & 0 & CUU & Leu & 0.13 \\
\hline 41 & -1 & CUU & Leu & 0.13 \\
\hline 45 & 0 & GUA & Val & 0.12 \\
\hline 45 & -1 & GGU & Gly & 0.16 \\
\hline
\end{tabular}

The -1 PRF efficiency in the heterologous translation system was determined to be 67\% (Fig. 23A), consistent with earlier in vivo reports (Cassan et al., 1994; Grentzmann et al., 1998b; Mathew et al., 2015; Plant and Dinman, 2006). Formation of 0-frame and -1-frame products starts after a 30-s delay which may be caused by an early translational pausing event (appearing as a prominent peptide band between $7 \mathrm{~s}$ to $30 \mathrm{~s}$ of translation (Fig. 21B \& 23A). In contrast, the -2-frame product appears after a much longer delay of $120 \mathrm{~s}$ (Fig. $21 \mathrm{C} \& 23 \mathrm{~A}$ ). At this time, the synthesis of the 0 -frame product is already completed on most ribosomes, suggesting that the $-2 \mathrm{PRF}$ may arise on a fraction of ribosomes that undergo long translation pausing. Addition of exogenous (bacterial) LeutRNA $^{\text {Leu(UUA) }}$ decreases the -1 PRF efficiency to $4 \%$ (Fig. 23B). A similarly reduced frameshifting efficiency is observed when the UUA codon is mutated to UUC, which does not interrupt the slippery run of six Us, but changes the identity of the tRNA reading the second slippery codon to the abundant tRNA ${ }^{\text {Phe }}$ (Fig. 23C). Thus, reassigning the second codon of the SS1 to an abundant tRNA has the same effect as adding excess of tRNA ${ }^{\text {Leu(UUA) }}$ to the native sequence. Shortening the SS1 to four U residues decreased PRF to 2\%, which is consistent with earlier reports. Disrupting SS1 preventing any slippages diminishes the PRF efficiency to about 1\%, which is the background level of these experiments (Fig. 23C). 
A



B

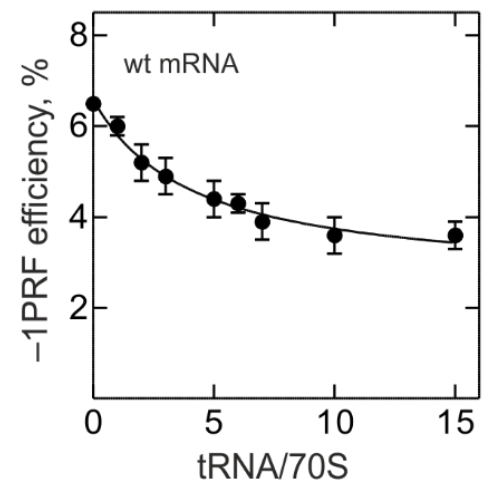

TC/70S:
C

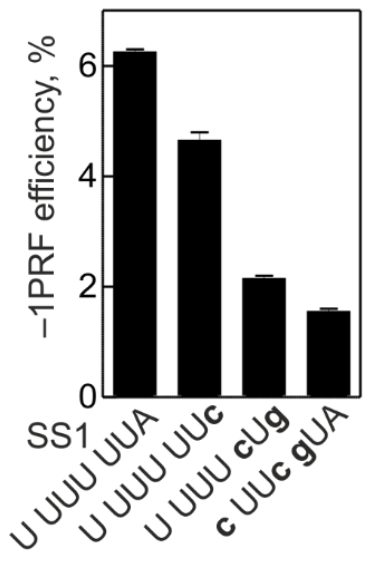

$\begin{array}{llllllll}0 & 1 & 2 & 3 & 5 & 7 & 10 & 15\end{array}$

$\leftarrow-1$-frame

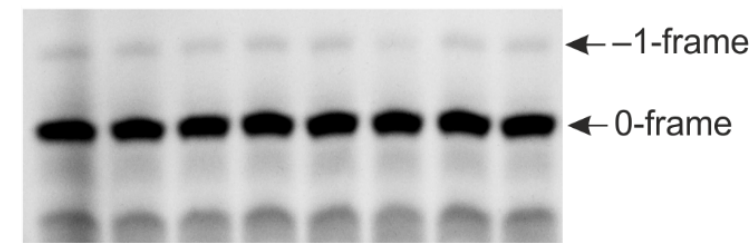

Figure 23. Frameshifting efficiency and its modulation on SS1 of gag-pol overlap measured in E. coli heterologous translation system with native human tRNA.

(A) Time courses of -1PRF on wt mRNA (closed circles) as well as -1PRF (open circles) and -2PRF (closed triangles) on mRNA where all stop codons in -2-frame were mutated to sense codons (no-stop).

(B) Concentration dependence of $-1 \mathrm{PRF}$ efficiency on exogenous tRNA ${ }^{\mathrm{Leu}(\mathrm{UUA})}$ from E. coli measured on wt mRNA. Bottom panel: Titration of E. coli TC(Leu-UUA) on wt mRNA. Excesses of TC(Leu-UUA) are shown above the gel.

(C) Effect of mutations in SS1 on -1PRF. The background of the measurements is $\pm 1 \%$. The s.e.m was calculated from 3-5 independent experiments.

\subsubsection{The putative second slippery sequence}

To test the effect of pSS2 that arises in virus isolates resistant to anti-HIV treatment, we introduced mutations that should make pSS2 more or less slippery (Fig. 24A-C). As long as the SS1 sequence is unchanged, mutations in pSS2 have little effect on overall-1PRF, but change the -2 PRF efficiency, which, in turn, leads to slight variations in -1 frameshifting. The -2PRF efficiency is higher when both SS1 and pSS2 are slippery, suggesting that $-2 \mathrm{PRF}$ results from dual -1-slippages on both sites rather than from -2-slippage on pSS2 alone. Replacing the rare CUU codon in pSS2 with the abundant CUG reduces -2PRF indicating that the second slippage is due to "hungry" frameshifting on pSS2. When the U-string in SS1 is disrupted, the frameshifting efficiency is higher in the construct where pSS2 is slippery compared to the native sequence. The presumed secondary structure of the 
mRNA downstream of pSS2 (Fig. 24A) has no effect. Disruption of both SS decreases frameshifting to background levels. Thus, pSS2 supports a low-level frameshifting event that can rescue HIV-1 when SS1 is mutated, but also causes -2PRF, which in the native sequence leads to premature termination of translation.

A

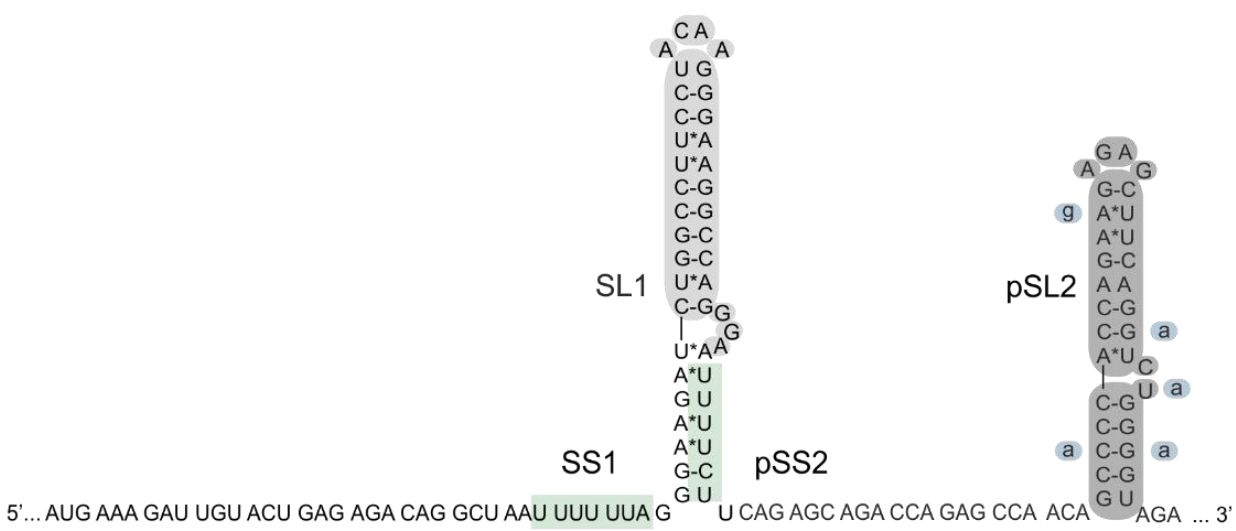

B

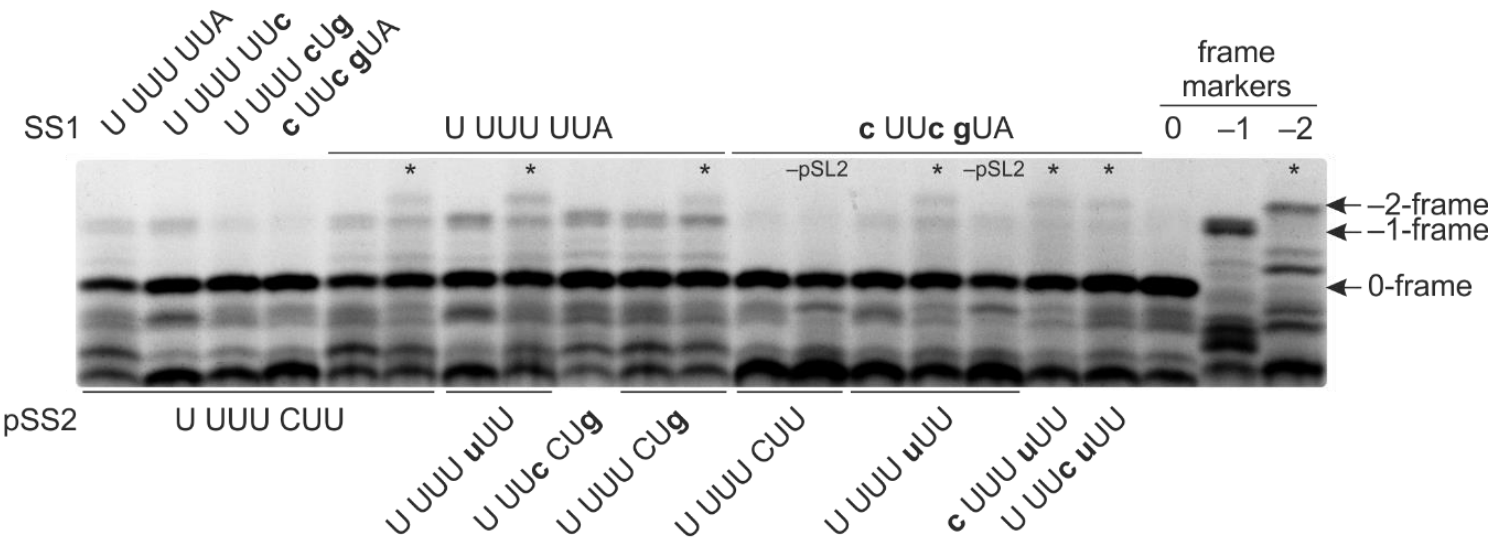

C

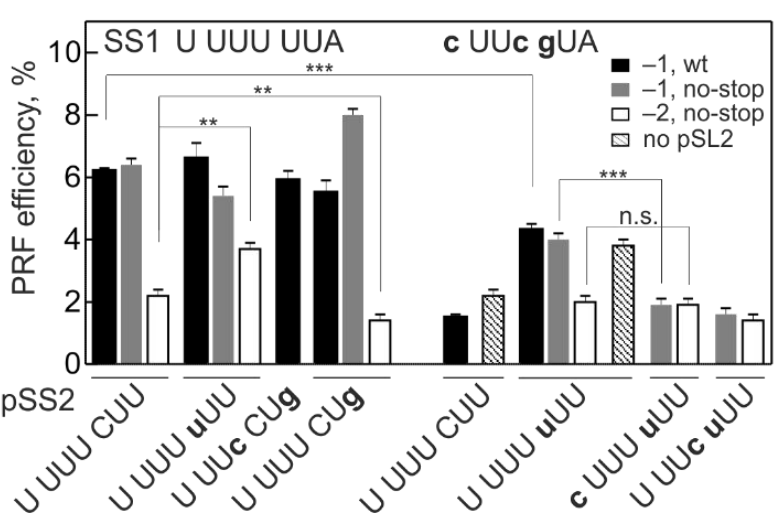

Figure 24. Interplay between SS1 and pSS2.

(A) Scheme of the wt mRNA used for translation experiments with indicated SS1, pSS2, SL1 and pSL2 frameshifting elements. Small letters on the sides of pSL2 correspond to mutations introduced to disturb its structure. The pSL2 structure was predicted by mFold software. 
(B) Examples of translation reactions with HIV-1 mRNA variants containing mutations in SS1, pSS2 and pSL2. Sequences of SS1 and pSS2 variants are indicated above and below the gel, respectively. Mutated nts are in small bold letters. -pSL2 indicates mutated pSL2. * represent mRNAs with removed stop codons in -2-frame.

(C) Modulation of -1 and -2 frameshifting efficiency by interplay between SS1 and SS2. SS1 sequences are shown above the bars, pSS2 sequences are indicated below the graph. -1PRF is determined with wt mRNA (black bars) or with no-stop mRNA (grey bars); -2PRF is measured with no-stop mRNA (white bars); the absence of pSL2 is indicated by textured pattern. Two-tailed twosample equal variance t-test was performed between marked samples. n.s. means not significant, $* *$ indicates $\mathrm{p} \leq 0.01, * * *$ is $\leq 0.001$.

\subsubsection{Frameshifting efficiency in HIV-1 measured with human $80 \mathrm{~S}$ ribosomes}

To further verify our results obtained with eukaryotic/bacterial heterologous translation system, we studied -1PRF in HIV-1 using mammalian in vitro reconstituted homologous system. As compared to cellular lysates (e.g., rabbit reticulocyte lysate), this system has the advantage of providing a fully controlled environment due to the high purity of individual components and translation speed similar to in vivo rates. In eukaryotic mRNAs a start codon AUG was introduced $8 \mathrm{nt}$ prior to the SS1 and the codon following AUG was mutated from CAG (Ala) to GUA (Val) to maintain a Kozak sequence required for efficient translation initiation. wt mRNA contained native SS1, SL1, pSS2 and pSL2 elements. Ribosomal subunits (40S and 60S), initiation factors (eIF1A, eIF1, eIF2, eIF3, eIF4A, eIF4B, eIF5, and eIF5B) and Met-tRNA $\mathrm{i}_{\mathrm{i}}$ were used to form the 80S ICs with HIV mRNAs of interest. Translation was performed with total human tRNA aminoacylated with Val, Ala, Asn, Phe, Gly and Arg aa in the presence or absence of Leu, providing natural distribution of all tRNA isoacceptors. Translation of wt mRNA results in 0-frame peptide Met-Val-Ala-Asn-PheLeu-Gly (MVANFLG) and -1-frame peptides Met-Val-Ala-Asn-Phe-Phe-Arg (MVANFFR) and Met-Val-Ala-Asn-Phe-Leu-Arg (MVANFLR). To determine the translation efficiency and identify the elution positions of the synthesized peptides from RP-HPLC, 0-frame and -1-frame control mRNAs were made. The -1 -frame control contained a frameshifted nucleotide sequence cloned in-frame and slippery sites were mutated in both mRNAs to prevent slippages.

Translation of the -1 -frame control mRNA yields a significant amount of frameshifting products MVANFLR/FFR, whereas the 0-frame control mRNA shows no Arg incorporation, as expected (Fig. 25A). High efficiency of translation and the lack of misincorporation products suggest that the experimental set-up could be used to study -1PRF on the HIV-1 
mRNA. The -1PRF efficiency in this fully reconstituted eukaryotic translation system is about $20-25 \%$ in the presence of native amounts of tRNA ${ }^{\text {Leu(UUA) }}$ (Fig. 25A,B).

A
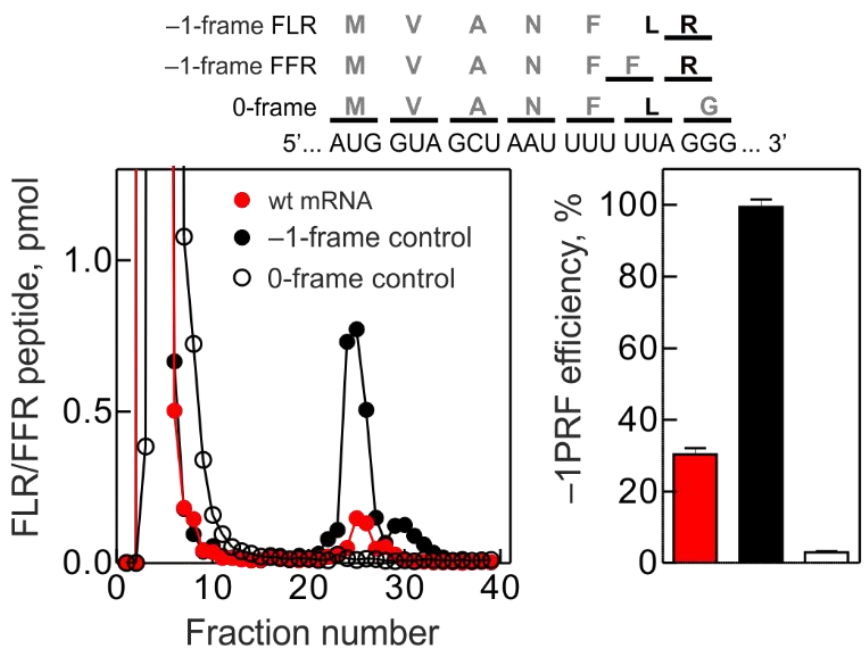

B

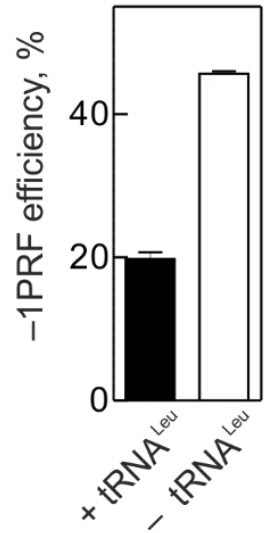

Figure 25. Translation of the eukaryotic gag-pol wt mRNA using a fully reconstituted homologous mammalian in vitro translation system.

(A) Top panel: Sequence of gag-pol mRNA optimized for translation by eukaryotic translational machinery. Peptides produced in 0 - and -1 -frames are indicated above the sequence. Left panel: HPLC profile of -1 frameshifting peptides synthesized with wt (red circles), -1 -frame control (black circles) and 0-frame control (open circles) mRNAs. Peptides were monitored using [ $\left.{ }^{3} \mathrm{H}\right] \mathrm{Arg}$. Right panel: -1 PRF efficiency measured with wt, -1 -frame and 0-frame control mRNAs. Color code is as in the left panel. -1 PRF efficiency was calculated using $\left[{ }^{3} \mathrm{H}\right] \operatorname{Arg}$ on the frameshifting peptide MVANFLR or FFR and $\left[{ }^{14} \mathrm{C}\right]$ Leu indicative of general translation efficiency. The experiment was performed by Dr. Akanksha Goyal.

(B) -1PRF efficiency measured with HIV-1 gag-pol mRNA in the presence ( + tRNA $\left.^{\text {Leu }}\right)$ and in the absence $\left(-\right.$ tRNA $\left.^{\mathrm{Leu}}\right)$ of total Leu-tRNA ${ }^{\mathrm{Leu}}$ containing all isoacceptors in native ratios. The -1 -frame peptide was identified based on $\left[{ }^{3} \mathrm{H}\right]$ Arg incorporation.

As discussed above (see 3.1.2), Leu-tRNA ${ }^{\text {Leu(UUA) }}$ limitation leads to a significant increase in $-1 \mathrm{PRF}$ efficiency in the bacterial system. To validate this finding using mammalian components, we prepared human aa-tRNA excluding Leu from the aminoacylation mix. When leucine was omitted from the aminoacylation mixture, the-1PRF efficiency increased from about $20 \%$ to more than $40 \%$ (Fig. 25B). Because we translate only the first 7 aa, Leu depletion does not interfere with the translation efficiency. This data suggest that the abundance of $\mathrm{TRNA}^{\mathrm{Leu}(\mathrm{UUA})}$ acts as the main modulator of the frameshifting efficiency in HIV-1 regardless of the experimental system. 
3.2 Investigation of the role of the mRNA secondary structure and a potential enhancer sequence in -1PRF in HIV-1

\subsubsection{Studying potential enhancer sequence in the gag-pol gene of HIV-1 using the} E. coli in vitro translation system

As described in the Introduction, the HIV-1 gag-pol frameshifting site contains the SL1 following the SS1. The structure of SL1 is extensively studied, however, its significance for -1PRF in HIV-1 remains unclear (Bidou et al., 1997; Brunelle et al., 1999; Cassan et al., 1994; Dulude et al., 2002; Garcia-Miranda et al., 2016; Kang, 1998; Kim et al., 2001). To determine the role of the mRNA secondary structure, we employed the E. coli in vitro reconstituted translation system and a variety of mRNA constructs with mutations or deletions in the SL1 region. Unless stated otherwise, we used a 1:1 molar ratio between tRNA $^{\text {Leu(UUA) }}$ and 70S because at this ratio the partitioning between the FLR and the FFR routes is similar to that obtained in vivo (see 3.1).

Removal of nts forming the lower stem (mRNA 38, the number indicates the nt length of the mRNA sequence after SS1) or both upper and lower stems (mRNA 23) has no significant effect on the -1PRF efficiency in HIV-1 in our system (Fig. 26A). This is consistent with the previous reports suggesting that the lower stem indeed plays only a marginal role in stimulating frameshifting (Dulude et al., 2002; Garcia-Miranda et al., 2016; Gaudin et al., 2005; Marcheschi et al., 2011; Mazauric et al., 2009). However, truncating the mRNA further down to $8 \mathrm{nt}$ did not alter frameshifting efficiency either, suggesting that also the upper stem is not needed. On the other hand, truncating the sequence downstream of the SS1 to $5 \mathrm{nt}$ decreases frameshifting efficiency significantly from $30 \%$ (wt) to about $10 \%$ (Fig. 26A), suggesting that the SS1 alone is not sufficient for frameshifting. Rather, the residues 5-8 nt after the SS1 appear to act as an enhancer akine to the enhancer playing a role in +1 PRF. To identify the exact nts critical for frameshifting in HIV-1, we mutated positions 4 to 12 after the SS1 without changing the length of the wt mRNA (short for HPLC). Replacement of positions 1-3 from GGG to any other nts except for GGU are known to decrease the frameshifting efficiency in vivo in human cells (Mathew et al., 2015) and were not tested in our experiments. In addition, keeping the GGG codon unchanged allowed us to rely on the same radioactive labels to distinguish 0 -frame and -1-frame peptides regardless of the downstream sequence. First, we sequentially mutated single nts at the positions 4 to 12 after the SS1 (Fig. 26B). Substitutions of nt 4 to 7 have the biggest effect on -1 PRF decreasing its efficiency to $15-20 \%$, especially when mutated to the 
complementary nt (Fig. 26B). On the contrary, replacements of nt 8 to 12 either have no effect or even slightly increase the frameshifting efficiency, potentially by stabilizing base pairing in parts of the SL1 (Fig. 26B). To study synergetic effect of nt following the SS1 on $-1 P R F$ efficiency, we created mRNA variants in which nts 4-8 or 4-12 were simultaneously mutated (see Fig. 26C, mRNA sequence, mutated nt are indicated as lower-case letters). In cucuaCUGG mRNA, nts 4-8 (AAGAU) were mutated to cucua while 9-12 nt (CUGG) remained unchanged (Fig. 26C). -1PRF efficiency with this mRNA is about $17 \%$ as compared to wt, in agreement with the effects of single mutations at these positions (compare Fig. 26B \& C). Although nt 8-12 alone did not seem to contribute to -1PRF efficiency, we tested the cumulative effect of positions 4-12. We designed cucuagUaa and ccucaaUaa mRNAs, in which 4-9 (cucuag or ccucaa, respectively) and 11-12 (aa) nt were mutated in different manner; U10 was left unchanged (Fig. 26C). Regardless of exact mutations, changes of nt in positions 4-12 lower frameshifting to less than $10 \%$ suggesting cooperative effect of positions 4-7 and 9-12. Finally, truncating SL1 to $23 \mathrm{nt}$ combined with 4-12 nt mutations does not change-1PRF efficiency as compared to mutations alone, and it remains at about $10 \%$ (ccucaaUaa $23 \mathrm{nt}$ mRNA). All of the presented data suggest that -1PRF in HIV-1 could be indeed stimulated by an enhancer sequence spanning the first 4-12 nt following the SS1 and probably encompassing the GGG intercodon. However, any introduced mutations changing the secondary structure may result in SL1 remodelling, which also could affect the frameshift efficiency. To exclude this possibility, we swapped the nt sequence corresponding to the potential enhancer with its complementary sequence (see Fig. 26A, inverted lower stem mRNA), which allowed us to change the nt identity after the SS1 without disturbing the SL1. Frameshifting efficiency on the inverted lower stem mRNA is comparable to that on mRNAs with mutated enhancer (about 15\%) confirming the existence and the role of the specific sequence within the frameshifting motif for-1PRF in HIV-1. 
A

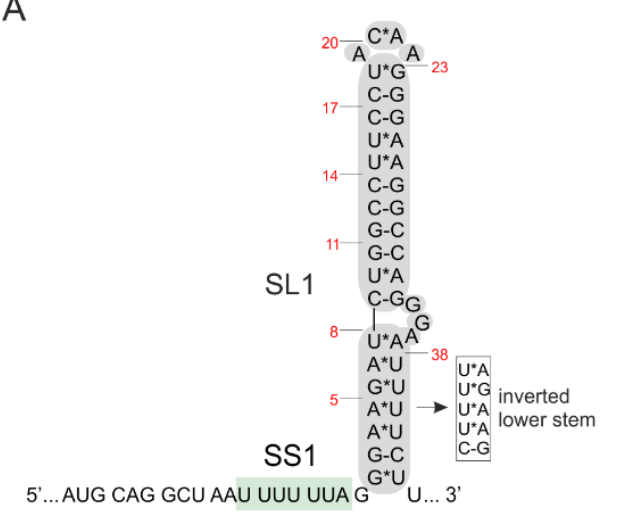

B
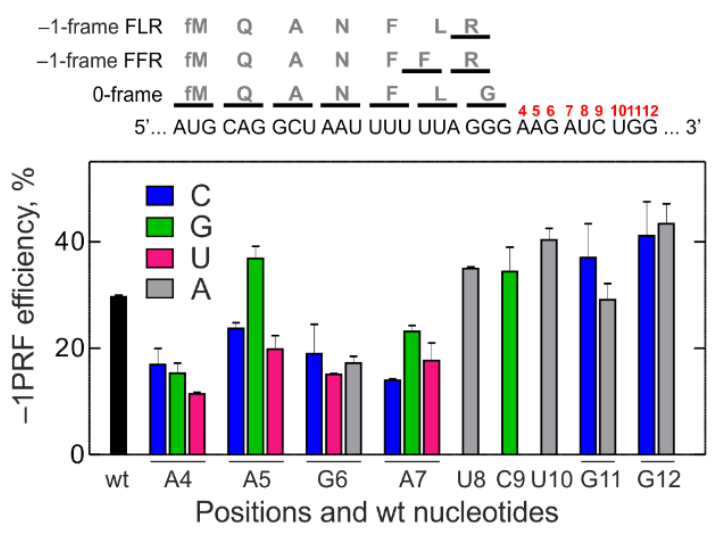

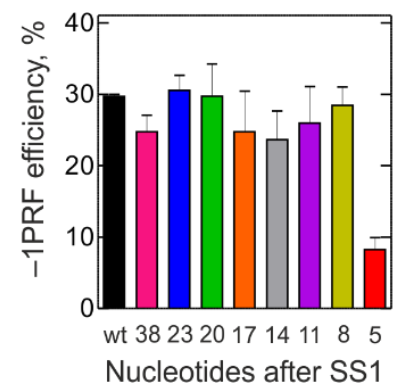

C

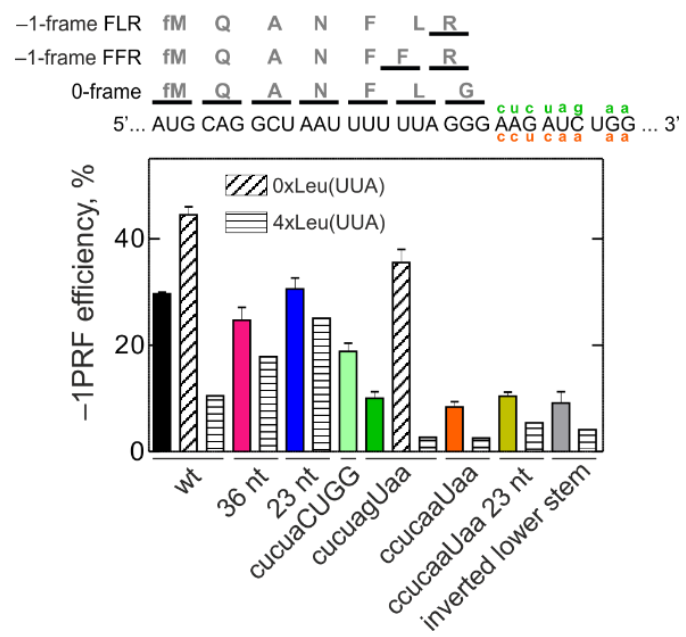

Figure 26. Effect of variations in the potential enhancer sequence following the SS1 in the gag-pol frameshifting site of HIV-1.

(A) Left panel: gag-pol frameshifting motif. SS1 is highlighted in light green, SL1 is in grey. Positions of mRNA truncations are marked with lines. Red numbers on the sides correspond to nt positions starting from the G following the SS1. Right panel: -1PRF efficiency measured with wt (black) and mRNAs truncated at 38 (magenta), 23 (blue), 20 (green), 17 (orange), 14 (grey), 11 (purple), 8 (yellow) and 5 (red) nts after the SS1.

(B) Upper panel: sequence of HIV-1 wt mRNA from start codon AUG to the end of potential enhancer (12 nt after the SS1). Aa incorporated into 0- and-1-frames are shown above the sequence. Red numbers correspond to nts positions starting from the G following the SS1. Lower panel:-1PRF efficiency determined on mRNAs with single-nucleotide substitutions in positions 4-12 after the SS1. Positions and identity of nts in wt mRNA are shown below. Substituted nts are color-coded: C is in blue, $\mathrm{G}$ is in green, $\mathrm{U}$ is in magenta and $\mathrm{A}$ is in grey. Wt mRNA is depicted in black.

(C) Effect of the potential enhancer sequence on FLR and FFR routes of -1PRF in HIV-1. Upper panel: same as in (B), but with indicated nt substitutions in cucuagUaa (green) and ccucaaUaa (orange) mRNAs. Lower panel: frameshifting efficiency on wt (black), mRNA truncated at position $36 \mathrm{nt}$ (magenta), $23 \mathrm{nt}$ (blue), cucuaCUGG (light green), cucuagUaa (green), ccucaaUaa (orange), ccucaaUaa $23 \mathrm{nt}$ (yellow) and inverted lower stem (grey) mRNAs determined at at 0-fold (diagonal 
pattern), 1-fold (respective colours) and 4-fold (horizontal pattern) excesses of tRNA ${ }^{\text {Leu(UUA) }}{ }^{\text {Small }}$ letters in mRNA names refer to mutated nts following GGG codon after SS1 (either 4-8 or 4-12 nt); capital letters refer to unchanged nts, e.g., cucuaCUGG means that 4-8 nt were mutated to cucaa while 9-12 nt CUGG remained as in wt sequence.

All the experiments described above were carried out at equimolar concentrations of tRNA $^{\text {Leu(UUA) }}$ and $70 \mathrm{~S}$ allowing for both routes of frameshifting to take place. We then explored which frameshifting regime is stimulated by the enhancer. To do so, we translated wt and cucuagUaa (mutated 4-12 nt) mRNAs in the absence of tRNA ${ }^{\text {Leu(UUA) }}$ allowing only the FFR route to take place. Interestingly, the -1PRF efficiency on both mRNAs is about 40-45\% suggesting that the FFR route is independent of the enhancer (Fig. 26C). To supress the FFR and to maximize the FLR route, we increased the excess of tRNA ${ }^{\text {Leu(UUA) }}$ to 4-fold. The increase of tRNA ${ }^{\mathrm{Leu}(\mathrm{UUA})}$ abundance significantly lowers the frameshifting efficiency, as shown with wt mRNA $\left(30 \%\right.$ at 1 -fold vs $10 \%$ at 4 -fold Leu-tRNA ${ }^{\text {Leu(UUA) }}$ excess; Fig. 15A \& 26C). -1PRF measured on mRNAs with either mutated or inverted lower stem is $<5 \%$ (Fig. 26C). This notion suggests that the enhancer affects primarily the FLR route. This is in agreement with the published data that show that translocation-dependent frameshifting is modulated by downstream regulatory mRNA sequences, typically a SL or a pseudoknot (Caliskan et al., 2014; Chen et al., 2014). Intriguingly, increase in the tRNA $^{\text {Leu(UUA) }}$ concentration has no effect on frameshifting with truncated mRNAs (38 nt and $23 \mathrm{nt}$ ) (Fig. 26C), which could either suggest that the FFR route is still operational or represent an artefact resulting from the different behaviour of the shortened mRNAs in the ribosomal mRNA tunnel or the peptidyl-tRNA drop-off at different steps of translation. Hence, 1-12 nt after the SS1 constitute the potential enhancer sequences in HIV-1, which modulates the efficiency of the FLR frameshifting route. In the future, the role of this potential enhancer sequence for -1PRF in HIV-1 will be further investigated using in vitro reconstituted mammalian translation system and human cell culture with dual-luciferase reporters described in $\mathrm{M} \& \mathrm{M}$ (2.1.8). 
3.3 Characterization of frameshifting motif and frameshifting efficiency in $6 \mathrm{~K}$ mRNA of Semliki Forest virus

\subsubsection{Determination of mRNA secondary structure in SFV}

HIV-1 and phylogenetically distant alphaviruses including SFV and MIDV share the same $\mathrm{SS}$ sequence of $\mathrm{U}_{1} \mathrm{UUU}_{4} \mathrm{UUA}_{7}$, but have different downstream stimulatory secondary structure elements in the mRNA. The secondary structures of HIV-1 and MIDV were experimentally determined and shown to be a bulged SL and a pseudoknot, respectively. On the contrary, the secondary structure predictions suggested that the downstream element in SFV is an extended SL, but this finding was not tested experimentally (Chung et al., 2010). Our goal was to solve the mRNA secondary structure in the SFV frameshifting mRNA using chemical probing (Moore, 1975; Peattie and Gilbert, 1980; Stern et al., 1988; Weeks, 2010). This approach allows us to determine which regions of the mRNA are single- or doublestranded based on the nucleotide accessibility for chemical modifications. For chemical probing, we designed two model SFV mRNAs: wt and test. Both mRNAs contain a native SFV frameshifting site bearing the SS and the predicted SL, but the test mRNA was optimized for translation with $E$. coli ribosomes by introducing a SD sequence $8 \mathrm{nt}$ upstream of the start codon AUG and an AUG 8 nt upstream of the SS. In addition, in the test mRNA we mutated the internal methionine AUG codon (59-61 nt downstream of the SS) into AUC to prevent translation initiation at this position. Chemical probing was performed with both free mRNAs and with the test mRNA in an IC. We used DMS, CMCT and KE to probe the mRNA secondary structure. These reagents add chemical adducts to various nts if they are located in the single-stranded RNA region and are thus accessible for modifications. RNA double-stranded regions are protected from chemical modifications due to base pairing to the complementary strand. DMS modifies nts via methylation of N1 adenosine and N3 of cytosine, CMCT reacts primarily with $\mathrm{N} 3$ of uridine and to a lesser extent with $\mathrm{N} 1$ of guanine and KE alters the N1 of guanine (Ziehler and Engelke, 2001). Upon RNA modification, RT reaction is performed with the fluorescence labeled primer binding to the 3' end of the SFV mRNA sequence and synthesizing its cDNA copy. The presence of the modified base hinders the progression of the RT resulting in the production of shortened DNA fragments, which could be then visualized on the sequencing PAGE.

To determine the structure of the SFV mRNA, our probing data was compared with the structure predicted by the bioinformatics analysis (Chung et al., 2010). Nucleotides between the SS and position 65 in the potential SL are well-resolved (Fig. 27A-C). One way to resolve 
the downstream sequence would be to anneal a synthetic DNA oligo to the 3' end of the mRNA, which would harbor a primer-binding site instead (Fig. 27A,C). Unlike RNA extensions, this DNA fragment should not interfere with the original mRNA secondary structure. As predicted by bioinformatics analysis (Chung et al., 2010), SFV SL contains a long lower stem encompassing nt 16-26 after the SS, as seen from the lack of chemical modifications of this region (Fig. 27B,C). Interestingly, C27 is not modified suggesting that it also belongs to the upper stem, although the bioinformatical analysis predicted it to be a part of the loop separating the lower and the upper stems. Notably, this loop is also seen in our analysis, because 28-29 nt are accessible to DMS modification. The upper stem was predicted to span nt 30-35, however, we see that adjacent nt 36-39 are also protected from modifications and might thus belong to the upper stem, although their base pairing partners are unclear (Fig. 27B,C). Both stems are GC-rich. The upper stem is closed by a large bulge spanning nt 40-49. Nucleotides 49-52 were predicted to form a small stem, which is not seen in our data. According to the bioinformatics analysis, C54 is base paired with G61, whereas we show that although C54 is non-modified, G61 is modified. In addition, when G61 is mutated to C61 in the test mRNA, the latter nt is protected. This data leaves the questions about the existence of the C54-G61 pair and other possible interactions of C54 open. Finally, we confirm the presence of the unstructured loop AGUAAU on top of the upper stem (Fig. 27B,C). Hence, despite the discussed differences, the determined structure of SFV SL largely resembles the one previously predicted by bioinformatic analysis (Chung et al., 2010). As expected, SS is found in the single-stranded region of the SFV mRNA. Modifications introduced to the test mRNA do not change the overall structure of the SL in SFV, however, seem to influence base-pairing patterns of several nts, e.g., C14, G24 and A53 (Fig. 27B,C). The presence of the 70S (IC) also does not affect the mRNA structure, most likely because the ribosome resides on an mRNA region distal from the SL (Fig. 27A-C). 
A

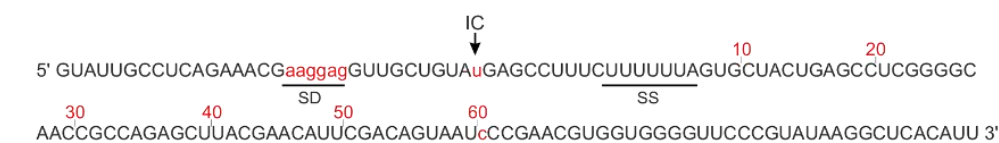

B

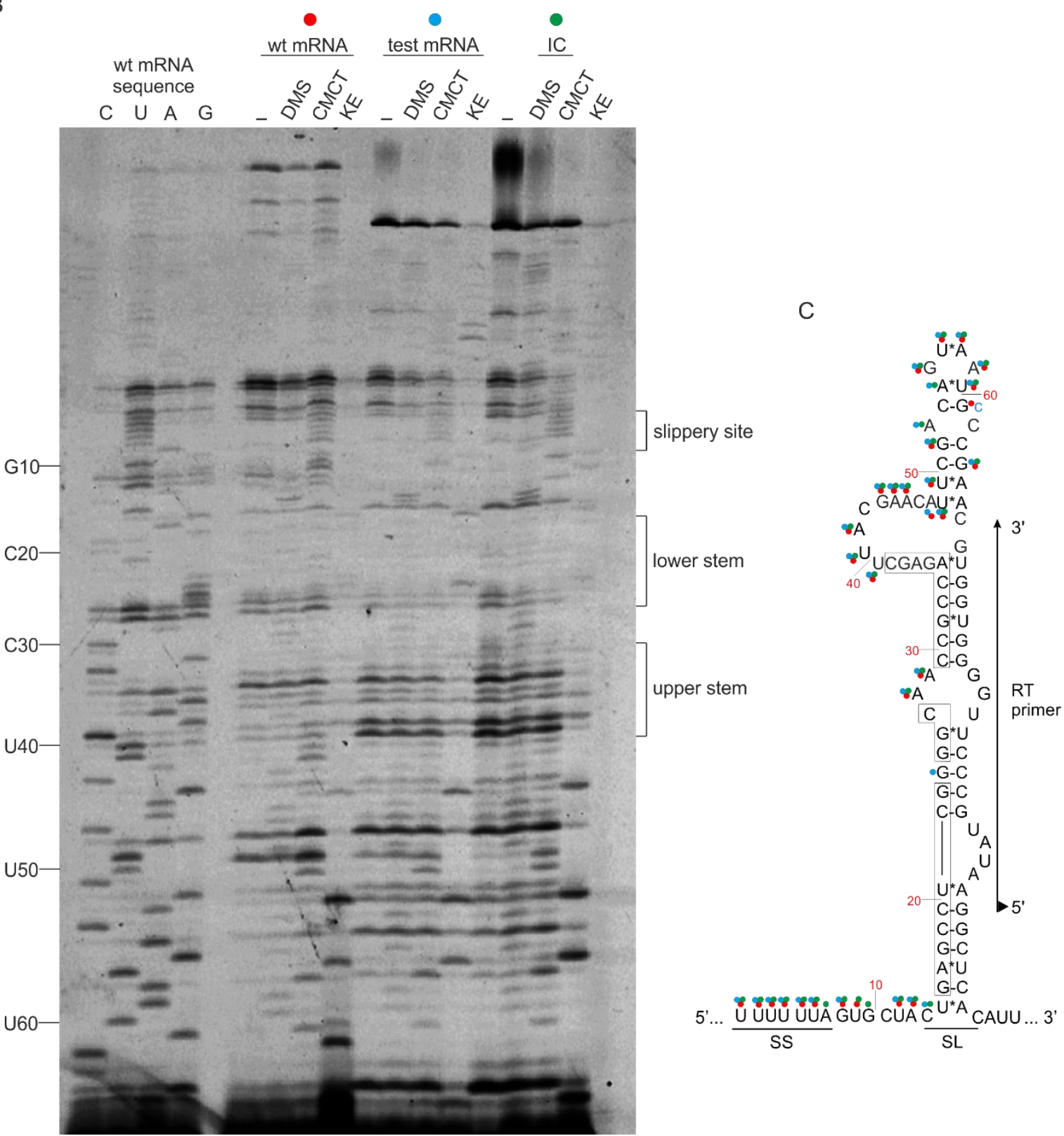

Figure 27. Determination of the mRNA secondary structure in SFV 6K frameshifting site using chemical probing.

(A) Sequence of the SFV test mRNA with introduced SD-sequence (SD) and start codon AUG. SD and SS are underlined; mutated nt as compared to wt are in small red letters; numbers indicate nt positions starting from the SS. The position of the 70S in the IC is marked with an arrow.

(B) Example of a sequencing gel showing the positions of RT stops due to chemical modifications of the RNA. mRNAs and chemical probing reagents are indicated above the gel; - stands for untreated control. C, U, A, G are sequencing lanes prepared with wt mRNA without prior modifications, where RT was stopped by addition of ddNTPs. Numbered nts to the left refer to the nts in the SFV frameshifting site starting from the slippery sequence. 
(C) mRNA secondary structure of SFV based on bioinformatics prediction and probing results. Slippery site (SS) and stem-loop (SL) elements are indicated and underlined. Modified nts are marked with circles: red for the wt mRNA, blue for the test mRNA and green for test mRNA in the IC. Sequences in boxes indicate nt forming lower and upper stems of the SL. Primer-binding site for RT is marked with an arrow; triangle on the 5' of the primer indicates its fluorescence label Atto647N.

\subsubsection{Characterization of -1 frameshifting on SFV frameshifting motif}

We next determined the -1PRF efficiency on the SFV frameshifting site. We utilised our in vitro reconstituted bacterial translation system, as described for HIV-1. SFV model mRNAs were optimized for translation with E. coli components by introducing a SD sequence and a start codon AUG. In addition, the second codon after AUG, CUU (Leu), was mutated to AAG (Lys) to improve translation efficiency with E. coli purified tRNAs (Fig. 28A). The short SS/SL mRNA contains both native frameshifting elements, whereas short SS/- has a wt SS but no SL (cut $18 \mathrm{nt}$ after the SS). In mRNAs CGAU and GACU nts 3-6 and 7-10 downstream of the SS, respectively, are mutated to the complementary nts (Chung et al., 2010). 
A

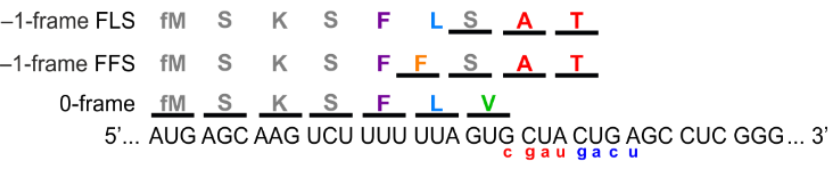

B

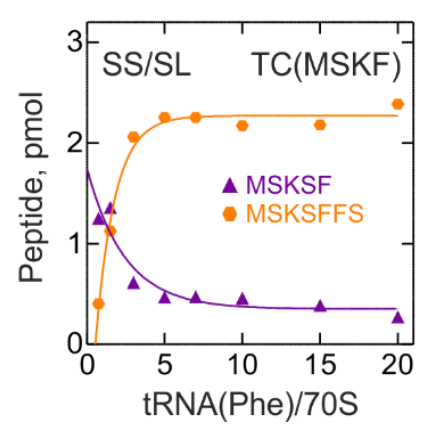

E

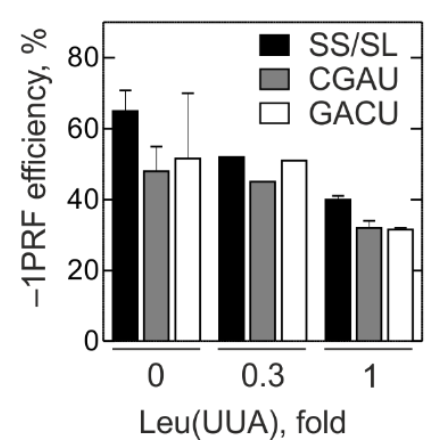

C

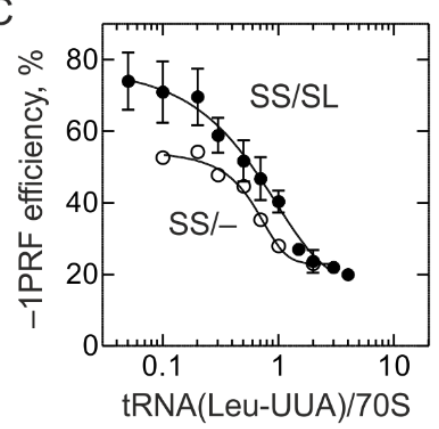

$\mathrm{D}$

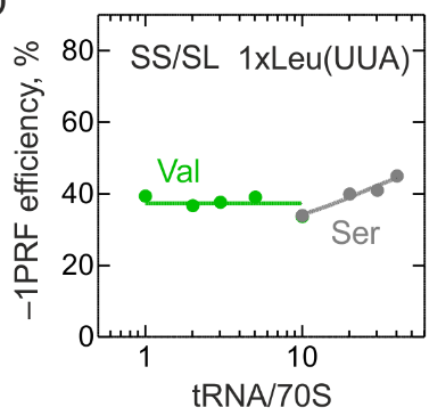

Figure 28. Characterisation of the FFS and FLS -1 frameshifting regimes with the SFV mRNA.

(A) Sequence of short SFV model mRNA. 0-frame and -1-frame peptides as well as CGAU (red) and GACU (blue) mutations in the mRNA are indicated.

(B) Effect of Phe-tRNA ${ }^{\text {Phe }}$ on FFS peptide formation in the absence of Leu-tRNA ${ }^{\text {Leu(UUA) }}$ measured on short SS/SL mRNA. Translation was carried out using TC(MSKF). MSKSF peptides are shown as purple triangles, MSKSFFS peptides as orange hexagons.

(C) Concentration dependence of -1PRF in SFV on the TC with Leu-tRNA ${ }^{\mathrm{Leu(UUA})}$ monitored at SS/SL (closed circles) and SS/- (opened circles).

(D) Effect of Val-tRNA ${ }^{\text {Val }}$ (green circles) and Ser-tRNA ${ }^{\text {Ser }}$ (grey circles) concentration on -1PRF efficiency in SFV. Translation was carried out using equimolar concentrations of Leu-tRNA ${ }^{\text {Leu(UUA) }}$ and ribosomes on SS/SL mRNA.

(E) Influence of nt mutations downstream of the SS on -1PRF efficiency in SFV. Translation was performed using 0-fold, 0.3-fold and 1-fold of Leu-tRNA ${ }^{\text {Leu(UUA) }}$ over the 70S on SS/SL (black), CGAU (grey) and GACU (white) mRNAs.

Translation of SFV mRNAs results in 0-frame peptides fMet-Ser-Lys-Ser-Phe (MSKSF), fMet-Ser-Lys-Ser-Phe-Leu (MSKSFL) and fMet-Ser-Lys-Ser-Phe-Leu-Val (MSKSFLV) (Fig. 28A). By analogy to HIV-1, -1PRF on the SFV mRNA is expected to yield two products: fMet-Ser-Lys-Ser-Phe-Phe-Ser (MSKSFFS) and fMet-Ser-Lys-Ser-Phe- 
Leu-Ser (MSKSFLS) (Fig. 28A). To facilitate the identification of -1-frame products, we monitored incorporation of Ala and Thr into MSKSFFSAT/MSKSFLSAT peptides on short SS/SL and SS/- mRNA, and Arg into MSKSFFSRS/MSKSFLSRS or MSKSFFSAR/MSKSFLSAR peptides on the CGAU and the GACU mRNA constructs, respectively. Translation products were separated by RP-HPLC using the same gradient as for HIV-1 peptides. 0 -frame products were identified based on $\left[{ }^{14} \mathrm{C}\right]$ Val while -1 -peptides were distinguished using $\left[{ }^{14} \mathrm{C}\right] \mathrm{Ala}$ and $\left[{ }^{14} \mathrm{C}\right] \mathrm{Thr}$ or $\left[{ }^{14} \mathrm{C}\right] \mathrm{Arg}$ for CGAU and GACU mRNAs. The -1 frameshifting efficiency was calculated as a ratio between -1-frame peptides and the sum of -1-frame and all 0 -frame products, multiplied by $100 \%$.

Because HIV-1 and SFV share the same SS sequence, we hypothesized that -1PRF in SFV also results in two peptides, FFS and FLS, depending on the presence of the LeutRNA $^{\text {Leu(UUA) }}$ isoacceptor (Fig. 28A). The FFS product is formed efficiently in the absence of Leu-tRNA ${ }^{\mathrm{Leu}(\mathrm{UUA})}$ and its amount depends on the concentration of Phe-tRNA ${ }^{\text {Phe }}$ (Fig. 28B). When titrating with Leu-tRNA ${ }^{\mathrm{Leu}(\mathrm{UUA})}$, we observed a dramatic decrease in -1 PRF efficiency from about $70 \%$ in the absence of tRNA ${ }^{\text {Leu(UUA) }}$ to about $18 \%$ in the presence of saturating amounts of tRNA ${ }^{\mathrm{Leu}(\mathrm{UUA})}$ (Fig. 28C). This indicates that - similarly to HIV-1 - the FFS route is operational when tRNA ${ }^{\mathrm{Leu}(\mathrm{UUA})}$ is absent or in limited supply, whereas under saturating translation conditions the FLS route becomes prevalent. FFS peptides are likely to result from the single P-site MSKSF-tRNA ${ }^{\text {Phe }}$ slippage when LeutRNA $^{\text {Leu(UUA) }}$ is absent in the A site. To better understand the FLS regime, we tested the competition between 0-frame Val-tRNA ${ }^{\mathrm{Val}}$ and -1-frame Ser-tRNA ${ }^{\text {Ser }}$ for binding at the codon following the SS, GUG. Titration of these tRNAs in the presence of equimolar amounts of tRNA ${ }^{\text {Leu(UUA) }}$ (1:1 molar ratio to $\left.70 \mathrm{~S}\right)$ does not change the frameshifting efficiency appreciably (Fig. 28D). These results suggest that similarly to HIV-1, FLS products result from dual slippage of the SS tRNAs Phe and Leu(UUA) in the late stage of translocation before the GUG codon is presented in the A site.

Next, we studied the effect of the SL on both frameshifting regimes in SFV. Removal of the SL decreases -1PRF in the absence of tRNA ${ }^{\text {Leu(UUA) }}$ from about $70 \%$ (SS/SL) to about $50 \%$ (Fig. 28C). This finding is surprising because single-tRNA slippage is typically independent of downstream stimulators and is triggered by a translational pause. The effect of the SL is also seen at low or equimolar amounts of $\operatorname{tRNA}^{\mathrm{Leu(UUA})}(1: 1$ molar ratio to $70 \mathrm{~S})$ where $-1 \mathrm{PRF}$ on SS/- mRNA is about $25 \%$ as compared to about $40 \%$ on SS/SL mRNA. However, when tRNA ${ }^{\mathrm{Leu}(\mathrm{UUA})}$ is present in large excesses, the -1-frameshifting efficiency 
on both mRNA constructs, with and without the SL, is the same (about 20\%), i.e. the SL does not seem to play a role in -1 -frameshifting.

As discussed in the Introduction, mutations in the first 18-20 nt downstream of the SS in SFV were shown to be detrimental for the frameshifting efficiency in vivo in human cells (Chung et al., 2010). These nts might act as either a downstream enhancer or a recognition motif for a microRNA or a protein, which stimulate -1 slippage by binding to this region. To test the functional significance of this sequence, we measured the -1PRF efficiency on the short CGAU and the GACU mRNA at different amounts of tRNA ${ }^{\text {Leu(UUA) }}$ (Fig. 28A,E). Because we use an in vitro reconstituted translation system with highly purified components, we could exclude the effect of small interfering RNAs or exogenous proteins. In the absence of tRNA ${ }^{\mathrm{Leu}(\mathrm{UUA})}$ mutating the CGAU sequence 3-6 nt downstream of the SS decreases the -1 PRF efficiency from about $70 \%$ to about $48 \%$, whereas changing the GACU sequence 7-10 nt nts downstream does not have an appreciable effect (Fig. 28E). When tRNA ${ }^{\text {Leu(UUA) }}$ is present at 0.3 molar ratio to the $70 \mathrm{~S}$, no effect on frameshifting is seen while at 1:1 molar ratio a $10 \%$ decrease in the frameshifting efficiency is observed with both mRNAs. This data suggest that mutating nts adjacent to the SS in SFV has a very moderate effect on -1PRF efficiency in vitro in the bacterial translation system and might argue for the presence of trans-acting factors in vivo in human cells.

\subsection{3 -1PRF in SFV measured with total human tRNA}

By analogy to HIV-1, we verified our key findings on SFV frameshifting in translation experiments with human total tRNA prepared from HeLa cell extracts and long SFV mRNAs optimized for Tris-Tricine PAGE. We prepared model mRNAs with stop codon UAG $51 \mathrm{nt}$ downstream of AUG in 0-frame to distinguish between 0-frame (17 aa) and -1-frame (32 aa) peptides. Unlike in short mRNAs described above, the second codon of the SS, CUC, remained unchanged (Fig. 29A). To check the translation efficiency and confirm the positions of peptides on a gel, we used 0 -frame ( 0 mRNA) and -1 -frame ( -1 mRNA) control mRNAs. In both mRNAs the SS was disrupted to prevent the slippage and in the $-1 \mathrm{mRNA}$ the -1 -frame codon sequence was introduced in 0 -frame. 
A

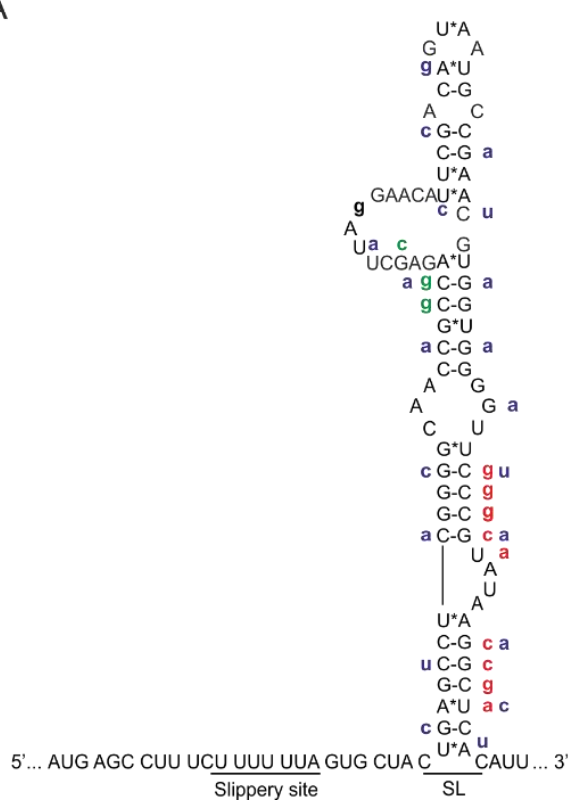

B

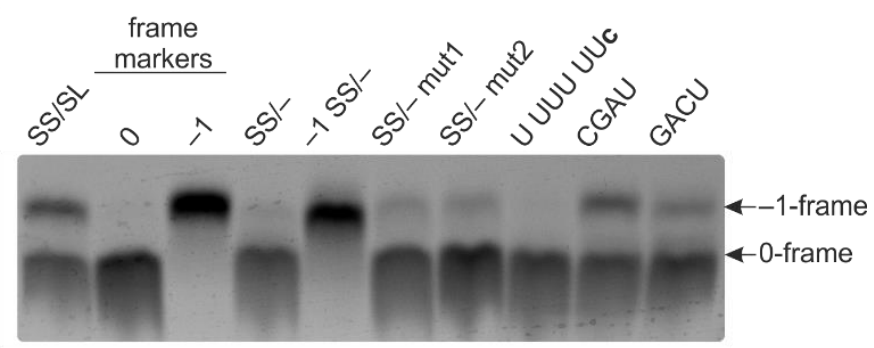

C



D

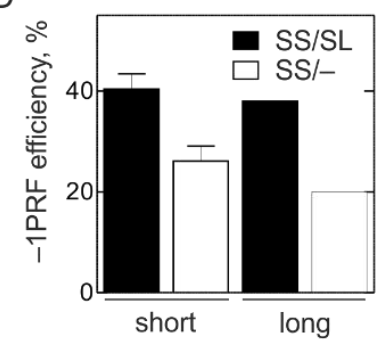

Figure 29. -1PRF in SFV determined with human total tRNA.

(A) Outline of the SFV frameshifting motif. Slippery site and stem-loop (SL) are indicated. Small nts on the sides of the SL correspond to mutations introduced into SS/- (purple), SS/- mut1 (red), SS/- mut2 (red and green combined).

(B) Examples of translation reactions with SFV mRNAs visualized with Tris-Tricine SDS-PAGE. mRNAs and frame markers are indicated. -1 -frame and 0 -frame products are marked with arrows.

(C) -1PRF efficiency determined from the protein band intensities in the gel with different SFV mRNA constructs.

(D) Comparison between -1 frameshifting efficiency measured with short (such as used for the peptide analysis by HPLC) and long mRNAs using individually purified tRNAs from E. coli. Translation was performed at 1:1 molar ratio of tRNA ${ }^{\mathrm{Leu(UUA})}$ to $70 \mathrm{~S}$. SS/SL and SS/- are in black and white, respectively.

Translation with long SS/SL mRNA containing both native frameshifting signals results in a frameshifting efficiency of about $40 \%$, which is consistent with the results obtained with E. coli tRNAs (Fig. 29). We note that the-1PRF efficiency reported in vivo in human cells is lower, about $15 \%$ (Chung et al., 2010). Mutations disturbing (SS/- mut1 and mut2 mRNAs) and removing (SS/-) the SL element have a dramatic effect on frameshifting, lowering its efficiency by 4 -fold to about $10 \%$ (Fig. 29B,C). On the contrary, with purified E. coli tRNAs, the SL showed only a moderate effect on frameshifting, which is reduced less than 2-fold when the SL is removed (Fig. 29D). To understand the effect of the SL, we first tested the translation efficiency of SS/- mRNA to exclude a potential effect of mutations. The high translational efficiency of -1-frame control of SS/- mRNA suggests that introduced mutations do not impair synthesis of -1-peptide (Fig. 29B,C; -1 SS/- mRNA). 
Next, we translated short SS/SL and SS/- mRNAs that we utilize to determine the frameshifting efficiency by HPLC and the respective long mRNAs using bacterial individual tRNAs. The -1PRF efficiency on long SS/SL mRNA remains unchanged (about 40\%), however, -1-slippage on the long SS/- mRNA increases to about 25\% (Fig. 29D), as was reported for short SFV mRNAs. This data suggests that the effect of the SL could be connected to the tRNA abundance and rates of translation. Because of the pronounced effect of the SL observed with human tRNA, we then translated the long analogues of CGAU and the GACU mRNAs under the same conditions. However, mutations of nts downstream of the SS do not influence-1PRF in vitro regardless of the translation conditions (Fig. 29B,C). Finally, mutating the second codon of the SS UUA into highly abundant UUC decreases $-1 \mathrm{PRF}$ in SFV to less than 5\% (Fig. 29B,C). All together this data might indicate that -1PRF

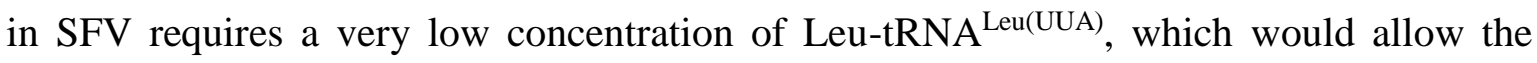
"hungry" FFS route to be prevalent. 


\subsection{Thermodynamic control of -1 programmed ribosomal frameshifting in dnaX}

Bock, L., Caliskan, N., Korniy, N., Peske, F., Rodnina, M.V. \& Grubmüller, H. (2019). Thermodynamic control of -1 programmed ribosomal frameshifting (submitted to Nat Commun).

As described in the Introduction, $-1 \mathrm{PRF}$ in E. coli dnaX gene is one of the best studied examples of backward slippage with a particularly high frameshifting efficiency of 50\%80\% (Caliskan et al., 2017; Chen et al., 2013; Tsuchihashi and Brown, 1992). The frameshifting motif consists of the $\mathrm{SS} \mathrm{A}_{1} \mathrm{AAA}_{4} \mathrm{AAG}_{7}$, a SL element and additionally a SDlike sequence upstream of the SS (Tsuchihashi and Brown, 1992). Typically, mutations of the SS nts alter frameshifting efficiency, however, many mutations which should abolish frameshifting because they interrupt the SS lead to surprisingly high-1PRF efficiencies. For example, $A_{1} G$ and $A_{4} G$ mutations, which should disfavour re-pairing in the -1 -frame, decrease the frameshifting efficiency to $20 \%$ and $46 \%$, respectively, instead of abolishing it completely, which would be expected based on their position (Tsuchihashi and Brown, 1992).

To understand what defines the shiftiness of frameshifting motifs and thereby the efficiency of -1PRF, we designed a set of dnaX mRNA constructs containing the native SDlike sequence and the SL, but with 64 different variants of the SS. All variants can be classified into four groups depending on the aa identity of the SS codons in the 0-frame: LysLys (wt), Phe-Phe, Lys-Phe and Phe-Lys (Fig. 30A). In addition, mutations were introduced in the first, fourth and seventh positions of the SS (Fig. 30A). To measure frameshifting on these mRNAs, we utilized the in vitro reconstituted translation system from E. coli and separated the 0- and -1-frame peptides by RP-HPLC as described before (Caliskan et al., 2017). The -1PRF efficiency for each mRNA construct was calculated as a ratio between -1 -frame peptide and the sum of -1 - and 0 -frame products, multiplied by $100 \%$. 

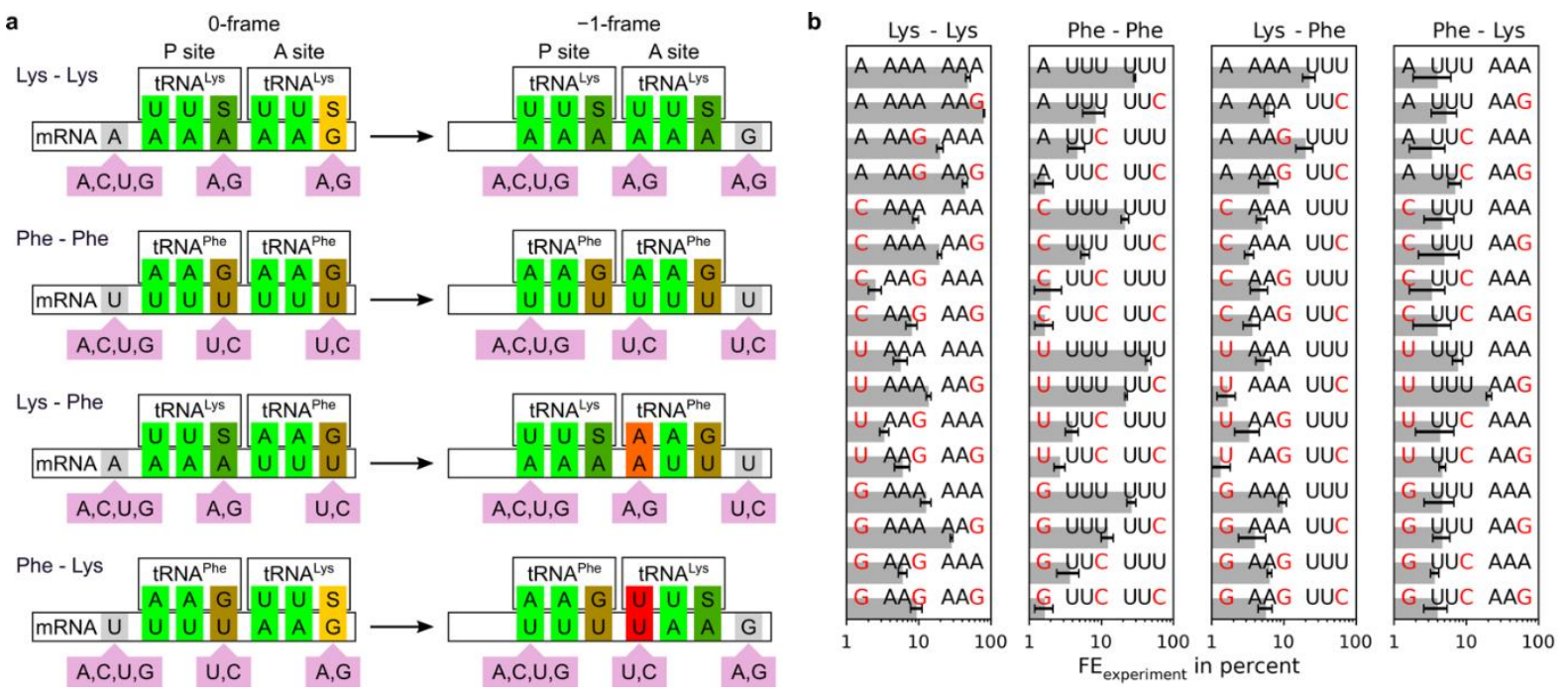

Figure 30. Variations of the E. coli dnaX SS and measured -1PRF efficiencies. Figure and figure legend are courtesy of Dr. Lars Bock.

(A) All possible mutations of the SS coding for the following tRNA pairs: Lys-Lys, Phe-Phe, LysPhe, and Phe-Lys. For each tRNA pair (upper row), the mRNA sequence (lower row) is shown for the 0 -frame (left) and the -1-frame (right) together with mutations (pink) that do not change the codon identity in the 0-frame. The resulting codon-anticodon interactions at the two SS codons are highlighted by different colors, with Watson-Crick (WC) interaction in light green, $\mathrm{G}-\mathrm{S}$ and $\mathrm{A}-\mathrm{S}$ pairs where $S$ denotes the modified $n t \mathrm{~mm}^{5} \mathrm{~s}^{2} \mathrm{U}$ in yellow and dark green, respectively, the $\mathrm{U}-\mathrm{G}$ wobble pair in brown, and A-A and U-U mismatch in different shades of red.

Table 27. $-1 \mathrm{PRF}$ efficiencies for the indicated dnaX slippery sequence variants

\begin{tabular}{|c|c|}
\hline Slippery site & -1 PRF efficiency \pm SD, $\%$ \\
\hline \multicolumn{2}{|c|}{ Lys-Lys } \\
\hline A AAA AAG & $80 \pm 1$ \\
\hline c AAA AAG & $19 \pm 1$ \\
\hline u AAA AAG & $14 \pm 1$ \\
\hline g AAA AAG & $29 \pm 1$ \\
\hline A AAg AAG & $43 \pm 3$ \\
\hline c AAg AAG & $8 \pm 1$ \\
\hline u AAg AAG & $6 \pm 1$ \\
\hline g AAg AAG & $9 \pm 2$ \\
\hline A AAA AAa & $48 \pm 4$ \\
\hline c AAA AAa & $9 \pm 0.6$ \\
\hline u AAA AAa & $6 \pm 1$ \\
\hline g AAA AAa & $13 \pm 2$ \\
\hline A AAg AAa & $20 \pm 2$ \\
\hline c AAg AAa & $3 \pm 0.5$ \\
\hline
\end{tabular}




\begin{tabular}{|c|c|}
\hline u AAg AAa & $4 \pm 0.4$ \\
\hline $\mathrm{g}$ AAg AAa & $6 \pm 1$ \\
\hline \multicolumn{2}{|c|}{ Phe-Phe } \\
\hline U UUU UUU & $45 \pm 4$ \\
\hline a UUU UUU & $29 \pm 1$ \\
\hline c UUU UUU & $21 \pm 2$ \\
\hline g UUU UUU & $26 \pm 4$ \\
\hline U UUc UUU & $4 \pm 1$ \\
\hline a UUc UUU & $4 \pm 1$ \\
\hline c UUc UUU & $2 \pm 1$ \\
\hline g UUc UUU & $4 \pm 1$ \\
\hline U UUU UUc & $22 \pm 0.6$ \\
\hline a UUU UUc & $8 \pm 3$ \\
\hline c UUU UUc & $6 \pm 1$ \\
\hline g UUU UUc & $12 \pm 2$ \\
\hline U UUc UUc & $3 \pm 0.4$ \\
\hline a UUc UUc & $2 \pm 0.4$ \\
\hline c UUc UUc & $2 \pm 0.5$ \\
\hline g UUc UUc & $2 \pm 0.4$ \\
\hline \multicolumn{2}{|c|}{ Lys-Phe } \\
\hline A AAA UUU & $23 \pm 5$ \\
\hline c AAA UUU & $5 \pm 1$ \\
\hline u AAA UUU & $5 \pm 1$ \\
\hline g AAA UUU & $10 \pm 1$ \\
\hline A AAg UUU & $20 \pm 5$ \\
\hline c AAg UUU & $5 \pm 1$ \\
\hline u AAg UUU & $3 \pm 1$ \\
\hline g AAg UUU & $6 \pm 0.4$ \\
\hline A AAA UUc & $6 \pm 1$ \\
\hline c AAA UUc & $3 \pm 0.6$ \\
\hline u AAA UUc & $2 \pm 0.5$ \\
\hline g AAA UUc & $4 \pm 2$ \\
\hline A AAg UUc & $6 \pm 2$ \\
\hline c AAg UUc & $4 \pm 1$ \\
\hline u AAg UUc & $1 \pm 0.5$ \\
\hline g AAg UUc & $6 \pm 1$ \\
\hline \multicolumn{2}{|c|}{ Phe-Lys } \\
\hline U UUU AAG & $21 \pm 2$ \\
\hline a UUU AAG & $5 \pm 2$ \\
\hline
\end{tabular}




\begin{tabular}{|l|l|}
\hline c UUU AAG & $5 \pm 3$ \\
\hline g UUU AAG & $5 \pm 1$ \\
\hline U UUc AAG & $5 \pm 0.5$ \\
\hline a UUc AAG & $7 \pm 2$ \\
\hline c UUc AAG & $4 \pm 2$ \\
\hline g UUc AAG & $4 \pm 1$ \\
\hline U UUU AAa & $7 \pm 1$ \\
\hline a UUU AAa & $4 \pm 2$ \\
\hline c UUU AAa & $4 \pm 2$ \\
\hline g UUU AAa & $5 \pm 2$ \\
\hline U UUc AAa & $4 \pm 2$ \\
\hline a UUc AAa & $3 \pm 2$ \\
\hline c UUc AAa & $4 \pm 2$ \\
\hline g UUc AAa & $4 \pm 0.8$ \\
\hline
\end{tabular}

Wt sequence of the SS is in bold, mutated nts are in small letters.

$-1 \mathrm{PRF}$ on the wt $\mathrm{SS} \mathrm{A}_{1} \mathrm{AAA}_{4} \mathrm{AAG}_{7}$ is about $80 \%$, whereas $\mathrm{A}_{1} \mathrm{G}$ and $\mathrm{A}_{4} \mathrm{G}$ mutations lower frameshifting to about $29 \%$ and $43 \%$, respectively (Fig. 30B; Table 27), confirming previously published data (Caliskan et al., 2017; Chen et al., 2013; Tsuchihashi and Brown, 1992). Several SS variants support efficient frameshifting, whereas others diminish frameshifting considerably (Fig. 30B; Table 27). Notably, the frameshifting efficiency was high not only with sequences where -1PRF results in canonical WC base pairs in the $1^{\text {st }}$ and $2^{\text {nd }}$ codon positions, but also with variants bearing mismatches in any position. Examples of such mismatches include C/U/G AAA AAA (19\%, 14\% and 29\%, respectively), A AAG AAA/G (20\% and 43\%, respectively), A/C/G UUU UUU (about 25\%), A AAG UUU (20\%) or U UUU AAG $(21 \%)$ sequences. Moreover, in some cases -1 -frame tRNAs have $1^{\text {st }}$ position mismatches on both slippery codons, such as with G/C AAG AAG or G AAG UUC sequences, and yet the frameshifting efficiency is not diminished completely but remains at 6-9\%. In addition, SS variants with identical codons in 0- and-1-frames, such as A AAA AAA or U UUU UUU, result in about 50\% -1PRF despite being "super-slippery". These findings suggest that $-1 \mathrm{PRF}$ relies on some characteristics of the complexes other than a simple complementarity. We note that the rate of translocation on the SS of dnaX is very low due to the presence of the mRNA secondary structure element (Caliskan et al., 2017), which leaves plenty of time for thermodynamic re-equilibration of tRNA binding in the two alternative frames.

Upon obtaining -1PRF efficiencies on all dnaX mRNA variants, we asked the questions whether the frameshifting efficiencies can be explained by the free-energy differences of 
tRNA interactions in 0 - and -1-frames, and - in the simplest model -whether these differences result from the free energies of the codon-anticodon base pairing. To answer this question, Dr. Lars Bock developed the free-energy model of -1PRF in dnaX (not presented here), which was then applied to our experimental data. We obtained the free energies of the base pairs in the 0 and -1 frame and show that the frameshifting efficiency of a given sequence can be reproduced and even predicted from the free energies of tRNA-mRNA base pairing in the two alternative frames. 


\section{Discussion}

\subsection{Frameshifting on the gag-pol mRNA of HIV-1}

\subsubsection{Routes to frameshifting on gag-pol HIV-1 mRNA}

In this study, we investigated the mechanism and modulation of -1PRF on gag-pol mRNA of HIV-1 using three in vitro reconstituted translation systems: homologous translation with $E$. coli components, heterologous bacterial system with native human tRNA and homologous mammalian translation system. The-1PRF efficiency differs depending on the type of a model system, a phenomenon which was noted before and attributed to different translation and degradation rates in vivo and in vitro and to differences between in vitro assays (Dinman et al., 1997; Kollmus et al., 1994; Parkin et al., 1992; Reil et al., 1993). Presumably, the presence of the bulk aa-tRNA also plays a role in defining the frameshifting efficiency (compare Figs. 15A \& 23A). However, regardless of the system used, we show that -1 PRF on HIV-1 mRNA operates in two regimes, one that is caused by a limitation of Leu-tRNA $^{\text {Leu(UUA) }}$ resulting in the FFR -1-frame product, and another where ribosomes slip during tRNA ${ }^{\text {Phe }}-\mathrm{tRNA}^{\mathrm{Leu}(\mathrm{UUA})}$ translocation over the SS codons yielding the FLR -1-frame product. The switch between the two regimes is modulated by the availability of Leu-

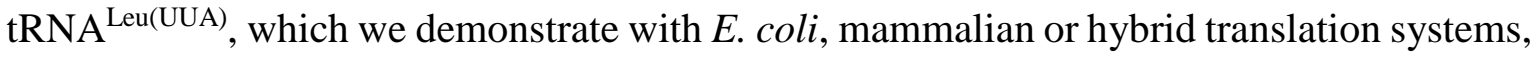
thereby minimizing the likelihood of potential translation system-dependent experimental artefacts and underscoring the notion that this frameshifting mechanism is universally conserved. We show that Leu-tRNA ${ }^{\mathrm{Leu}(\mathrm{UUA})}$ is rare in cell lines derived from human immune cells, which represent the natural reservoir for HIV-1 infection. This finding is supported by earlier in vivo experiments indicating that limitation of Leu in the culture medium leads to increased -1PRF in E. coli (Yelverton et al., 1994). The switch to "hungry" frameshifting is often caused by unfavorable conditions, e.g. aa starvation, as was described for "hungry" -1 frameshifting on E. coli dnaX mRNA (Caliskan et al., 2017; Gallant and Lindsley, 1993; Gallant and Lindsley, 1992, 1998). In contrast, HIV-1 can use both pathways constitutively due to the inherently low concentration of the key tRNA ${ }^{\text {Leu(UUA) }}$ isoacceptor in human cells.

Furthermore, we find that the ribosome on the HIV SS can slip into the $-1-,-2-$, or +1 -frames when some aa-tRNAs are lacking, but when all aa-tRNAs are supplied, the -1-product remains predominant. Translation of the E. coli dnaX mRNA can also lead to slippages into the -2-, +2-, or -4-frames when aa-tRNAs are in limiting supply (Caliskan et al., 2017; Yan et al., 2015). In the native gag-pol sequence, ribosomes shifting into the +1 - or -2-frame will soon encounter one of the multiple downstream stop codons, which 
lead to premature termination. Pre-termination prevents the formation of non-functional peptides, especially under conditions of aa-tRNA limitation. -1 frameshifting on many nonprogrammed tetra- and heptanucleotide slippery sites results in the production of truncated and non-functional peptides, because translation is typically terminated 5-10 codons after the frame is changed (Ketteler, 2012). However, in case of HIV-1, alternative slippages could still influence the ratio between Gag and Gag-Pol proteins and thus influence the overall-1PRF efficiency. Premature termination upon frameshifting can also result in the production of functional proteins. One example is E. coli gene copA encoding a copper ion transporter (Meydan et al., 2017). Here -1PRF causes pre-termination and formation of a truncated peptide $\operatorname{CopA}(\mathrm{Z})$, which turned out to be a copper chaperone protecting cells from excessive copper concentrations in the environment (Meydan et al., 2017). On the other hand, premature termination upon -1PRF in human CCR5 mRNA leads to mRNA degradation by the nonsense-mediated decay pathway, thus, regulating mRNA stability and gene expression (Belew et al., 2014).

\subsubsection{The role of the tRNA pool}

As the ratio of the Gag and Gag-Pol products is crucial for virus propagation (Biswas et al., 2004; Karacostas et al., 1993; Park and Morrow, 1991; Shehu-Xhilaga et al., 2001), HIV-1 must have evolved to achieve the desired -1PRF efficiency at the limited concentrations of tRNA ${ }^{\mathrm{Leu}(\mathrm{UUA})}$ prevalent in human cells. The UUA codon is rare in the human genome, as are all other A-ending codons. The respective cognate $\operatorname{RRNA}^{\mathrm{Leu}(\mathrm{UUA})}$ is significantly underrepresented in the tRNA pool as compared to tRNA ${ }^{\mathrm{Leu}(\mathrm{CUG})}$ reading the most abundant Leu codon CUG (Fig. 19 and (Wan Makhtar et al., 2017)). While in eukaryotes the tRNA expression is tissue-specific, the relative expression of tRNA isoacceptors in some tissues shows statistically significant correlation to the codon usage of tissue-specific genes (Dittmar et al., 2006). The low relative abundance of tRNA ${ }^{\text {Leu(UUA) }}$ in the lymphocyte-derived cell types may be a result of adaptation to the codon usage in these cells. On the other hand, the rare UUA codon accounts for $45 \%$ of all Leu codons in lateexpressing HIV-1 genes including gag and pol (Berkhout et al., 2002; Sharp et al., 1988; van Weringh et al., 2011). Thus the HIV-1 ORF may act as a sponge for tRNA ${ }^{\mathrm{Leu}(U U A)}$. The ratio between FLR and FFR routes is about $70 \%$ to $30 \%$, as reported with mammalian ribosomes (Jacks et al., 1988b) and 80\% to 20\%, as measured with E. coli 70 S (Cardno et al., 2015; Liao et al., 2011; Yelverton et al., 1994). If -1PRF occurred after Leu incorporation only, the low abundance and variations in the concentration of tRNA ${ }^{\text {Leu(UUA) }}$ could severely affect $-1 \mathrm{PRF}$ efficiency and thus impair virus propagation. Our data explain how HIV-1 might 
overcome this problem. When the concentration of tRNA ${ }^{\mathrm{Leu}(\mathrm{UUA})}$ decreases, the ribosome switches to the FFR route leading to robust -1 PRF at low tRNA ${ }^{\text {Leu(UUA) }}$ concentrations. In contrast, increasing the tRNA ${ }^{\mathrm{Leu}(\mathrm{UUA})}$ concentration above the 1:1 ratio to the ribosome leads to a significant reduction in the -1 PRF efficiency.

Our results suggest that tRNA ${ }^{\mathrm{Leu}(\mathrm{UUA})}$ enrichment in virus-infected human cells could become a new approach in antiviral therapy. Based on codon usage differences between retroviruses and the human host, multiple tRNA species were predicted, which are critical for retroviral protein synthesis but dispensable for human translation laying the foundation for the hypothetical tRNA Inhibition Therapy (TRIT) (Frias et al., 2013). Inactivation of these tRNAs should drastically reduce the elongation rate of viral protein synthesis leaving the host translation unaffected. One of the best targets of TRIT, which could be exploited in HIV-1 and other retroviruses (HIV-2, HTLV-1 and 2), is tRNA ${ }^{\text {Leu }}$ with the anticodon UAG reading the CUA codon of the mRNA (Frias et al., 2013). While TRIT remains hypothetical, a similar approach to exploit the codon usage disparity was already utilized to inhibit synthesis of HIV-1 proteins by translating the schlafen gene (SLFN11) (Li et al., 2012). Because SLFN11 mRNA has a codon usage similar to that of the late genes of HIV-1, its translation acts as a tRNA sponge and thus makes the cellular tRNA pool suboptimal for the translation of HIV-1 mRNAs (Li et al., 2012).

Given the low level of tRNA ${ }^{\mathrm{Leu}(\mathrm{UUA})}$ in human T-lymphocytes, the question remains how HIV-1 can satisfy its high demand for this tRNA to achieve an efficient translation of its late genes gag and pol. It is known that HIV-1 can package some cellular tRNAs, among them $\mathrm{tRNA}^{\mathrm{Lys}}$, tRNA ${ }^{\mathrm{Ile}}$ and to a lesser extent $\mathrm{tRNA}^{\mathrm{Leu(UUA})}$, during virion assembly (PavonEternod et al., 2010). Because tRNA packaging happens passively governed by the concentration gradient, these tRNAs must be present in the cell at significant concentrations. There are multiple indirect indications that HIV-1 itself can affect the tRNA pools by yet unknown mechanisms (van Weringh et al., 2011) and that HIV infection can change the cellular localization of individual aa-tRNA synthetases from the multi-aa-tRNA synthetase complex (Duchon et al., 2017), which may affect aminoacylation efficiencies. Other viruses whose genomes have a codon usage different from their host indeed alter the free tRNA pools by changing polysome-associated tRNA levels (vaccinia and influenza A) or by tRNA misacylation (influenza A and adenovirus) (Netzer et al., 2009; Pavon-Eternod et al., 2013), but the exact mechanism of HIV-1 action remains unknown. 


\subsubsection{The second slippery site}

Anti-HIV therapy with protease inhibitors leads to accumulation of mutations in the HIV-1 protease that impair the recognition of its specific cleavage sites. Secondary mutations also arise at the pSS2, which harbors the p1/p6 cleavage site of Gag polyprotein (Bally et al., 2000; Banke et al., 2009; de Oliveira et al., 2003; Larrouy et al., 2011; Pettit et al., 2002) that allow polyprotein maturation by the mutated protease. The $\mathrm{C}_{5} \mathrm{U}$ mutation in pSS2 substitutes Leu with Phe, which enhances van der Waals interactions between the substrate and the mutant protease, thereby increasing the protease activity by about 10 -fold (Ozen et al., 2014). The same mutation produces a $\mathrm{U}_{1} \mathrm{UUU}_{4} \mathrm{UUU}_{7} \mathrm{pSS} 2$, which can also support-1PRF, but the role of pSS2 depends on the sequence of SS1. With native SS1, the joint activity of SS1 and pSS2 is not different from SS1 alone. However, when SS1 is mutated to a non-shifty sequence, the $\mathrm{C}_{5} \mathrm{U}$ mutation in the pSS2 supports a level of -1PRF that may be sufficient for virus propagation. The finding that pSS2 can alleviate the detrimental effects of SS1 mutations is consistent with previous in vitro and in vivo reports (Brierley and Dos Ramos, 2006; Doyon et al., 1998; Garcia-Miranda et al., 2016; Girnary et al., 2007; Knops et al., 2012). Interestingly, during antiviral therapy, drug-resistant herpes simplex viruses also develop an unusual SS which supports both -1 and $+1 \mathrm{PRF}$ at levels sufficient for virus replication and pathogenicity despite the treatment (Griffiths, 2011; Pan and Coen, 2012). Similarly, the $\mathrm{C}_{5} \mathrm{U}$ mutation in the pSS2 of gag-pol HIV-1 mRNA does not only modulate the frameshifting efficiency, but also improves the activity of the mutant proteases that emerge upon protease inhibitor treatment. This suggests a mechanism for HIV-1 rescue to maintain its life cycle despite the damage caused by the therapy. Thus, HIV1 can constitutively use different frameshifting regimes and might have contingency mechanisms to ensure a low but crucial level of frameshifting required for its proliferation.

\subsubsection{The contribution of an mRNA enhancer sequence}

Several reports suggest a crucial contribution of SL1 for frameshifting in HIV-1 (Bidou et al., 1997; Cassan et al., 1994; Garcia-Miranda et al., 2016; Kollmus et al., 1994; Parkin et al., 1992). However, most constructs used to study the effect of the SL1 are truncated either immediately after the SS1 or after the next codon GGG leaving open the question about the role of nt 3' adjacent to SS1. The efficiency of -1PRF measured on such a short construct is indeed severely decreased as compared to the full-length SL1 (see Fig. 26A, black and red bars). However, by doing sequential mutation analysis, we show that this effect is independent of SL1 and can be attributed to specific nucleotide sequence within the HIV-1 
mRNA, which we call an enhancer. We identified that this enhancer is located within the first 4-12 nt after SS1 and that 4-7 nt are the most critical to maintain the -1PRF efficiency. We also hypothesize that the enhancer sequence includes the GGG codon after the SS1, because it was previously shown to be critical for -1PRF in HIV-1 in vivo in human cells (Mathew et al., 2015). As described in the Introduction (see 1.2.1.4), enhancer sequences act as modulators of both +1 and $-1 P R F$, and their presumed mechanism of action is via specific interactions with certain parts of the rRNA which lead to ribosome pausing and thereby promote frameshifting, similar to the mRNA secondary structures (Guarraia et al., 2007). Structural studies and profiling data indicated that the translating ribosome covers about $28 \mathrm{nt}$ of the mRNA sequence (about $13 \mathrm{nt}$ starting from the P-site codon) (Ingolia et al., 2009; Qu et al., 2011), suggesting that the nts within the enhancer in HIV-1 might indeed interact with the ribosome and thus stimulate -1PRF. We also note that despite the high mutation rate of HIV-1, the first $12 \mathrm{nt}$ after the SS1 show a high degree of conservation among different viral subtypes with the first 5 nt being invariable (Fig. 31, nt 8-19 (Baril et al., 2003a)), further supporting the importance of the enhancer sequence.

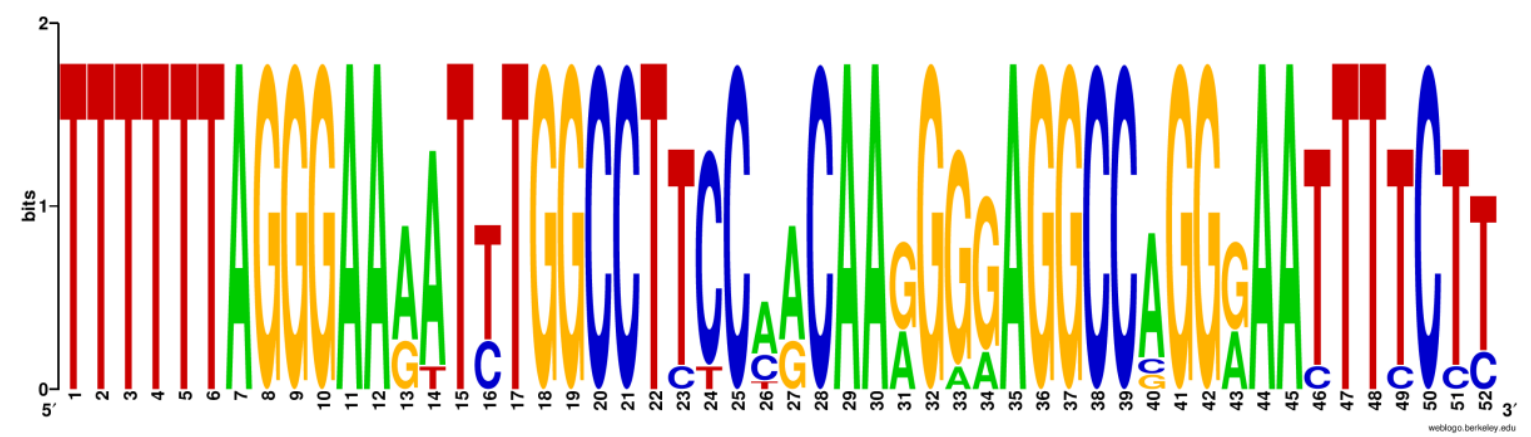

Figure 31. Comparison of frameshifting sites encompassing the SS1 (nt 1-7), the SL1 (nt 8-52) and the pSS2 (nt 46-52) derived from different HIV-1 subtypes of group M (subtypes A, B, C, D, E, F, $\mathrm{J}, \mathrm{K}(\mathrm{a})$ and $\mathrm{K}(\mathrm{b}))$. T is in red, $\mathrm{A}$ is in green, $\mathrm{G}$ is in yellow and $\mathrm{C}$ is in blue. Nts corresponding to the potential enhancer sequence are found at positions 8-19 (1-12 nt after SS1). DNA sequences of different viral subtypes were taken from (Baril et al., 2003a). Sequence logo was generated by https://weblogo.berkeley.edu.

We also show that only the FLR route is modulated by the presence of the downstream enhancer while the FFR pathway is independent of cis-acting stimulators and relies only on the availability of Leu-tRNA ${ }^{\mathrm{Leu}(\mathrm{UUA})}$. These results are in a good agreement with dnaX studies indicating that only frameshifting during translocation requires the SL while the "hungry" pathway operates regardless of the mRNA secondary structure (Caliskan et al., 2017). 
Interestingly, two alphaviruses, SFV and MIDV, which share the same SS sequence with HIV-1, also seem to comprise potential enhancers (Chung et al., 2010; Firth et al., 2008). MIDV is predicted to have a pseudoknot $6 \mathrm{nt}$ downstream of its SS (Fig. 32). Mutations and deletions within the pseudoknot decrease the frameshifting efficiency by about $50 \%$ while changes in the 6-nt spacer are detrimental for frameshifting lowering it to background level (Chung et al., 2010). This observation suggests that the spacer itself might act as an enhancer with the pseudoknot having only a modulatory function. SFV will be discussed in the next section.

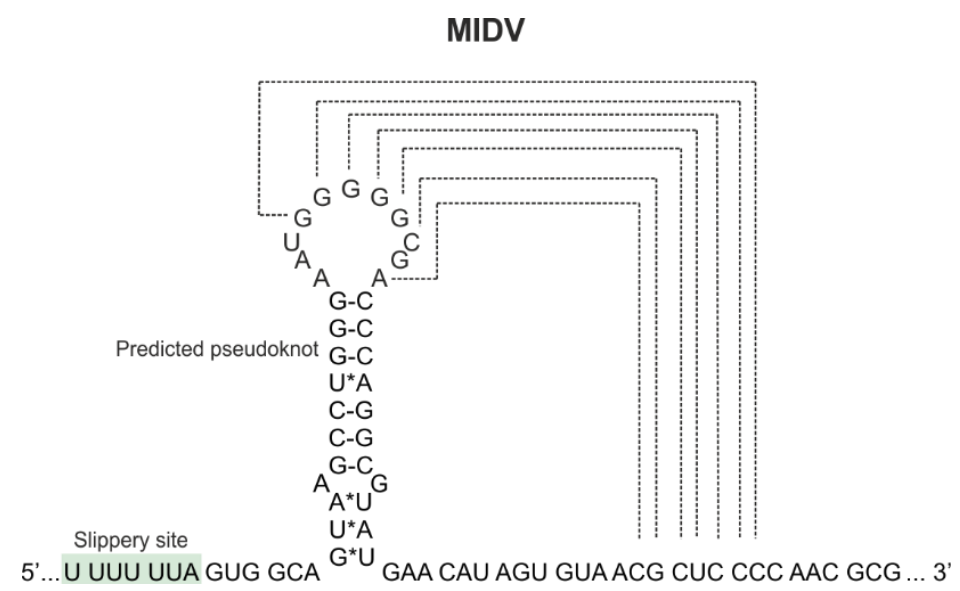

Figure 32. Frameshifting motif of MIDV (Chung et al., 2010). The slippery site is highlighted light green.

\subsection{Frameshifting on 6K mRNA of SFV}

Because HIV-1 and alphaviruses share the same SS, we hypothesized that the mechanism of -1PRF might be also conserved. Here we show that -1PRF in $6 \mathrm{~K}$ mRNA of SFV indeed follows the same frameshifting pathways as in HIV-1. The FLS route (analogue of FLR in HIV-1) takes place under saturating translation conditions and represents typical dual-slippage -1PRF during the late stage of translocation. In turn, the FFS peptide (which is analogous to FFR in HIV-1) is a product of a single P-site tRNA slippage in the presence of an empty A site due to the limited supply of aa-tRNAs. Thus mounting evidence suggests that the two frameshifting regimes - one at the late steps of translocation and another when the ribosome is waiting for a rare aa-tRNA to enter the A site - account for the majority of the reported-1PRF examples. Also, similarly to HIV-1, Leu-tRNA ${ }^{\text {Leu(UUA) }}$ acts as the main modulator of -1PRF in SFV and defines the ratio between FLS and FFS proteins. 
Frameshifting motifs of most alphaviruses harbour mRNA secondary structures, either SL or pseudoknots. SFV was predicted to comprise a SL, which was not experimentally verified (Chung et al., 2010). Here, using a chemical probing approach, we identify the presence of an extended SL $6 \mathrm{nt}$ after the SS. The SL spans over $79 \mathrm{nt}$ and consists of two stems separated by unstructured bulges and loops (see Fig. 27). It is very similar in size and composition to the SL of the Sindbis virus (SINV), and the frameshifting efficiencies measured with SINV and SFV are also in the same range (10\% and 15\%, respectively) (Chung et al., 2010). However, the contribution of the SL to-1PRF in SFV remains unclear. Chung and co-authors suggest that the secondary structure is dispensable and only the first 18-20 nt after the SS are critical for frameshifting. Unexpectedly, we show that the SL has a strong modulatory effect on frameshifting when the amount of Leu-tRNA ${ }^{\text {Leu(UUA) }}$ is limiting ( $\leq 1$ molecule per ribosome). However, under saturating conditions with Leu-tRNA ${ }^{\text {Leu(UUA) }}$ the contribution of the SL is negligible. This observation holds true in both homologous and heterologous (with HeLa tRNA) in vitro translation systems, however, in the presence of HeLa tRNA the effect of the SL is more dramatic (compare Figs. 29C \& D). This finding could be explained by the difference in translation rates between the two systems: slower translation could leads to a pause during which the ribosome slips into the-1-frame, making the SL dispensable. Interestingly, the replacements of the UUA codon to UUC in the SS1 of HIV-1 decreases the -1PRF efficiency by about 30\% (see Fig. 23C), whereas in SFV it abolishes frameshifting (see Fig. 29). This observation suggests that the rare Leu codon UUA and thus the tRNA ${ }^{\text {Leu(UUA) }}$ limitation might be of critical importance for -1PRF and that "hungry" FFS route might be dominant in SFV. Previously, the frameshifting efficiency in SFV was measured in 293T cells (Chung et al., 2010), in which the abundance of tRNA $^{\text {Leu(UUA) }}$ is high, i.e. its concentration is only 3 -fold lower that of tRNA ${ }^{\mathrm{Leu}(\mathrm{CUG})}$ (see Fig. 19). However, the natural reservoirs for SFV infection are neuronal cells (neurons and oligodendrocytes) and spinocerebral liquid (Fragkoudis et al., 2009), in which the level of tRNA $^{\text {Leu(UUA) }}$ remains to be determined. Thus, the published in vivo data on the effect of the SL on -1PRF in SFV could be biased due to the choice of the cell line, where the high abundance of tRNA ${ }^{\text {Leu(UUA) }}$ suppresses the FFS route. One other example of "hungry" frameshifting stimulated by an mRNA secondary structure was described for the bacterial $\mathrm{SS} \mathrm{U}_{1} \mathrm{UUC}_{4} \mathrm{AUA}_{7}$. Placing the SL from the MMTV gag-pol frameshifting site after this SS greatly increases the -1 PRF efficiency, but only under starvation conditions when tRNA $^{\text {Ile(AUA) }}$ is in a limited supply (Atkinson et al., 1997). 
As described before, the first 18-20 nt after the SS in SFV were shown to be critical for -1 PRF in SFV measured in human cells (Chung et al., 2010). Our mutation analysis performed in vitro shows that this sequence on its own does not play a significant role in frameshifting and does not function as a cis-acting enhancer like in HIV-1. Chung and co-authors hypothesized that either a protein or a miRNA could bind within the 18-20 nt downstream of the SS, thereby promoting frameshifting. This suggestion remains to be tested and the exact contribution of the 18-20 nt sequence following the SS in SFV is to be determined in the future.

\subsection{Conclusions}

In the present work, we compare frameshifting mechanisms in HIV-1 and in several other viruses and show that the mechanism of viral frameshifting is similar on prokaryotic (bacteria) and eukaryotic (mammals) ribosomes, highlighting the evolutionary significance of this process and suggesting that it relies on highly conserved components of the translation machinery. We indicate that most of the described cases of -1PRF follow two alternative frameshifting routes, dual-slippage during translocation under saturating translation conditions and single-slippage caused by aa-tRNA limitation and prolonged translation pause. We find that the availability of specific tRNAs could determine-1PRF efficiency and define the frameshifting pathways. We also provide evidence that the basal level of -1PRF could be stimulated by the SS alone, however, either an mRNA secondary structure or a specific enhancer sequence downstream of the SS is required to provide an additional layer of frameshifting modulation. This research expands our knowledge of frameshifting in human-pathogenic viruses and contributes to the understanding of virus-host interactions at the level of tRNA profiles and translation. 


\section{References}

1. Ablashi, D.V., Berneman, Z.N., Kramarsky, B., Whitman, J., Jr., Asano, Y., and Pearson, G.R. (1995). Human herpesvirus-7 (HHV-7): current status. Clin Diagn Virol 4, 1-13.

2. Adio, S., Sharma, H., Senyushkina, T., Karki, P., Maracci, C., Wohlgemuth, I., Holtkamp, W., Peske, F., and Rodnina, M.V. (2018). Dynamics of ribosomes and release factors during translation termination in E. coli. eLife 7.

3. Agirrezabala, X., Samatova, E., Klimova, M., Zamora, M., Gil-Carton, D., Rodnina, M.V., and Valle, M. (2017). Ribosome rearrangements at the onset of translational bypassing. Sci Adv 3, e1700147.

4. Ahn, D.G., Lee, W., Choi, J.K., Kim, S.J., Plant, E.P., Almazan, F., Taylor, D.R., Enjuanes, L., and Oh, J.W. (2011). Interference of ribosomal frameshifting by antisense peptide nucleic acids suppresses SARS coronavirus replication. Antiviral Res 91, 1-10.

5. Atkins, J., and Gesteland, R.F. (2010). Recoding: expansion of decoding rules enriches gene expression (Springer).

6. Atkins, J.F., Loughran, G., Bhatt, P.R., Firth, A.E., and Baranov, P.V. (2016). Ribosomal frameshifting and transcriptional slippage: From genetic steganography and cryptography to adventitious use. Nucleic Acids Res 44, 7007-7078.

7. Atkinson, J., Dodge, M., and Gallant, J. (1997). Secondary structures and starvationinduced frameshifting. Mol Microbiol 26, 747-753.

8. Bally, F., Martinez, R., Peters, S., Sudre, P., and Telenti, A. (2000). Polymorphism of HIV type 1 gag $\mathrm{p} 7 / \mathrm{p} 1$ and p1/p6 cleavage sites: clinical significance and implications for resistance to protease inhibitors. AIDS Res Hum Retroviruses 16, 1209-1213.

9. Banke, S., Lillemark, M.R., Gerstoft, J., Obel, N., and Jorgensen, L.B. (2009). Positive selection pressure introduces secondary mutations at Gag cleavage sites in human immunodeficiency virus type 1 harboring major protease resistance mutations. J Virol 83, 8916-8924.

10. Baranov, P.V., Gesteland, R.F., and Atkins, J.F. (2002). Recoding: translational bifurcations in gene expression. Gene 286, 187-201.

11. Baril, M., Dulude, D., Gendron, K., Lemay, G., and Brakier-Gingras, L. (2003a). Efficiency of a programmed -1 ribosomal frameshift in the different subtypes of the 
human immunodeficiency virus type 1 group M. RNA (New York, NY) 9, 12461253.

12. Baril, M., Dulude, D., Steinberg, S.V., and Brakier-Gingras, L. (2003b). The frameshift stimulatory signal of human immunodeficiency virus type 1 group $\mathrm{O}$ is a pseudoknot. J Mol Biol 331, 571-583.

13. Barry, J.K., and Miller, W.A. (2002). A -1 ribosomal frameshift element that requires base pairing across four kilobases suggests a mechanism of regulating ribosome and replicase traffic on a viral RNA. Proc Natl Acad Sci U S A 99, 11133-11138.

14. Bednarova, A., Hanna, M., Durham, I., VanCleave, T., England, A., Chaudhuri, A., and Krishnan, N. (2017). Lost in translation: defects in transfer RNA modifications and neurological disorders. Front Mol Neurosci 10, 135.

15. Belardinelli, R., Sharma, H., Caliskan, N., Cunha, C.E., Peske, F., Wintermeyer, W., and Rodnina, M.V. (2016). Choreography of molecular movements during ribosome progression along mRNA. Nat Struct Mol Biol 23, 342-348.

16. Belcourt, M.F., and Farabaugh, P.J. (1990). Ribosomal frameshifting in the yeast retrotransposon Ty: tRNAs induce slippage on a 7 nucleotide minimal site. Cell 62 , 339-352.

17. Belew, A.T., Meskauskas, A., Musalgaonkar, S., Advani, V.M., Sulima, S.O., Kasprzak, W.K., Shapiro, B.A., and Dinman, J.D. (2014). Ribosomal frameshifting in the CCR5 mRNA is regulated by miRNAs and the NMD pathway. Nature 512, 265-269.

18. Berkhout, B., Grigoriev, A., Bakker, M., and Lukashov, V.V. (2002). Codon and amino acid usage in retroviral genomes is consistent with virus-specific nucleotide pressure. AIDS Res Hum Retroviruses 18, 133-141.

19. Bidou, L., Stahl, G., Grima, B., Liu, H., Cassan, M., and Rousset, J.P. (1997). In vivo HIV-1 frameshifting efficiency is directly related to the stability of the stem-loop stimulatory signal. RNA (New York, NY) 3, 1153-1158.

20. Bieri, P., Greber, B.J., and Ban, N. (2018). High-resolution structures of mitochondrial ribosomes and their functional implications. Curr Opin Struct Biol 49, 44-53.

21. Biswas, P., Jiang, X., Pacchia, A., Dougherty, J., and Peltz, S. (2004). The human immunodeficiency virus type 1 ribosomal frameshifting site is an invariant sequence determinant and an important target for antiviral therapy. J Virol 78, 2082-2089.

22. Bjork, G.R. (1995). Genetic dissection of synthesis and function of modified nucleosides in bacterial transfer RNA. Prog Nucleic Acid Res Mol Biol 50, 263-338. 
23. Blinkowa, A.L., and Walker, J.R. (1990). Programmed ribosomal frameshifting generates the Escherichia coli DNA polymerase III gamma subunit from within the tau subunit reading frame. Nucleic Acids Res 18, 1725-1729.

24. Bohnsack, M.T., and Sloan, K.E. (2018). The mitochondrial epitranscriptome: the roles of RNA modifications in mitochondrial translation and human disease. Cell Mol Life Sci 75, 241-260.

25. Brakier-Gingras, L., Charbonneau, J., and Butcher, S.E. (2012). Targeting frameshifting in the human immunodeficiency virus. Expert Opin Ther Targets 16, 249-258.

26. Breitschopf, K., Achsel, T., Busch, K., and Gross, H.J. (1995). Identity elements of human tRNA(Leu): structural requirements for converting human tRNA(Ser) into a leucine acceptor in vitro. Nucleic Acids Res 23, 3633-3637.

27. Brierley, I. (1995). Ribosomal frameshifting viral RNAs. J Gen Virol 76 ( Pt 8), 1885-1892.

28. Brierley, I., and Dos Ramos, F.J. (2006). Programmed ribosomal frameshifting in HIV-1 and the SARS-CoV. Virus Res 119, 29-42.

29. Brunelle, M., Payant, C., Lemay, G., and Brakier-Gingras, L. (1999). Expression of the human immunodeficiency virus frameshift signal in a bacterial cell-free system: influence of an interaction between the ribosome and a stem-loop structure downstream from the slippery site. Nucleic Acids Res 27, 4783-4874.

30. Buhr, F., Jha, S., Thommen, M., Mittelstaet, J., Kutz, F., Schwalbe, H., Rodnina, M.V., and Komar, A.A. (2016). Synonymous codons direct cotranslational folding toward different protein conformations. Mol Cell 61, 341-351.

31. Bulmer, M. (1987). Coevolution of codon usage and transfer RNA abundance. Nature 325, 728-730.

32. Caliskan, N., Katunin, V.I., Belardinelli, R., Peske, F., and Rodnina, M.V. (2014). Programmed -1 frameshifting by kinetic partitioning during impeded translocation. Cell 157, 1619-1631.

33. Caliskan, N., Peske, F., and Rodnina, M.V. (2015). Changed in translation: mRNA recoding by -1 programmed ribosomal frameshifting. Trends Biochem Sci 40, 265274.

34. Caliskan, N., Wohlgemuth, I., Korniy, N., Pearson, M., Peske, F., and Rodnina, M.V. (2017). Conditional switch between frameshifting regimes upon translation of dnaX mRNA. Mol Cell 66, 558-567 e554. 
35. Cardno, T.S., Shimaki, Y., Sleebs, B.E., Lackovic, K., Parisot, J.P., Moss, R.M., Crowe-McAuliffe, C., Mathew, S.F., Edgar, C.D., Kleffmann, T., et al. (2015). HIV-1 and human PEG10 frameshift elements are functionally distinct and distinguished by novel small molecule modulators. PLoS One 10, e0139036.

36. Cassan, M., Delaunay, N., Vaquero, C., and Rousset, J.P. (1994). Translational frameshifting at the gag-pol junction of human immunodeficiency virus type 1 is not increased in infected T-lymphoid cells. J Virol 68, 1501-1508.

37. Chang, S.Y., Sutthent, R., Auewarakul, P., Apichartpiyakul, C., Essex, M., and Lee, T.H. (1999). Differential stability of the mRNA secondary structures in the frameshift site of various HIV type 1 viruses. AIDS Res Hum Retroviruses 15, 15911596.

38. Chen, C., Zhang, H., Broitman, S.L., Reiche, M., Farrell, I., Cooperman, B.S., and Goldman, Y.E. (2013). Dynamics of translation by single ribosomes through mRNA secondary structures. Nat Struct Mol Biol 20, 582-588.

39. Chen, J., Coakley, A., O'Connor, M., Petrov, A., O'Leary, S.E., Atkins, J.F., and Puglisi, J.D. (2015). Coupling of mRNA structure rearrangement to ribosome movement during bypassing of non-coding regions. Cell 163, 1267-1280.

40. Chen, J., Petrov, A., Johansson, M., Tsai, A., O'Leary, S.E., and Puglisi, J.D. (2014). Dynamic pathways of - 1 translational frameshifting. Nature 512, 328-332.

41. Chung, B.Y., Firth, A.E., and Atkins, J.F. (2010). Frameshifting in alphaviruses: a diversity of 3' stimulatory structures. J Mol Biol 397, 448-456.

42. Clare, J.J., Belcourt, M., and Farabaugh, P.J. (1988). Efficient translational frameshifting occurs within a conserved sequence of the overlap between the two genes of a yeast Ty1 transposon. Proc Natl Acad Sci U S A 85, 6816-6820.

43. Clark, M.B., Janicke, M., Gottesbuhren, U., Kleffmann, T., Legge, M., Poole, E.S., and Tate, W.P. (2007). Mammalian gene PEG10 expresses two reading frames by high efficiency -1 frameshifting in embryonic-associated tissues. J Biol Chem 282, 37359-37369.

44. Cobucci-Ponzano, B., Conte, F., Benelli, D., Londei, P., Flagiello, A., Monti, M., Pucci, P., Rossi, M., and Moracci, M. (2006). The gene of an archaeal alpha-Lfucosidase is expressed by translational frameshifting. Nucleic Acids Res 34, 42584268.

45. Cobucci-Ponzano, B., Rossi, M., and Moracci, M. (2012). Translational recoding in archaea. Extremophiles : life under extreme conditions 16, 793-803. 
46. Craigen, W.J., and Caskey, C.T. (1986). Expression of peptide chain release factor 2 requires high-efficiency frameshift. Nature 322, 273-275.

47. Cullen, B.R. (1991). Regulation of HIV-1 gene expression. Faseb J 5, 2361-2368.

48. Cunha, C.E., Belardinelli, R., Peske, F., Holtkamp, W., Wintermeyer, W., and Rodnina, M.V. (2013). Dual use of GTP hydrolysis by elongation factor G on the ribosome. Translation 1 , e24315.

49. Curran, J.F., and Yarus, M. (1988). Use of tRNA suppressors to probe regulation of Escherichia coli release factor 2. J Mol Biol 203, 75-83.

50. Danilevskaya, O., Slot, F., Pavlova, M., and Pardue, M.L. (1994). Structure of the Drosophila HeT-A transposon: a retrotransposon-like element forming telomeres. Chromosoma 103, 215-224.

51. de Oliveira, T., Engelbrecht, S., Janse van Rensburg, E., Gordon, M., Bishop, K., zur Megede, J., Barnett, S.W., and Cassol, S. (2003). Variability at human immunodeficiency virus type 1 subtype $\mathrm{C}$ protease cleavage sites: an indication of viral fitness? J Virol 77, 9422-9430.

52. Dever, T.E., and Green, R. (2012). The elongation, termination, and recycling phases of translation in eukaryotes. Cold Spring Harb Perspect Biol 4, a013706.

53. Dinman, J. (2012). Mechanisms and implications of programmed translational frameshifting. Wiley interdisciplinary reviews RNA 3, 661-673.

54. Dinman, J.D. (2006). Programmed ribosomal frameshifting goes beyond viruses: organisms from all three kingdoms use frameshifting to regulate gene expression, perhaps signaling a paradigm shift. Microbe Wash DC 1, 521-527.

55. Dinman, J.D., Richter, S., Plant, E.P., Taylor, R.C., Hammell, A.B., and Rana, T.M. (2002). The frameshift signal of HIV-1 involves a potential intramolecular triplex RNA structure. Proc Natl Acad Sci U S A 99, 5331-5336.

56. Dinman, J.D., Ruiz-Echevarria, M.J., Czaplinski, K., and Peltz, S.W. (1997). Peptidyl-transferase inhibitors have antiviral properties by altering programmed -1 ribosomal frameshifting efficiencies: development of model systems. Proc Natl Acad Sci U S A 94, 6606-6611.

57. Dittmar, K.A., Goodenbour, J.M., and Pan, T. (2006). Tissue-specific differences in human transfer RNA expression. PLoS Genet 2, e221.

58. Doerfel, L.K., Wohlgemuth, I., Kothe, C., Peske, F., Urlaub, H., and Rodnina, M.V. (2013). EF-P is essential for rapid synthesis of proteins containing consecutive proline residues. Science 339, 85-88. 
59. Dong, H., Nilsson, L., and Kurland, C.G. (1996). Co-variation of tRNA abundance and codon usage in Escherichia coli at different growth rates. J Mol Biol 260, 649663.

60. Donly, B.C., Edgar, C.D., Williams, J.M., and Tate, W.P. (1990). Tightly controlled expression systems for the production and purification of Escherichia coli release factor 1. Biochem Int 20, 437-443.

61. Doyon, L., Payant, C., Brakier-Gingras, L., and Lamarre, D. (1998). Novel Gag-Pol frameshift site in human immunodeficiency virus type 1 variants resistant to protease inhibitors. J Virol 72, 6146-6150.

62. Drummond, D.A., and Wilke, C.O. (2009). The evolutionary consequences of erroneous protein synthesis. Nat Rev Genet 10, 715-724.

63. Duchon, A.A., St Gelais, C., Titkemeier, N., Hatterschide, J., Wu, L., and MusierForsyth, K. (2017). HIV-1 exploits a dynamic multi-aminoacyl-tRNA synthetase complex to enhance viral replication. J Virol 91.

64. Dulude, D., Baril, M., and Brakier-Gingras, L. (2002). Characterization of the frameshift stimulatory signal controlling a programmed -1 ribosomal frameshift in the human immunodeficiency virus type 1. Nucleic Acids Res 30, 5094-5102.

65. Endoh, T., and Sugimoto, N. (2013). Unusual -1 ribosomal frameshift caused by stable RNA G-quadruplex in open reading frame. Anal Chem 85, 11435-11439.

66. Engelberg-Kulka, H., and Schoulaker-Schwarz, R. (1988). Stop is not the end: physiological implications of translational readthrough. J Theor Biol 131, 477-485.

67. Fang, Y., Treffers, E.E., Li, Y., Tas, A., Sun, Z., van der Meer, Y., de Ru, A.H., van Veelen, P.A., Atkins, J.F., Snijder, E.J., et al. (2012). Efficient -2 frameshifting by mammalian ribosomes to synthesize an additional arterivirus protein. Proc Natl Acad Sci U S A 109, E2920-E2928.

68. Farabaugh, P.J. (1996). Programmed translational frameshifting. Microbiol Rev 60, 103-134.

69. Farabaugh, P.J. (1997). Programmed alternative reading of teh genetic code. In (Austin, Texas, USA, Heidelberg, Germany: RG Landes Company, SpringerVerlag), pp. 69-101.

70. Farabaugh, P.J. (2000). Translational frameshifting: implications for the mechanism of translational frame maintenance. Prog Nucleic Acid Res Mol Biol 64, 131-170.

71. Farabaugh, P.J., Zhao, H., and Vimaladithan, A. (1993). A novel programed frameshift expresses the POL3 gene of retrotransposon Ty3 of yeast: frameshifting without tRNA slippage. Cell 74, 93-103. 
72. Fayet, O., and Prère, M.-F. (2010). Programmed ribosomal -1 frameshifting as a tradition: the bacterial transposable elements of the IS3 family. In Recoding: Expansion of Decoding Rules Enriches Gene Expression, J.F. Atkins, and R.F. Gesteland, eds. (Springer New York), pp. 259-280.

73. Fersht, A.R. (1977). Editing mechanisms in protein synthesis. Rejection of valine by the isoleucyl-tRNA synthetase. Biochemistry 16, 1025-1030.

74. Firth, A.E., Chung, B.Y., Fleeton, M.N., and Atkins, J.F. (2008). Discovery of frameshifting in Alphavirus 6K resolves a 20-year enigma. Virol J 5, 108.

75. Fischer, N., Neumann, P., Bock, L.V., Maracci, C., Wang, Z., Paleskava, A., Konevega, A.L., Schroder, G.F., Grubmuller, H., Ficner, R., et al. (2016). The pathway to GTPase activation of elongation factor SelB on the ribosome. Nature 540, 80-85.

76. Florin, T., Maracci, C., Graf, M., Karki, P., Klepacki, D., Berninghausen, O., Beckmann, R., Vazquez-Laslop, N., Wilson, D.N., Rodnina, M.V., et al. (2017). An antimicrobial peptide that inhibits translation by trapping release factors on the ribosome. Nat Struct Mol Biol 24, 752-757.

77. Fragkoudis, R., Tamberg, N., Siu, R., Kiiver, K., Kohl, A., Merits, A., and Fazakerley, J.K. (2009). Neurons and oligodendrocytes in the mouse brain differ in their ability to replicate Semliki Forest virus. J Neurovirol 15, 57-70.

78. Freed, E.O. (2001). HIV-1 replication. Somat Cell Mol Genet 26, 13-33.

79. Frias, D., Monteiro-Cunha, J.P., Mota-Miranda, A.C., Fonseca, V.S., de Oliveira, T., Galvao-Castro, B., and Alcantara, L.C. (2013). Human retrovirus codon usage from tRNA point of view: therapeutic insights. Bioinform Biol Insights 7, 335-345.

80. Gallant, J., and Lindsley, D. (1993). Ribosome frameshifting at hungry codons: sequence rules, directional specificity and possible relationship to mobile element behaviour. Biochem Soc Trans 21, 817-821.

81. Gallant, J.A., and Lindsley, D. (1992). Leftward ribosome frameshifting at a hungry codon. J Mol Biol 223, 31-40.

82. Gallant, J.A., and Lindsley, D. (1998). Ribosomes can slide over and beyond "hungry" codons, resuming protein chain elongation many nucleotides downstream. Proc Natl Acad Sci U S A 95, 13771-13776.

83. Garcia-Miranda, P., Becker, J.T., Benner, B.E., Blume, A., Sherer, N.M., and Butcher, S.E. (2016). Stability of HIV frameshift site RNA correlates with frameshift efficiency and decreased virus infectivity. J Virol 90, 6906-6917. 
84. Garofalo, R., Wohlgemuth, I., Pearson, M., Lenz, C., Urlaub, H., and Rodnina, M.V. (2019). Broad range of missense error frequencies in cellular proteins. Nucleic Acids Res.

85. Gaudin, C., Mazauric, M.H., Traikia, M., Guittet, E., Yoshizawa, S., and Fourmy, D. (2005). Structure of the RNA signal essential for translational frameshifting in HIV1. J Mol Biol 349, 1024-1035.

86. Geslain, R., and Pan, T. (2010). Functional analysis of human tRNA isodecoders. J Mol Biol 396, 821-831.

87. Gesteland, R., and Atkins, J. (1996). Recoding: dynamic reprogramming of translation. Annu Rev Biochem 65, 741-809.

88. Gesteland, R.F., Weiss, R.B., and Atkins, J.F. (1992). Recoding: reprogrammed genetic decoding. Science 257, 1640-1641.

89. Girnary, R., King, L., Robinson, L., Elston, R., and Brierley, I. (2007). Structurefunction analysis of the ribosomal frameshifting signal of two human immunodeficiency virus type 1 isolates with increased resistance to viral protease inhibitors. J Gen Virol 88, 226-235.

90. Goodenbour, J.M., and Pan, T. (2006). Diversity of tRNA genes in eukaryotes. Nucleic Acids Res 34, 6137-6146.

91. Grentzmann, G., Ingram, J., Kelly, P., Gesteland, R., and Atkins, J. (1998). A dualluciferase reporter system for studying recoding signals. RNA (New York, NY) 4, 479-565.

92. Griffiths, A. (2011). Slipping and sliding: frameshift mutations in herpes simplex virus thymidine kinase and drug-resistance. Drug Resist Updat 14, 251-259.

93. Groisman, I., and Engelberg-Kulka, H. (1995). Translational bypassing: a new reading alternative of the genetic code. Biochem Cell Biol 73, 1055-1059.

94. Guarraia, C., Norris, L., Raman, A., and Farabaugh, P.J. (2007). Saturation mutagenesis of $\mathrm{a}+1$ programmed frameshift-inducing mRNA sequence derived from a yeast retrotransposon. RNA (New York, NY) 13, 1940-1947.

95. Hardin, A., Villalta, C.F., Doan, M., Jabri, M., Chockalingham, V., White, S.J., and Fowler, R.G. (2007). A molecular characterization of spontaneous frameshift mutagenesis within the trpA gene of Escherichia coli. DNA repair 6, 177-189.

96. Hartmuth, K., Raker, V.A., Huber, J., Branlant, C., and Luhrmann, R. (1999). An unusual chemical reactivity of Sm site adenosines strongly correlates with proper assembly of core U snRNP particles. J Mol Biol 285, 133-147. 
97. Hellen, C.U.T. (2018). Translation termination and ribosome recycling in eukaryotes. Cold Spring Harb Perspect Biol 10.

98. Hjerten, S. (1962). "Molecular sieve" chromatography on polyacrylamide gels, prepared according to a simplified method. Arch Biochem Biophys Suppl 1, 147151.

99. Holtkamp, W., Cunha, C.E., Peske, F., Konevega, A.L., Wintermeyer, W., and Rodnina, M.V. (2014a). GTP hydrolysis by EF-G synchronizes tRNA movement on small and large ribosomal subunits. EMBO J 2;33(9), 1073-1085.

100. Holtkamp, W., Wintermeyer, W., and Rodnina, M.V. (2014b). Synchronous tRNA movements during translocation on the ribosome are orchestrated by elongation factor G and GTP hydrolysis. BioEssays : news and reviews in molecular, cellular and developmental biology 36, 908-918.

101. Honda, A., Nakamura, T., and Nishimura, S. (1995). RNA signals for translation frameshift: influence of stem size and slippery sequence. Biochem Biophys Res Commun 213, 575-582.

102. Horsfield, J., Wilson, D., Mannering, S., Adamski, F., and Tate, W. (1995). Prokaryotic ribosomes recode the HIV-1 gag-pol-1 frameshift sequence by an E/P site post-translocation simultaneous slippage mechanism. Nucl Acids Res 23, 14871494.

103. Hung, M., Patel, P., Davis, S., and Green, S.R. (1998). Importance of ribosomal frameshifting for human immunodeficiency virus type 1 particle assembly and replication. J Virol 72, 4819-4824.

104. Ingolia, N.T., Ghaemmaghami, S., Newman, J.R., and Weissman, J.S. (2009). Genome-wide analysis in vivo of translation with nucleotide resolution using ribosome profiling. Science 324, 218-223.

105. Jacks, T., Madhani, H., Masiarz, F., and Varmus, H. (1988a). Signals for ribosomal frameshifting in the Rous sarcoma virus gag-pol region. Cell 55, 447-505.

106. Jacks, T., Power, M.D., Masiarz, F.R., Luciw, P.A., Barr, P.J., and Varmus, H.E. (1988b). Characterization of ribosomal frameshifting in HIV-1 gag-pol expression. Nature 331, 280-283.

107. Jackson, R.J., Hellen, C.U., and Pestova, T.V. (2010). The mechanism of eukaryotic translation initiation and principles of its regulation. Nat Rev Mol Cell Biol 11, 113127. 
108. Jackson, R.J., Hellen, C.U., and Pestova, T.V. (2012). Termination and posttermination events in eukaryotic translation. Adv Protein Chem Struct Biol 86, 4593.

109. Jagger, B.W., Wise, H.M., Kash, J.C., Walters, K.A., Wills, N.M., Xiao, Y.L., Dunfee, R.L., Schwartzman, L.M., Ozinsky, A., Bell, G.L., et al. (2012). An overlapping protein-coding region in influenza A virus segment 3 modulates the host response. Science 337, 199-204.

110. Jang, S.K., Pestova, T.V., Hellen, C.U., Witherell, G.W., and Wimmer, E. (1990). Cap-independent translation of picornavirus RNAs: structure and function of the internal ribosomal entry site. Enzyme 44, 292-309.

111. Johnson, K.A. (2009). Fitting enzyme kinetic data with KinTek Global Kinetic Explorer. Methods Enzymol 467, 601-626.

112. Kang, H. (1998). Direct structural evidence for formation of a stem-loop structure involved in ribosomal frameshifting in human immunodeficiency virus type 1 . Biochim Biophys Acta 1397, 73-78.

113. Karacostas, V., Wolffe, E.J., Nagashima, K., Gonda, M.A., and Moss, B. (1993). Overexpression of the HIV-1 gag-pol polyprotein results in intracellular activation of HIV-1 protease and inhibition of assembly and budding of virus-like particles. Virology 193, 661-671.

114. Kendra, J.A., de la Fuente, C., Brahms, A., Woodson, C., Bell, T.M., Chen, B., Khan, Y.A., Jacobs, J.L., Kehn-Hall, K., and Dinman, J.D. (2017). Ablation of programmed -1 ribosomal frameshifting in Venezuelan Equine Encephalitis virus results in attenuated neuropathogenicity. J Virol 91.

115. Ketteler, R. (2012). On programmed ribosomal frameshifting: the alternative proteomes. Front Genet 3, 242.

116. Kim, H.K., Liu, F., Fei, J., Bustamante, C., Gonzalez, R.L., Jr., and Tinoco, I., Jr. (2014). A frameshifting stimulatory stem loop destabilizes the hybrid state and impedes ribosomal translocation. Proc Natl Acad Sci U S A 111, 5538-5543.

117. Kim, Y.G., Maas, S., and Rich, A. (2001). Comparative mutational analysis of cisacting RNA signals for translational frameshifting in HIV-1 and HTLV-2. Nucleic Acids Res 29, 1125-1131.

118. Knops, E., Brakier-Gingras, L., Schulter, E., Pfister, H., Kaiser, R., and Verheyen, J. (2012). Mutational patterns in the frameshift-regulating site of HIV-1 selected by protease inhibitors. Med Microbiol Immunol 201, 213-218. 
119. Kobayashi, Y., Zhuang, J., Peltz, S., and Dougherty, J. (2010). Identification of a cellular factor that modulates HIV-1 programmed ribosomal frameshifting. J Biol Chem 285, 19776-19784.

120. Kollmus, H., Honigman, A., Panet, A., and Hauser, H. (1994). The sequences of and distance between two cis-acting signals determine the efficiency of ribosomal frameshifting in human immunodeficiency virus type 1 and human T-cell leukemia virus type II in vivo. J Virol 68, 6087-6091.

121. Kothe, U., Paleskava, A., Konevega, A.L., and Rodnina, M.V. (2006). Single-step purification of specific tRNAs by hydrophobic tagging. Anal Biochem 356, 148-150.

122. Kozak, M. (1987). An analysis of 5'-noncoding sequences from 699 vertebrate messenger RNAs. Nucleic Acids Res 15, 8125-8148.

123. Kuhlenkoetter, S., Wintermeyer, W., and Rodnina, M.V. (2011). Different substrate-dependent transition states in the active site of the ribosome. Nature 476, 351-354.

124. Kurland, C. (1979). Reading frame errors on ribosomes. Nonsense Mutations and tRNA Suppressors Academic Press, New York, NY, 97-108.

125. Larrouy, L., Lambert-Niclot, S., Charpentier, C., Fourati, S., Visseaux, B., Soulie, C., Wirden, M., Katlama, C., Yeni, P., Brun-Vezinet, F., et al. (2011). Positive impact of HIV-1 gag cleavage site mutations on the virological response to darunavir boosted with ritonavir. Antimicrob Agents Chemother 55, 1754-1757.

126. Larsen, B., Wills, N., Gesteland, R., and Atkins, J. (1994). rRNA-mRNA base pairing stimulates a programmed -1 ribosomal frameshift. J Bacteriol 176, 68426851.

127. Leger, M., Dulude, D., Steinberg, S.V., and Brakier-Gingras, L. (2007). The three transfer RNAs occupying the A, P and E sites on the ribosome are involved in viral programmed -1 ribosomal frameshift. Nucleic Acids Res 35, 5581-5592.

128. Li, M., Kao, E., Gao, X., Sandig, H., Limmer, K., Pavon-Eternod, M., Jones, T.E., Landry, S., Pan, T., Weitzman, M.D., et al. (2012). Codon-usage-based inhibition of HIV protein synthesis by human schlafen 11. Nature 491, 125-128.

129. Li, Y., Treffers, E.E., Napthine, S., Tas, A., Zhu, L., Sun, Z., Bell, S., Mark, B.L., van Veelen, P.A., van Hemert, M.J., et al. (2014). Transactivation of programmed ribosomal frameshifting by a viral protein. Proc Natl Acad Sci U S A 111, E21722181. 
130. Liao, P.Y., Choi, Y.S., Dinman, J.D., and Lee, K.H. (2011). The many paths to frameshifting: kinetic modelling and analysis of the effects of different elongation steps on programmed -1 ribosomal frameshifting. Nucleic Acids Res 39, 300-312.

131. Lin, Z., Gilbert, R.J., and Brierley, I. (2012). Spacer-length dependence of programmed -1 or -2 ribosomal frameshifting on a U6A heptamer supports a role for messenger RNA (mRNA) tension in frameshifting. Nucleic Acids Res 40, 86748689.

132. Lorenz, C., Lunse, C.E., and Morl, M. (2017). tRNA modifications: impact on structure and thermal adaptation. Biomolecules 7.

133. Loughran, G., Chou, M.Y., Ivanov, I.P., Jungreis, I., Kellis, M., Kiran, A.M., Baranov, P.V., and Atkins, J.F. (2014). Evidence of efficient stop codon readthrough in four mammalian genes. Nucleic Acids Res 42, 8928-8938.

134. Loveland, A.B., Demo, G., Grigorieff, N., and Korostelev, A.A. (2017). Ensemble cryo-EM elucidates the mechanism of translation fidelity. Nature 546, 113-117.

135. Low, J.T., Garcia-Miranda, P., Mouzakis, K.D., Gorelick, R.J., Butcher, S.E., and Weeks, K.M. (2014). Structure and dynamics of the HIV-1 frameshift element RNA. Biochemistry 53, 4282-4291.

136. Lusso, P., Cocchi, F., Balotta, C., Markham, P.D., Louie, A., Farci, P., Pal, R., Gallo, R.C., and Reitz, M.S., Jr. (1995). Growth of macrophage-tropic and primary human immunodeficiency virus type 1 (HIV-1) isolates in a unique CD4+ T-cell clone (PM1): failure to downregulate CD4 and to interfere with cell-line-tropic HIV1. J Virol 69, 3712-3720.

137. Luthi, K., Moser, M., Ryser, J., and Weber, H. (1990). Evidence for a role of translational frameshifting in the expression of transposition activity of the bacterial insertion element IS1. Gene 88, 15-20.

138. Maag, D., Fekete, C.A., Gryczynski, Z., and Lorsch, J.R. (2005). A conformational change in the eukaryotic translation preinitiation complex and release of eIF1 signal recognition of the start codon. Mol Cell 17, 265-275.

139. Maartens, G., Celum, C., and Lewin, S.R. (2014). HIV infection: epidemiology, pathogenesis, treatment, and prevention. Lancet (London, England) 384, 258-271.

140. Machnicka, M.A., Olchowik, A., Grosjean, H., and Bujnicki, J.M. (2014). Distribution and frequencies of post-transcriptional modifications in tRNAs. RNA Biol 11, 1619-1629.

141. Mahlab, S., Tuller, T., and Linial, M. (2012). Conservation of the relative tRNA composition in healthy and cancerous tissues. RNA (New York, NY) 18, 640-652. 
142. Maldonado, R., and Herr, A.J. (1998). Efficiency of T4 gene 60 translational bypassing. J Bacteriol 180, 1822-1830.

143. Manktelow, E., Shigemoto, K., and Brierley, I. (2005). Characterization of the frameshift signal of Edr, a mammalian example of programmed -1 ribosomal frameshifting. Nucleic Acids Res 33, 1553-1563.

144. Marcheschi, R.J., Staple, D.W., and Butcher, S.E. (2007). Programmed ribosomal frameshifting in SIV is induced by a highly structured RNA stem-loop. J Mol Biol $373,652-663$.

145. Marcheschi, R.J., Tonelli, M., Kumar, A., and Butcher, S.E. (2011). Structure of the HIV-1 frameshift site RNA bound to a small molecule inhibitor of viral replication. ACS Chem Biol 6, 857-864.

146. Mathew, S.F., Crowe-McAuliffe, C., Graves, R., Cardno, T.S., McKinney, C., Poole, E.S., and Tate, W.P. (2015). The highly conserved codon following the slippery sequence supports -1 frameshift efficiency at the HIV-1 frameshift site. PLoS One 10, e0122176.

147. Matsufuji, S., Matsufuji, T., Miyazaki, Y., Murakami, Y., Atkins, J.F., Gesteland, R.F., and Hayashi, S. (1995). Autoregulatory frameshifting in decoding mammalian ornithine decarboxylase antizyme. Cell 80, 51-60.

148. Mazauric, M.-H., Seol, Y., Yoshizawa, S., Visscher, K., and Fourmy, D. (2009). Interaction of the HIV-1 frameshift signal with the ribosome. Nucleic Acids Res 37, 7654-7718.

149. Mejlhede, N., Atkins, J.F., and Neuhard, J. (1999). Ribosomal -1 frameshifting during decoding of Bacillus subtilis cdd occurs at the sequence CGA AAG. J Bacteriol 181, 2930-2937.

150. Melian, E.B., Hinzman, E., Nagasaki, T., Firth, A.E., Wills, N.M., Nouwens, A.S., Blitvich, B.J., Leung, J., Funk, A., Atkins, J.F., et al. (2010). NS1' of flaviviruses in the Japanese encephalitis virus serogroup is a product of ribosomal frameshifting and plays a role in viral neuroinvasiveness. J Virol 84, 1641-1647.

151. Melnikov, S., Ben-Shem, A., Garreau de Loubresse, N., Jenner, L., Yusupova, G., and Yusupov, M. (2012). One core, two shells: bacterial and eukaryotic ribosomes. Nat Struct Mol Biol 19, 560-567.

152. Meydan, S., Klepacki, D., Karthikeyan, S., Margus, T., Thomas, P., Jones, J.E., Khan, Y., Briggs, J., Dinman, J.D., Vazquez-Laslop, N., et al. (2017). Programmed ribosomal frameshifting generates a copper transporter and a copper chaperone from the same gene. Mol Cell 65, 207-219. 
153. Milligan, J.F., Groebe, D.R., Witherell, G.W., and Uhlenbeck, O.C. (1987). Oligoribonucleotide synthesis using T7 RNA polymerase and synthetic DNA templates. Nucleic Acids Res 15, 8783-8798.

154. Milon, P., and Rodnina, M.V. (2012). Kinetic control of translation initiation in bacteria. Crit Rev Biochem Mol Biol 47, 334-348.

155. Moazed, D., and Noller, H.F. (1987). Interaction of antibiotics with functional sites in $16 \mathrm{~S}$ ribosomal RNA. Nature 327, 389-394.

156. Moore, G. (1975). Chemical modification of ribosomes with dimethyl sulfate: a probe to the structural organization of ribosomal proteins and RNA. Can J Biochem $53,328-337$.

157. Mouzakis, K.D., Lang, A.L., Vander Meulen, K.A., Easterday, P.D., and Butcher, S.E. (2013). HIV-1 frameshift efficiency is primarily determined by the stability of base pairs positioned at the mRNA entrance channel of the ribosome. Nucleic Acids Res 41, 1901-1913.

158. Mullis, K.B. (1990). Target amplification for DNA analysis by the polymerase chain reaction. Ann Biol Clin (Paris) 48, 579-582.

159. Munroe, D., and Jacobson, A. (1990). mRNA poly(A) tail, a 3' enhancer of translational initiation. Mol Cell Biol 10, 3441-3455.

160. Namy, O., Moran, S.J., Stuart, D.I., Gilbert, R.J., and Brierley, I. (2006). A mechanical explanation of RNA pseudoknot function in programmed ribosomal frameshifting. Nature 441, 244-247.

161. Napthine, S., Ling, R., Finch, L.K., Jones, J.D., Bell, S., Brierley, I., and Firth, A.E. (2017). Protein-directed ribosomal frameshifting temporally regulates gene expression. Nat Commun 8, 15582.

162. Netzer, N., Goodenbour, J.M., David, A., Dittmar, K.A., Jones, R.B., Schneider, J.R., Boone, D., Eves, E.M., Rosner, M.R., Gibbs, J.S., et al. (2009). Innate immune and chemically triggered oxidative stress modifies translational fidelity. Nature 462, 522-526.

163. Novoa, E.M., Pavon-Eternod, M., Pan, T., and Ribas de Pouplana, L. (2012). A role for tRNA modifications in genome structure and codon usage. Cell 149, 202-213.

164. Ofori, L.O., Hilimire, T.A., Bennett, R.P., Brown, N.W., Jr., Smith, H.C., and Miller, B.L. (2014). High-affinity recognition of HIV-1 frameshift-stimulating RNA alters frameshifting in vitro and interferes with HIV-1 infectivity. J Med Chem 57, 723-732. 
165. Olubajo, B., and Taylor, E.W. (2005). A -1 frameshift in the HIV-1 env gene is enhanced by arginine deficiency via a hungry codon mechanism. Mutat Res 579, 125-132.

166. Ozen, A., Lin, K.H., Kurt Yilmaz, N., and Schiffer, C.A. (2014). Structural basis and distal effects of Gag substrate coevolution in drug resistance to HIV-1 protease. Proc Natl Acad Sci U S A 111, 15993-15998.

167. Pan, D., and Coen, D.M. (2012). Net -1 frameshifting on a noncanonical sequence in a herpes simplex virus drug-resistant mutant is stimulated by nonstop mRNA. Proc Natl Acad Sci U S A 109, 14852-14857.

168. Pan, T. (2018). Modifications and functional genomics of human transfer RNA. Cell Res 28, 395-404.

169. Park, J., and Morrow, C.D. (1991). Overexpression of the gag-pol precursor from human immunodeficiency virus type 1 proviral genomes results in efficient proteolytic processing in the absence of virion production. J Virol 65, 5111-5117.

170. Parkin, N.T., Chamorro, M., and Varmus, H.E. (1992). Human immunodeficiency virus type 1 gag-pol frameshifting is dependent on downstream mRNA secondary structure: demonstration by expression in vivo. J Virol 66, 5147-5151.

171. Passmore, L.A., Schmeing, T.M., Maag, D., Applefield, D.J., Acker, M.G., Algire, M.A., Lorsch, J.R., and Ramakrishnan, V. (2007). The eukaryotic translation initiation factors eIF1 and eIF1A induce an open conformation of the $40 \mathrm{~S}$ ribosome. Mol Cell 26, 41-50.

172. Pavon-Eternod, M., David, A., Dittmar, K., Berglund, P., Pan, T., Bennink, J.R., and Yewdell, J.W. (2013). Vaccinia and influenza A viruses select rather than adjust tRNAs to optimize translation. Nucleic Acids Res 41, 1914-1921.

173. Pavon-Eternod, M., Wei, M., Pan, T., and Kleiman, L. (2010). Profiling non-lysyl tRNAs in HIV-1. RNA (New York, NY) 16, 267-273.

174. Peattie, D.A., and Gilbert, W. (1980). Chemical probes for higher-order structure in RNA. Proc Natl Acad Sci U S A 77, 4679-4682.

175. Peske, F., Kuhlenkoetter, S., Rodnina, M.V., and Wintermeyer, W. (2014). Timing of GTP binding and hydrolysis by translation termination factor RF3. Nucleic Acids Res 42, 1812-1820.

176. Peske, F., Rodnina, M.V., and Wintermeyer, W. (2005). Sequence of steps in ribosome recycling as defined by kinetic analysis. Mol Cell 18, 403-412.

177. Pestova, T.V., and Hellen, C.U. (2003). Coupled folding during translation initiation. Cell 115, 650-652. 
178. Pettit, S.C., Henderson, G.J., Schiffer, C.A., and Swanstrom, R. (2002). Replacement of the P1 amino acid of human immunodeficiency virus type 1 Gag processing sites can inhibit or enhance the rate of cleavage by the viral protease. $\mathrm{J}$ Virol 76, 10226-10233.

179. Pisarev, A.V., Unbehaun, A., Hellen, C.U., and Pestova, T.V. (2007). Assembly and analysis of eukaryotic translation initiation complexes. Methods Enzymol 430, 147-177.

180. Plant, E.P. (2012 ). Ribosomal frameshift signals in viral genomes. In Viral Genomes - Molecular Structure, Diversity, Gene Expression Mechanisms and HostVirus Interactions, P.M. Garcia, ed. (InTech).

181. Plant, E.P., and Dinman, J.D. (2006). Comparative study of the effects of heptameric slippery site composition on -1 frameshifting among different eukaryotic systems. RNA (New York, NY) 12, 666-673.

182. Qiao, Q., Yan, Y., Guo, J., Du, S., Zhang, J., Jia, R., Ren, H., Qiao, Y., and Li, Q. (2017). A review on architecture of the gag-pol ribosomal frameshifting RNA in human immunodeficiency virus: a variability survey of virus genotypes. J Biomol Struct Dyn 35, 1629-1653.

183. Qu, X., Wen, J.D., Lancaster, L., Noller, H.F., Bustamante, C., and Tinoco, I., Jr. (2011). The ribosome uses two active mechanisms to unwind messenger RNA during translation. Nature 475, 118-121.

184. Ramsey, J., and Mukhopadhyay, S. (2017). Disentangling the frames, the state of research on the Alphavirus $6 \mathrm{~K}$ and TF proteins. Viruses 9.

185. Ratner, L., Haseltine, W., Patarca, R., Livak, K.J., Starcich, B., Josephs, S.F., Doran, E.R., Rafalski, J.A., Whitehorn, E.A., Baumeister, K., et al. (1985). Complete nucleotide sequence of the AIDS virus, HTLV-III. Nature 313, 277-284.

186. Reil, H., Kollmus, H., Weidle, U.H., and Hauser, H. (1993). A heptanucleotide sequence mediates ribosomal frameshifting in mammalian cells. J Virol 67, 55795584.

187. Rodnina, M.V. (2012). Quality control of mRNA decoding on the bacterial ribosome. Adv Protein Chem Struct Biol 86, 95-128.

188. Rodnina, M.V. (2016). The ribosome in action: tuning of translational efficiency and protein folding. Protein Sci 25, 1390-1406.

189. Rodnina, M.V. (2018). Translation in prokaryotes. Cold Spring Harb Perspect Biol 4;10(9), a032664. 
190. Rodnina, M.V., Beringer, M., and Wintermeyer, W. (2006). Mechanism of peptide bond formation on the ribosome. Q Rev Biophys 39, 203-225.

191. Rodnina, M.V., Fischer, N., Maracci, C., and Stark, H. (2017). Ribosome dynamics during decoding. Philos Trans R Soc Lond B Biol Sci 372.

192. Rodnina, M.V., Fricke, R., Kuhn, L., and Wintermeyer, W. (1995). Codondependent conformational change of elongation factor Tu preceding GTP hydrolysis on the ribosome. Embo J 14, 2613-2619.

193. Rodnina, M.V., Savelsbergh, A., Katunin, V.I., and Wintermeyer, W. (1997). Hydrolysis of GTP by elongation factor G drives tRNA movement on the ribosome. Nature 385, 37-41.

194. Rodnina, M.V., Semenkov, Y.P., and Wintermeyer, W. (1994). Purification of fMet-tRNA(fMet) by fast protein liquid chromatography. Anal Biochem 219, 380381.

195. Rodnina, M.V., Stark, H., Savelsbergh, A., Wieden, H.J., Mohr, D., Matassova, N.B., Peske, F., Daviter, T., Gualerzi, C.O., and Wintermeyer, W. (2000). GTPases mechanisms and functions of translation factors on the ribosome. Biol Chem 381, 377-387.

196. Rodnina, M.V., and Wintermeyer, W. (1995). GTP consumption of elongation factor Tu during translation of heteropolymeric mRNAs. Proc Natl Acad Sci U S A 92, 1945-1949.

197. Rodnina, M.V., and Wintermeyer, W. (2001a). Fidelity of aminoacyl-tRNA selection on the ribosome: kinetic and structural mechanisms. Annu Rev Biochem $70,415-435$.

198. Rodnina, M.V., and Wintermeyer, W. (2001b). Ribosome fidelity: tRNA discrimination, proofreading and induced fit. Trends Biochem Sci 26, 124-130.

199. Rodnina, M.V., and Wintermeyer, W. (2009). Recent mechanistic insights into eukaryotic ribosomes. Curr Opin Cell Biol 21, 435-443.

200. Saini, S., Bhalla, P., Gautam, H., Baveja, U.K., Pasha, S.T., and Dewan, R. (2012). Resistance-associated mutations in HIV-1 among patients failing first-line antiretroviral therapy. J Int Assoc Physicians AIDS Care (Chic) 11, 203-209.

201. Salter, R.D., Howell, D.N., and Cresswell, P. (1985). Genes regulating HLA class I antigen expression in T-B lymphoblast hybrids. Immunogenetics 21, 235-246.

202. Samatova, E., Konevega, A.L., Wills, N.M., Atkins, J.F., and Rodnina, M.V. (2014). High-efficiency translational bypassing of non-coding nucleotides specified by mRNA structure and nascent peptide. Nat Commun 5, 4459. 
203. Sanchez-Pescador, R., Power, M.D., Barr, P.J., Steimer, K.S., Stempien, M.M., Brown-Shimer, S.L., Gee, W.W., Renard, A., Randolph, A., Levy, J.A., et al. (1985). Nucleotide sequence and expression of an AIDS-associated retrovirus (ARV-2). Science 227, 484-492.

204. Savelsbergh, A., Katunin, V.I., Mohr, D., Peske, F., Rodnina, M.V., and Wintermeyer, W. (2003). An elongation factor G-induced ribosome rearrangement precedes tRNA-mRNA translocation. Mol Cell 11, 1517-1523.

205. Schagger, H., and von Jagow, G. (1987). Tricine-sodium dodecyl sulfatepolyacrylamide gel electrophoresis for the separation of proteins in the range from 1 to $100 \mathrm{kDa}$. Anal Biochem 166, 368-379.

206. Scolnick, E., Tompkins, R., Caskey, T., and Nirenberg, M. (1968). Release factors differing in specificity for terminator codons. Proc Natl Acad Sci U S A 61, 768-774.

207. Sharma, H., Adio, S., Senyushkina, T., Belardinelli, R., Peske, F., and Rodnina, M.V. (2016). Kinetics of spontaneous and EF-G-accelerated rotation of ribosomal subunits. Cell Rep 16, 2187-2196.

208. Sharp, P.M., Cowe, E., Higgins, D.G., Shields, D.C., Wolfe, K.H., and Wright, F. (1988). Codon usage patterns in Escherichia coli, Bacillus subtilis, Saccharomyces cerevisiae, Schizosaccharomyces pombe, Drosophila melanogaster and Homo sapiens; a review of the considerable within-species diversity. Nucleic Acids Res 16, 8207-8211.

209. Shatsky, I.N., Terenin, I.M., Smirnova, V.V., and Andreev, D.E. (2018). Capindependent translation: what's in a name? Trends Biochem Sci 43(11), 882-895.

210. Shehu-Xhilaga, M., Crowe, S.M., and Mak, J. (2001). Maintenance of the Gag/GagPol ratio is important for human immunodeficiency virus type 1 RNA dimerization and viral infectivity. J Virol 75, 1834-1841.

211. Snyder, J.E., Kulcsar, K.A., Schultz, K.L., Riley, C.P., Neary, J.T., Marr, S., Jose, J., Griffin, D.E., and Kuhn, R.J. (2013). Functional characterization of the alphavirus TF protein. J Virol 87, 8511-8523.

212. Soll, D. (1990). The accuracy of aminoacylation--ensuring the fidelity of the genetic code. Experientia 46, 1089-1096.

213. Staple, D.W., and Butcher, S.E. (2003). Solution structure of the HIV-1 frameshift inducing stem-loop RNA. Nucleic Acids Res 31, 4326-4331.

214. Staple, D.W., and Butcher, S.E. (2005). Solution structure and thermodynamic investigation of the HIV-1 frameshift inducing element. J Mol Biol 349, 1011-1023. 
215. Steitz, J.A., and Jakes, K. (1975). How ribosomes select initiator regions in mRNA: base pair formation between the 3 ' terminus of $16 \mathrm{~S}$ rRNA and the mRNA during initiation of protein synthesis in Escherichia coli. Proc Natl Acad Sci U S A 72, 47344738.

216. Stern, S., Moazed, D., and Noller, H.F. (1988). Structural analysis of RNA using chemical and enzymatic probing monitored by primer extension. Methods Enzymol 164, 481-489.

217. Tabor, S., and Richardson, C.C. (1985). A bacteriophage T7 RNA polymerase/promoter system for controlled exclusive expression of specific genes. Proc Natl Acad Sci U S A 82, 1074-1078.

218. Taliaferro, D., and Farabaugh, P.J. (2007). An mRNA sequence derived from the yeast EST3 gene stimulates programmed +1 translational frameshifting. RNA (New York, NY) 13, 606-613.

219. Telenti, A., Martinez, R., Munoz, M., Bleiber, G., Greub, G., Sanglard, D., and Peters, S. (2002). Analysis of natural variants of the human immunodeficiency virus type 1 gag-pol frameshift stem-loop structure. J Virol 76, 7868-7873.

220. Torres, A.G., Batlle, E., and Ribas de Pouplana, L. (2014). Role of tRNA modifications in human diseases. Trends Mol Med 20, 306-314.

221. Tsuchihashi, Z., and Brown, P.O. (1992). Sequence requirements for efficient translational frameshifting in the Escherichia coli dnaX gene and the role of an unstable interaction between tRNA(Lys) and an AAG lysine codon. Genes Dev 6, 511-519.

222. Tsuchihashi, Z., and Kornberg, A. (1990). Translational frameshifting generates the gamma subunit of DNA polymerase III holoenzyme. Proc Natl Acad Sci U S A 87, 2516-2520.

223. Turner, B.G., and Summers, M.F. (1999). Structural biology of HIV. J Mol Biol 285, 1-32.

224. Urbonavicius, J., Qian, Q., Durand, J.M., Hagervall, T.G., and Bjork, G.R. (2001). Improvement of reading frame maintenance is a common function for several tRNA modifications. Embo J 20, 4863-4873.

225. van Tol, H., Stange, N., Gross, H.J., and Beier, H. (1987). A human and a plant intron-containing tRNATyr gene are both transcribed in a HeLa cell extract but spliced along different pathways. Embo J 6, 35-41. 
226. van Weringh, A., Ragonnet-Cronin, M., Pranckeviciene, E., Pavon-Eternod, M., Kleiman, L., and Xia, X. (2011). HIV-1 modulates the tRNA pool to improve translation efficiency. Mol Biol Evol 28, 1827-1834.

227. Vimaladithan, A., and Farabaugh, P.J. (1994). Special peptidyl-tRNA molecules can promote translational frameshifting without slippage. Mol Cell Biol 14, 81078116.

228. Wain-Hobson, S., Sonigo, P., Danos, O., Cole, S., and Alizon, M. (1985). Nucleotide sequence of the AIDS virus, LAV. Cell 40, 9-17.

229. Wan Makhtar, W.R., Browne, G., Karountzos, A., Stevens, C., Alghamdi, Y., Bottrill, A.R., Mistry, S., Smith, E., Bushel, M., Pringle, J.H., et al. (2017). Short stretches of rare codons regulate translation of the transcription factor ZEB2 in cancer cells. Oncogene 36, 6640-6648.

230. Wang, X., Xuan, Y., Han, Y., Ding, X., Ye, K., Yang, F., Gao, P., Goff, S.P., and Gao, G. (2019). Regulation of HIV-1 Gag-Pol expression by Shiftless, an inhibitor of programmed -1 ribosomal frameshifting. Cell 176, 625-635.e614.

231. Weeks, K.M. (2010). Advances in RNA structure analysis by chemical probing. Curr Opin Struct Biol 20, 295-304.

232. Weiss, A., Wiskocil, R.L., and Stobo, J.D. (1984). The role of T3 surface molecules in the activation of human T cells: a two-stimulus requirement for IL 2 production reflects events occurring at a pre-translational level. J Immunol 133, 123-128.

233. Weiss, R.B., Dunn, D.M., Atkins, J.F., and Gesteland, R.F. (1987). Slippery runs, shifty stops, backward steps, and forward hops: $-2,-1,+1,+2,+5$, and +6 ribosomal frameshifting. Cold Spring Harb Symp Quant Biol 52, 687-693.

234. Weiss, R.B., Dunn, D.M., Shuh, M., Atkins, J.F., and Gesteland, R.F. (1989). E. coli ribosomes re-phase on retroviral frameshift signals at rates ranging from 2 to 50 percent. New Biol 1, 159-169.

235. Wickner, R.B. (1989). Yeast virology. Faseb J 3, 2257-2265.

236. Wills, N.M., Moore, B., Hammer, A., Gesteland, R.F., and Atkins, J.F. (2006). A functional -1 ribosomal frameshift signal in the human paraneoplastic Ma3 gene. J Biol Chem 281, 7082-7088.

237. Wilson, W., Braddock, M., Adams, S.E., Rathjen, P.D., Kingsman, S.M., and Kingsman, A.J. (1988). HIV expression strategies: ribosomal frameshifting is directed by a short sequence in both mammalian and yeast systems. Cell 55, 11591169. 
238. Xu, J., Hendrix, R.W., and Duda, R.L. (2004). Conserved translational frameshift in dsDNA bacteriophage tail assembly genes. Mol Cell 16, 11-21.

239. Yan, S., Wen, J.D., Bustamante, C., and Tinoco, I., Jr. (2015). Ribosome excursions during mRNA translocation mediate broad branching of frameshift pathways. Cell $160,870-881$.

240. Yelverton, E., Lindsley, D., Yamauchi, P., and Gallant, J.A. (1994). The function of a ribosomal frameshifting signal from human immunodeficiency virus-1 in Escherichia coli. Mol Microbiol 11, 303-313.

241. Yu, C.H., Teulade-Fichou, M.P., and Olsthoorn, R.C. (2014). Stimulation of ribosomal frameshifting by RNA G-quadruplex structures. Nucleic Acids Res 42, 1887-1892.

242. Zaher, H.S., and Green, R. (2009). Quality control by the ribosome following peptide bond formation. Nature 457, 161-166.

243. Ziehler, W.A., and Engelke, D.R. (2001). Probing RNA structure with chemical reagents and enzymes. Curr Protoc Nucleic Acid Chem Chapter 6, Unit 6.1. 


\section{Acknowledgements}

Most of all, I would like to express my sincere gratitude to my supervisor Prof. Marina V. Rodnina who I know for almost nine years. In the beginning of my Bachelor in $2010 \mathrm{I}$ applied for a summer internship in her department, and this short research stay has reinforced my passion for science and layed a foundation for my future Master and $\mathrm{PhD}$ studies in Göttingen. Marina has been an amazing mentor and I truly thank her for all the scientific expertise that she had passed on me but also for the constant personal support, understanding, guidance and advice. I also thank Dr. Ekaterina Samatova and Dr. Frank Peske for their daily help with experimental design, insightful discussions, constructive criticism and cosy talks with a cup of coffee. Special thanks goes to Ekaterina for being a wonderful friend and keeping me motivated throughout my $\mathrm{PhD}$. I thank all of my colleagues and friends from Rodnina lab who created a wonderful working atmosphere. A big thanks to Betty, the best labmate ever, who had answers to all of my questions and I could rely on her in all situations.

I would like to thank my TAC members, Prof. Holger Stark and Prof. Stefan Pöhlmann, for contributing to the success of my graduate school. I also thank all of my collaborators, Prof. Stefan Pöhlmann and Dr. Markus Hoffmann from German Primate Center, Dr. Akanksha Goyal from Rodnina lab, Dr. Lars Bock from Grübmüller lab and Dr. Maria M. Anokhina from Lührmann lab, for sharing their knowledge and expertise and making my scientific advances possible. I thank the coordination office of Molecular Biology MSc/PhD program, Dr. Steffen Burkhardt and Kerstin Grüniger, for making my integration in Germany very smooth and helping with all kinds of professional, organizational and personal questions and issues. I would also like to thank my funding agency, Boehringer Ingelheim Fonds, for allowing me to attend many conferences and meetings and all the personal support that I have received as a fellow.

Finally, I would like to thank my family and friends for their everlasting love, care and support; without them, my $\mathrm{PhD}$ journey would not have been so successful and enjoyable. 